
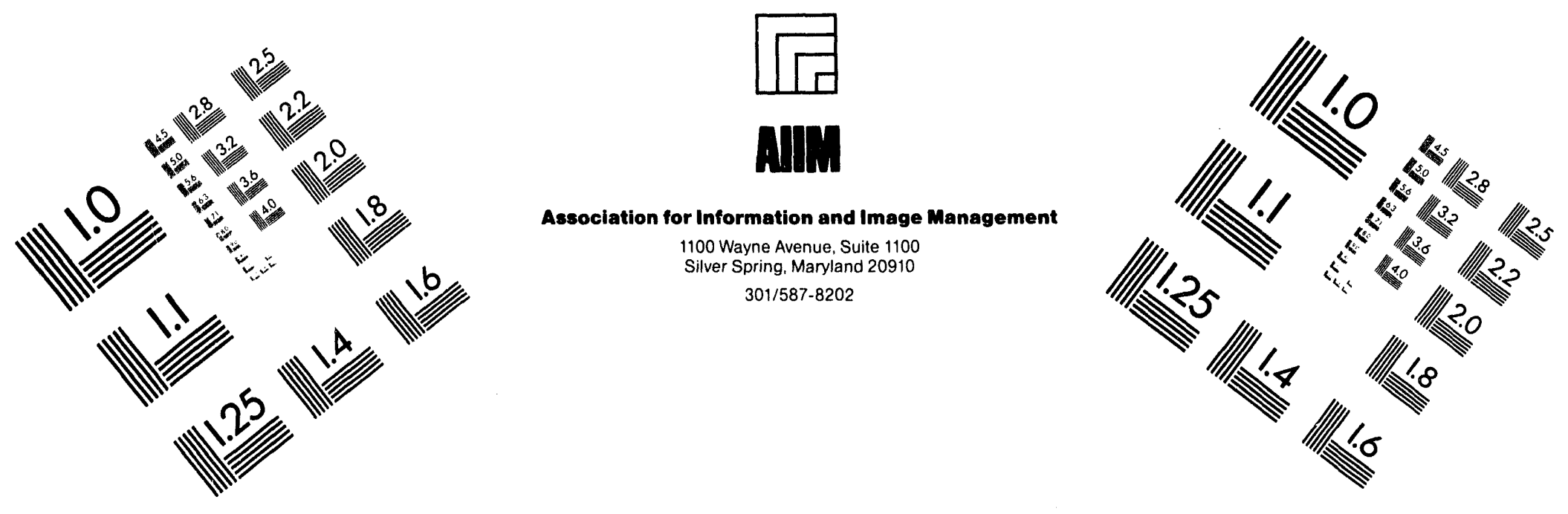

\title{
Centimeter
}

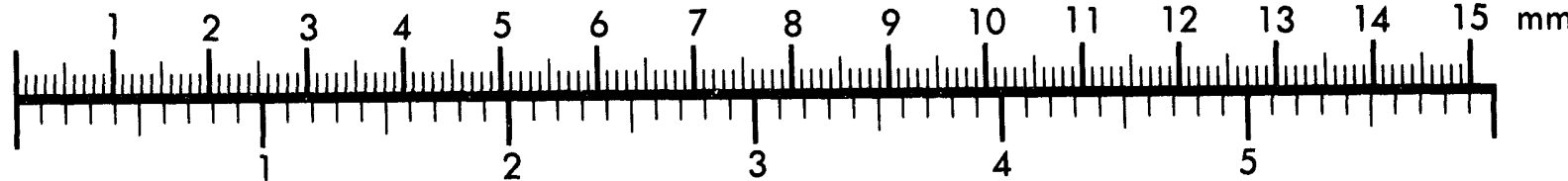

Inches
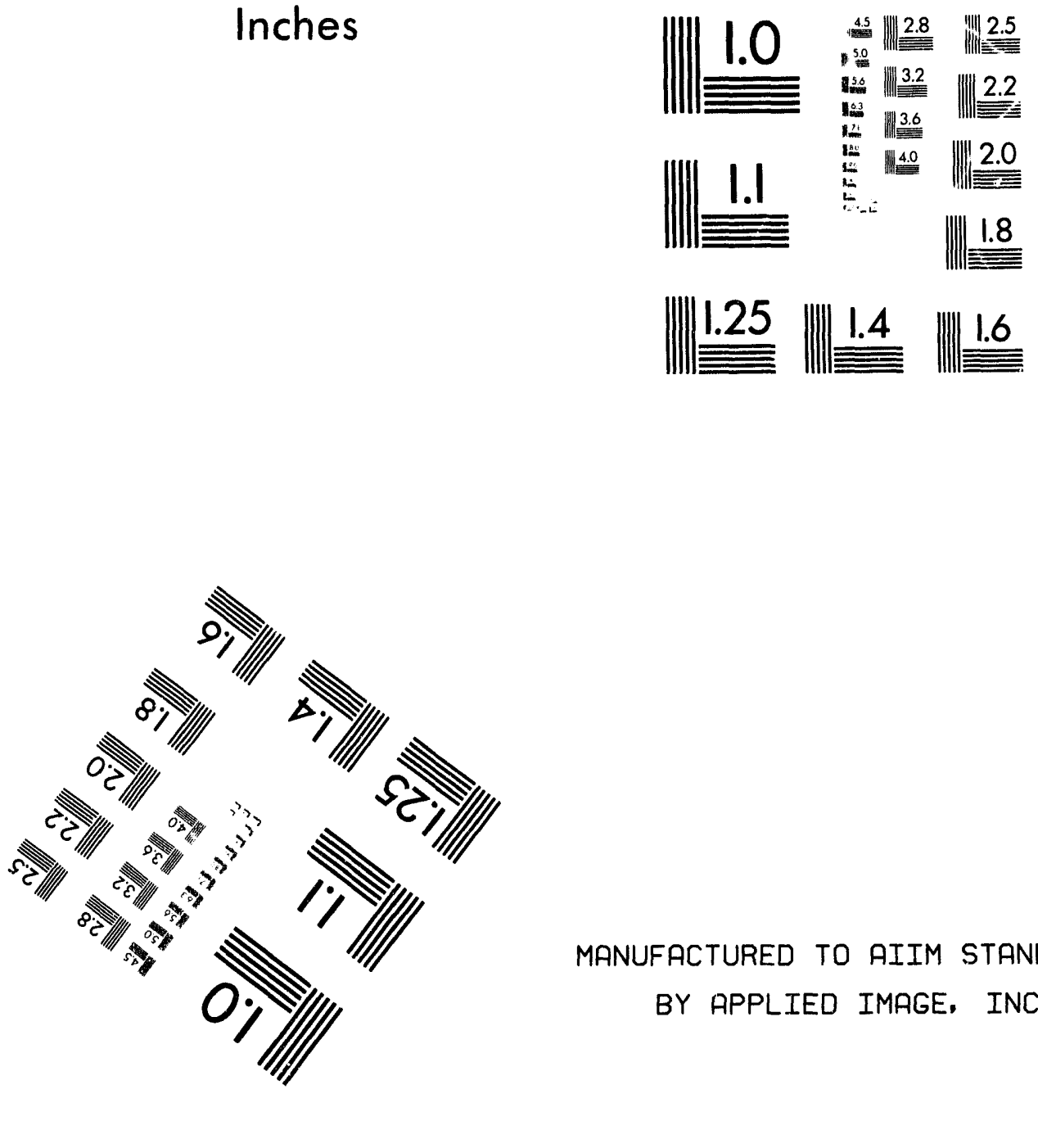

MANUFACTURED TO AIIM STANDARDS

BY APPLIED IMAGE, INC.

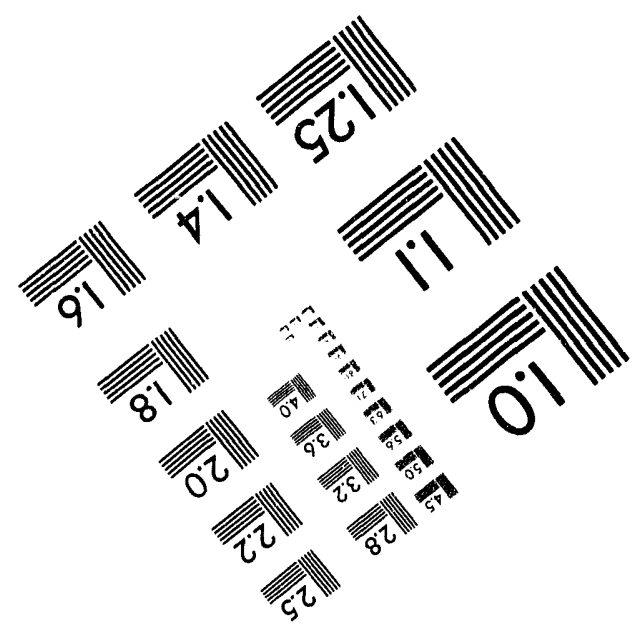



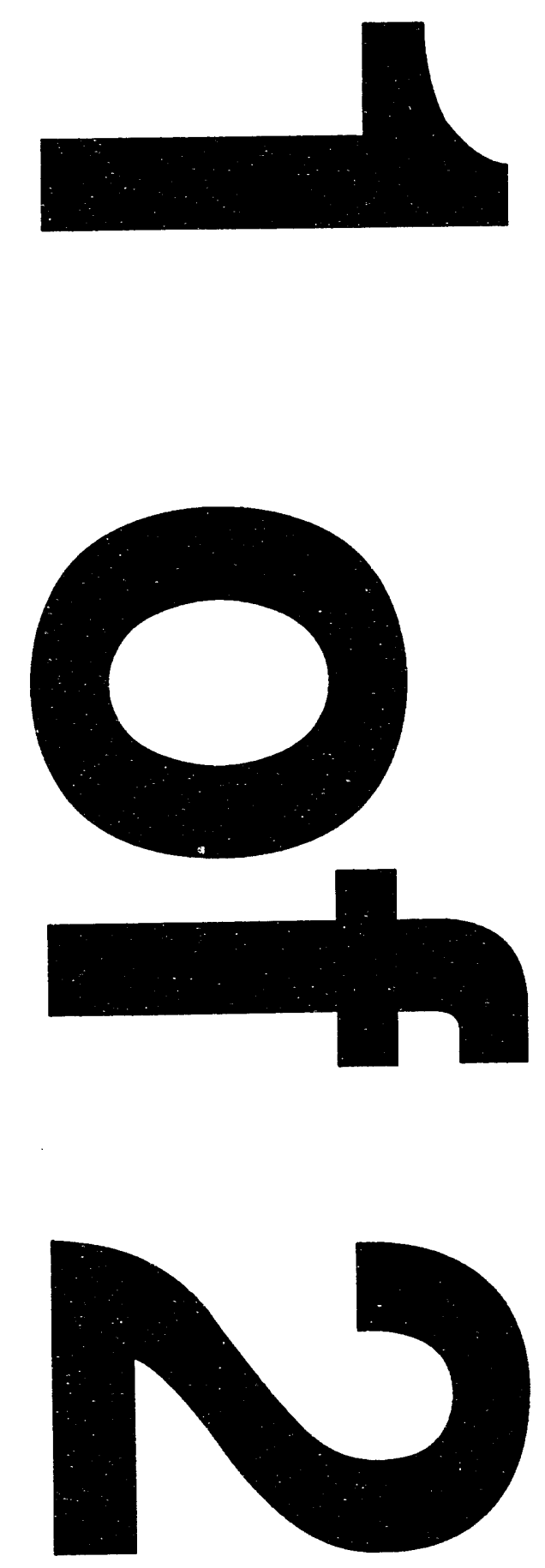
LBL-35914

UC-401

HYDROGENATION OF NITRILES ON A WELL-CHARACTERIZED NICKEL SURFACE: FROM SURFACE SCIENCE STUDIES TO LIQUID PHASE CATALYTIC ACTIVITY MEASUREMENTS

DENIS EMMANUEL GARDIN

Ph.D. Thesis

DEPARTMENT OF CHEMISTRY

University of California

and

MATERIALS SCIENCES DIVISION

Lawrence Berkeley Laboratory

University of California

Berkeley CA 94720

DECEMBER 1993

This work was supported by the Director, Office of Energy Research, Office of Basic Energy Sciences, Materials Sciences Division, of the U.S. Department of Energy under Contract No. DE-AC03-76SF00098 


\section{Hydrogenation of Nitriles on a Well-Characterized Nickel Surface: From Surface Science Studies to Liquid Phase Catalytic Activity Measurements}

Copyright (C) 1993

by

Denis Emmanuel Gardin

The Government reserves for itself and others acting on its behalf a royalty free, nonexclusive, irrevocable, world-wide license for governmental purposes to publish, distribute, translate, duplicate, exhibit, and perform any such data copyrighted by the contractor.

The U.S. Department of Energy has the right to use this document for any purpose whatsoever including the right to reproduce all or any part thereof 


\author{
Abstract \\ Hydrogenation of Nitriles on a Well-Characterized Nickel Surface : \\ From Surface Science Studies to \\ Liquid Phase Catalytic Activity Measurements \\ by \\ Denis Emmanuel Gardin \\ Doctor of Philosophy in Chemistry \\ University of California at Berkeley \\ Professor Gabor A. Somorjai, Chair
}

The work described in this thesis is aimed at providing information about the mechanism and factors affecting the performance of nickel-based catalyst in nitrile hydrogenation reactions. The catalytic surface is modeled by a nickel single crystal surface which can be cleaned and characterized in an ultra-high vacuum environment. In the first part, the techniques of surface science are used to characterize the bonding of adsorbates and to identify surface intermediates which might play a role during the hydrogenation of nitriles. In the second part, liquid-phase hydrogenation reactions of olefins are carried out on a polycrystalline platinum foil prepared in UHV.

The adsorption of acetonitrile on $\mathrm{Ni}(111)$ leads to an ordered $(2 \times 2)$ overlayer. Low-energy electron diffraction (LEED) intensity vs. energy (I-V) curves for this structure have been measured and analysed using an automated search method based on the Tensor LEED approximation. The adsorbed acetonitrile is bonded to the surface by both carbon and nitrogen with the $\mathrm{C}-\mathrm{N}$ axis almost parallel to the metal surface. The rehybridized acetonitrile on the surface is non-linear with a $\mathrm{C}-\mathrm{C}-\mathrm{N}$ angle estimated at $123^{\circ}$. Coadsorption of acetonitrile and hydrogen has also been studied, but no reaction between acetonitrile and hydrogen is observed in vacuum on $\mathrm{Ni}(111)$.

The bonding and geometry of methylamine $\left(\mathrm{CH}_{3} \mathrm{NH}_{2}\right)$ and ethylamine $\left(\mathrm{CH}_{3} \mathrm{CH}_{2} \mathrm{NH}_{2}\right)$ on $\mathrm{Ni}(111)$ have been investigated with high resolution electron energy loss vibrational spectroscopy (HREELS). Both amines adsorb molecularly at $150 \mathrm{~K}$ through the nitrogen lone pair. Significant metal-hydrogen interactions in the alkyl chain were indicated by "softened" C-H stretching modes with frequencies shifted to $2660-2680 \mathrm{~cm}^{-1}$. Thermal desurption spectroscopy (TDS) and HREELS were used to monitor their desorption and 
thermal decomposition on the $\mathrm{Ni}(111)$ surface. Both $\mathrm{CH}_{3} \mathrm{NH}_{2}$ and $\mathrm{CH}_{3} \mathrm{CH}_{2} \mathrm{NH}_{2}$ are dehydrogenated in the temperature range $300 \mathrm{~K}-400 \mathrm{~K}$. $\mathrm{CH}_{3} \mathrm{NH}_{2}$ is dehydrogenated to $\mathrm{HCN}$ at about $330 \mathrm{~K}$, which further decomposes above $360 \mathrm{~K} . \mathrm{CH}_{3} \mathrm{CH}_{2} \mathrm{NH}_{2}$ is dehydrogenated to $\mathrm{CH}_{3} \mathrm{CN}$, initially by $\alpha-\mathrm{C}-\mathrm{H}$ bond scission, leading to desorption of that molecule at 350 $\mathrm{K}$. Based on our spectra, we propose a mechanism for the dehydrogenation processes of $\mathrm{CH}_{3} \mathrm{NH}_{2}$ and $\mathrm{CH}_{3} \mathrm{CH}_{2} \mathrm{NH}_{2}$ on $\mathrm{Ni}(111)$.

The proposed dehydrogenation pathway of ethylamine was also examined by extended Hückel calculations. The binding energies of the decomposition products and intermediate surface species formed on $\mathrm{Ni}(111)$ from adsorption of ethylamine $\left(\mathrm{CH}_{3} \mathrm{CH}_{2} \mathrm{NH}_{2}\right)$ were calculated using a semi-empirical model based on the extended Hückel theory to calculate the energies of the surface ligands and the gas phase molecules. The results provide information about the energetics of the intermediate surface species which is not directly accessible experimentally.

The thermal decomposition of these simple amines on $\mathrm{Ni}(111)$ produces a $c(5 \sqrt{3} \times 9)$ rect LEED pattern similar to the one reported earlier after reaction of $\mathrm{H}_{2} \mathrm{~S}_{2} \mathrm{C}_{2} \mathrm{H}_{4}$, $\mathrm{CO}, \mathrm{NO}$ and $\mathrm{CH}_{3} \mathrm{CN}$ on a $\mathrm{Ni}(111)$ surface. We have measured LEED I-V curves of the structure obtained after deposition of carbon and nitrogen on a $\mathrm{Ni}(111)$ surface. The similarity between these I-V curves show that carbon and nitrogen have similar local geometries. The most intense spots of the $c(5 \sqrt{3} \times 9)$ rect LEED pattern are explained by the formation of a (100) orientation nickel monolayer, with the carbon or nitrogen atoms in the 4-fold hollow sites. This is supported by the qualitative similarity of the I-V curves with those of the $\mathrm{Ni}(100)-(2 \times 2)-2 \mathrm{C}$ structure for which $\mathrm{C}$ is found in the 4-fold hollow site.

In order to correlate the liquid phase activity and selectivity of a catalytic surface with its structure and composition, we have built and tested the first liquid phase hydrogenation cell coupled to an ultra-high vacuum surface analysis chamber. This novel apparatus is tested with the hydrogenation of cyclohexene to cyclohexane on a polycrystalline platinum foil, and then with the hydrogenation of 1-hexene to n-hexane. The hydrogenation of propionitrile is also attempted but no activity is detected. Hydrogenations of olefins and nitriles were also carried out on $\mathrm{Ni}(111)$ but no products could be formed. We explain the lack of activity of our nickel sample by the poisoning of the nickel surface by residual oxides in the liquid.

We finally review the techniques of surface science that have been applied to molecular level studies at both solid-gas and solid-liquid interfaces. We review the information 
accumulated from solid-gas interfaces studies on the effect of changing coverage, on bonding, and on trends of bonding across the periodic table. We discuss what is known about the surface structure, the surface chemical bond, the dynamics of surface atoms (diffusion, growth) and the reactivity of metal surfaces from solid-gas interface studies. In each section the available solid-liquid interface studies are also indicated. We hope to provide directions for future studies for those interested in correlating phenomena at solid-liquid and solid-gas interfaces. 


\section{Contents}

Acknowledgements $\quad$ v

1 Introduction 1

References ......................... 2

2 Experimental Methods 4

2.1 UHV chamber for surface preparation and analysis .......... 5

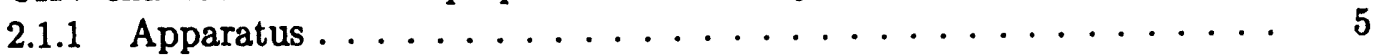

2.1.2 Sample preparation $\ldots \ldots \ldots \ldots \ldots$

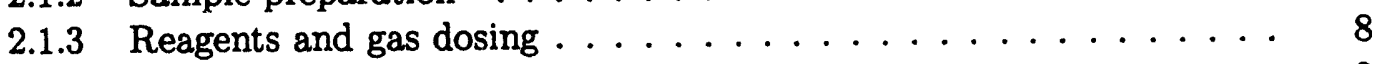

2.2 Surface Analysis Techniques . . . . . . . . . . . . . . . . 9

2.2.1 Auger electron spectroscopy (AES) . . . . . . . . . . . . 9

2.2.2 Thermal desorption spectroscopy (TDS) . . . . . . . . . . . 11

2.2.3 High-resolution electron energy loss spectroscopy (HREELS) . . . 13

2.2.4 Low-energy electron diffraction (LEED) . . . . . . . . . . . . . . 17

2.3 Reaction Cell for Studying Liquid Phase Catalytic Reactions on Well-Characterized

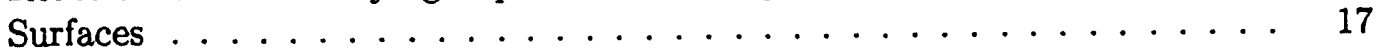

2.3.1 The UHV chamber . . . . . . . . . . . . . . . . . 19

2.3 .2 Transfer system . . . . . . . . . . . . . . . . . . 20

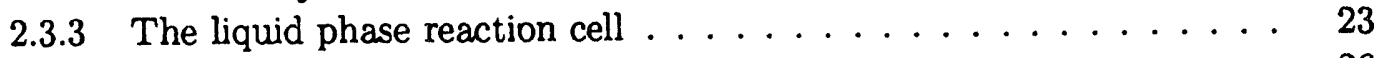

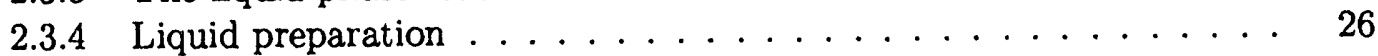

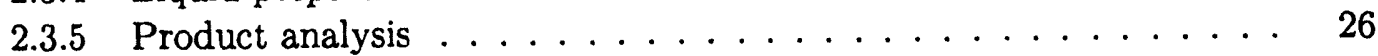

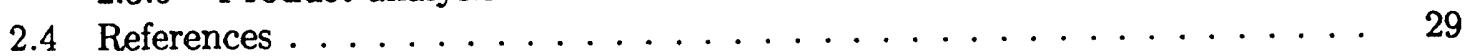

3 Bonding and Reactivity of $\mathrm{CH}_{3} \mathrm{CN}$ on $\mathrm{Ni}(111)$

3.1 Tensor LEED Analysis of the $\mathrm{Ni}(111)-\mathrm{p}(2 \times 2)-\mathrm{CH}_{3} \mathrm{CN}$ Structure . . . . . . 31

3.1 .1 Introduction . . . . . . . . . . . . . . . . 31

3.1.2 Principles of LEED structure determinations . . . . . . . . . . 32

3.1 .3 Results and discussion . . . . . . . . . . . . . . 35

3.2 Reactivity of Acetonitrile with Hydrogen on $\mathrm{Ni}(111) \ldots \ldots . . . . .44$

3.2.1 Hydrogen adsorption on $\mathrm{Ni}(111) \ldots \ldots \ldots 44$

3.2 .2 Acetonitrile and hydrogen coadsorption . . . . . . . . . . 46

3.3 References . . . . . . . . . . . . . . . . . . 48 
4 Bonding and Reactivity of $\mathrm{CH}_{3} \mathrm{NH}_{2}$ and $\mathrm{CH}_{3} \mathrm{CH}_{2} \mathrm{NH}_{2}$ on $\mathrm{Ni}(111) \quad 50$

4.1 Introduction ......................... 50

4.2 Vibrational Spectra of Molecular Methylamine and Ethylamine Adsorbed on

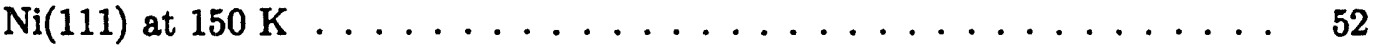

4.2 .1 Methylamine ......................... 52

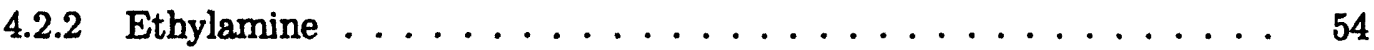

4.2 .3 Discussion . . . . . . . . . . . . . . . . . . 54

4.3 Thermal Decomposition of Methylamine and Ethylamine on $\mathrm{Ni}(111) \ldots \ldots$

4.3.1 Methylamine decomposition ............... 58

4.3.2 Ethylamine decomposition . . . . . . . . . . . . . 64

4.4 Summary . . . . . . . . . . . . . . . . . . 72

4.5 References . . . . . . . . . . . . . . . . . . 76

5 Molecular Modeling of Amine Dehydrogenation $\quad 78$

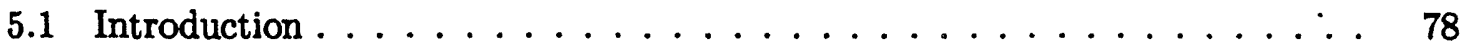

5.2 The Energy Calculation . . . . . . . . . . . . . . . . 79

5.2.1 Extended-Hückel theory . . . . . . . . . . . . . . 80

5.2 .2 Model . . . . . . . . . . . . . . . . . . . . 81

5.3 Results . . . . . . . . . . . . . . . . . . . 83

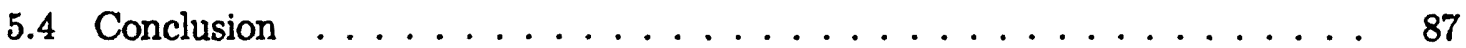

5.5 References . . . . . . . . . . . . . . . . . . . 89

6 Adsorbate Induced Reconstruction of the Ni(111) Surface 91

6.1 Introduction . . . . . . . . . . . . . . . . . . 91

$6.2 \mathrm{Ni}(111)-\mathrm{c}(5 \sqrt{ } 3 \times 9)$ rect-C and $\mathrm{Ni}(111)-\mathrm{c}(5 \sqrt{ } 3 \times 9)$ rect-N Surface Structures . . 92

6.2.1 Preparation method of the $\mathrm{Ni}(111)-\mathrm{c}(5 \sqrt{ } 3 \times 9)$ rect-C structure . . . . 92

6.2.2 LEED intensity analysis of the $\mathrm{Ni}(111)-\mathrm{c}(5 \sqrt{ } 3 \times 9)$ rect-C structure . . 93

6.2.3 Formation of the $\mathrm{Ni}(111)-\mathrm{c}(5 \sqrt{ } 3 \times 9)$ rect- $\mathrm{N}$ structure by decomposition of nitrogen containing molecules . . . . . . . . . . 100

6.2.4 LEED intensities of the $\mathrm{Ni}(111)-\mathrm{c}(5 \sqrt{ } / 3 \times 9)$ rect- $\mathrm{N}$ structure . . . . . . 101

6.2.5 Formation of $\mathrm{Ni}(111)-\mathrm{c}(5 \sqrt{ } 3 \times 9)$ rect-S by $\mathrm{H}_{2} \mathrm{~S}$ decomposition $\ldots . .103$

6.3 Formation of the $\mathrm{Ni}(111)-{ }^{-}(2 \times 6)^{\prime}-\mathrm{N}$ Structure . . . . . . . . . . . . . . . 103

6.4 Molecular Adsorption and Decomposition on the Ni(111)-c $(5 \sqrt{ } 3 \times 9)$ rect-C Superstructure . . . . . . . . . . . . . . . . 105

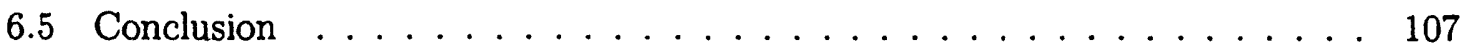

6.6 References . . . . . . . . . . . . . . . . . . 108

7 Liquid Phase Hydrogenation over Well-Characterized Surfaces 110

7.1 Introduction . . . . . . . . . . . . . . . . . . 110

7.2 Cyclohexene Hydrogenation . . . . . . . . . . . . . . . 111

7.2 .1 Reaction rate at $50^{\circ} \mathrm{C} \ldots \ldots \ldots \ldots 113$

7.2 .2 Reaction rate as a function of temperature . . . . . . . . . . 113

7.3 1-Hexene Hydrogenation . . . . . . . . . . . . . . . . 117

7.4 Miscellaneous . . . . . . . . . . . . . . . . . . . . . . . . . . 119

7.4 .1 Hydrogenation on nickel . . . . . . . . . . . . . . . . 119 
7.4.2 Hydrogenation of nitrile . . . . . . . . . . . . . . . . 119

7.5 References . . . . . . . . . . . . . . . . . . 120

8 Correlations of Atomic Structure and Reactivity at Solid-Gas and SolidLiquid Interfaces

8.1 Introduction . . . . . . . . . . . . . . . . . . 121

8.2 The Surface Chemical Bond . . . . . . . . . . . . . . . . 127

8.2 .1 Cluster-like bonding . . . . . . . . . . . . . . . . . . 127

8.2.2 Binding energy trends across the periodic table . . . . . . . . 128

8.2.3 Coverage dependence of the heat of adsorption . . . . . . . . 136

8.2.4 Temperature dependent changes of structure and bonding. . . . . . 136

8.3 Surface Structure . . . . . . . . . . . . . . . . . . . . . 136

8.3.1 Surface reconstruction and relaxation . . . . . . . . . 136

8.3.2 Adsorbate structure . . . . . . . . . . . . . . . . 155

8.3.3 Defect sites and rough surfaces are chemically more active . . . . 156

8.4 Coadsorption . . . . . . . . . . . . . . . . 156

8.5 Dynamics at Surfaces . . . . . . . . . . . . . . . . . 160

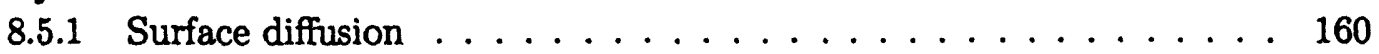

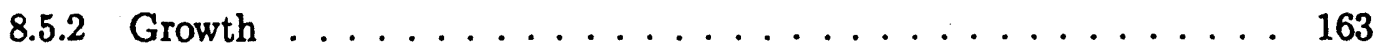

8.6 Surface Reactions . . . . . . . . . . . . . . . . . . . 163

8.6.1 Structure sensitive and structure insensitive reactions . . . . . 163

8.6 .2 Structure and bonding modifiers . . . . . . . . . . . . 167

8.6.3 Enhanced activity at oxide-metal interfaces . . . . . . . . . . 171

8.7 The Missing Links . . . . . . . . . . . . . . . . . . . . . . 171

8.8 References . . . . . . . . . . . . . . . . . . . . 175 


\section{Acknowledgements}

All this work would not have been possible without the help and contribution of many people that I wish to thank. As a student at the Ecole Normale Supérieure in Paris, in 1989, I was looking for an opportunity to spend some time in an American university as an exchange student. Professor Michel Che, head of the Surface Reactivity and Structure laboratory at the University of Paris VI, introduced me to the research laboratory of RhônePoulenc, the largest french pharmaceutical company. Rhône-Poulenc was building a network of scientific collaborations with universities throughout the world. Soon I met Professor Gabor Somorjai at a workshop organized in Paris by Rhône-Poulenc. Gabor gave me the tremendous opportunity to join his international group of scientists at the University of California at Berkeley. I would like to thank Gabor for all the support and the precious advices that he gave me during my stay in Berkeley.

My thanks to Gabor Somorjai and Georges Cordier, senior scientist at RhônePoulenc, responsible for this collaboration. I was given a very exciting and challenging research project, with almost unlimited freedom. Vincent Maurice and Colette Knight taught me the basics of surface science and UHV techniques. Michael Quinlan, Pedro Pereira, Jim Powers, and Sabrina Fu were constant sources of encouragement. And I want to thank James Batteas, Pin Chen, Marie-Paule Delplancke, Kazu Kobayashi and Zafira Nomikou for their support and friendship. My collaborations during the last two years with Angelo Barbieri, Peter Ditlevsen, Nick Materer, Colin Stanners, Jean-Paul Biberian and Michel Van Hove were as fruitful as enjoyable. During my trips to France, I always had very interesting and useful conversations with Eric Brazi, Pierre Fouilloux, Jean Jenck, and Marc Joucla at the C.N.R.S./Rhône-Poulenc Laboratory, in Décines.

I thank also Bob Kehr, Gloria Osterloh, and Brigid Tung for their help.

The design and building of new equipment for research would not be possible without the contributions of the people in the machine shops. For its professionalism, I would like to thank particularly Ron Dalporto of the department of chemistry machine shop.

And most of all, I thank my fiancée Savandara Arellano who made my life in the bay area so enjoyable.

This work was supported in part by the Director, Office of Energy Research, Office of Basic Energy Sciences, Materials Sciences Division of the US Department of Energy under Contract No. DE-AC03-76SF00098. 


\section{Chapter 1}

\section{Introduction}

The hydrogenation of nitriles is commercially the most commonly used procedure for the preparation of diverse amines. Amines find application in many fields of modern technology. Low-molecular weight amines $\left(\mathrm{C}_{1}-\mathrm{C}_{6}\right)$ are valuable intermediates in the chemical and pharmaceutical industries, while the higher, fatty amines are used in the preparation of surface active agents and corrosion inhibitors [1]. The hydrogenation of adiponitrile produces hexamethylenediamine, a starting compound for nylon 6,6 production $[2,3]$.

These reactions are usually carried out in the liquid phase at elevated hydrogen pressures (1-40 atm) and temperatures ranging from 50 to $250^{\circ} \mathrm{C}$ in the presence of various metallic catalysts. Because of the high reactivity of partially hydrogenated intermediates, the hydrogenation of nitriles usually leads to a mixture a primary, secondary and tertiary amines. This can be very important since for example, the quality of nylon 6,6 depends greatly on the grade of the hexamethylenediamine that is used. Therefore it is highly desirable to control the selectivity of the reaction towards the desired product. The kind of active metal used in nitrile hydrogenation has a decisive influence on the composition of the product mixture [4].

Suitable metals for the catalytic hydrogenation of nitriles are $\mathrm{Ni}, \mathrm{Co}, \mathrm{Cu}, \mathrm{Pd}$, $\mathrm{Pt}$, and $\mathrm{Rh}$ [5]. Nickel and cobalt are the catalyst of choice when the aim is to produce the primary amines. Palladium- and platinum- based catalysts are known to be selective towards tertiary amines. Raney nickel is commonly used, since it combines satisfactory activity with exceptionnally high selectivity towards primary amines. Nickel is cheap, and the particle size and specific density of Raney nickel are particularly attractive for liquid phase hydrogenations because it can be separated from the product mixture by settling and 
filtration.

The work described in this thesis is aimed at providing information about the mechanism and factors affecting the performance of nickel-based catalysts in nitrile hydrogenations. The catalytic surface is modeled by a nickel single crystal surface which can be cleaned and characterized in an ultra-high vacuum environment. In chapter 3, 4, 5 and 6 , the techniques of surface science are used to characterize the bonding of nitriles and arnines to a $\mathrm{Ni}(111)$ surface and to identify surface intermediates which might play a role during the hydrogenation of nitriles.

In order to correlate the liquid phase activity and selectivity of a catalytic surface with its structure and composition, we have built and tested a liquid phase hydrogenation cell coupled to an ultra-high vacuum surface analysis chamber. The axperimental set-up is described in chapter 2. The apparatus was initially designed to study the hydrogenation of nitriles on a nickel surface. In the course of the study, we realized that the nickel surface is oxidized very quickly and irreversibly in the liquid environment. Liquid-phase hydrogenations of cyclohexene and 1-hexene on a platinum foil were carried out successfully. The results are reported in chapter 7 .

This attempt to combine the techniques of surface science to liquid phase catalytic measurement is a contribution towards the fundamental understanding of molecular processes at the solid-liquid interface. In chapter 8 , we discuss what is known about the surface structure, the surface chemical bond, the dynamics of surface atoms (diffusion, growth) and the reactivity of metal surfaces from solid-gas interface studies. In each section the available solid-liquid interface studies are also indicated. We hope to provide directions for future studies for those interested in correlating phenomena at solid-liquid and solid-gas interfaces.

\section{References}

(1) F.E. Friedli, and R.M. Gilbert, J. Am. Oil Chem. Soc., 67 (1990) 48.

[2] A.Y. Lazaris, E.N. Zil'berman, É.V. Lunicheva, and A.M. Vedin, Zh. Prikl. Chim., 38 (1965) 449.

[3] F. Medina, P. Salagre, J.E. Sueiras, and J.L.G. Fierro, J. Mol. Cat., 68 (1991) L17-20.

[4] J. Volf, and J. Pašek, Stud. Surf. sci. and Cat., vol.27, p.105 (Elsevier, Amsterdam, 1983). 
[5] C.L. Thomas, Catalatyc Processes and Proven Catalysts (Academic Press, New-York, 1970) 


\section{Chapter 2}

\section{Experimental Methods}

In this thesis, we have been working with the idea that the fundamental understanding of catalytic reactions requires the use of well-characterized surfaces (i.e. surfaces with known structure and composition). For that purpose, single crystal faces and polycrystalline foil of high purity materials, prepared in an ultra-high vacuum (UHV) environment, were used as model catalytic surfaces. On such surfaces, the determination of the structure and reactivity of adsorbates by various surface characterization techniques is possible. UHV is necessary during the preparation and characterization of the surface and it ensures that gases, other that those of interest, do not adsorb on the metal surface during surface characterization experiment. When liquid phase catalytic reaction needs to be carried out, the transfer of the catalytic surface, from the UHV to a liquid phase reaction cell, is necessary. One main experimental challenge in this work was to design and build a transfer system to move the model catalyst from UHV to a liquid environment.

This chapter first describes the ultra-high vacuum system used during this research for studying the structure and bonding of adsorbates on single crystal surfaces. The principles of sample preparation and surface analysis techniques are overviewed. The design of the liquid phase reaction cell coupled to a UHV system, that was built during the course of this thesis, is then reported. 


\subsection{UHV chamber for surface preparation and analysis}

\subsubsection{Apparatus}

A schematic diagram of the ultra-high vacuum system used in this work is shown in figure 2.1 and a photograph is shown in figure 2.2. A $400 \mathrm{l} / \mathrm{s}$ ion pump (Varian) provides the main pumping for the chamber. Base pressure of $\sim 2 \times 10^{-10}$ torr can be achieved after a 36 hours bake out at $450 \mathrm{~K}$. A $200 \mathrm{l} / \mathrm{s}$ diffusion pump (Varian) provides auxiliary pumping, especially during cycles of argon sputtering. The stainless steel chamber is constructed in two levels: The lower level is devoted to the high resolution electron energy loss spectrometer enclosed in $\mu$-metal shielding to reduce the background magnetic fields. The upper level of the vacuum system contains equipment for analysing and cleaning the sample : a four-grid retarding field energy analyser (Varian) for low-energy electron diffraction and Auger spectroscopy, a glancing incidence electron gun (Cliftronics) for Auger spectroscopy, a quadrupole mass spectrometer (UTI $100 \mathrm{C}$ ) for residual gas analysis and thermal desorption spectroscopy, an ion sputtering gun (PHI) for sample cleaning, a nude ionization gauge (Varian) for pressure measurement and two variable leak valves (Varian) for gas exposure.

The single crystal sample is transfered from one level to the other by an extended travel $(250 \mathrm{~mm})$ manipulator. The sample is mounted by welding thin ( 0.020 inch dia.) $\mathrm{Ni}$ wire to the back side of the sample and to the closed ends of two stainless steel tubes, through which liquid nitrogen can flow in order to obtain sample temperatures as low as 100 $\mathrm{K}$. The sample is heated to temperatures as high as $1100 \mathrm{~K}$ by passing 10 to $20 \mathrm{~A}$ through the sample. Sample temperatures are measured with a digital thermometer (Doric) and a chromel-alumel thermocouple spotwelded to the top of the sample.

\subsubsection{Sample preparation}

\section{Sample materials}

The Ni(111) samples used in this thesis were cut from a nickel boule $(99.995 \%$ pure) purchased from Monocrystals. The single crystal was cut by spark erosion into a thin $(\sim 1 \mathrm{~mm})$ disc to within $1^{\circ}$ of the (111) orientation as determined by Laue back reflection $\mathrm{x}$-ray diffraction. The samples were mechanically polished using diamond paste and alumina powder (down to $0.05 \mu \mathrm{m}$ diameter). The 0.005 inch thick $\mathrm{Pt}$ foil $(99.995 \%$ pure) was cut with scissors in a $1 \mathrm{~cm} \times 1 \mathrm{~cm}$ piece. 


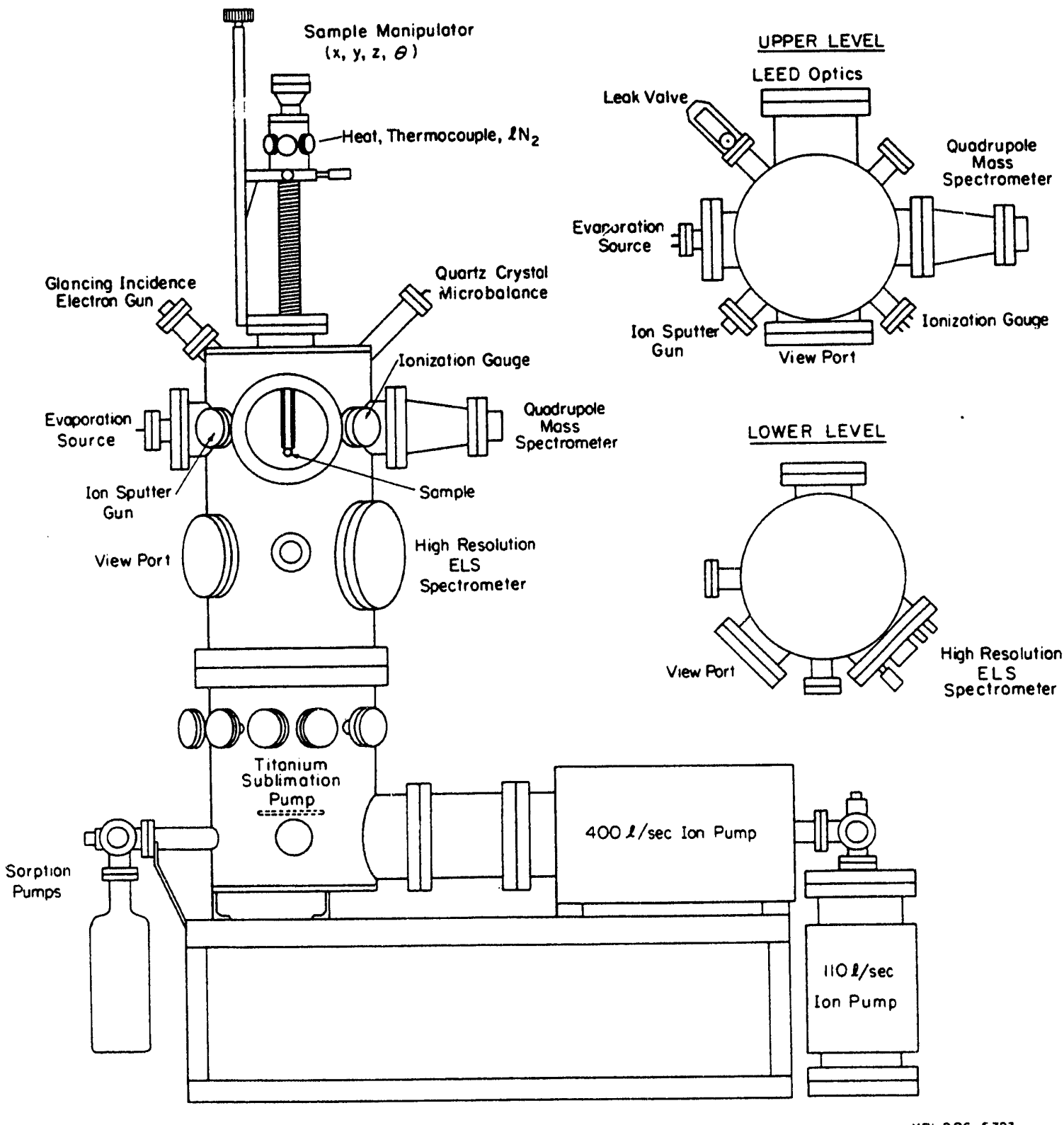

XBL. B O6- 5323

Figure 2.1: Schematic diagram of the vacuum system. Sample cleaning, Auger electron spectroscopy, thermal desorption spectroscopy and low-energy electron diffraction occur on the upper level, while vibrational spectroscopy is performed on the lower level . 


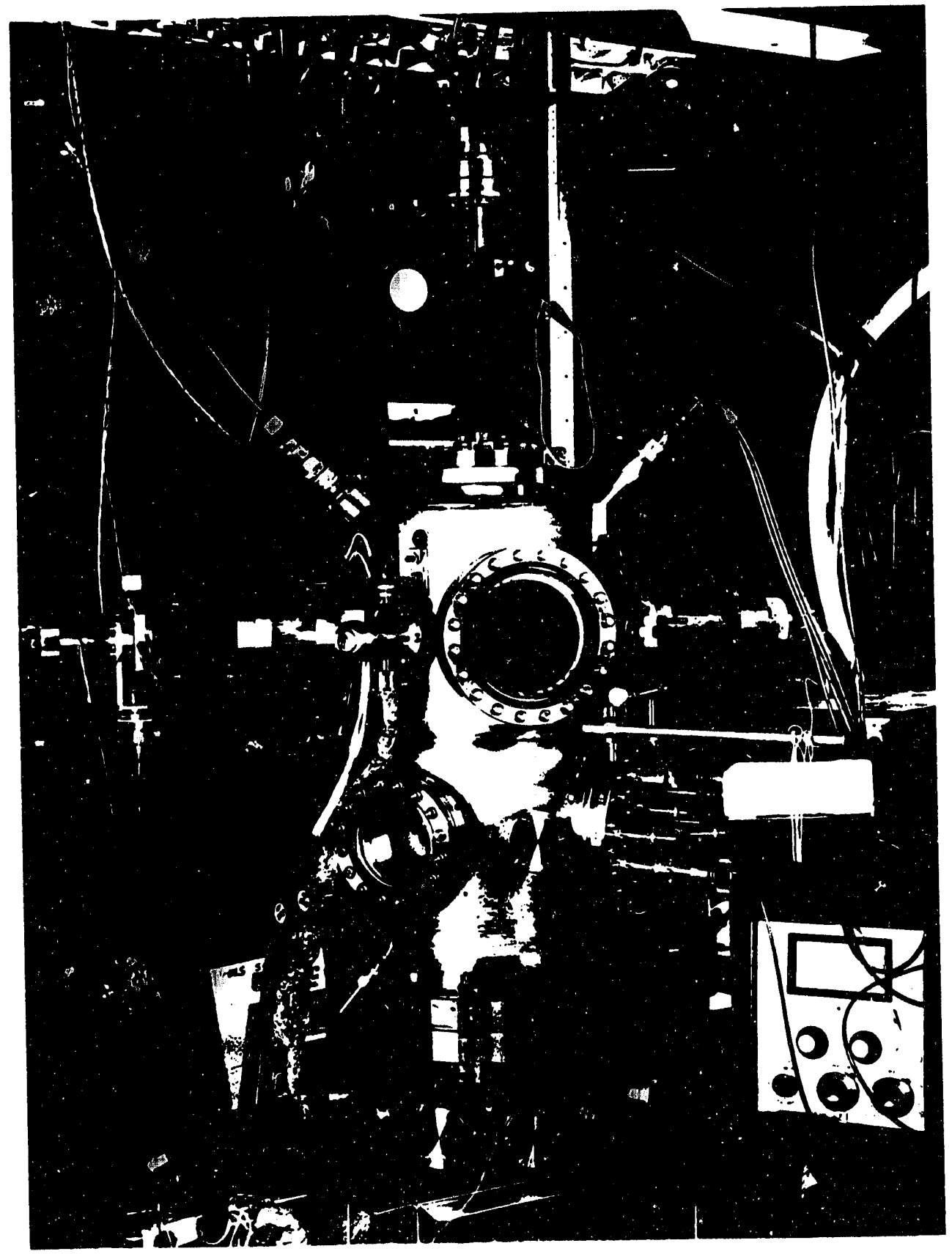

Figure 2.2: Photograph of vacuum system shown in figure 2.1. 


\begin{tabular}{|l|l|l|}
\hline Reagent & Source & Purity (wt \%) \\
\hline Acetonitrile $\left(\mathrm{CH}_{3} \mathrm{CN}\right)$ & Fluka & $>99 \%$ \\
Methylamine $\left(\mathrm{CH}_{3} \mathrm{NH}_{2}\right)$ & Fluka & $>99 \%$ \\
Ethylamine $\left(\mathrm{CH}_{3} \mathrm{CH}_{2} \mathrm{NH}_{2}\right)$ & Fluka & $>99 \%$ \\
Ethylene $\left(\mathrm{CH}_{2} \mathrm{CH}_{2}\right)$ & Matheson & $>99 \%$ \\
Cyclohexene $\left(\mathrm{C}_{6} \mathrm{H}_{10}\right)$ & Fluka & $>99.5 \%$ \\
1-hexene $\left(\mathrm{C}_{6} \mathrm{H}_{12}\right)$ & Aldrich & $>99 \%$ \\
Octane $\left(\mathrm{C}_{8} \mathrm{H}_{18}\right)$ & Fischer Scientific & $>99 \%$ \\
Argon $(\mathrm{Ar})$ & Airco & \\
Oxygen $\left(\mathrm{O}_{2}\right)$ & Matheson & \\
Nitrogen $\left(\mathrm{N}_{2}\right)$ & Liquid Air & \\
Hydrogen $\left(\mathrm{H}_{2}\right)$ & Liquid Air & \\
\hline
\end{tabular}

Table 2.1: List of reagents used in this thesis.

\section{Sample cleaning}

For the Ni(1i1) samples, the main impurities observed were sulfur and carbon. Sulfur can be removed by cycles of $\mathrm{Ar}^{+}$sputtering at $900-1000 \mathrm{~K}\left(5 \times 10^{-5}\right.$ torr $\mathrm{Ar}, 1.0 \mathrm{keV}$, 15 minutes), while carbon requires heating the sample in $5 \times 10^{-7}$ torr $\mathrm{O}_{2}$ at $700-800 \mathrm{~K}$ for 5-10 minutes. After cleanliness of the sample has been checked by Auger spectroscopy, the sample is annealed in vacuum for 5 minutes at $1100 \mathrm{~K}$. For cleaning $\mathrm{Pt}$ foils, a similar procedure was followed.

\subsubsection{Reagents and gas dosing}

A list of the reagents used in this thesis is found in table 2.1. Nitriles and hydrocarbons were outgassed by series of freeze-pump-thaw cycles at $77 \mathrm{~K}$ before use. Amines and other gases were used as supplied.

Dosing of gases into the vacuum chamber is achieved through variable leak valves either by backfilling the chamber or by introduction through a microchannel doser facing the sample surface to prevent too much contamination of the chamber walls. The unit of gas exposure is the Langmuir (L), which corresponds to a $10^{-6}$ torr second. The Langmuir is a convenient unit of exposure for surface science studies as it corresponds, for a one Langmuir exposure, to roughly one atom or molecule striking the surface per available surface site [1]. In this thesis, all the exposures reported are uncorrected for the ion gauge sensitivity. 


\begin{tabular}{|c|c|c|}
\hline Technique & Principle & Applications \\
\hline $\begin{array}{l}\text { Auger electron } \\
\text { spectroscopy (AES) }\end{array}$ & $\begin{array}{l}\text { Detection and analysis } \\
\text { of Auger electrons emit- } \\
\text { ted by surface atoms }\end{array}$ & $\begin{array}{l}\text { Surface elemental com- } \\
\text { position }\end{array}$ \\
\hline $\begin{array}{l}\text { Thermal } \\
\text { desorption spectroscopy } \\
\text { (TDS) }\end{array}$ & $\begin{array}{l}\text { Detection of desorption } \\
\text { products as a function of } \\
\text { temperature }\end{array}$ & $\begin{array}{l}\text { Binding energy, surface } \\
\text { coverage, surface reac- } \\
\text { tions }\end{array}$ \\
\hline $\begin{array}{l}\text { High-resolution electron } \\
\text { energy loss spectroscopy } \\
\text { (HREELS) }\end{array}$ & $\begin{array}{l}\text { Inelastic scattering of } \\
\text { low energy }(1-150 \mathrm{eV}) \\
\text { elcatrons }\end{array}$ & $\begin{array}{l}\text { Vibrational spec- } \\
\text { troscopy of adsorbates }\end{array}$ \\
\hline $\begin{array}{l}\text { Low-energy electron } \\
\text { diffraction (LEED) }\end{array}$ & $\begin{array}{l}\text { Diffraction of low energy } \\
(10-500 \mathrm{eV}) \text { electrons }\end{array}$ & Surface structure \\
\hline
\end{tabular}

Table 2.2: List of surface science analysis techniques used in this thesis.

\subsection{Surface Analysis Techniques}

Many techniques have been developed over the last 30 years to study the structure, bonding and reactivity of submonolayer quantities of molecules adsorbed on metal surfaces. A list of the surface science techniques used in this thesis is shown in table 2.2. In many of these, including AES, HREELS and LEED, the surface and adsorbates are probed by measuring the energy of slow electrons (3-1000 eV) that are emitted, scattered or diffracted by the surface. Electrons in this energy range are surface sensitive; they are able to penetrate through or escape from only the first few atomic layers near the surface [2]. A review of the principles and applications of these techniques can be found in the literature $[3,4,5]$. In this section, we overview the techniques that were used in this thesis (table 2.2).

\subsubsection{Auger electron spectroscopy (AES)}

When an excited atom is left with a missing electron in its inner shell, de-excitation can be accompanied by $x$-ray radiation or by transfer of the energy to an outer shell electron with a given kinetic energy (figure 2.3). This second process is known as the Auger process and the kinetic energy of the ejected electron (Auger electron) is characteristic of the element from which it has been ejected $[6,7,8]$. 


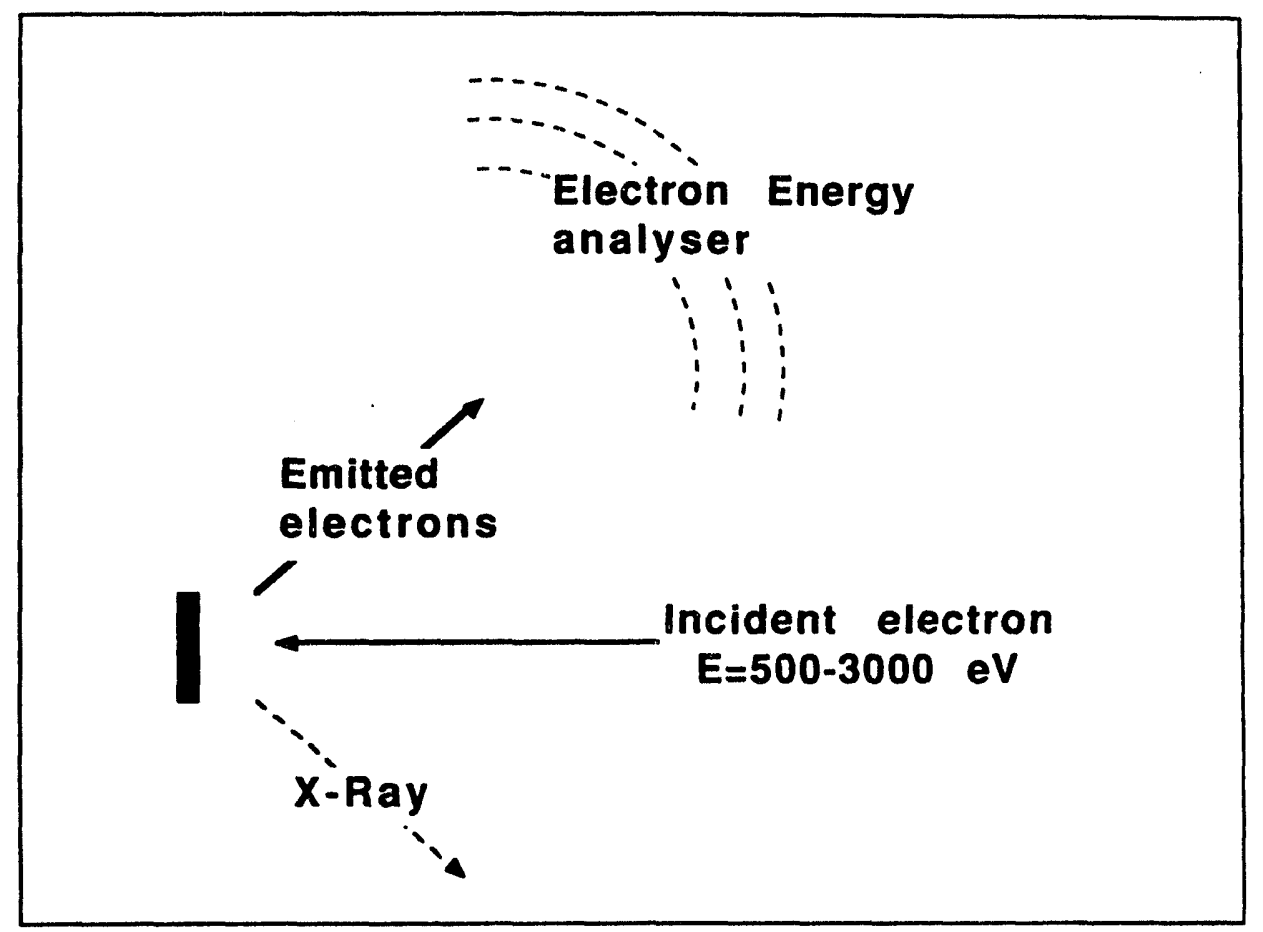

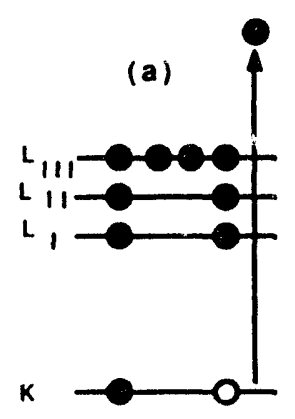

Excitation
Auger electron

(b)

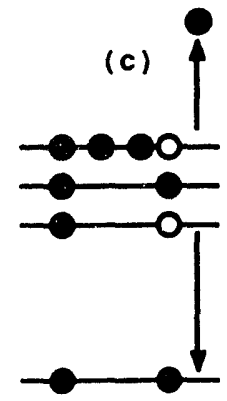

De-excitation

\section{Auger Electron Spectroscopy}

XBL $9311-1561$

Figure 2.3: Principle of Auger electron spectroscopy : Excitation of an atom with a core hole (a), de-excitation of the ionized atom via x-ray radiation (b), de-excitation of the ionized atom via emission of an Auger electron. 
Auger electron spectroscopy consists in the excitation of surface atoms and the measurement of the kinetic energy of emitted electrons. In this work, the excitation of surface atoms was achieved by an electron beam with energies typically of $2 \mathrm{keV}$ impinging on the surface. The Auger electrons were detected and analysed with a four-grid LEED optics used as a retarding field analyser. The spectra were recorded in the first derivative mode $\left(\frac{d N(E)}{d E}\right)$ in order to readily distinguish the Auger electrons from the relatively smooth background of secondary electrons. Analysis of the chemical composition of the surface is done by comparing the measured electron energies to tables of Auger electron energies [9]. An AES spectra of clean and $\mathrm{CH}_{3} \mathrm{CH}_{2} \mathrm{NH}_{2}$ covered $\mathrm{Ni}(111)$ surface is shown in figure 2.4.

The amount of submonolayer elements on the surface can be quantified by measuring the ratio of the characteristic Auger peaks of the element in the spectra ta those of the metal surfaces.

\subsubsection{Thermal desorption spectroscopy (TDS)}

Thermal desorption spectroscopy (TDS), also referred to as temperature programmed desorption (TPD), probes the kinetics of desorption from surfaces. It provides information on adsorption state, energy of bonding, amount of adsorbed product, chemical reactions on surfaces and adsorbate-adsorbate interactions. In a typical TDS experiment, an adsorbate covered surface is heated (usually linearly with time) in UHV, and the desorption products are detected as a function of temperature with a mass spectrometer (figure 2.5). For TDS experiments performed under conditions of rapid pumping speeds, the mass spectrometer signal is proportional to the desorption rate. For some simple cases, where the activation energy does not change with coverage, it has been shown [10] that the temperature of the maximun desorption rate, $T_{p}$, is related to the activation energy for desorption, $E_{d}$, the preexponential factor, $A$, the heating rate, $\beta$, and the initial surface coverage, $\theta_{o}$, by :

$$
\begin{gathered}
E_{d} /\left(R T_{p}\right)^{2}=\left(A_{1} / \beta\right) \exp \left(\frac{-E_{d}}{R T}\right) \text { for first order and } \\
E_{d} /\left(R T_{p}\right)^{2}=\left(A_{2} / \beta\right) \theta_{o} \exp \left(\frac{-E_{d}}{R T}\right) \text { for second order desorptions. }
\end{gathered}
$$

In this thesis, TD spectra were used to determine the binding energy of adsorbate, follow surface chemical reactions and detect their products. During the desorption experiments, the crystal face was pointed towards the mass spectrometer, which was $\sim \overline{\mathrm{cm}}$ from the 


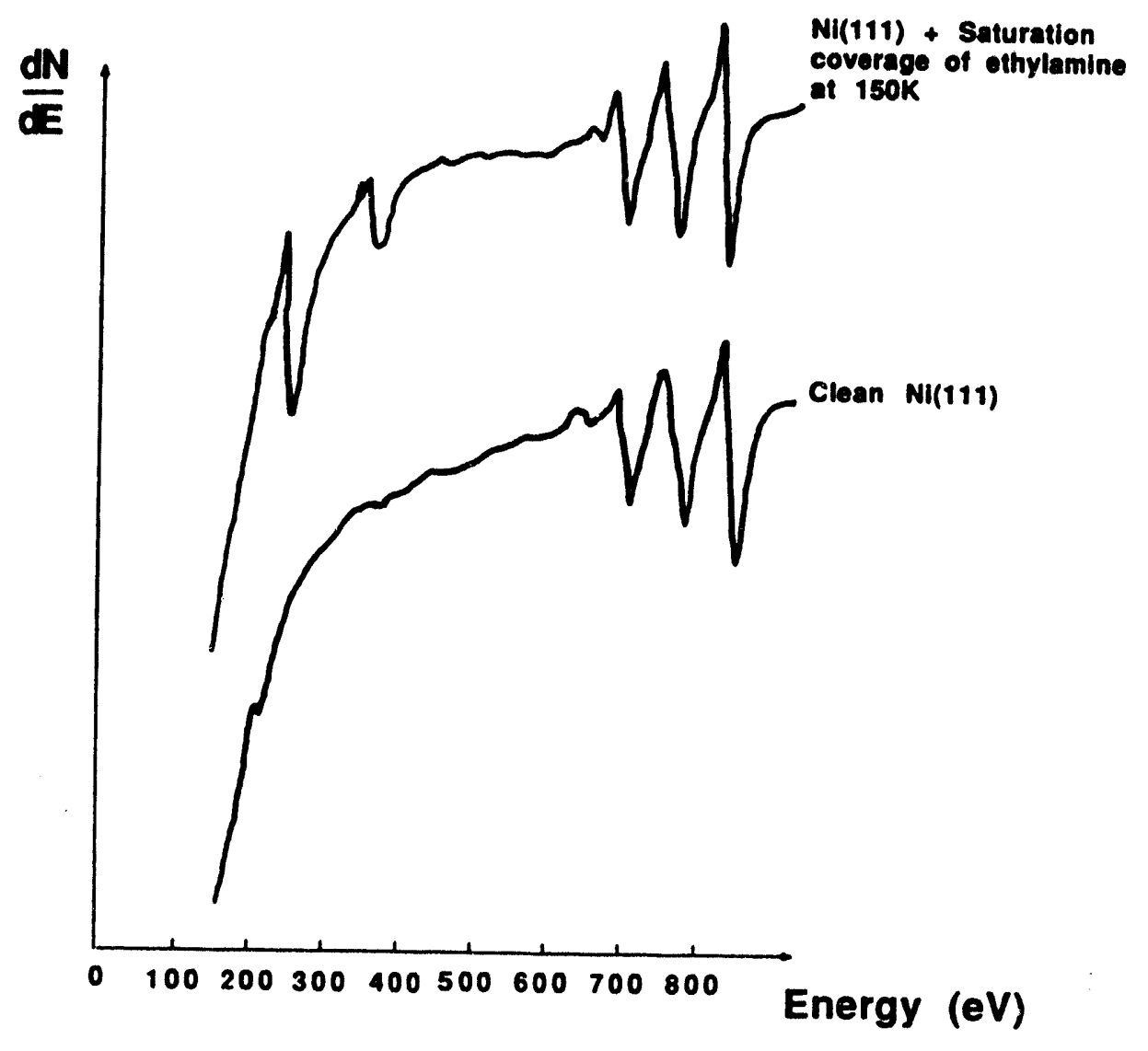

Examples of Auger spectra

XBL $9311-1562$

Figure 2.4: AES spectra of clean and $\mathrm{CH}_{3} \mathrm{CI}_{2} \mathrm{NH}_{2}$ covered $\mathrm{Ni}(111)$ surface. 
crystal. The heating ramp was achieved by running a constant current through the crystal $(20 \mathrm{~A})$, leading to a heating rate of $8-15 \mathrm{~K} / \mathrm{s}$ from 100 to $800 \mathrm{~K}$.

\subsubsection{High-resolution electron energy loss spectroscopy (HREELS)}

A schematic diagram of an HREELS experiment on a c(4x2) monolayer of $\mathrm{CO}$ on $\mathrm{Ni}(111)$ is shown in figure 2.6. A monoenergetic electron beam $(1-10 \mathrm{eV})$ is incident on the CO-covered surface. Most of the electrons are elastically scattered, but 0.1-1 percent lose discrete amounts of energy, as a result of exciting surface vibrations. The electrons scattered from the surface (usually those in a small solid angle about the specular direction) are energy analysed, and the number of electrons are plotted versus energy loss to give a HREEL spectrum like that in figure 2.6. Figure 2.7 shows a schematic of the HREEL spectrometer used in this thesis [11].

The theory of the electron scattering is reviewed in reference [12]. There are two basic scattering mechanisms that need to be known to fully interpret HREEL spectra, in particular intensities and seleztion rules: Long range electron scattering at 10-100 $\AA$ distances from the surface is called dipole scattering. It is due to interactions between dynamic dipole moments associated with each vibrational mode and the electrostatic potential of the incoming electron. Short range scattering involves interactions between the incoming electron and charge densities of adsorbates through polarization (impact scattering), or electron capture in the immediate vicinity of the adsorbate (resonance scattering). Long and short range interactions can be distinguished since the former have a strong angular dependence, with appreciable intensity only around the specular scattering. Short range interactions, on the other hand, are more isotropic. A dipole moment selection rule applies to the electrostatic-dipole interaction, so that only vibrations with dipole components perpendicular to the surface are detected this way. This selection rule is useful for assigning the vibrational modes, because vibrations that belong to totally symmetric representations $\left(A_{1}, A^{\prime}\right.$, and $\left.A\right)$ are usually intense in the specular direction, and are almost absent in non specular directions. Additional information can be obtained by isotopically labelling the adsorbate, and by comparison with gas or liquid phase compounds and with organometallic analogues. 


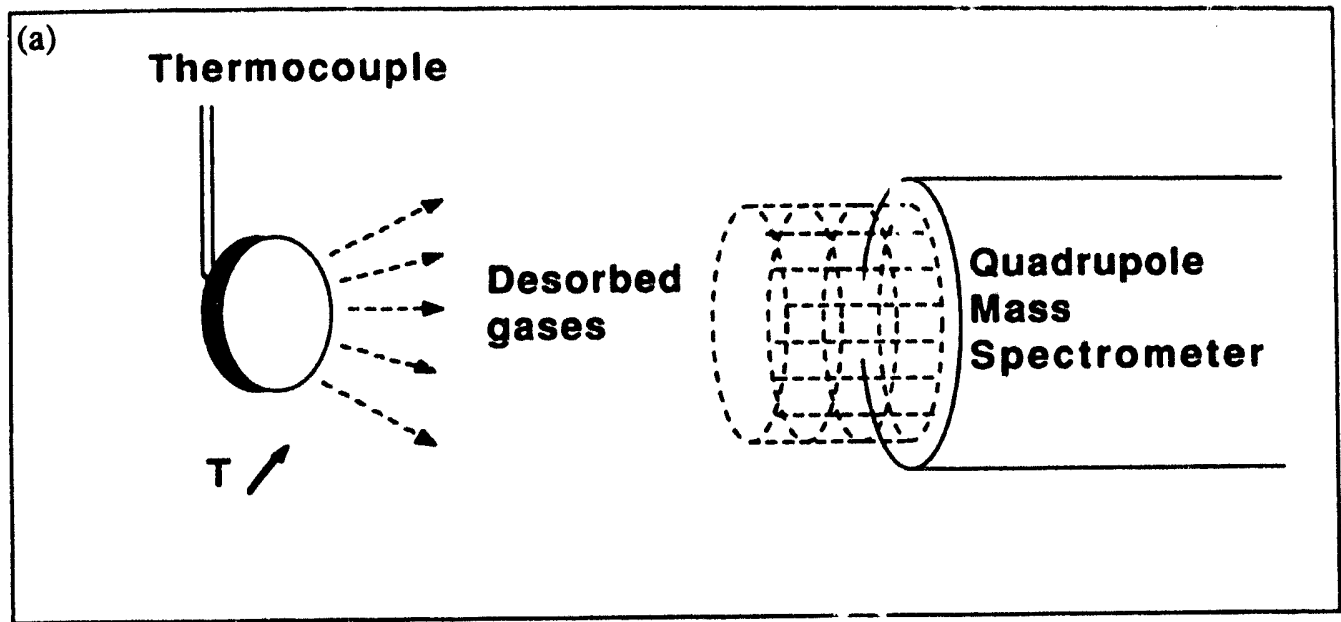

(b)

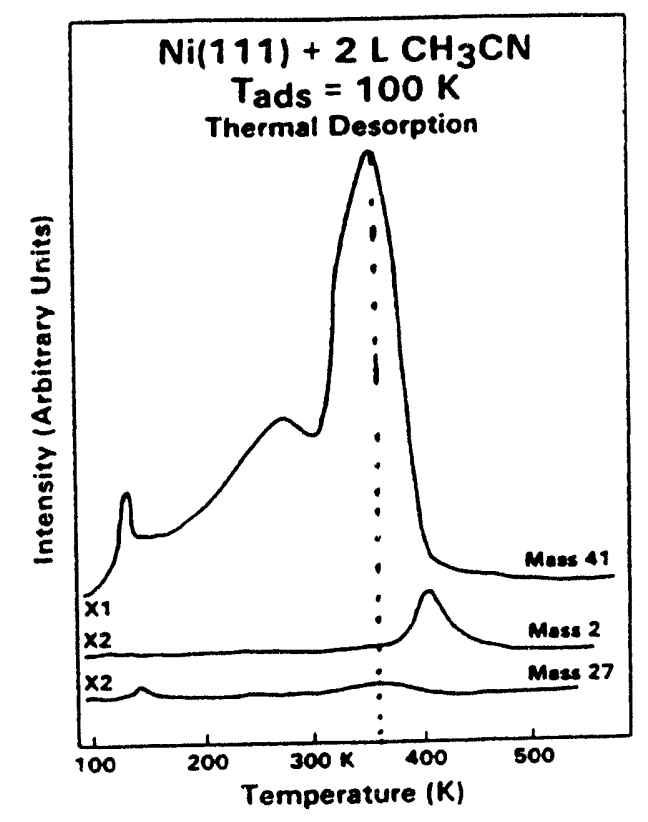

TPD spectrum of acetonitrile on $\mathrm{Ni}(111)$

\section{Temperature Programmed Desorption}

XBL $9311-1563$

Figure 2.5: Schematic of the thermal desorption spectroscopy (TDS) experiment (a) and $\mathrm{TD}$ spectrum of acetonitrile adsorbed on $\mathrm{Ni}(111)$ (b). 


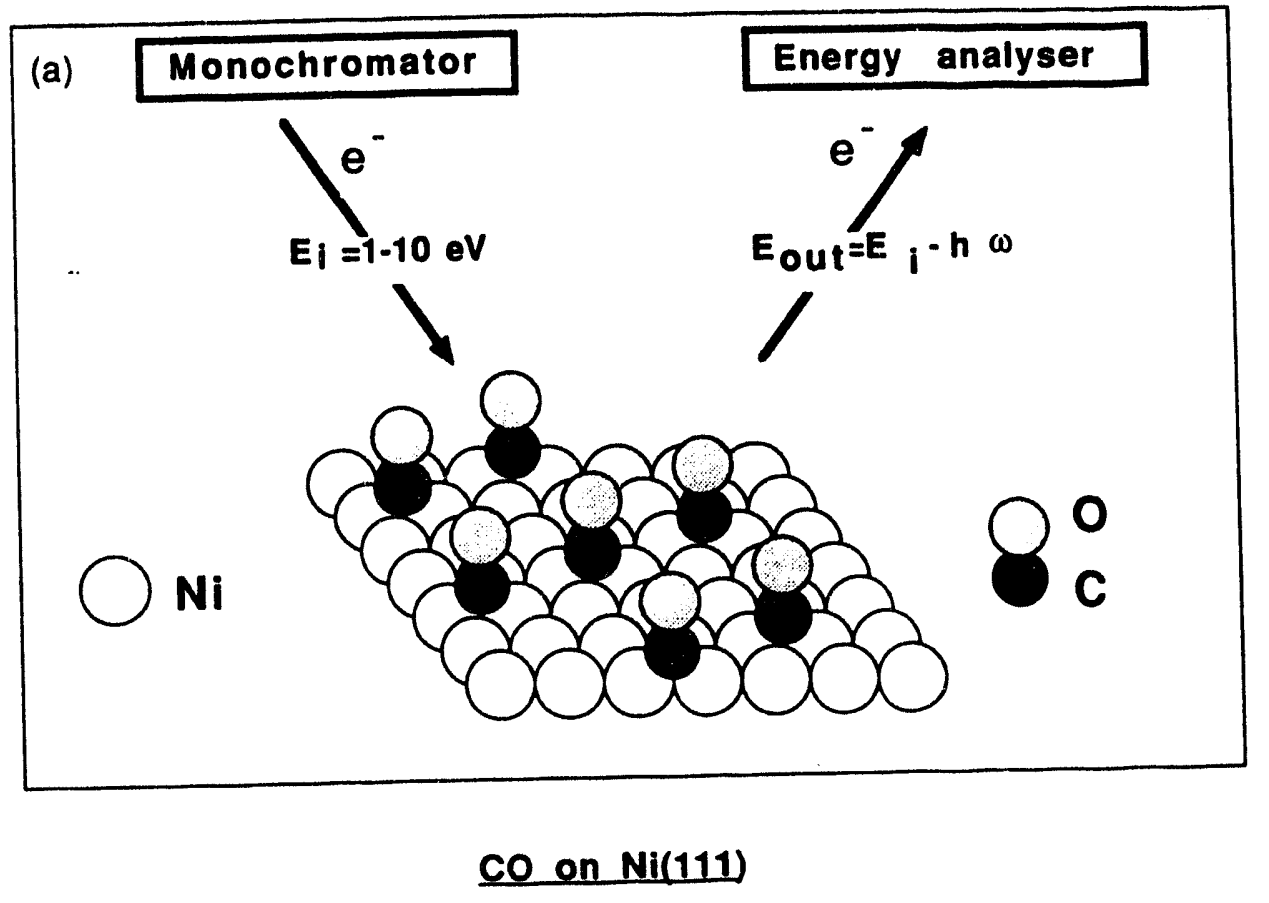

(b)

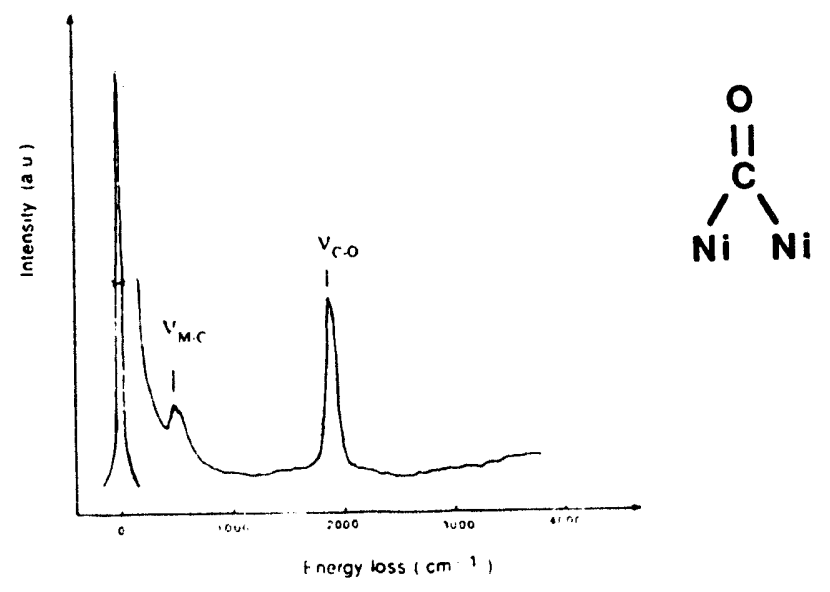

High Resolution Electron Energy Loss Spectrocopy

XBL $9311-1564$

Figure 2.6: Schematic of the high resolution electron energy loss spectroscopy experiment, illustrated with the vibrational spectrum of $\mathrm{Ni}(111)-\mathrm{c}(4 \times 2)-\mathrm{CO}$. 


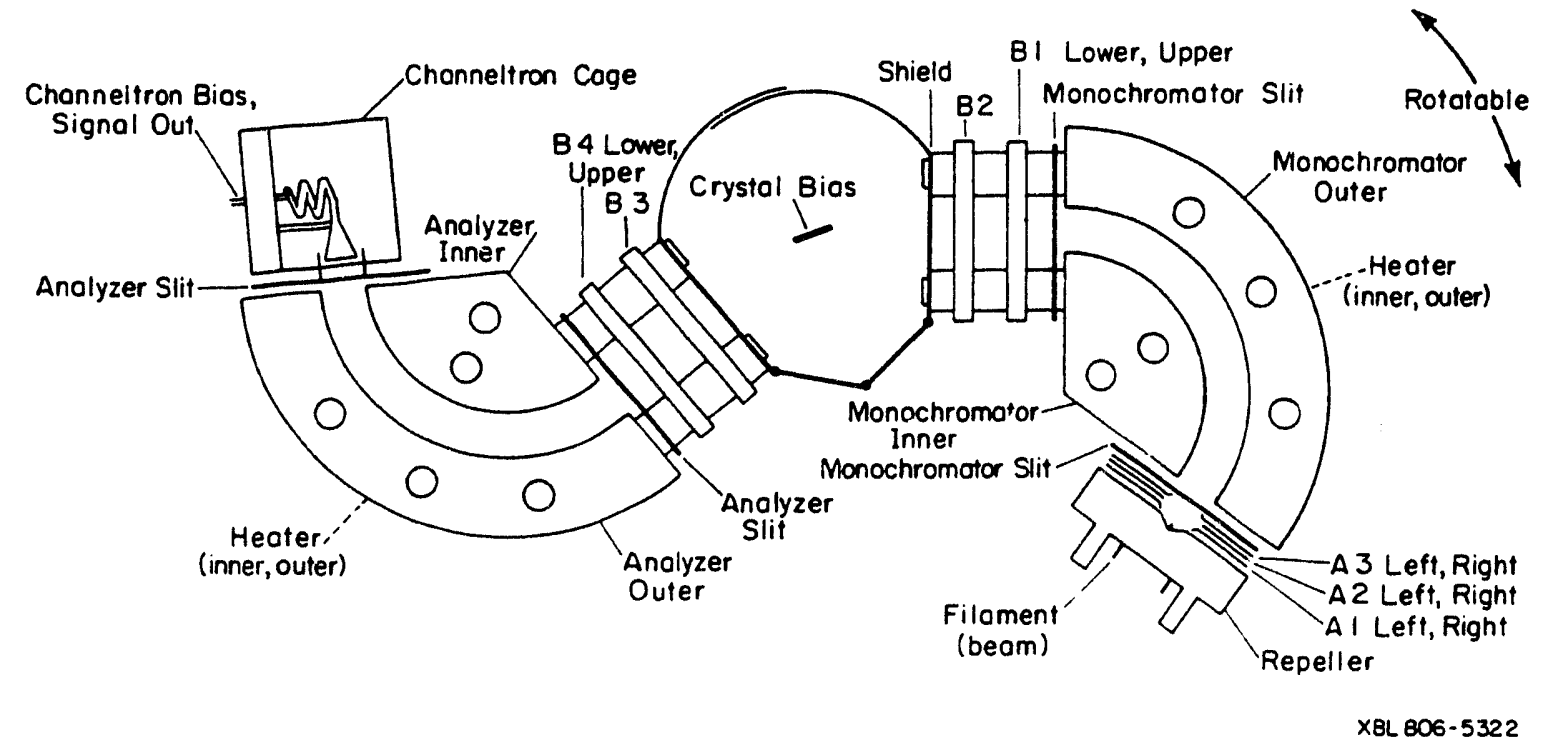

Figure 2.7: Schematic diagram of the HREEL spectrometer. 


\subsubsection{Low-energy electron diffraction (LEED)}

Figure 2.8 shows a schematic of the LEED experiment. A monochromatic electron beam with energy between $10-500 \mathrm{eV}$ is incident on a single crystal sample. Since the electrons in this energy range have de Broglie wavelengths comparable to the interatomic distances of most solids, they diffract from the periodic arrangement of atoms in the near surface region. The diffraction pattern is then viewed by accelerating the electrons onto a phosphorescent screen. From the position and symmetry of the diffraction spots, the size and orientations of the 2-D unit cells can be determined.

From LEED experiments, it is also possible to determine the precise positions of atoms (tc within $0.05 \AA$ ) in the near surface region by doing a dynamical analysis of LEED spot intensities as a function of electron energy $[13,14,15]$. We will describe in section 3.1.2 the procedure for determining structure of surfaces by measuring LEED spot intensities versus electron energy curves (LEED I-V curves).

\subsection{Reaction Cell for Studying Liquid Phase Catalytic Re- actions on Well-Characterized Surfaces}

To understand the role of surfaces in catalytic reactions that are carried out at high pressures and in the gas phase or the liquid phase, it is important to work with wellcharacterized surfaces. During the last 30 years, various surface science techniques have been developed to prepare and characterize surfaces at the atomic scale in an ultra-high vacuum (UHV) environment $[3,4,5]$. Auger spectroscopy, low energy electron diffraction (LEED), high resolution electron energy loss spectroscopy (HREELS), $x$-ray photoelectron spectroscopy (XPS) and scanning tunneling microscopy (STM) belong to the most commonly used techniques for surface characterization. Various types of high-pressure gas phase reaction cells have been designed that combine with UHV chambers [16] to study gas phase catalytic reactions on model surfaces [17] and characterize these surfaces in UHV before and after the reactions. These combined surface science and reaction kinetics studies on the same well-characterized surfaces have yielded important new informations concerning the molecular ingredients of metal catalysis.

Several research groups have built instruments that couple an UHV chamber for surface characterization and a liquid phase reaction cell for studying electrochemical reac- 
(a)

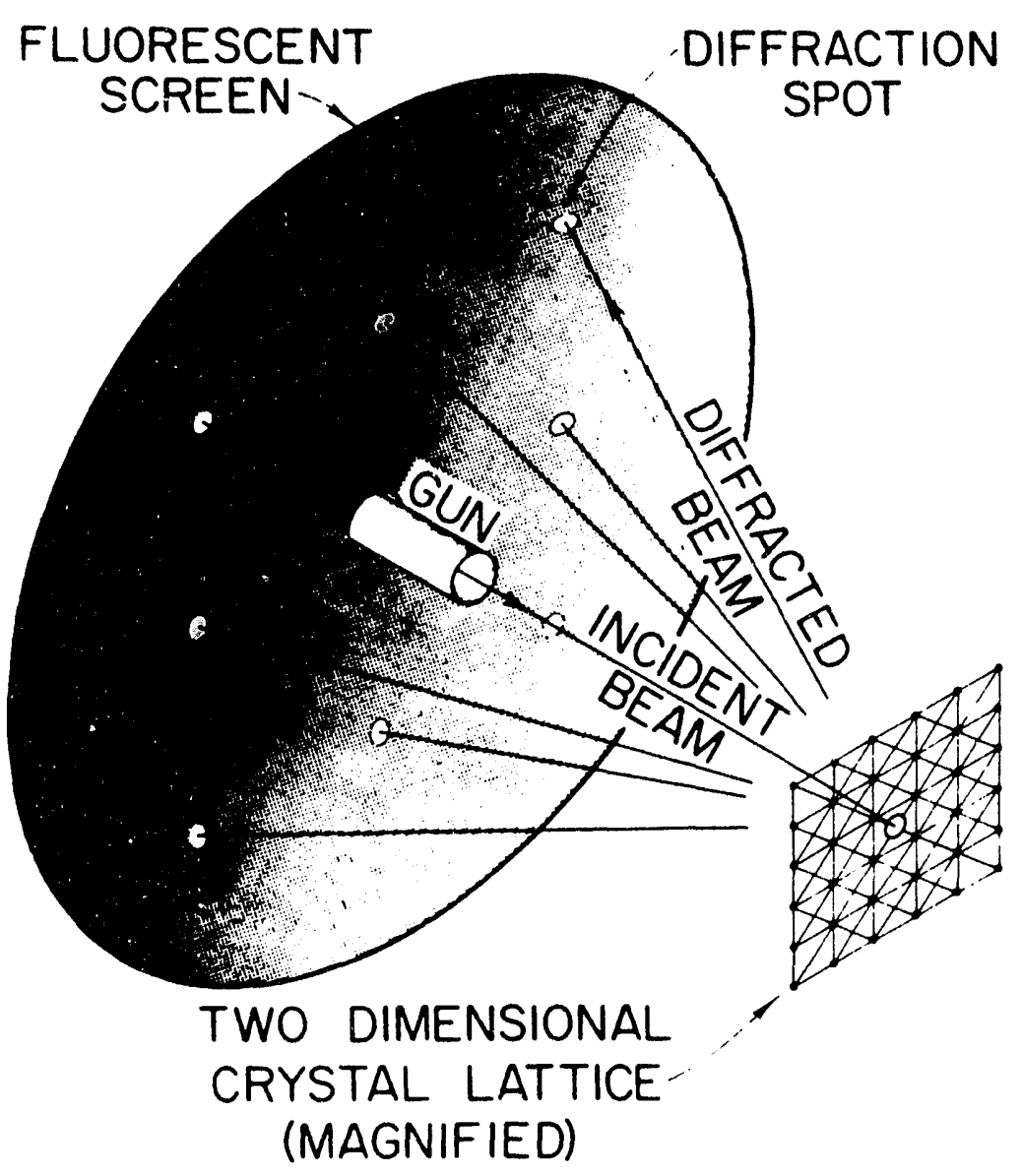

(b)

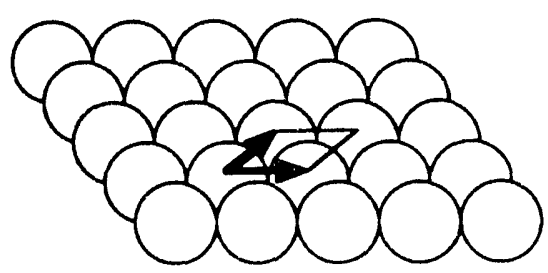

$\mathrm{Ni}(111)$

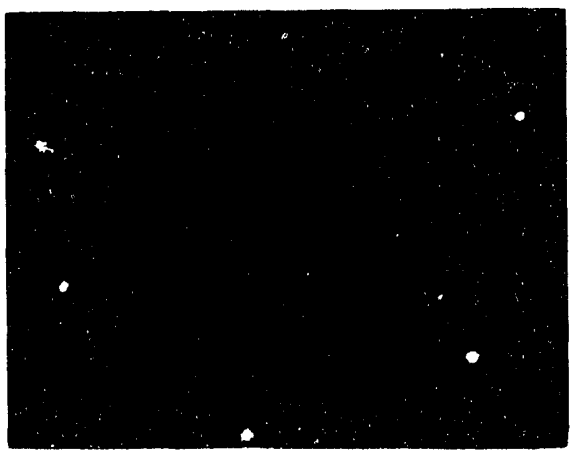

LEED Pattern

Figure 2.8: (a) Scheme of the low-energy electron diffraction experiment from an idealized crystal and (b) LEED pattern of a clean $\mathrm{Ni}(111)$ surface $(\mathrm{E}=77 \mathrm{eV})$. 
tions [18-22]. In this section, we describe the construction of the first reaction cell attached to a surface preparation and characterization chamber for studying liquid phase catalytic reactions. Unlike reaction cells designed for the study of electrochemical reactions, liquid phase catalytic reactors require a good mixing of the reactants and products in order to avoid mass transfer limitations in the measurement of reaction kinetics [23]. We have tested this apparatus by the study of the liquid phase hydrogenation of cyclohexene to cyclohexane on a $1 \mathrm{~cm}^{2}$ polycrystalline platinum foil cleaned and characterized in the UHV chamber prior and after the reaction. The main characteristics of our apparatus are :

a) The chamber has a base pressure of $1 \times 10^{-9}$ torr, which is maintained constant even during the liquid phase reaction. The sample can be cleaned in the UHV chamber by argon sputtering and oxygen heat treatments.

b) The sample is mounted at the end of two long 1/4 in. O.D. stainless steel tubes. It can be resistively heated or cooled by circulating liquid nitrogen through the tubes.

c) During the transfer from UHV to the liquid reaction cell, the sample is moved vertically down to the cell in two steps. First, a hydraulic system closes a cylinder around the sample, isolating the sample from the rest of the UHV chamber. The inside of the cylinder is then pumped by a diffusion pump, keeping the pressure in the $10^{-8}$ torr range. Then, after opening the gate valve at the bottom of the cylinder to access to the liquid cell, the sample can be lowered to its reaction position, by a $8 \mathrm{in}$. long vertical z-motion.

d) To allow good mass transfer at the liquid-solid interface, a liquid jet with a velocity up to $6 \mathrm{~m} / \mathrm{s}$ produced by a small gear pump is impinged on the surface, creating a thin liquid film on the studied surface.

e) The pressure during the reaction can go up to 2 atmospheres, while the temperature of the liquid can be adjusted up to about $70^{\circ} \mathrm{C}$.

f) A septum on the side of the cell allows sampling for gas chromatography analysis to monitor the progress of the reaction.

\subsubsection{The UHV chamber}

The UHV chamber (figure 2.9) is a common Varian all stainless steel chamber pumped by a $400 \mathrm{l} / \mathrm{s}$ Varian ion pump achieving pressures in the low $10^{-9}$ torr range. The chamber is equipped with a cylindrical mirror analyzer (CMA) for Auger measurements, a quadrupole mass spectrometer for residual gas analysis and an ion gun for argon bombard- 
ments of the surface during cleaning procedures. The CMA is mounted on bellows so that it can be moved close to the surface during Auger analysis and retracted prior the transfer to allow the isolating cylinder to be lowered around the sample. Two 6 in. diameter ports facing each other at the top and the bottom of the chamber are available to install the transfer system.

\subsubsection{Transfer system}

The transfer system (figure 2.10) is installed on the two 6 in. ports facing each other and separated by $11 \mathrm{in.}$. It allows the transfer of the sample from its cleaning and analysis position, in the center of the UHV chamber, down to the liquid phase reaction cell without loss of the main chamber vacuum integrity. The sample is hold at the extremity of two $1 / 4$ in. O.D.and 29 in. long stainless st ${ }^{-} 3$ tubes, welded to a $2^{3 / 4}$ in. flange installed at the top of the transfer system. It can be resistively heated or cooled by circulating liquid nitrogen through the tubes. The temperature of the sample is measured by a chromelalumel thermocouple spotwelded to its side. The translational moves that are made during the transfer are kept parallel to the vertical axis going through the two 6 in. ports. A differentially pumped rotary platform allows $0^{\circ}-360^{\circ}$ rotations of the sample. The transfer is made in two consecutive steps :

a) The sample can be separated from the main chamber by an isolating cylinder, which is closed by lowering its mobile upper part till it comes in contact with its immobile bottom part (see figure 2.10). A viton O-ring insures the sealing between the two parts of the isolating cylinder. The movement of the upper part is made possible by two hydraulic pistons. This movement can be reversed by inverting the pressure in the pistons, which pulls the sample back into its UHV analysis position. The inside of the cylinder is pumped by a $200 \mathrm{l} / \mathrm{s}$ diffusion pump, also used to pump the gas manifold and the liquid reaction cell.

b) The isolating cylinder is scparated from the liquid cell by a $2^{3 / 4}$ in. gate valve. When the pressure in the empty liquid cell is lowered down to the pressure in the isolating cylinder, the gate valve can be opened. The sample can then be lowered all the way to the liquid cell, using the $8 \mathrm{in}$. z-motion linear travel device. The sealing between the liquid cell and the isolating cylinder is made possible by an O-ring (made of Kalrez rather than Viton for its chemical inertness) compressed by a small circular plate of the sample holder (figure 


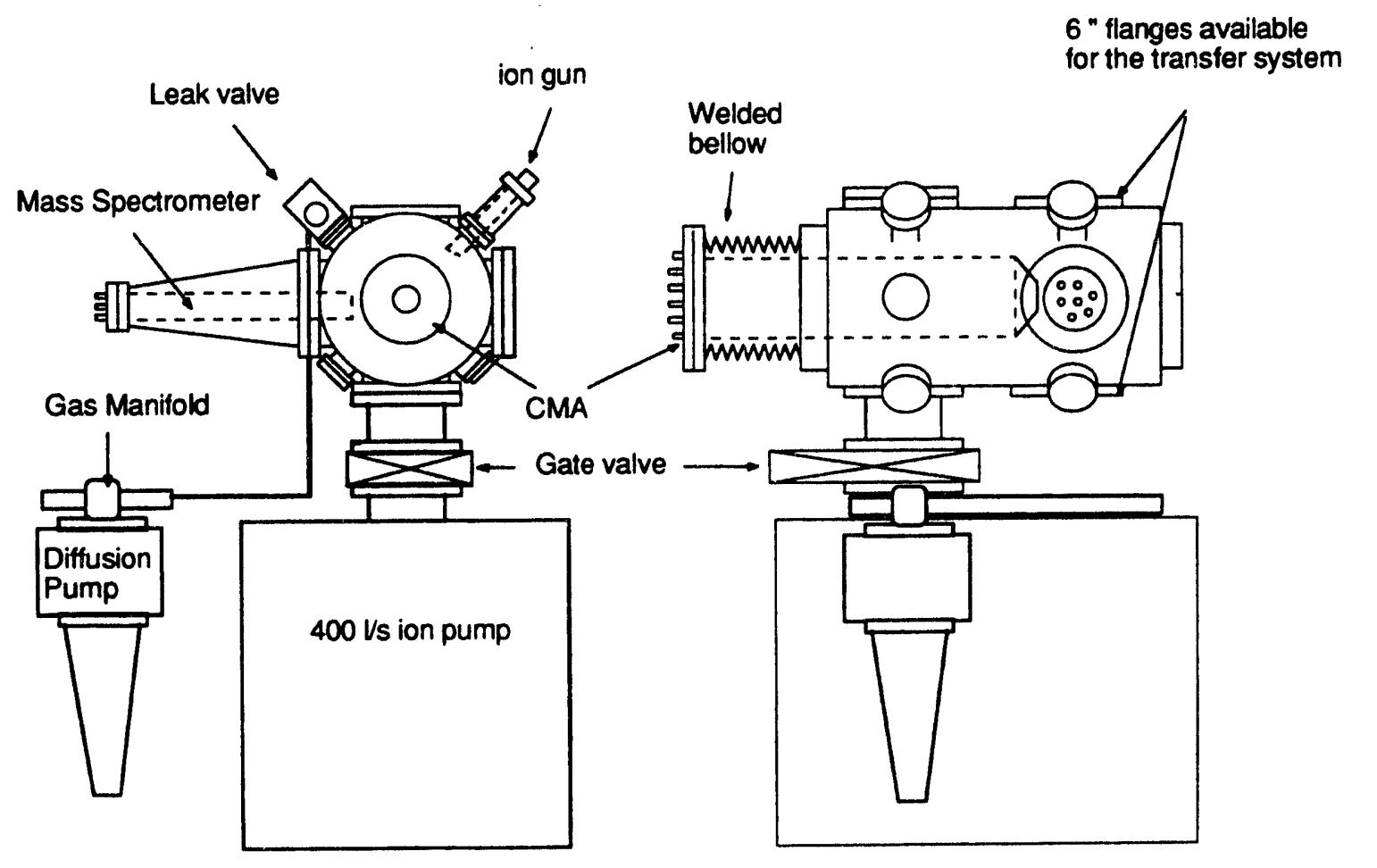

a)

b)

XBL $9311-1565$

Figure 2.9: View of the Varian UHV chamber used to install the transfer system to the liquid phase reaction cell: (a) front view, (b) left view. 


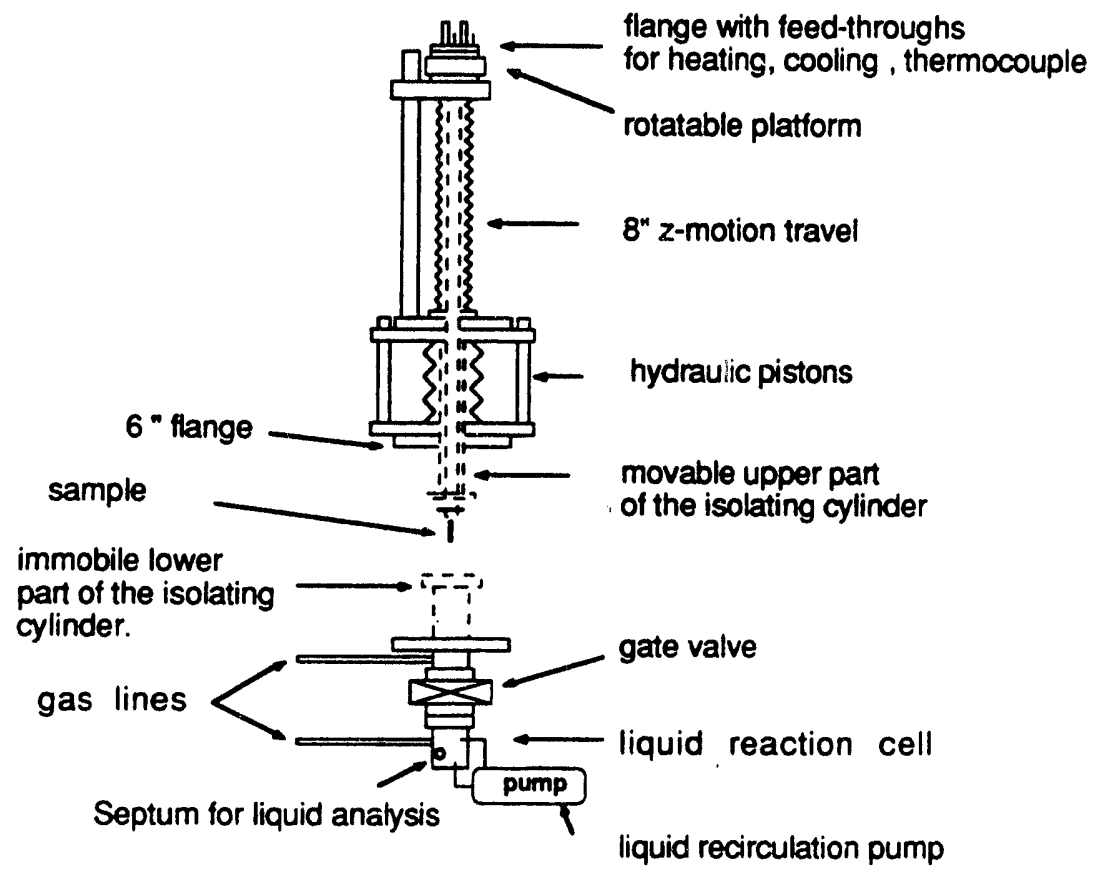

a)

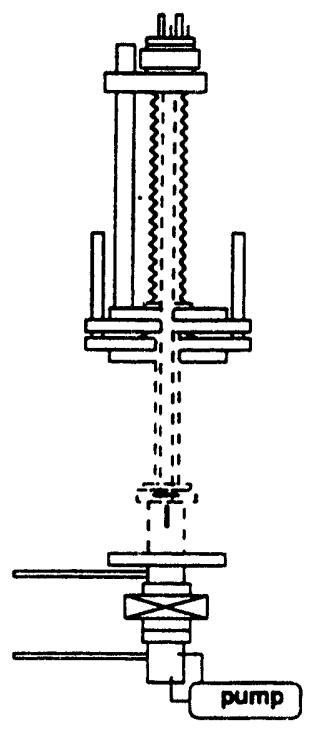

b)

XBL 9311.1566

Figure 2.10: View of the transfer system : (a) The isolating cylinder is opened and the 8 in. z-motion travel is fully extended, which places the sample surface in its preparation and characterization position. (b) The isolating cylinder is closed. The isolating cylinder is then pumped by a diffusion pump. 
2.11). The sealing is good enough so that the pressure in the isolating cylinder can be kept at $10^{-7}$ torr while the pressure in the liquid cell is 2 atmospheres.

The sample can be replaced easily by removing the liquid reaction cell and transfering the sample to its lower position. The sample holder (figure 2.11) can be unscrewed and taken out after disconnecting the thermocouple wires. A new sample may be spotwelded to the sample holder, which is then reinstalled at the end of the two long stainless steel tubes. This operation does not require to break the vacuum inside the main chamber.

The cleanliness of the transfer was tested by cleaning a platinum foil in UHV, before its transfer in the liquid cell and transfer back in the UHV. The Auger spectrum of the surface, before and after the transfer is shown on figure 2.12. The carbon contamination during the trans.er, estimated by measuring the Auger peaks ratio $\mathrm{C}_{273} / \mathrm{Pt}_{237}$ [24], is less than $15 \%$ of a monolayer.

After a liquid phase reaction, the liquid is evacuated from the reaction cell. The residual liquid and vapors are pumped by a mechanical pump and trapped in a liquid nitrogen trap on the vacuum line. When the pressure in the reaction cell decreases below 0.1 torr, the sample is then transfered back into the isolating cylinder. The gate valve between the reaction cell and the isolating cylinder is closed as soon as possible to prevent the contamination of the isolating cylinder by residual organic vapors in the reaction cell. The isolating cylinder can then be pumped down to the $10^{-8}$ torr range with the diffusion pump. It takes about 60 minutes to do so. After that, the isolating cylinder can be opened on the UHV chamber. It takes few hours to reach pressures below $2 \times 10^{-9}$ torr. A reaction can usually be run every day, without altering the base pressure in the UHV chamber.

\subsubsection{The liquid phase reaction cell}

The liquid phase reaction cell (figure 2.13 ) is made of a $1^{1 / 2}$ in. diameter, $3^{1 / 2}$ in. long copper pipe, welded to a $2^{3 / 4}$ in. flange. It is gold plated inside to prevent any background activity. Inlets and outlets equipped with swage-lock fittings connect the cell to the gas manifold, a mechanical pump, the liquid recirculation pump and to a glass manifold where the liquid is purified prior the reaction. An aperture covered by a $3 / 8 \mathrm{in}$. diameter septum is used to take liquid samples for analysis by gas chromatography. The cell is vacuum tight and can be pumped in the $10^{-5}$ torr range with the diffusion pump. The cell can be heated by a heating cord tied around the copper part and connected to 


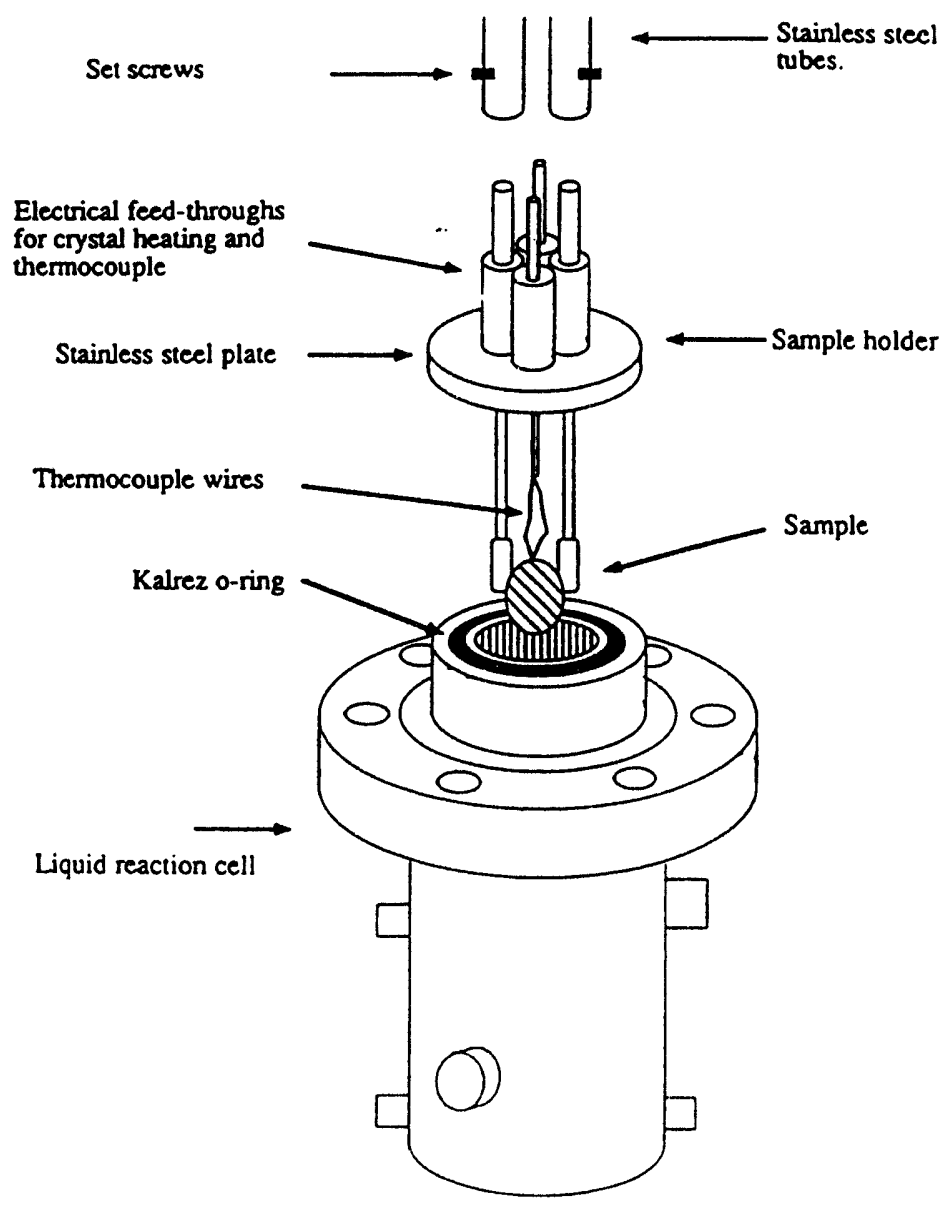

\section{View of the liquid-phase hydrogenation reaction cell}

XBL $935-726$

Figure 2.11: View of the sample holder and the top of the reaction cell. The Kalrez O-ring is compressed by the circular plate of the sample holder when the reaction cell is closed. The sealing is good enough to allow $2 \mathrm{~atm}$ in the reaction cell while the isolating cylinder is still in the $10^{-7}$ torr pressure range. The sample holder can be removed easily to change the sample. 


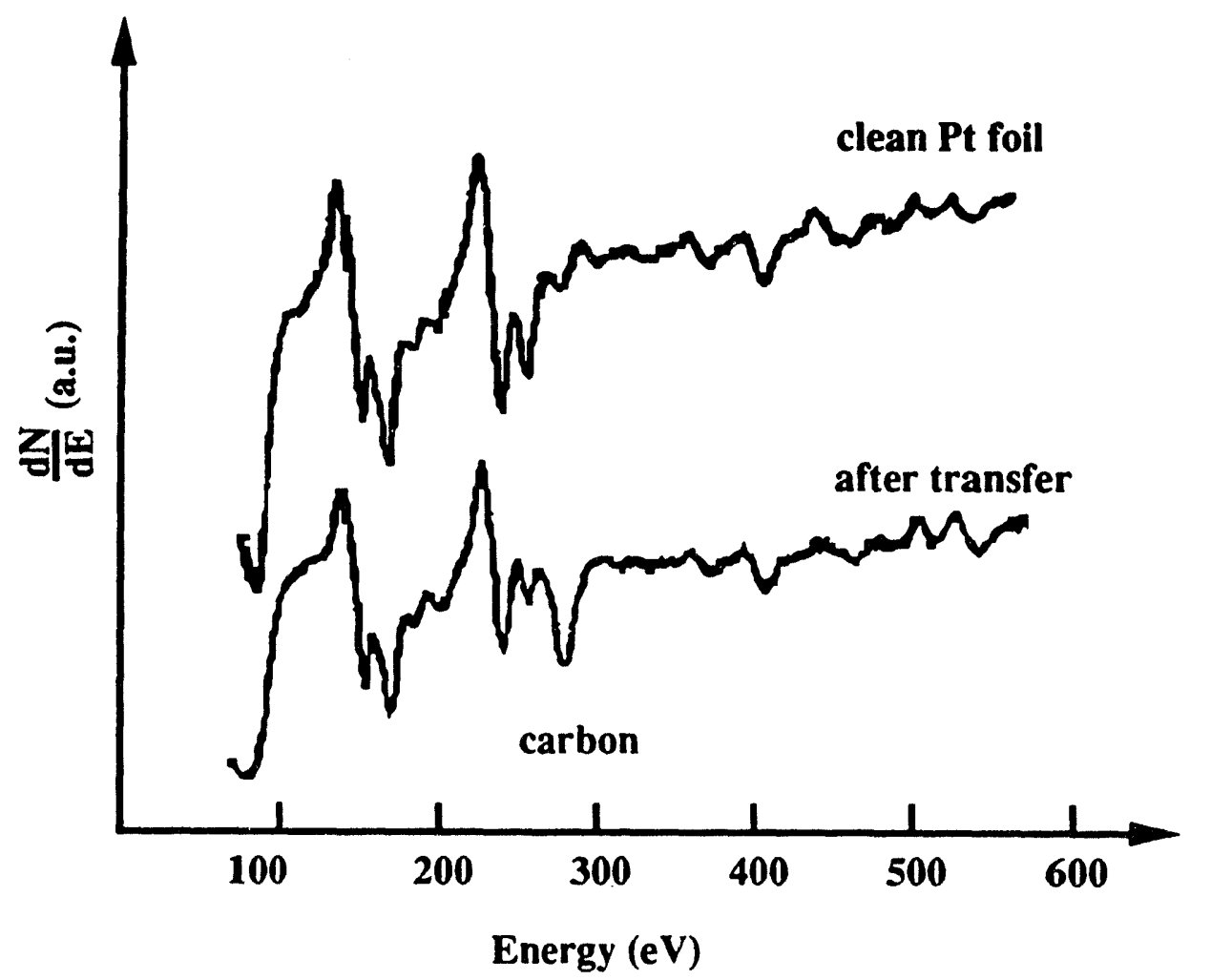

XBL 9311.1567

Figure 2.12: Auger spectra of the clean platinum foil and of the platinum surface after its transfer in the reaction cell. The carbon contamination is estimated to be less than $15 \%$ of a monolayer by the measure of the $\mathrm{C}_{273} / \mathrm{Pt}_{237}$ ratio. 
a temperature controller. The temperature of the reaction mixture is measured by the thermocouple spotwelded to the sample edge. It takes about 10 minutes to stabilize the liquid temperature at $50^{\circ} \mathrm{C}$ with temperature fluctuations of less than $1^{\circ} \mathrm{C}$. The liquid recirculation pump is a gear pump made by Micropump with Teflon and stainless steel parts only. It has a dead volume of $5 \mathrm{ml} .1 / 8 \mathrm{in.}$ O.D., 1/16 in. I.D. stainless steel tubes are used to transfer the liquid to the pump and to produce the thin liquid jet incident on the surface of the sample. The pump is driven by a Cole-Parmer drive for micropumps, equipped with a controller which allows the variation of jet velocities from $0.5 \mathrm{~m} / \mathrm{s}$ to 6 $\mathrm{m} / \mathrm{s}$.

\subsubsection{Liquid preparation}

Before its introduction in the reaction cell, the liquid needs to be degassed and purified. We have built a two compartment glass manifold (figure 2.14) that permits freezepump-thaw cycles of the liquid. The liquid is evaporated in vacuum from one compartment to the other. A pressure of Helium on the liquid is used to facilitate the transfer of the liquid to the reaction cell.

\subsubsection{Product analysis}

The reaction is followed by gas chromatography. A septum on the wall of the liquid phase reaction cell allows sampling of the liquid with a $10 \mu l$ syringe (Hamilton). The analysis is done with a HP5790A gas chromatograph equipped with a flame ionization detector (FID). Internal standards are added to the reaction mixture to follow the product built-up with accuracy. 


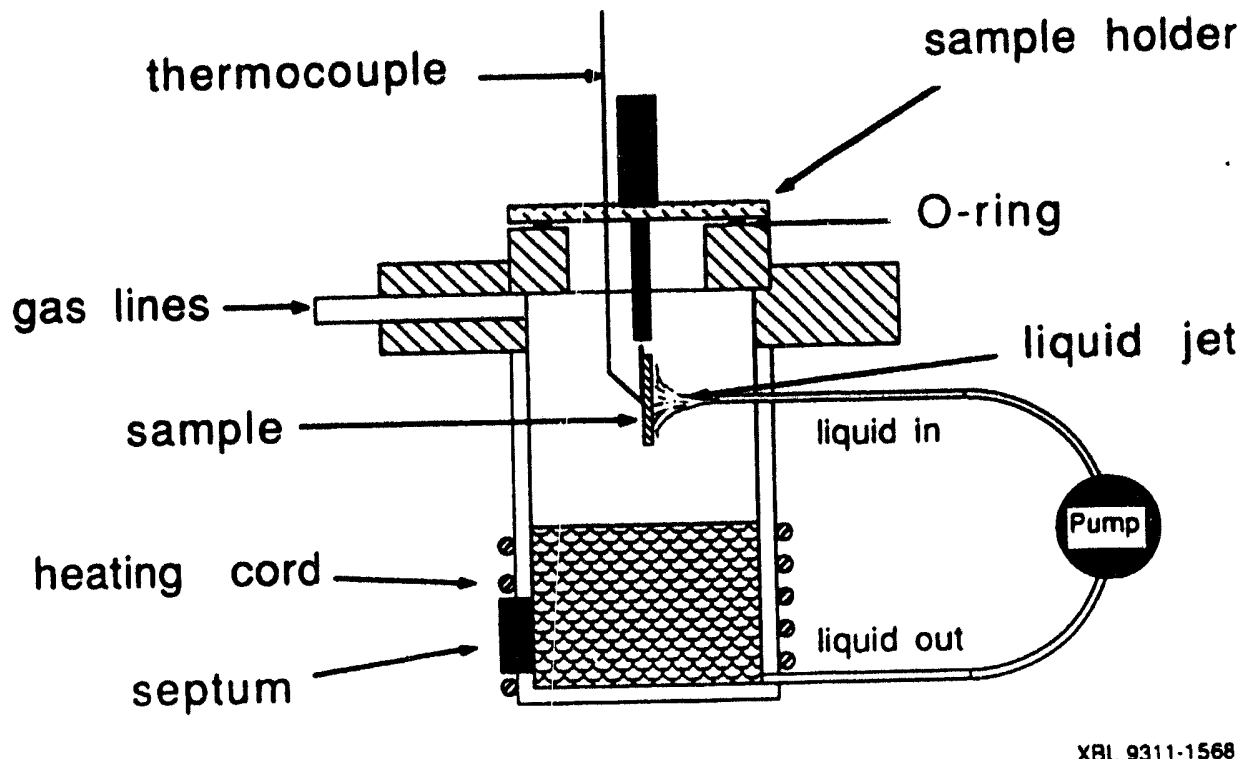

Figure 2.13: Schematic of the liquid phase reaction cell. The inside of the cell is gold plated to prevent background activity of the copper walls of the cell. During the reaction, a liquid jet produced by a gear pump is impinged on the sample surface. The liquid can be heated by a heating cord tied around the cell and controlled by a temperature controller which reads the temperature at the sample surface. 


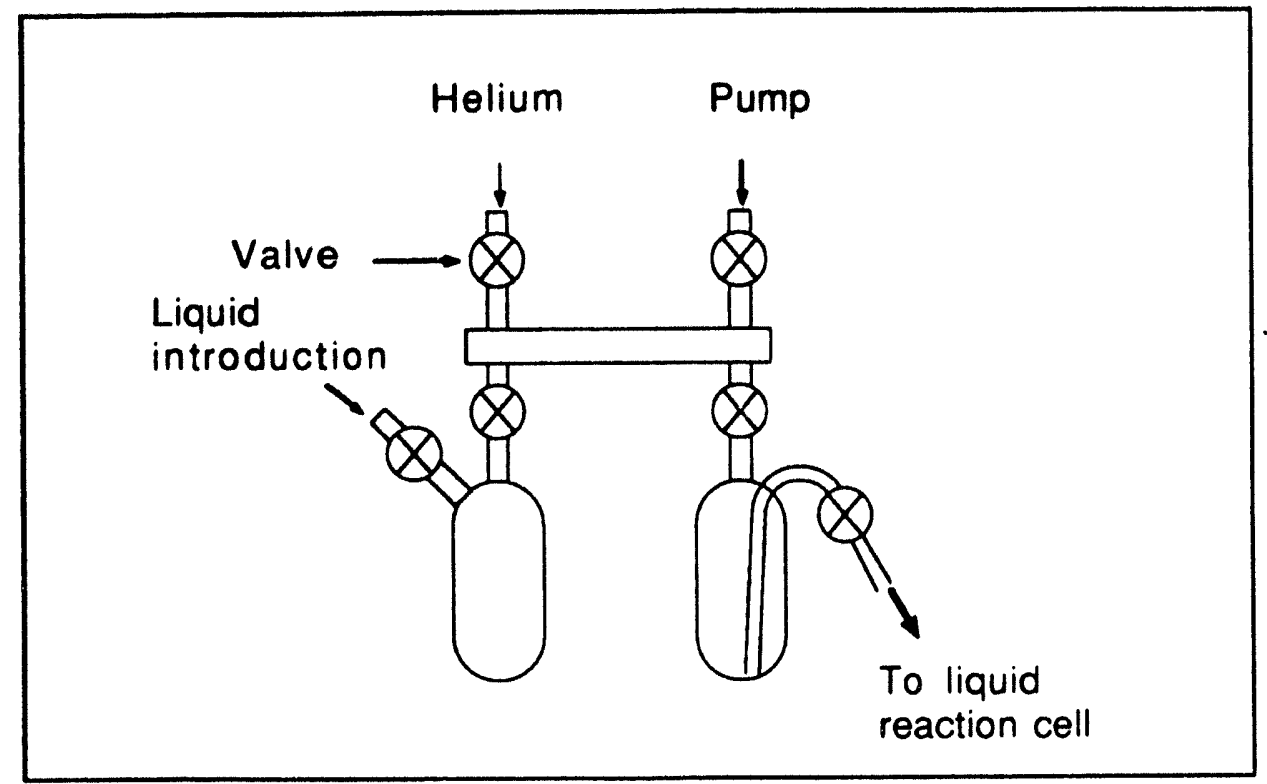

XBL $9311-1569$

Figure 2.14: Schematic of the glass manifold used to purify the liquid prior reaction and to introduce it in the liquid reaction cell. The liquid is first introduced in the left compartment where it undergoes a series of freeze-pump-thaw cycles. It is then evaporated in vacuum to to the right compartment, where its temperature is adjusted to the reaction temperature. The transfer to the reaction cell is eased by the use of He to pressurize the liquid. 


\subsection{References}

[1] J.F. O'Hanlon, A User's Guide to Vacuum Technology (John Willey, New-York, 1980).

[2] G.A. Somorjai, Chemistry in Two Dimensions : Surfaces (Cornell University Press, Ithaca, 1981).

[3] G.A. Somorjai, Principles of Surface Chemistry (Prentice-Hall, Englewood Cliffs ,1972).

[4] G. Ertl, and J. Kuppers, Low Energy Electrons and Surface Chemistry (Verlag Chemie, Weinheim,1974).

[5] D.P. Woodruff, T.A. Delchar, Modern Techniques of Surface Sciences (Cambridge University Press, 1986).

[6] C.C. Chang, "Analytical Auger Electron Spectroscopy", Chapter 20, in Characterization of Solid Surfaces, P.F. Kane and G.B. Larrabee, eds. (Plenum, New-York, 1974).

[7] R.R. Rye, J.E. Houston, D.R. Jennison, T.E. Madey, and P.H Holloway, "Chemical Information in Auger Electron Spectroscopy", Ind. Eng. Chem. Prod. Res. Dev., 18 (1979) 2 .

[8] N.A. Alford, A. Barrie, I.W. Drummond and Q.C. Herd, "Auger Electron Spectroscopy (AES) : An Appraisal", Surface and Interface Analysis, 1 (1979) 36.

[9] W.A. Coghlan, and R.E Clausing, A Catalogue of Auger Transitions for the Elements, Oak Ridge National Laboratory, ORNL-TM-3576, Nov. 1971.

[10] P.A. Redhead, Vacuum, 12 (1962) 203.

[11] C.M. Mate, Ph.D. Thesis (University of California, Berkeley, 1986).

[12] H. Ibach, and D.L. Mills, Electron Energy Loss Spectroscopy and Surface Vibrations (Academic, New-York, 1982).

[13] M.A. Van Hove, and S.Y. Tong, Surface Crystallography by LEED : Theory, Computation and Structural Results (Springer-Verlag, New-York, 1979).

[14] L.J. Clarke, Surface Crystallography : An Introduction to Low Energy Electron Diffraction (Wiley, New-York, 1985). 
[15] M.A. Van Hove, W.H Weinberg, and C.-M. Chan, Low-Energy Electron Diffraction (Springer-Verlag, Berlin Heidelberg, 1986).

[16] C.T. Campbell, Adv. Catal., 36 (1989) 1.

[17] J.A. Rodriguez, and D.W. Goodman, Surf. Sci. Rep., 14 (1991) 1.

[18] A.T. Hubbard, Acct. Chem. Res., 13 (1980) 177.

[19] A.S. Homa, E.Yeager, and B.D. Cahan, J. Electroanal. Chem., 150 (1983) 181.

[20] P.N. Ross, Jr., and F.T. Wagner, Adv. Electrochem. Electr. Eng., 13 (1984) 69.

[21] M. Wasberg, L. Palaikis, S. Wallen, M. Kamrath, and A. Wieckowski, J. Electroanal. Chem., 256 (1988) $\dot{5} 1$.

[22] L.H. Leung, T.W. Gregg, and D.W. Goodman, Rev. Sci. Instr., 62 (1991) 1857.

[23] L.K. Doraiswamy, and D.G. Tajbl, Cat. Rev. -Sci. Eng., 10 (1974) 177.

[24] J.P. Biberian, and G.A. Somorjai, Appl. Surf. Sci., 2 (1979) 253. 


\section{Chapter 3}

\section{Bonding and Reactivity of $\mathrm{CH}_{3} \mathrm{CN}$ on $\mathrm{Ni}(111)$}

\subsection{Tensor LEED Analysis of the Ni(111)-p(2x2)- $\mathrm{CH}_{3} \mathrm{CN}$ Structure}

\subsubsection{Introduction}

The determination of the structure of nitriles (R-CN) on nickel surfaces is fundamental to the understanding of their bonding and reactivity in catalysis. The adsorption of nitriles (R-CN) on metal surfaces is also particularly interesting because these polar molecules have been found to bond in a variety of ways on metallic clusters $[1,2,3,4]$.

The adsorption of acetonitrile on nickel, as a function of surface crystallography and composition, was studied by Muetterties and co-workers $[5,6,7]$. The $\mathrm{Ni}(111), \mathrm{Ni}(100)$ and $\mathrm{Ni}(110)$ surfaces and also the stepped $9(111) \times(111)$ and stepped-kinked $7(111) \times(310)$ surfaces were investigated by TDS and LEED. Adsoi bed at $300 \mathrm{~K}$, acetonitrile was weakly and reversibly bound on the (111), stepped, and stepped-kinked surfaces. Acetonitrile formed an ordered $\mathrm{p}(2 \times 2)$ structure on the Ni(111) surface. The thermal desorption temperature was measured at about $90^{\circ} \mathrm{C}$. Some irreversible decomposition, probably focused at step or kink sites, was observed in the thermal desorption experiments. Consistently then, acetonitrile on the "super-stepped" (110) surface largely underwent decomposition on heating; very little reversible chemisorption was observed; the thermal desorption maximum was then $110^{\circ} \mathrm{C}$. On the $\mathrm{Ni}(100)$ surface, acetonitrile produced a $\mathrm{c}(2 \times 2)$ structure and the 
thermal desorption temperature was $110^{\circ} \mathrm{C}$. On the basis of these studies, it was postulated that acetonitrile chemisorbs on nickel surfaces by bonding through the nitrogen atom only, with the C-N bond vector largely normal to the surface plane. This bonding feature for acetonitrile is analoguous to that in most metal-acetonitrile complexes where the nitrogen atom only is bonded (and weakly bonded) to a metal atom.

The adsorption of nitriles has also been studied on a few metal surfaces, by $\mathrm{x}$-ray photoelectron spectroscopy (XPS) [10-13], high resolution electron energy loss spectroscopy (HREELS) $[13,14]$ and near-edge $x$-ray absorption fine structure (NEXAFS) [15]. Although some models for the adsorption geometry have been suggested from these studies, neither precise adsorption sites nor structural parameters have been determined so far. Vibrational spectroscopy (HREELS) and XPS studies of acetonitrile on Ni(111) $[11 ; 14]$ and $\mathrm{Pt}(111)[13]$ indicate that the molecule rehybridizes to a di- $\sigma$ bonded configuration with the C-N bond axis nearly parallel to the surface. Vibrational features at $1680 \mathrm{~cm}^{-1}$ on $\mathrm{Ni}(111)$ and $1615 \mathrm{~cm}^{-1}$ on $\mathrm{Pt}(111)$, assigned to a $\mathrm{C}-\mathrm{N}$ stretch, are indicative of a $\mathrm{C}=\mathrm{N}$ double bond. This model contradicts the model proposed by Muetterties et al $[5,6,7]$ but is similar to the structure of nitriles bonded to triiron and triosmium clusters [1]. This type of bonding has also been proposed for $\mathrm{HCN}$ on $\mathrm{Ru}(0001)$ [16] and acetonitrile on W(100)-(5x1)-C [17].

In this section, we describe the measurement and analysis of LEED intensity vs. energy (I-V) curves for the $\mathrm{Ni}(111)-\mathrm{p}(2 \times 2)-\mathrm{CH}_{3} \mathrm{CN}$ structure. In addition to determining the structure of the adsorbed acetonitrile, we have investigated by nigh-resolution electron energy loss spectroscopy the coadsorption of acetonitrile and hydrogen on $\mathrm{Ni}(111)$.

\subsubsection{Principles of LEED structure determinations}

While the position of the spots on a LEED pattern depends only on the size and symmetry of the surface unit cell, the intensity of the spots contains information about the location of the atoms within the first three layers. The determination of the structure of an ordered surface can be achieved by analysing the intensity of the diffraction spots as a function of the beam energy.

First, the intensity of the LEED spots is measured as a function of electron energy by a method which is described in the next paragraph. Then, the experimental intensity vs. voltage curves (I-V curves) are compared to those calculated, using a computer program that simulates the mechanism of diffraction. Each model geometry of the surface generates 
a different set of I-V curves. The model that provides the best fit to the experimental I-V curves is regarded as an accurate representation of the actual surface structure.

A Dage-MTI SIT-68 high-sensitivity video camera interfaced to a PC was used to digitize the LEED pattern on the phosphorous screen of the Varian LEED optics allowing for the acquisition of a complete set of LEED patterns in approximately $300 \mathrm{~s}$ (figure 3.1). The I-V curves are generated by computing the intensity of each individual diffraction spot in a LEED pattern for each energy. The intensity of a spot is determined by integrating the pixel intensities of a spot within a window and substracting the intensity averaged over the window frame.

In this work, theoretical calculations were performed on an IBM RISC 6000 workstation. The structural optimization was done using an automated search method [18] based on the Tensor LEED (TLEED) approximation [19, 20]. With this method, only a single full dynamical calculation is necessary for each possible adsorption model to provide reference diffraction amplitudes and their dependence on displacements from this reference structure. Subsequently, for any model with a geometry within 0.3-0.4 $\AA$ of the reference structure, the LEED intensities can be calculated in a few seconds.

TLEED combined with an automated search algorithm directed by $R$-factor [21] values, quantifying the fit between experimental and theoretical I-V curves, can locate the best-fit geometry within minutes. After the best-fit structure is obtained, this process must be iterated using the result as a new reference structure in order to minimize any error introduced by the TLEED approximation. The fit between our theoretical and experimental I-V curves was quantified by Pendry's R-factor (Rp factor) [22] which emphasizes peak positions in the spectra at the expense of peak heights.

The dynamical LEED computations for the reference structures treated the molecule and the first two substrate layers as three separate composite layers using the Beeby matrix inversion scheme, which treats multiple scattering within a layer exactly [21]. Hydrogen was ignored. Eight phase shifts were used in the calculation. Scattering between the layers and towards the bulk was computed using renormalized forward scattering (RFS). Electron damping was simulated by the imaginary part of the optical potential and was set to $\mathrm{V}_{0 i}=-4 \mathrm{eV}$. Thermal vibrations were modeled using temperature dependent phase shifts. These phase shifts were based on isotropic vibrations of the same amplitude for the $\mathrm{CH}_{3} \mathrm{CN}$ molecule and the nickel atoms. The Debye temperature of nickel atoms was set to $375 \mathrm{~K}$, implying a Debye temperature of $466 \mathrm{~K}$ for the carbon and nitrogen. Other 


\section{Video LEED Data Acquisition}

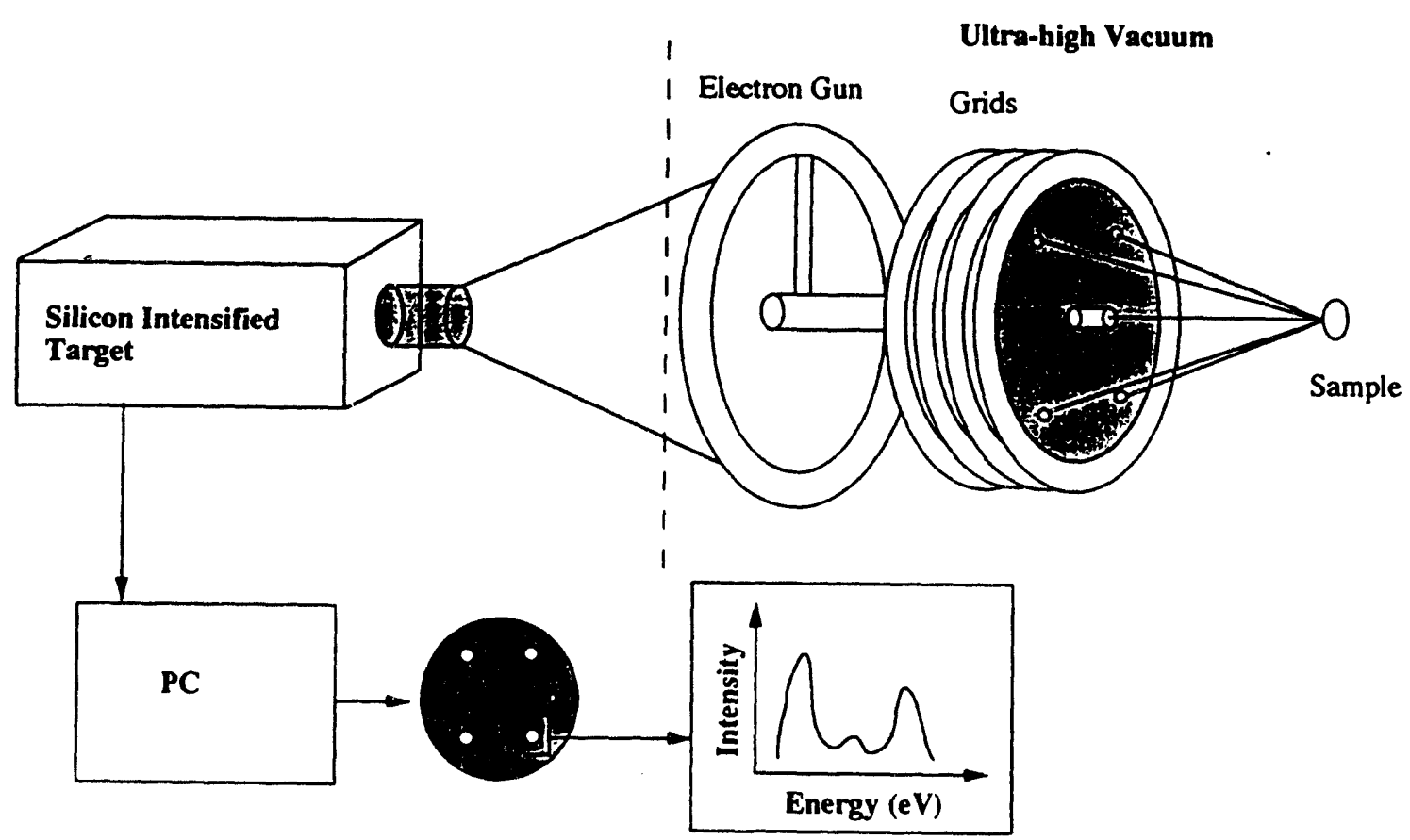

XBL $9311-1587$

Figure 3.1: Schematic of a video-LEED experiment. LEED patterns for various energy of the electron beam are digitalized by a video camera, stored in the hard-disk of a PC. The intensity of each individual diffraction spot is then determined by integrating the pixel intensities within a window frame around the spot. 
computational procedures are described in the theory section of reference [23]. For models which lower the symmetry of the surface we assumed that the various domain orientations were equally populated. The diffracted intensity is the average of the intensities diffracted by the individual domains

\subsubsection{Results and discussion}

The $\mathrm{Ni}(111)$ surface was cooled to $190 \mathrm{~K}$ by circulating liquid nitrogen through the manipulator and exposed to $10^{-8}$ torr of $\mathrm{CH}_{3} \mathrm{CN}$ during $100 \mathrm{~s}$ (1 Langmuir exposure), leading to the formation of a sharp (2x2) LEED pattern (figure 3.2). After a few minutes, the LEED pattern began to degrade due to electron beam damage. To overcome this problem, the electron beam current was minimized to 0.1-0.3 $\mu \mathrm{A}$ and LEED patterns for different electron beam energies were collected from various parts of the crystal surface. We have checked that this method does not alter the I-V curves by reproducing the experiment for various positions of the electron beam on the crystal surface and by collecting data in order of both increasing and decreasing beam energies.

The I-V curves from the $\mathrm{Ni}(111)-\mathrm{p}(2 \times 2)-\mathrm{CH}_{3} \mathrm{CN}$ structure, collected for a total energy range of $1125 \mathrm{eV}$, were symmetry-averaged, leading to a total of 7 independent beams ( 3 integer-order beams +4 half-order beams). The coverage of the surface was estimated to be about 0.25 monolayer by comparing the $\mathrm{N}_{380 \mathrm{eV}} / \mathrm{Ni}_{880 \mathrm{eV}}$ AES ratio with that measured from the $\mathrm{Ni}(111)-\mathrm{c}(4 \times 2)-\mathrm{NO}$ structure which we have proved recently to have a coverage of 0.5 monolayer [24]. Ten different adsorption models were tried for the Ni(111)-p(2x2)$\mathrm{CH}_{3} \mathrm{CN}$ structure. Four models (figure $3.3 \mathrm{a}$-d) have the acetonitrile molecule linearly adsorbed perpendicular to the surface and six models have the acetonitrile bonded to the surface by both the carbon and nitrogen atoms with the $\mathrm{C}-\mathrm{N}$ axis almost parallel to the surface (figure $3.3 \mathrm{e}-\mathrm{j}$ ). The geometry within the linear acetonitrile was initially taken to be the same as for acetonitrile in the gas phase $(\mathrm{d}(\mathrm{C}-\mathrm{N})=1.15 \AA, \mathrm{d}(\mathrm{C}-\mathrm{C})=1.57 \AA)$ and the $\mathrm{Ni}-\mathrm{N}$ distance started at $1.9 \AA$. For the side-on bonding of the acetonitrile, the geometry is taken from that of the triiron cluster, $\mathrm{Fe}_{3}\left(\mathrm{CH}_{3} \mathrm{CH}_{2} \mathrm{CH}_{2} \mathrm{CN}\right)(\mathrm{CO})_{9}[1]$, substituting the $\mathrm{CH}_{3} \mathrm{CH}_{2}$ group with $\mathrm{H}$ and adjusting the geometry to that of the methyl group. Top $\left(\mu_{1}\right)$, bridge $\left(\mu_{2}\right)$, and hollow adsorption site $\left(\mu_{3}\right)$ were investigated for both geometries of the acetonitrile. 

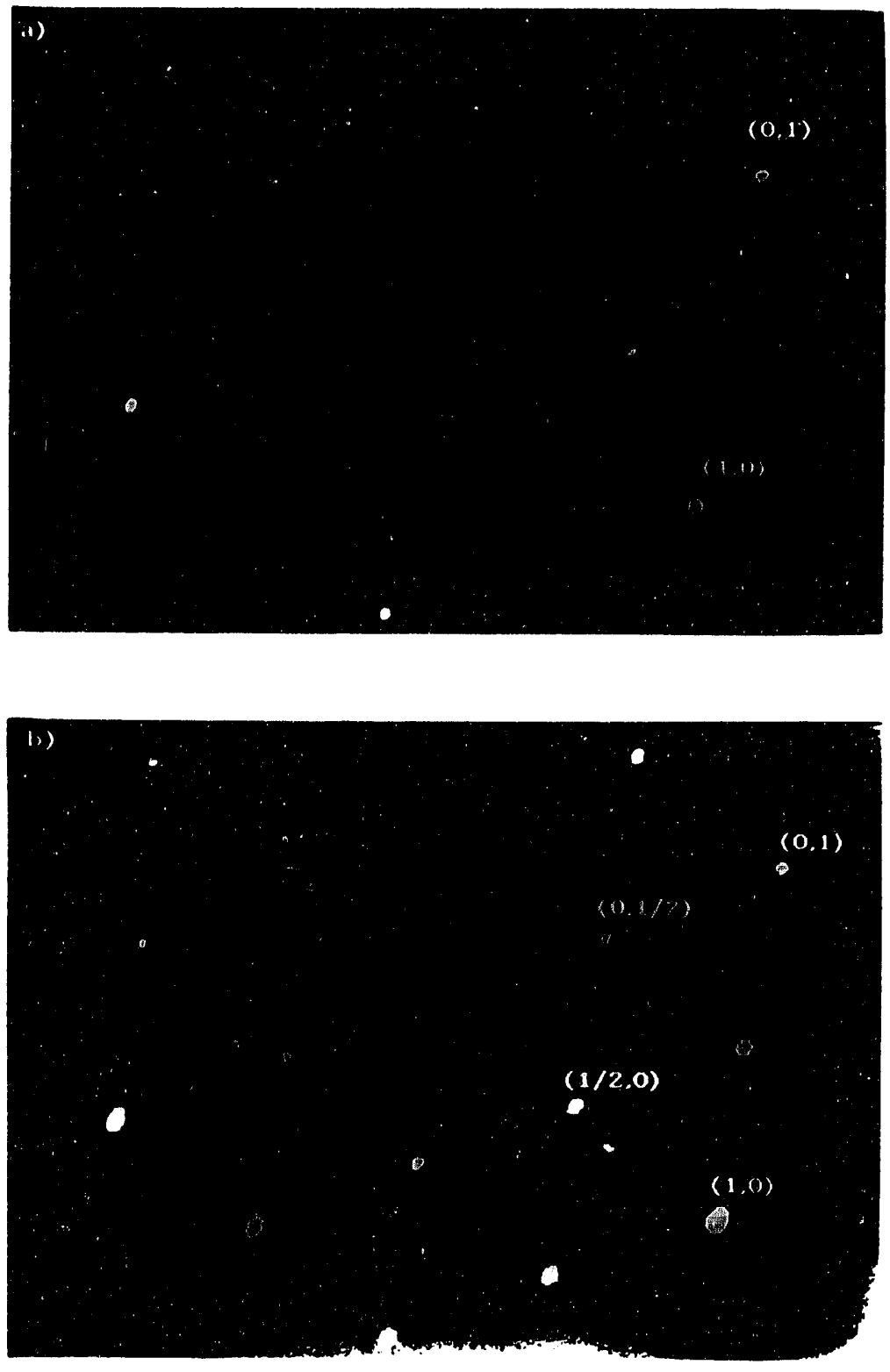

Figure 3.2: Experimental LEED patterns at $190 \mathrm{~K}:$ (a) clean $\mathrm{Ni}(111)$ LEED pattern at 67 $\mathrm{eV}$, and (b) $\mathrm{Ni}(111)-\mathrm{p}(2 \times 2)-\mathrm{CH}_{3} \mathrm{CN}$ LEED pattern at $67 \mathrm{eV}$. 


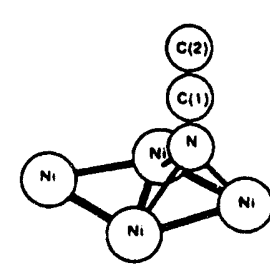

a)

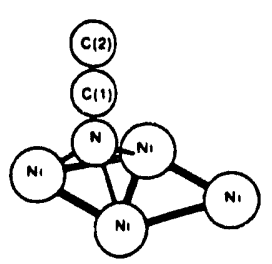

b)

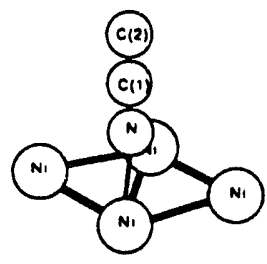

c)

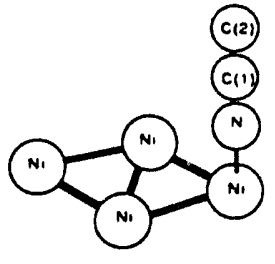

d)

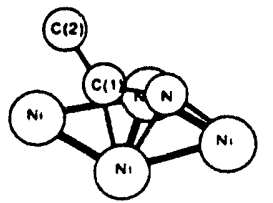

e)

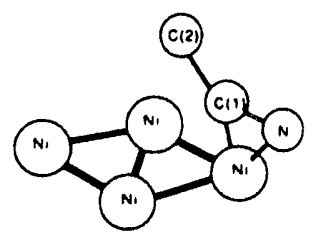

h)

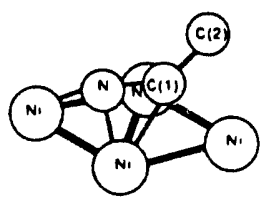

f)

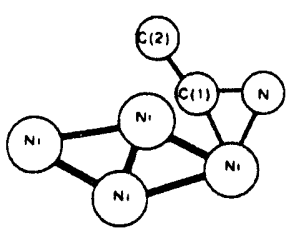

i)

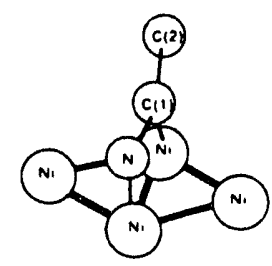

g)

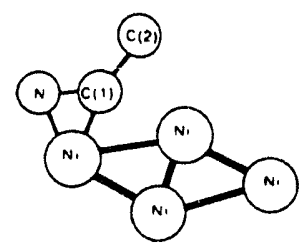

j)

X81 939.1303

Figure 3.3: Schematic of the various models which were tried for the $\mathrm{Ni}(111)-\mathrm{p}(2 \times 2)-\mathrm{CH}_{3} \mathrm{CN}$ structure : (a-d) models with the linear acetonitrile adsorbed end-on perpendicular to the surface, and (e-j) models with the acetonitrile bonded side-on to the surface by both the carbon and nitrogen with its $\mathrm{C}-\mathrm{N}$ axis almost parallel to the surface. 
The Rp-factor results of the calculations followed by an optimization of the vertical position of the atoms in the acetonitrile molecule are shown in table 3.1 (The fit is less sensitive to variations in coordinates parallel to the surface, and was thus not attempted at this stage). The model with the acetonitrile bonded side-on with the $\mathrm{N}$ atom in the fcc hollow site (model e) and the one with the acetonitrile bonded side-on on a top site (model i) gave a comparable fit, and a more careful analysis was needed to distinguish between the two. Optimization of all the parameters for these two models was carried out in successive steps. First, only the vertical displacements of the molecular atoms and of the first two nickel substrate layers were allowed to relax, while the lateral coordinates were frozen. Lateral relaxations were then allowed. This resulted in an optimal Rp-factor $=0.23$ for the $\mu_{3}$ bonded acetonitrile (model e) and Rp-factor $=0.33$ for the $\mu_{1}$ bonded acetonitrile (model i). The selection of model $e$ is particularly evident in the comparison of theoretical and experimental I-V curves for half-order beams. It is understandable that the two models produce similar LEED I-V curves since one can go from one geometry to the other by a lateral translation of the acetonitrile along the symmetry plane of the surface and by a vertical translation of the molecule of about $0.5 \AA$. At normal incidence, I-V curves are not very sensitive to lateral displacement and a vertical translation of $0.5 \AA$ corresponds to a phase shift of about $2 \pi$, giving a phase factor $\exp i k d=\exp (i \times 2 \pi \times \sqrt{150 / E(\mathrm{eV})} \times d) \simeq 1$ for $\mathrm{E} \simeq 150 \mathrm{eV}$ and $\mathrm{d}=2 \times 0.5 \AA$.

It is interesting to notice that model $\mathrm{e}$ is somewhat similar to the one found by dynamical LEED analysis of the $\mathrm{p}(2 \times 2)$ structure of $\mathrm{C}_{2} \mathrm{H}_{2}$ on $\mathrm{Ni}(111)$ [25] (figure 3.4). $\mathrm{C}_{2} \mathrm{H}_{2}$ adsorbs with the $\mathrm{C}-\mathrm{C}$ bond parallel to the surface in a $\mu$-bridging bonding site. It seems that the nitrogen lone pair of electrons allows the bonding to a third metal atom, displacing the molecule from its $\mu$-bridging site towards the fcc hollow site.

The atomic coordinates of the best-fit geometry are shown in table 3.2 and the corresponding I-V curves are reported in figure 3.5. Side and top views of the Ni(111)$\mathrm{p}(2 \times 2)-\mathrm{CH}_{3} \mathrm{CN}$ structure are shown in figure 3.6. Error bars were estimated using Pendry's method [22]. Analysis of the vertical displacements of the nickel atoms shows some buckling in the first nickel layer of $0.13 \pm 0.06 \AA$. The nickel atom $\mathrm{Ni}(1)$ bonded to the nitrogen in the axis of the $\mathrm{C}-\mathrm{N}$ bond relaxes outward by $0.10 \pm 0.03 \AA$ (figure 3.6). Vertical displacements of nickel atoms in the second metal layer are within error bars $(0.05 \AA)$. Some lateral displacements are observed in the first nickel layer. The directions of these displacements relative to the clean surface are shown in figure 3.6. Their magnitudes are about $0.05 \AA$ 


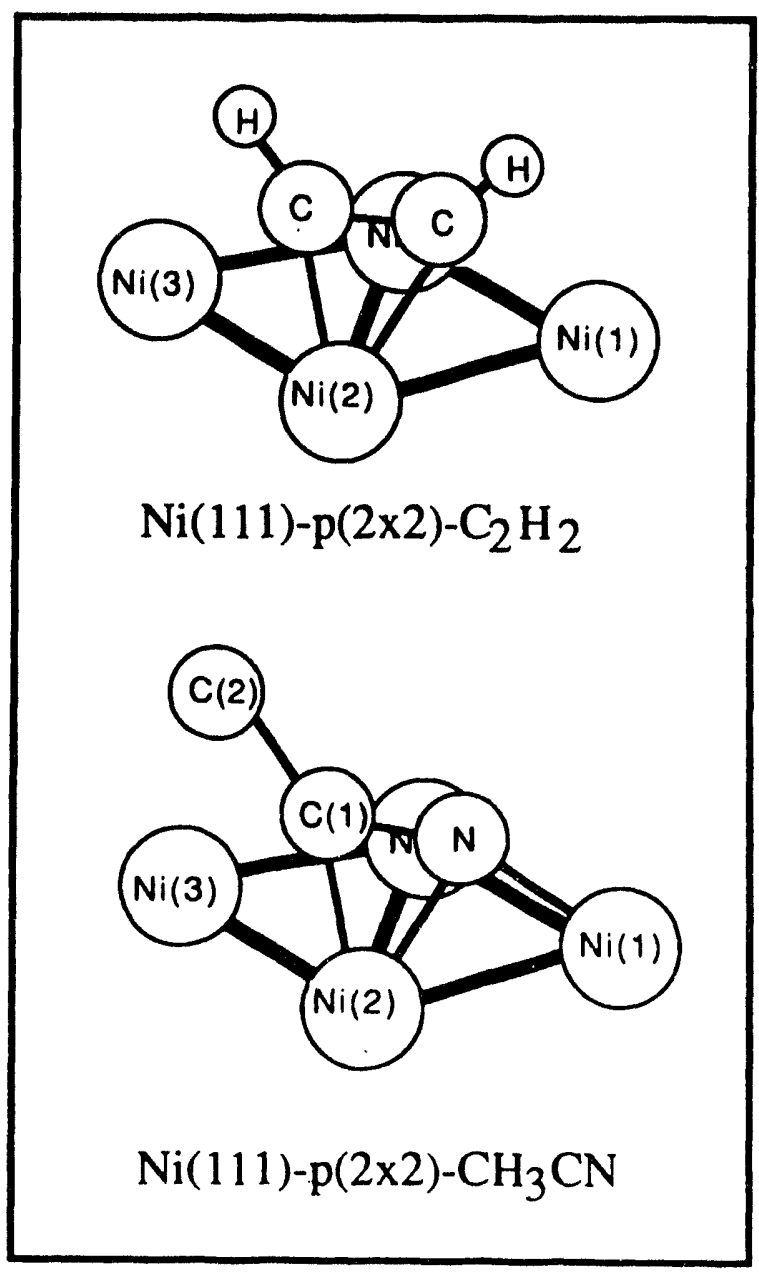

XBL 939-1302

Figure 3.4: Comparison of the models proposed for the $\mathrm{Ni}(111)-\mathrm{p}(2 \times 2)-\mathrm{C}_{2} \mathrm{H}_{2}[25]$ and the $\mathrm{Ni}(111)-\mathrm{p}(2 \times 2)-\mathrm{CH}_{3} \mathrm{CN}$ structures (H omitted). 


\begin{tabular}{|l|c|c|c|}
\hline Model & \multicolumn{3}{|c|}{ Rp-factor } \\
\hline & no fit & fit 1 & fit 2 \\
\hline a linear fcc & 0.80 & 0.56 & \\
b linear hcp & 0.76 & 0.60 & \\
c linear bridge & 0.65 & $*$ & \\
d linear top & 0.74 & 0.61 & \\
& & & \\
e bent $\mu_{3}$ fcc & 0.50 & 0.42 & 0.23 \\
f bent $\mu_{3}$ hcp & 0.61 & $*$ & \\
g bent $\mu_{2}$ & 0.72 & 0.62 & \\
h bent $\mu_{1}(1)$ & 0.71 & 0.56 & \\
i bent $\mu_{1}(2)$ & 0.49 & 0.42 & 0.33 \\
j bent $\mu_{1}(3)$ & 0.59 & $*$ & \\
\hline
\end{tabular}

Table 3.1: Rp-factors for various $\mathrm{Ni}(111)-\mathrm{p}(2 \times 2)-\mathrm{CH}_{3} \mathrm{CN}$ models; 'fil 1' refers to the optimization of only the vertical positions of the acetonitrile atoms; '*' means that the search led to unrealistic bond lengths; 'fit 2' refers to the optimization of all the parameters.

but their error bars are large $(0.10 \AA)$.

Various bond lengths and bond angles for the adsorbed acetonitrile and gas phase acetonitrile are reported in table 3.3. The C-N bond length $(1.28 \pm 0.15 \AA)$ and the C-C$\mathrm{N}$ bond angle $\left(123 \pm 15^{\circ}\right)$ are close to those reported for the $\mathrm{Fe}_{3}\left(\mathrm{CH}_{3} \mathrm{CH}_{2} \mathrm{CH}_{2} \mathrm{CN}\right)(\mathrm{CO})_{9}$ complex (1.25 $\AA$ and $135^{\circ}$ respectively) [1]. These are indicative of a rehybridization of the acetonitrile molecule into a $\mathrm{sp}^{2}$ configuration. HREEL spectra for adsorbed acetonitrile on $\operatorname{Ni}(111)[13,26]$ show a weak band at $1650-1680 \mathrm{~cm}^{-1}$ which can now be unambiguously interpreted as a $\mathrm{C}-\mathrm{N}$ stretching vibration. This result also confirms the conclusions of an XPS study for acetonitrile adsorbed on $\mathrm{Ni}(111)$ [11], in which the chemical shift of the $\mathrm{C}(1 \mathrm{~s})$ in the spectra was interpreted as due to the bonding of the acetonitrile through both the $\mathrm{N}$ and $\mathrm{C}$ atoms. The $\mathrm{C}-\mathrm{C}$ bond length is about $1.67 \pm 0.15 \AA$ (note the large uncertainty due to large error bar in the lateral coordinates) which is somewhat longer than a C-C single bond in the gas phase $(1.57 \AA)$. However in the HREEL spectrum of acetonitrile on $\mathrm{Ni}(111)[13,25]$, the vibrational frequency of the peak assigned to $\nu(\mathrm{C}-\mathrm{C})$ is in the range 900-920 $\mathrm{cm}^{-1}$ which is close to the frequency $\left(920 \mathrm{~cm}^{-1}\right)$ of gas phase acetonitrile. We cannot conclude therefore that a significant weakening of the $\mathrm{C}-\mathrm{C}$ bond occurs. The $\mathrm{Ni}-\mathrm{N}$ bonds lengths are $1.80 \pm 0.15 \AA$ and $2.00 \pm 0.15 \AA$, and the Ni-C(1) bond length is 


\begin{tabular}{|l|c|c|c|}
\hline atom & $\mathrm{X}$ & $\mathrm{Y}$ & $\mathrm{Z}$ \\
\hline $\mathrm{C}(2)$ & -2.01 & 0.00 & 0.00 \\
$\mathrm{C}(1)$ & -1.19 & 0.00 & 1.45 \\
$\mathrm{~N}$ & 0.09 & 0.00 & 1.53 \\
$\mathrm{Ni}(1)$ & 1.41 & 0.00 & 2.76 \\
$\mathrm{Ni}(2)$ & -0.68 & -1.28 & 2.86 \\
$\mathrm{Ni}\left(2^{\prime}\right)$ & -0.68 & +1.28 & 2.86 \\
$\mathrm{Ni}(3)$ & -3.00 & 0.00 & 2.89 \\
$\mathrm{Ni}(4)$ & 2.91 & 0.00 & 4.89 \\
$\mathrm{Ni}(5)$ & 0.75 & -1.28 & 4.90 \\
$\mathrm{Ni}\left(5^{\prime}\right)$ & 0.75 & +1.28 & 4.90 \\
$\mathrm{Ni}(6)$ & -1.42 & 0.00 & 4.92 \\
\hline Bulk & 0.00 & 0.00 & 6.93 \\
$\mathrm{Bulk}$ repeat vector & 1.41 & 0.00 & 2.03 \\
2D unit cell & 0.00 & 4.98 & 0.00 \\
vector & 4.31 & 2.49 & 0.00 \\
\hline
\end{tabular}

Table 3.2: Atomic coordinates of the best-fit geometry $(R p=0.23)$ of $N i(111)-p(2 \times 2)$ $\mathrm{CH}_{3} \mathrm{CN}$, consistent with the $\mathrm{C}_{s}$ symmetry of the ove ${ }^{\prime}$ zyer. $\mathrm{X}$ and $\mathrm{Y}$ coordinates are parallel to the surface; $\mathrm{Z}$ is perpendicular to the surface and positive towards the bulk. Side view and top-view of the structure in figure 3.6. Atoms labeled with the same number are symmetry equivalent (eg. $\mathrm{Ni}(5)$ and $\left.\mathrm{Ni}\left(5^{\prime}\right)\right)$. 

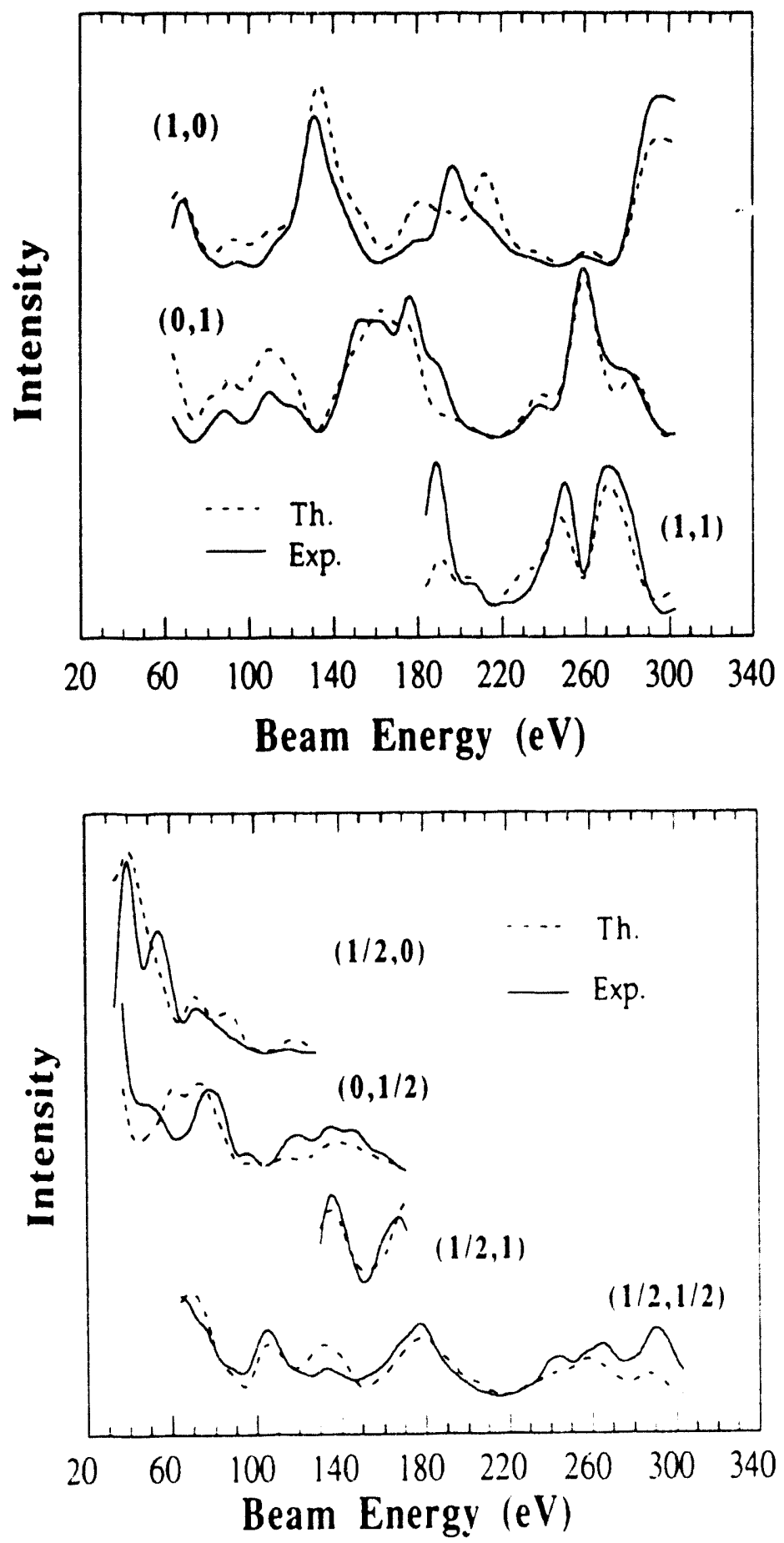

Figure 3.5: $1-\mathrm{V}$ curves for the $\mathrm{Ni}(111)-\mathrm{p}(2 \times 2)-\mathrm{CH}_{3} \mathrm{CN}$ structure, which illustrate the agreement between theory and experiment for all beams. 

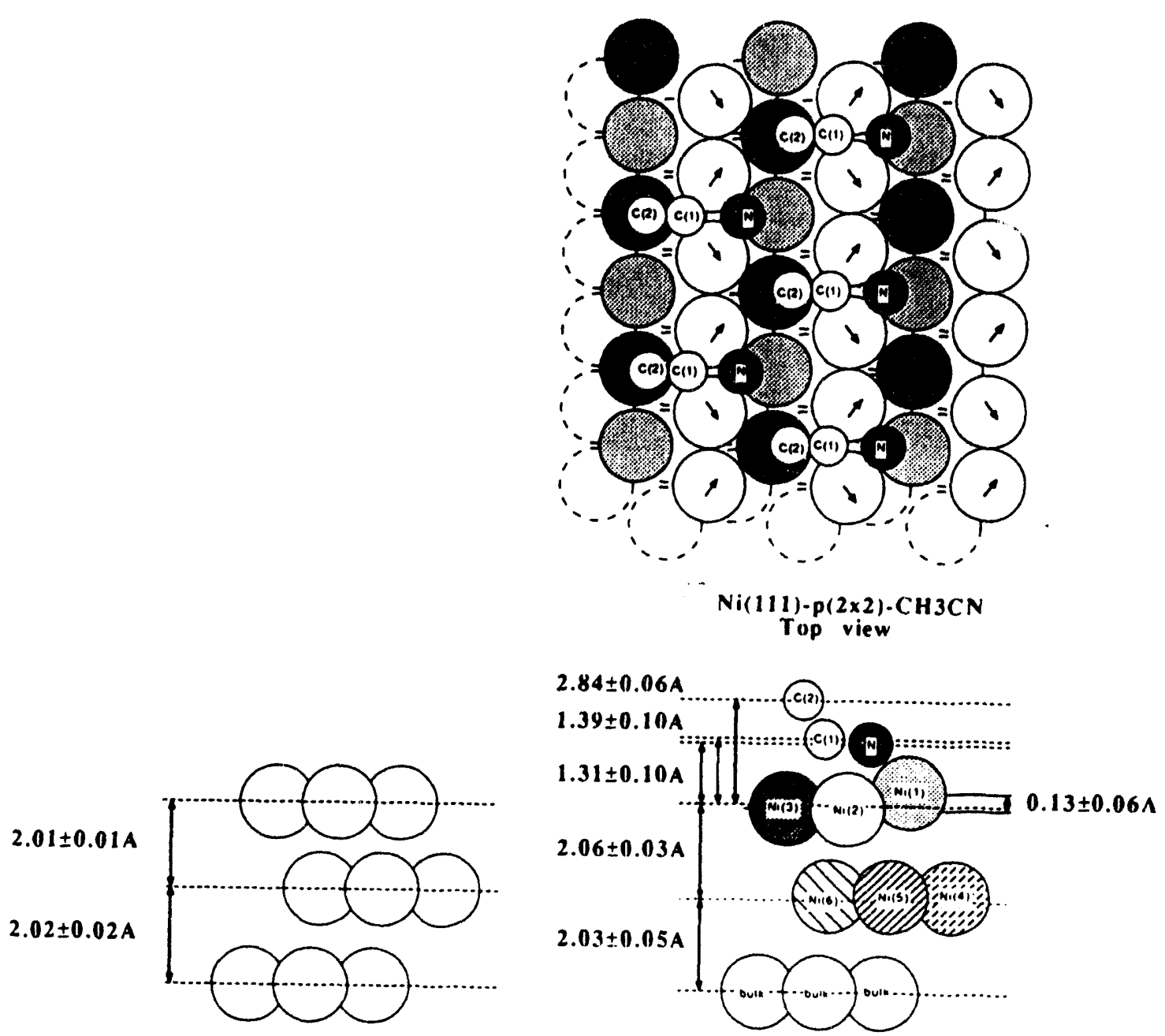

Clean $\mathrm{Ni}(111)$ Nil111)-p(2x2)-CH3CN Side View

$\mathrm{Ni}(111)-\mathrm{p}(2 \times 2)-\mathrm{CH} 3 \mathrm{CN}$

$\mathbf{R p}=\mathbf{0 . 2 3}$

XBL $939 \cdot 1300$

Figure 3.6: Side view and top view of the $\mathrm{Ni}(111)-\mathrm{p}(2 \times 2)-\mathrm{CH}_{3} \mathrm{CN}$ structure (H omitted), compared with the clean $\mathrm{Ni}(111)$ surface. Selected interlaycr spacings are shown (between averaged $\mathrm{Ni}$ planes where these are buckeld as shown). Inequivalent $\mathrm{Ni}$ atoms are shaded differently. Possible Ni relaxations are indicated by arrows. 


\begin{tabular}{|l|l|}
\hline $\mathrm{Ni}(111)-\mathrm{p}(2 \times 2)-\mathrm{CH}_{3} \mathrm{CN}$ & Gas phase $\mathrm{CH}_{3} \mathrm{CN}$ \\
\hline $\mathrm{d}(\mathrm{C}-\mathrm{C})=1.67 \pm 0.15 \AA$ & $\mathrm{d}(\mathrm{C}-\mathrm{C})=1.57 \AA$ \\
$\mathrm{d}(\mathrm{C}-\mathrm{N})=1.28 \pm 0.15 \AA$ & $\mathrm{d}(\mathrm{C}-\mathrm{N})=1.16 \AA$ \\
angle(CCN) $=123 \pm 15^{\circ}$ & angle(CCN) $=180^{\circ}$ \\
& \\
& \\
$\mathrm{d}(\mathrm{N}-\mathrm{Ni}(1))=1.80 \pm 0.15 \AA$ & \\
$\mathrm{d}(\mathrm{N}-\mathrm{Ni}(2))=2.00 \pm 0.15 \AA$ & \\
$\mathrm{d}(\mathrm{C}-\mathrm{Ni}(2))=1.97 \pm 0.15 \AA$ & \\
$\mathrm{d}(\mathrm{C}-\mathrm{Ni}(3))=2.31 \pm 0.15 \AA$ & \\
\hline
\end{tabular}

Table 3.3: Various bond lengths and bond angles for the $\mathrm{Ni}(111)-\mathrm{p}(2 \times 2)-\mathrm{CH}_{3} \mathrm{CN}$ structure and $\mathrm{CH}_{3} \mathrm{CN}$ in the gas phase.

$1.97 \pm 0.15 \AA$. These metal-molecule bond lengths are very similar to what is found for the $\mathrm{Fe}_{3}\left(\mathrm{CH}_{3} \mathrm{CH}_{2} \mathrm{CH}_{2} \mathrm{CN}\right)(\mathrm{CO})_{9}$ complex [1], where the Fe-Fe distances (2.48-2.62 $\AA$ ) are very close to Ni-Ni distances $(2.49 \AA)$.

\subsection{Reactivity of Acetonitrile with Hydrogen on $\mathrm{Ni}(111)$}

Since we are interested by the reactivity of acetonitrile and hydrogen on nickel surfaces, we have studied the coadsorption of acetonitrile and hydrogen on $\mathrm{Ni}(111)$, both by LEED and HREELS. Before we report our observations, we shall remind what is known about the adsorption of hydrogen alone on $\mathrm{Ni}(111)$.

\subsubsection{Hydrogen adsorption on $\mathrm{Ni}(111)$}

Hydrogen adsorption on $\mathrm{Ni}(111)$ has been studied by TDS [27] and LEED [28]. In a UHV environment, $\mathrm{H}_{2}$ is reversibly dissociated on $\mathrm{Ni}(111)$, and desorbs from the surface, after recombination, with a desorption peak maximum around $380 \mathrm{~K}$. Below $270 \mathrm{~K}$, a c $(2 \times 2)$ structure can be observed by LEED. A dynamical LEED analysis of the $\mathrm{Ni}(111)-\mathrm{c}(2 \times 2)-2 \mathrm{H}$ structure [28] has shown that $\mathrm{H}$ atoms order on $\mathrm{Ni}(111)$ in a honcycomb structure with a closest $\mathrm{H}$-H distance equal to $2.87 \AA$ (figure 3.7 ). 


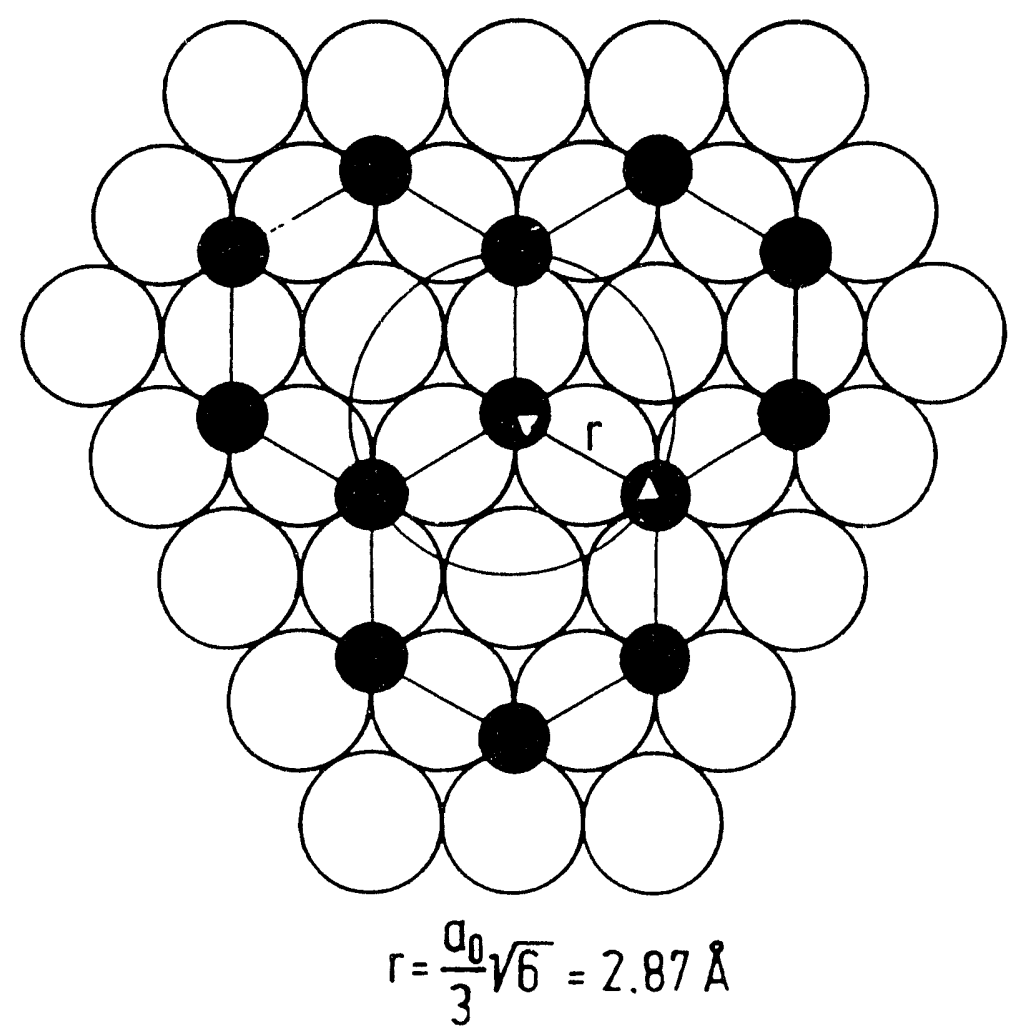

XBL $9311-1560$

Figure 3.7: Structure model of the $\mathrm{c}(2 \times 2)-2 \mathrm{H}$ phase observed below $270 \mathrm{~K}$ for hydrogen adsorption on $\mathrm{Ni}(111)$. Indicated is the closest mutual $\mathrm{H}-\mathrm{H}$ distance, $\mathrm{r}_{H-H}$. 


\begin{tabular}{|lrrrr|}
\hline & & & \multicolumn{2}{c|}{ Ni(111) } \\
\cline { 5 - 6 } mode & gas [26] & Pt(111) $[10]$ & ref [11] & this work \\
\hline torsion- $\mathrm{CH}_{3} \mathrm{CN}$ & & 280 & 360 & 370 \\
metal-CH ${ }_{3} \mathrm{CN}$ sym str & & & & \\
metal-CH ${ }_{3} \mathrm{CN}$ asym str & & 410 & & \\
CCN bend & 361 & 605 & 520 & 540 \\
$\mathrm{CC}$ str & 920 & 950 & 900 & 920 \\
$\mathrm{CH}_{3}$ rock & 1041 & 1060 & 1020 & 1030 \\
$\mathrm{CH}_{3}$ sym def & 1389 & 1375 & 1400 & 1430 \\
$\mathrm{CH}_{3}$ d def & 1454 & 1435 & 1400 & 1430 \\
$\mathrm{CN}_{\text {str }}$ & 2268 & 1615 & 1680 & 1650 \\
$\mathrm{CH}_{3}$ sym str & 2954 & 2960 & 2910 & 2960 \\
$\mathrm{CH}_{3}$ d str & 3009 & 3005 & & \\
\hline
\end{tabular}

Table 3.4: Vibrational frequencies $\left(\mathrm{cm}^{-1}\right)$ of acetonitrile.

\subsubsection{Acetonitrile and hydrogen coadsorption}

We have studied acetonitrile and hydrogen coadsorption by HREELS, hoping to detect some hydrogenated species on the surface. The HREEL spectra were taken at 150 $\mathrm{K}$, in the specular direction. In figure 3.8a, we show the HREEL spectrum of the $\mathrm{Ni}(111)$ $\mathrm{p}(2 \times 2)-\mathrm{CH}_{3} \mathrm{CN}$ structure, obtained after $1 \mathrm{~L}$ exposure of acetonitrile. The vibrational peaks assignment is reported in table 3.4 and compared to the previous assignment of [14] .

When hydrogen is then adsorbed on that surface (up to $100 \mathrm{~L}$ exposure), very little changes are observed in the vibrational spectrum (figure $3.8 \mathrm{~b}$ ). Heating the surface up to $350 \mathrm{~K}$ (which corresponds to the desorption temperature of acetonitrile) did not bring any new features in the vibrational spectrum. However, heating the surface above $380 \mathrm{~K}$ lead to the desorption of hydogen from the surface, which indicates that some hydrogen can effectively be coadsorbed with acetonitrile on the surface but does not react with it under these conditions.

When hydrogen is first adsorbed on $\mathrm{Ni}(111)$ (10 L exposure) and then exposed to acetonitrile, HREELS shows only very weak peaks which can be attributed to a very small amount of acetonitrile on the surface (figure 3.8c). No new fcatures are observed in the vibrational spectrum after heating the surface up to $350 \mathrm{~K}$.

In conclusion, acetonitrile and hydrogen do not react on $\mathrm{Ni}(111)$ in UHV. 
Chapter 3. Bonding and Reactivity of $\mathrm{CH}_{3} \mathrm{CN}$ on $\mathrm{Ni}(111)$

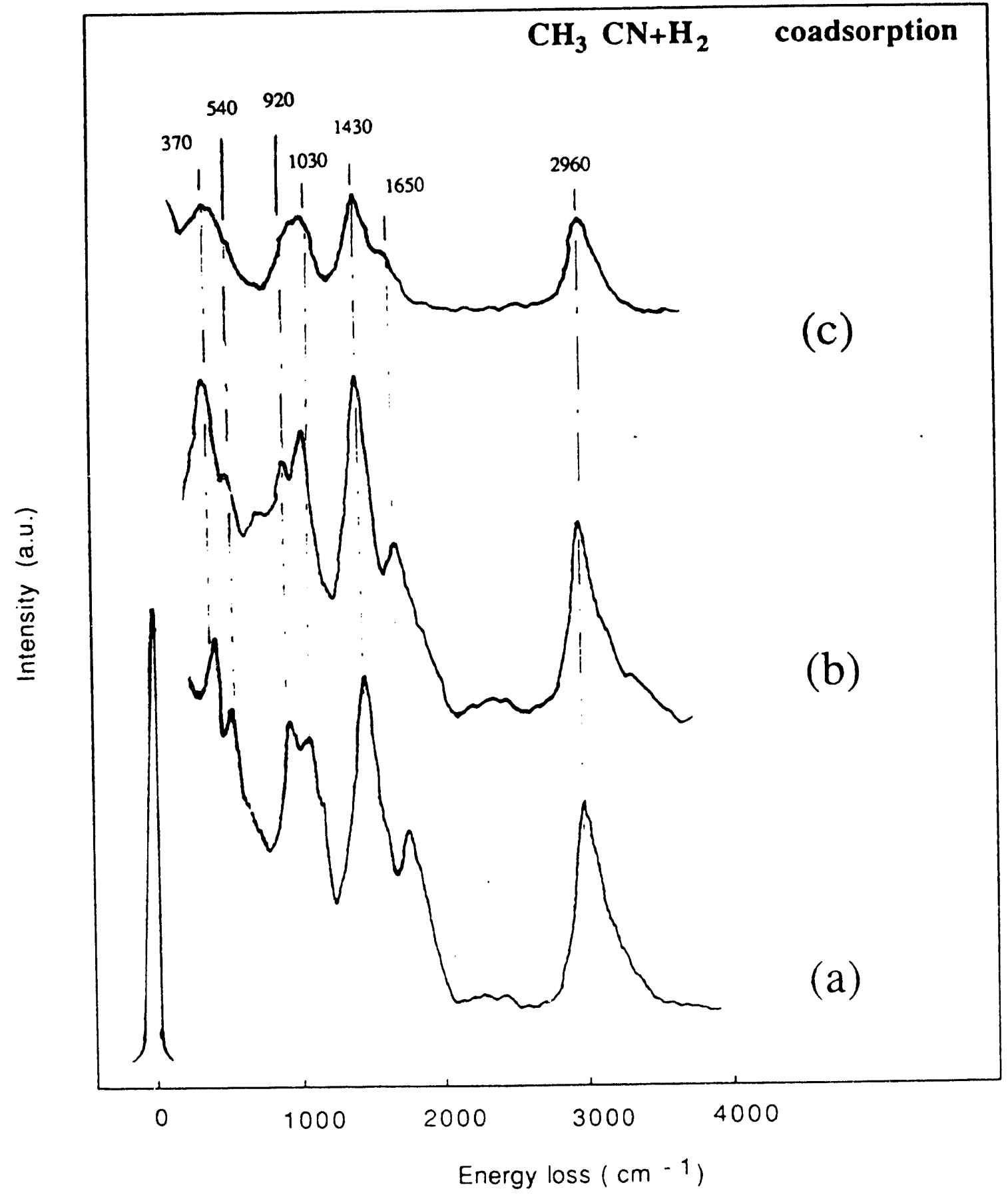

XBL 9311.1588

Figure 3.8: HREEL spectra at $150 \mathrm{~K}$, in the specular direction, of $\mathrm{Ni}(111)-\mathrm{p}(2 \times 2)-\mathrm{CH}_{3} \mathrm{CN}$ (a) $, \mathrm{Ni}(111)-\mathrm{p}(2 \times 2)-\mathrm{CH}_{3} \mathrm{CN}+100 \mathrm{~L}, \mathrm{H}_{2}$ (b), $10 \mathrm{~L} \mathrm{H}_{2}+1 \mathrm{~L} \mathrm{CH}_{3} \mathrm{CN}$ (c) 
Chapter 3. Bonding and Reactivity of $\mathrm{CH}_{3} \mathrm{CN}$ on $\mathrm{Ni}(111)$

\subsection{References}

[1] M.A. Andrews, C.B. Knobler, and H.D. Kaesz, J. Am. Chem. Soc., 101 (1979) 7260; Z. Dawoodi, M.J. Mays, and P.R. Raithby, J. Organometal. Chem., 219 (1989) 103.

[2] F.J. Garcia Alonso, M. Garcia Sanz, V. Rieva, A. Anillo Abril, A. Tiripicchio, and F. Ugozzoli, Organometallics, 11 (1992) 801.

[3] T.C. Wright, G. Wilkinson, M.Motevalli, and M.B. Hursthouse, J. Chem. Soc., Dalton Trans. (1986) 2017.

[4] I.W. Bassi, and M. Calcaterra, J. Organomet. Chem., 110 (1976) 129.

[5] C.M. Friend, J. Stein, and E.L. Muetterties, J. Am. Chem. Soc., 103 (1981) 767.

[6] C.M. Friend, E.L. Muetterties, and J.L. Gland, J. Phys. Chem., 85 (1981) 3256.

[7] R.M. Wexler, and E.L. Muetterties, J. Phys. Chem., 88 (1984) 4037.

[8] P.N. Rylander, Catalytic Hydrogenation over Platinum Metals (Academic Press, New York and London, 1967), p.203.

[9] J.C. Hemminger, E.L. Muetterties, and G.A. Somorjai, J. Am. Chem. Soc., 101 (1979) 62.

[10] K. Kishi, and S. Ikeda, Surf. Sci., 107. (1981) 405.

[11] K. Kishi, Y. Okino, and Y. Fujimoto, Surf. Sci., 176 (1986) 23.

[12] T. Nakayama, K. Inamura, Y. Inoue, S.Ikeda, and K. Kishi, Surf. Sci., 179 (1987) 47.

[13] B.A. Sexton, and N.R. Avery, Surf. Sci., 129 (1983) 21.

[14] C.M. Friend, E.L. Muetterties, and J.L. Gland, J. Phys. Chem., 85 (1981) 3256.

[15] P.A. Stevens, R.J. Madix, and J. Stöhr, J. Chem . Phys., 91 (1989) 4338.

[16] W.H. Weinberg, D.F. Johnson, Y.-Q. Wang, J.E. Parmeter, and M.M. Hills, Surf. Sci., 235 (1990) L299.

[17] C.M. Friend, and J.G. Serafin, J. Chem. Phys., 88 (1988) 4037. 
[18] M.A. Van Hove, W. Moritz, H. Over, P.J. Rous, A. Wander, A. Barbieri, N. Materer, U. Starke, D. Jentz, J. M. Powers, G. Held, and G.A. Somorjai, Surf. Sci., in press.

[19] P.J. Rous, and J.B. Pendry, Surf. Sci., 219 (1989) 355 and 373.

[20] P.J. Rous, Prog. Surf. Sci., 39 (1992) 3.

[21] M.A. Van Hove, W.H. Weinberg, and C.-M. Chan, Low-Energy Electron Diffraction (Springer-Verlag, Berlin, Heidelberg, New York,1986).

[22] J.B. Pendry, J. Phys. C, 13 (1980) 937.

[23] U. Starke, A. Barbieri, N. Materer, M.A. Van Hove, and G.A. Somorjai, Surf. Sci., 286 (1993) 1.

[24] N. Materer, A.Barbieri, D.E. Gardin, U. Starke, J.D. Batteas, M.A. Van Hove, and G.A. Somorjai, submitted to Surf. Sci.

[25] G. Casalone, M.G. Cattania, F. Merati, and M. Simonetta, Surf. Sci., 120 (1982) 171.

[26] D.E. Gardin, and G.A. Somorjai, J. Phys. Chem., 96 (1992) 9424.

[27] J. Lapujoulade, and K.S. Neil, J. Chem. Phys., 57 (1972) 3535; K. Christmann, O. Schober, G. Ertl, and M. Neumann, J. Chem. Phys., 60 (1974) 4528.

[28] R.J. Behm, G. Ertl, M.A. Van Hove, and W.H. Weinberg, J. Chem .Phys.,70 (1979) 4168.

[29] J.E.D. Davies, J. Mol. Struct., 9 (1971) 483. 


\section{Chapter 4}

\section{Bonding and Reactivity of $\mathrm{CH}_{3} \mathrm{NH}_{2}$ and $\mathrm{CH}_{3} \mathrm{CH}_{2} \mathrm{NH}_{2}$ on . $\mathrm{Ni}(111)$}

\subsection{Introduction}

As it was shown in chapter 3 , acetonitrile and hydrogen do not seem to react on $\mathrm{Ni}(111)$ in a UHV environment. Because of the low hydrogen pressure in the UHV chamber, we expect that the dehydrogenation of amines to the corresponding nitriles is more favorable thermodynamically than the hydrogenation of nitriles. In this chapter, the study of the adsorption and reactivity of methylamine $\left(\mathrm{CH}_{3} \mathrm{NH}_{2}\right)$ and ethylamine $\left(\mathrm{CH}_{3} \mathrm{CH}_{2} \mathrm{NH}_{2}\right)$ on $\mathrm{Ni}(111)$ is reported.

Amines have the ability to adsorb molecularly through the nitrogen lone pair on transition metal surfaces under ultra-high vacuum (UHV) conditions, at a temperature high enough for activating $\mathrm{C}-\mathrm{H}, \mathrm{N}-\mathrm{H}, \mathrm{C}-\mathrm{N}$ or $\mathrm{C}-\mathrm{C}$ bonds. When heating the surface, the investigation of their surface reactivity by various surface science techniques is possible.

So far, only few studies of the adsorption of amines on well-characterized surfaces have been reported in the literature. The high resolution elcctron energy loss vibrational spectroscopy (HREELS) study of $\mathrm{CH}_{3} \mathrm{NH}_{2}$ on $\mathrm{Ni}(100), \mathrm{Ni}(111), \mathrm{Cr}(100)$ and $\mathrm{Cr}(111)$ by Baca et al [1] confirmed that methylamine adsorbs molecularly at $300 \mathrm{~K}$ like ammonia through the nitrogen lone pair. The adsorption of $\mathrm{CH}_{3} \mathrm{NH}_{2}$ was also investigated on $\mathrm{Ni}(111)$ 
[2], $\mathrm{Ni}(100)$ [3], $\mathrm{Pt}(111)$ [4], $\mathrm{Pt}(100)$ [5], $\mathrm{Mo}(100)[6], \mathrm{W}(100)$ [7], $\mathrm{Rh}(111)$ [8] and $\mathrm{Ru}(100)$ [9]. Methylamine was found to dehydrogenate on all surfaces. No C-N bond scission was observed on $\mathrm{Pt}(111)$ [5] (desorption of $\mathrm{HCN}$ and $\mathrm{C}_{2} \mathrm{~N}_{2}$ was detected), while some was found on $\mathrm{Rh}(111)$ [9] and $\mathrm{Pt}(100)$ [5]. On $\mathrm{Ni}(111)$ [2] and $\mathrm{Ni}(100)$ [3], methylamine was totally decomposed leaving atomic carbon and nitrogen on the surface.

Ethylamine $\left(\mathrm{CH}_{3} \mathrm{CH}_{2} \mathrm{NH}_{2}\right)$ thermal decomposition was studied on $\mathrm{W}(100)$, $\mathrm{W}(100)-(5 \times 1)-C$, and $\mathrm{W}(100)-(2 \times 1)-O$ [11]. On $\mathrm{W}(100)$, ethylamine undergoes $\mathrm{C}-\mathrm{N}$ and $\mathrm{C}-\mathrm{C}$ bond scission leading mainly to methane and ammonia desorption. In contrast, on $\mathrm{W}(100)-(5 \times 1)-\mathrm{C}$, neither $\mathrm{C}-\mathrm{C}$ nor $\mathrm{C}-\mathrm{N}$ bond scission were observed after ethylamine adsorption. Acetonitrile $\left(\mathrm{CH}_{3} \mathrm{CN}\right)$ was the major product detected. An initial selective $\alpha-\mathrm{C}-\mathrm{H}$ bond activation was proposed to account for the product distribution. The W(100)-(2x1)$\mathrm{O}$ surface was inert with respect to $\mathrm{C}-\mathrm{H}, \mathrm{N}-\mathrm{H}$ or $\mathrm{C}-\mathrm{N}$ bond scission, resulting primarily in molecular ethylamine desorption.

Other larger amines were investigated by Inamura et al [10] on evaporated nickel films by $\mathrm{x}$-ray photoelectron spectroscopy (XPS). It was found that all amines adsorb molecularly on the surface through nitrogen lone-pair electrons below $200 \mathrm{~K}$. With the rise of temperature up to $330 \mathrm{~K}$, various surface complexes were observed that were similar to those obtained after adsorption of the corresponding nitriles.

In this chapter, the adsorption of $\mathrm{CH}_{3} \mathrm{NH}_{2}$ and $\mathrm{CH}_{3} \mathrm{CH}_{2} \mathrm{NH}_{2}$ on $\mathrm{Ni}(111)$ at 150 $\mathrm{K}$ is examined by HREELS. The spectra obtained indicate that both molecules adsorbed through the nitrogen lone-pair electrons. A weakening of the $\alpha-\mathrm{C}-\mathrm{H}$ bonds is indicated by a broad band at $2660-2680 \mathrm{~cm}^{-1}$, assigned to $\mathrm{C}-\mathrm{H}$ stretching vibrations shifted to lower frequencies. The desorption and thermal decomposition were also investigated. Upon heating, the desorption of amines competes with their dehydrogenation. On Ni(111), both methylamine and ethylamine dehydrogenate between $300 \mathrm{~K}$ and $400 \mathrm{~K}$. Dehydrogenated methylamine completely decomposes, leaving carbon and nitrogen on the surface, while in the case of ethylamine, acetonitrile is found to desorb at $350 \mathrm{~K}$. We propose that the dehydrogenation process begins with $\alpha-\mathrm{C}-\mathrm{H}$ bonds scission. 


\begin{tabular}{|llrrrr|}
\hline & & & & \multicolumn{2}{c|}{ Ni(111) } \\
\cline { 5 - 6 } & mode & gas & {$\left[\mathrm{Pt}\left(\mathrm{CH}_{3} \mathrm{NH}_{2}\right)_{2} \mathrm{Cl}_{2}\right]$} & ref $[1]$ & this work \\
\hline $\mathrm{A}_{1}^{\prime}$ & $\mathrm{NH}_{2}$ sym str & 3360 & $3270,3240,3140$ & 3240 & 3260 \\
$\nu_{2}$ & $\mathrm{CH}_{3}$ asym str & 2962 & 3016 & 2960 & 2920 \\
$\nu_{3}$ & $\mathrm{CH}_{3}$ sym str & 2820 & 2928,2896 & 2820 & 2660 \\
$\nu_{4}$ & $\mathrm{NH}_{4}$ def & 1623 & $1596,1581,1575$ & 1570 & 1580 \\
$\nu_{5}$ & $\mathrm{CH}_{3}$ asym def & 1474 & 1465,1453 & 1485 & 1460 \\
$\nu_{6}$ & $\mathrm{CH}_{3}$ sym def & 1430 & $1429,1417,1405$ & & \\
$\nu_{7}$ & $\mathrm{CH}_{3}$ rock & 1130 & 990 & 1195 & 1200 \\
$\nu_{8}$ & $\mathrm{CN}_{\text {str }}$ & 1044 & 1037,1017 & 1010 & 1020 \\
$\nu_{9}:$ & $\mathrm{NH}_{2}$ wag & 780 & 740 & 730 & 730 \\
$\mathrm{~A}^{\prime \prime}$ & & & & \\
$\nu_{10}$ & $\mathrm{NH}_{2}$ asym str & 3424 & & 3305 & 3340 \\
$\nu_{11}$ & $\mathrm{NH}_{2}$ asym str & 2985 & & & 3000 \\
$\nu_{12}$ & $\mathrm{CH}_{3}$ asym def & 1485 & & & \\
$\nu_{13}$ & $\mathrm{NH}_{2}$ twist & & & & \\
$\nu_{14}$ & $\mathrm{CH}_{3}$ rock & 1195 & & & \\
$\nu_{15}$ & torsion & 265 & & & \\
& metal-N str & & & & \\
\hline
\end{tabular}

Table 4.1: Vibrational frequencies $\left(\mathrm{cm}^{-1}\right)$ of methylamine.

\subsection{Vibrational Spectra of Molecular Methylamine and Ethyl- amine Adsorbed on $\mathrm{Ni}(111)$ at $150 \mathrm{~K}$}

\subsubsection{Methylamine}

After adsorption of 1 monolayer ( $3 \mathrm{~L}$ as shown by TDS experiments) of methylamine at $150 \mathrm{~K}$ on the clean $\mathrm{Ni}(111)$ face, no ordered LEED superstructure is observed. The HREEL spectrum of the surface (figure 4.1) is taken in the specular direction with a beam energy of $3 \mathrm{eV}$. The adsorption of methylamine on the surface decreases the elastic peak from about $5 \times 10^{4}$ counts/s to $8 \times 10^{3}$ counts/s. The observed vibrational frequencies are compared in table 4.1 to those of gas phase methylamine [14], of cis- $\left[\mathrm{Pt}\left(\mathrm{CH}_{3} \mathrm{NH}_{2}\right)_{2} \mathrm{Cl}_{2}\right]$ [15] and to those reported by Baca et al [1] for methylamine on Ni(111). Our spectrum differs only slightly from the one reported in reference [1]. We detect a peak at $525 \mathrm{~cm}^{-1}$ which we assign to the nickel-nitrogen stretching. We also observe a broad band at 2660 $\mathrm{cm}^{-1}$. 


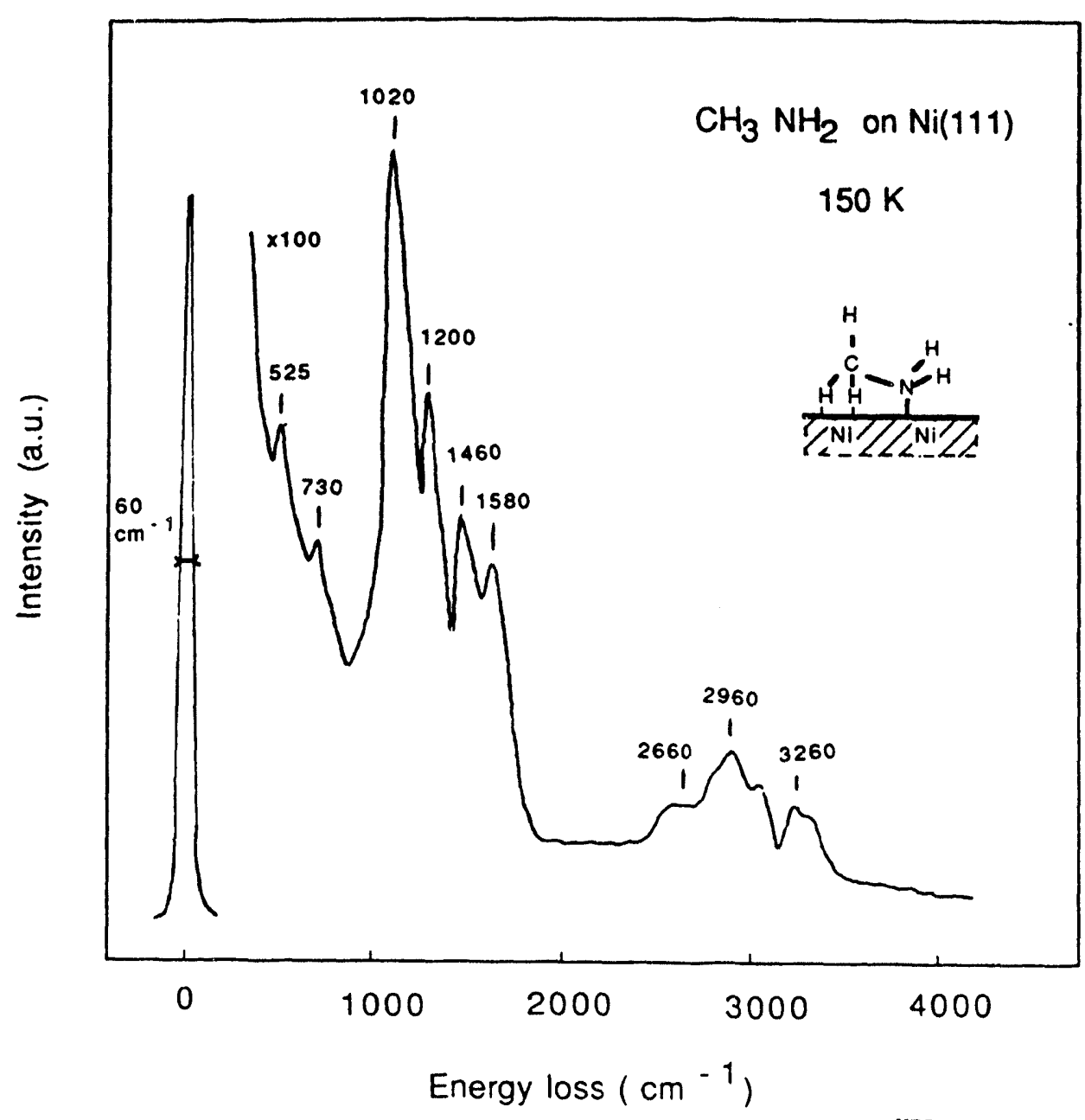

Figure 4.1: HREEL spectrum and proposed geometry of methylamine adsorbed on $\mathrm{Ni}(111)$ at $150 \mathrm{~K}$. Exposure $=3 \mathrm{~L}$. 


\begin{tabular}{|llrrr|}
\hline & & \multicolumn{2}{c|}{ gas } & \\
\cline { 3 - 4 } & mode & gauche & trans & Ni(111) \\
\hline $\mathrm{A}^{\prime}$ & & & \\
$\nu_{1}$ & $\mathrm{NH}_{2}$ sym str & 3343 & & 3200 \\
$\nu_{2}$ & $\mathrm{CH}_{3}$ d str & 2977 & 3040 \\
$\nu_{3}$ & $\mathrm{CH}_{2}$ sym str & 2885 & & 2680 \\
$\nu_{4}$ & $\mathrm{CH}_{3}$ sym str & 2880 & & 2960 \\
$\nu_{5}$ & $\mathrm{NH}_{4}$ def & 1622 & & 1540 \\
$\nu_{6}$ & $\mathrm{CH}_{2}$ d def & 1487 & & \\
$\nu_{7}$ & $\mathrm{CH}_{3}$ d def & 1465 & & $\succ 1440$ \\
$\nu_{8}$ & $\mathrm{CH}_{3}$ sym def & 1378 & & \\
$\nu_{9}$ & $\mathrm{CH}_{2}$ wag & 1397 & & $\succ 1360$ \\
$\nu_{10}$ & $\mathrm{CH}_{3}$ d rock & 1016 & 1119 & 1140 \\
$\nu_{11}$ & $\mathrm{CC}_{\text {str }}$ & 892 & 882 & 880 \\
$\nu_{12}$ & $\mathrm{NH}_{2}$ wag & 773 & 789 & 760 \\
$\nu_{13}$ & $\mathrm{CN}_{\text {str }}$ & 1086 & 1055 & 1080 \\
$\nu_{14}$ & $\mathrm{CCN}_{\text {bend }}$ & 403 & & \\
\hline
\end{tabular}

Table 4.2: Vibrational frequencies $\left(\mathrm{cm}^{-1}\right)$ of ethylamine.

\subsubsection{Ethylamine}

One monolayer ( $3 \mathrm{~L}$ exposure) of ethylamine adsorbed on $\mathrm{Ni}(111)$ at $150 \mathrm{~K}$ shows a similar behavior : no ordered superstructure can be formed, and the ethylamine adsorption reduces the elastic peak intensity. However, many loss peaks can be observed on the HREEL spectrum (figure 4.2). In table 4.2, we compare observed vibrational frequencies with the vibrational analysis of ethylamine by Hamada et al [17]. In their study, by careful comparison of the experimental data with results of ab initio MO calculations of force constants, Hamada et al managed to assign bands of their infrared spectrum, in the 100-2000 $\mathrm{cm}^{-1}$ spectral range, to the Trans and Gauche rotational isomers of ethylamine. From this set of data and from those reported by Wolff and Ludwig [18] for the $2000-3500 \mathrm{~cm}^{-1}$ spectral range, we are able to propose an assignment for most of our observed vibrational peaks. Similar to the case of methylamine, we also observe a broad band at $2680 \mathrm{~cm}^{-1}$.

\subsubsection{Discussion}

All spectra are consistent with the interpretation of methylamine and ethylamine adsorbed molecularly on $\mathrm{Ni}(111)$ at $150 \mathrm{~K}$ through their nitrogen lone-pair electrons. The 


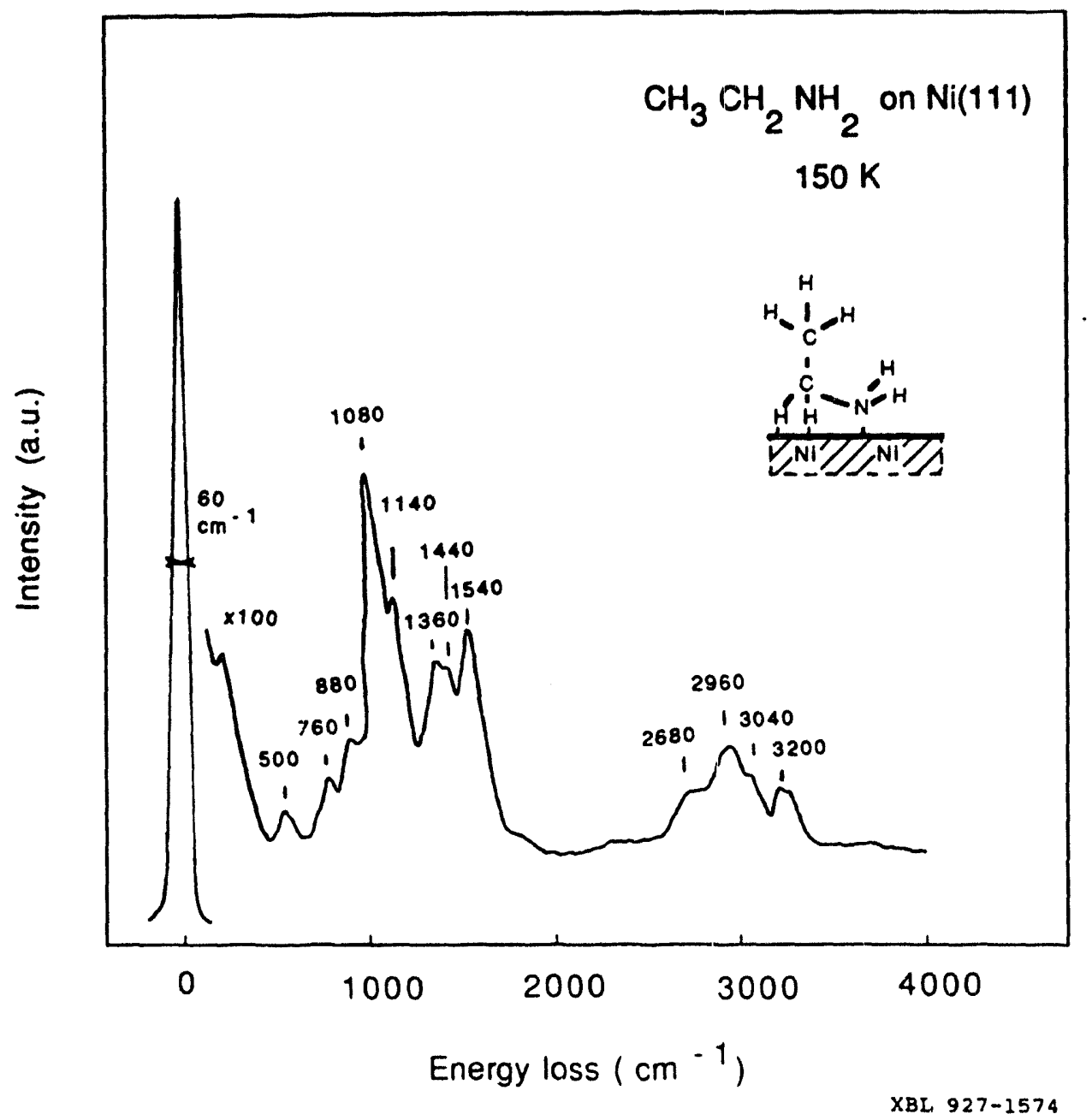

Figure 4.2: HREEL spectrum and proposed geometry of ethylamine adsorbed on $\mathrm{Ni}(111)$ at $150 \mathrm{~K}$. Exposure $=3 \mathrm{~L}$ ( 1 monolayer $)$. 
observed nickel-nitrogen stretching vibrations at $525 \mathrm{~cm}^{-1}$ (methylamine) and $500 \mathrm{~cm}^{-1}$ (ethylamine) are comparable to the nickel-nitrogen stretching of $\mathrm{NH}_{3}$ on $\mathrm{Ni}(111)$ at 490 $\mathrm{cm}^{-1}$ [19]. The interpretation of the broad bands at $2660 \mathrm{~cm}^{-1}$ for methylamine and at $2680 \mathrm{~cm}^{-1}$ for ethylamine needs particular attention. Whereas a combination of the $\mathrm{CH}_{3}$ rocking and $\mathrm{CH}_{3}$ deformation modes at $1200 \mathrm{~cm}^{-1}$ and $1460 \mathrm{~cm}^{-1}$ respectively, could explain the presence of the band at $2660 \mathrm{~cm}^{-1}$ for methylamine, no such combination is possible for ethylamine. The presence of decomposition fragments responsible for the bands at 2660 $\mathrm{cm}^{-1}$ and $2680 \mathrm{~cm}^{-1}$ are unlikely since very little changes in the spectra are observed up to $300 \mathrm{~K}$. It is possible that these bands are due to a second layer of amines, with hydrogen bonding to the first layer. However, the amines dosing was done at $200 \mathrm{~K}$ sometimes, above the multilayer desorption temperature, and the bands at $2660 \mathrm{~cm}^{-1}$ and $2680 \mathrm{~cm}^{-1}$ were still present. We then tentatively assign the $2660 \mathrm{~cm}^{-1}$ and $2680 \mathrm{~cm}^{-1}$ bands to 'softened' C-H stretching vibrations, similar to those observed with cyclohexane adsorbed on various transition metal surfaces [16]. On $\mathrm{Ni}(111)$, for example, cyclohexane exhibits lowered frequency $\mathrm{C}-\mathrm{H}$ stretching vibrations at $2720 \mathrm{~cm}^{-1}$. C-H bonds in the alkyl chain of the amine must therefore be weakened by interactions between hydrogen atoms and nickel surface atoms. Raval and Chesters [16] have shown strong correlations between the extent of the perturbation of the $\mathrm{C}-\mathrm{H}$ bonds, as indicated by the shifting in the $\mathrm{C}-\mathrm{H}$ vibration frequency, and the tendency of the cyclohexane to be dehydrogenated. This suggests that the perturbed $\mathrm{C}-\mathrm{H}$ bond provides a major dehydrogenation pathway on the surface and this should be kept in mind when we study the thermal decomposition pathways of methylamine and ethylamine at higher temperatures.

When methylamine is adsorbed on $\mathrm{Ni}(111)$, hydrogen atoms from the methyl group must therefore interact directly with nickel surface atoms, forming multicenter C-H-metal bonds, as suggested by the proposed geometry of methylamine adsorbed on $\mathrm{Ni}(111)$ (figure 4.1). With ethylamine, it is unclear which hydrogen atoms interact with the surface. Because of the size of the $\mathrm{CH}_{3}$ group, the conformation of ethylamine will most likely be the Trans form, on the flat $\mathrm{Ni}(111)$ surface (figure 4.3). In the gas-phase, the two conformers in thermal equilibrium can be distinguished by their different $\mathrm{CH}_{3}$ rocking frequencies, at $1119 \mathrm{~cm}^{-1}$ for the Trans, and $1016 \mathrm{~cm}^{-1}$ for the Gauche. The higher frequency in the Trans form is explained by the closer interactions of the $\mathrm{CH}_{3}$ group and the $\mathrm{NH}_{2}$ group in this conformation (figure 4.3). On $\mathrm{Ni}\left(111\right.$ ), we note that the observed $\mathrm{CH}_{3}$ rocking frequency at $1140 \mathrm{~cm}^{-1}$ agree well with ethylamine adsorbed in the Trans form. But because-gas 


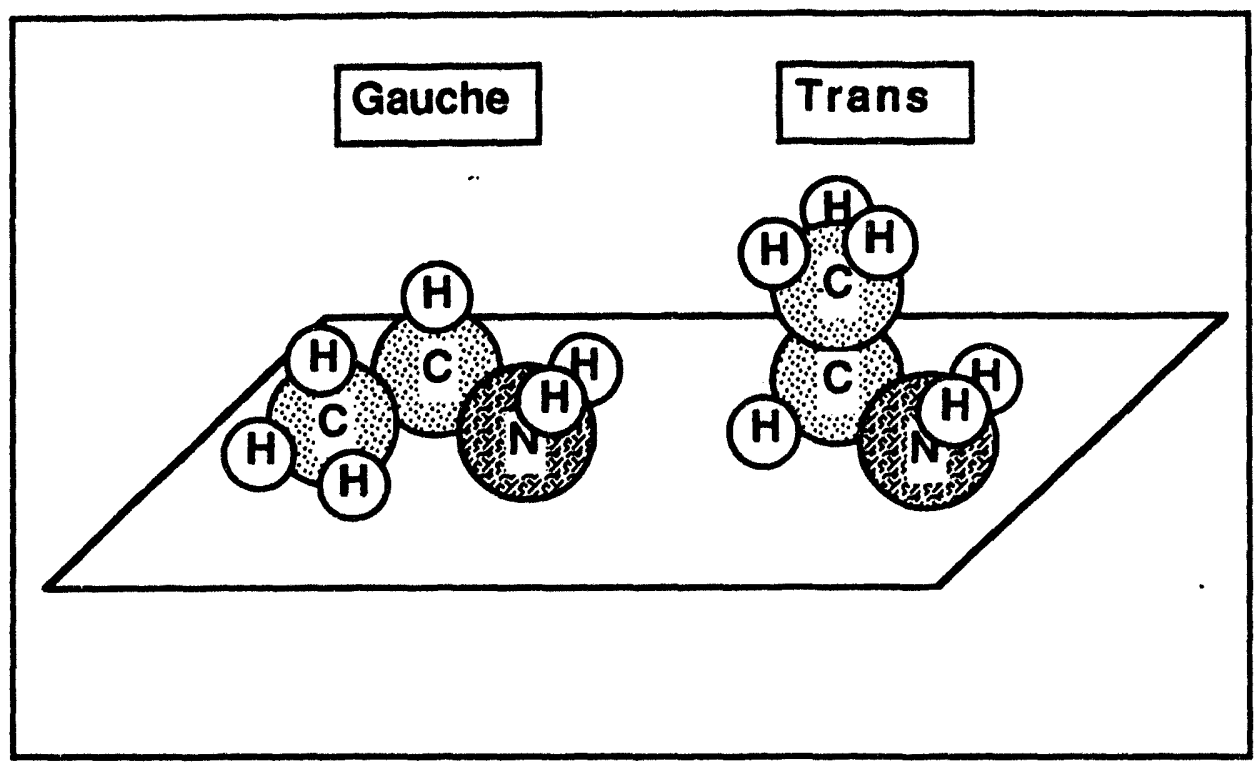

XBL $927-1575$

Figure 4.3: Trans and Gauche conformation of ethylamine on a flat surface. The encumbrance of the $\mathrm{CH}_{3}$ group and the HREEL spectrum indicate that ethylamine must be adsorbed in the Trans form on $\mathrm{Ni}(111)$.

phase $\mathrm{CH}_{3}$ rocking modes are apt to mix with $\mathrm{C}-\mathrm{N}$ stretching or $\mathrm{C}-\mathrm{C}$ stretching modes, as shown by MO calculations [17], one should be cautious about determining the ethylamine conformation only from vibrational data, especially if the C-C and C-N bonds are seriously affected by the adsorption. Based on steric considerations, we propose that ethylamine is adsorbed molecularly on $\mathrm{Ni}(111)$ at $150 \mathrm{~K}$ through the nitrogen lone-pair electrons with the methyl group pointing away from the nickel surface (figure 4.2), while hydrogen atoms of the $\mathrm{CH}_{2}$ group interact directly with nickel surface atoms. 


\subsection{Thermal Decomposition of Methylamine and Ethylamine on $\mathrm{Ni}(111)$}

\subsubsection{Methylamine decomposition}

TDS

Thermal desorption spectroscopy experiments were performed by adsorption of methylamine at $150 \mathrm{~K}$, and then resistively heating the surface up to $900 \mathrm{~K}$ at a rate of $8 \mathrm{~K} / \mathrm{s}$. Following the exposure of the surface to $3 \mathrm{~L}$ of methylamine, the major products detected are methylamine (31 amu), hydrogen (2 amu) and nitrogen (28 amu) (figure 4.4). A small amount of carbon monoxide (28 amu), from background adsorption is also detected. $\mathrm{CH}_{3} \mathrm{NH}_{2}$ desorbs between $\sim 200 \mathrm{~K}$ and $\sim 330 \mathrm{~K} ; \mathrm{H}_{2}$ desorbs with a maximum at $380 \mathrm{~K}$ and up to $450 \mathrm{~K} ; \mathrm{N}_{2}$ desorbs at $\sim 800 \mathrm{~K}$ and $\mathrm{CO}$ at $420 \mathrm{~K}$.

The evolution of the TDS spectra ( $31 \mathrm{amu}$ and $2 \mathrm{amu}$ ) as a function of coverage is shown on figure 4.5. At low coverages (less than $1.0 \mathrm{~L}$ exposure), we reproduce the results of Chorkendorff et al [2] who found that all the adsorbed methylamine dehydrogenates on $\mathrm{Ni}(111)$, leading to $\mathrm{H}_{2}$ and $\mathrm{N}_{2}$ desorption and carbon diffusion into the bulk. At higher coverage, $\mathrm{CH}_{3} \mathrm{NH}_{2}$ desorption occurs with a maximum shifting from $320 \mathrm{~K}$ for $1.0 \mathrm{~L}$ exposure to $250 \mathrm{~K}$ for $3 \mathrm{~L}$. Above $3 \mathrm{~L}$, a low temperature peak at $\sim 170 \mathrm{~K}$ starts to appear and is attributed to the growth of a second layer of $\mathrm{CH}_{3} \mathrm{NH}_{2}$. The amount of desorbed $\mathrm{H}_{2}$

increases with coverage up to $1 \mathrm{~L}$ and st,ays constant above $1 \mathrm{~L} . \mathrm{H}_{2}$ desorption temperature $(380 \mathrm{~K})$ is similar to that from an $\mathrm{H}_{2}$ precovered clean $\mathrm{Ni}(111)$ surface [20]. Most of the dehydrogenation process must therefore occur below $380 \mathrm{~K}$, leaving only carbon and hydrogen on the surface above $380 \mathrm{~K}$. However, the shoulder observed on the $\mathrm{H}_{2}$ desorption peak up to $450 \mathrm{~K}$ indicates that dehydrogenation of $\mathrm{CH}_{3} \mathrm{NH}_{2}$ is totally completed only at $450 \mathrm{~K}$.

\section{HREELS}

After adsorption of 1 monolayer of methylamine ( $3 \mathrm{~L}$ exposure as shown by TDS results), the surface is heated to various temperatures and then cooled to $150 \mathrm{~K}$. Decomposition of the adsorbates as a function of treatment temperatures is followed by HREELS (figure 4.6). When the surface is heated up to $270 \mathrm{~K}$, the HREELS spectrum shows bands with lower intensity, because some methylamine (about $2 / 3$ of a monolayer from TDS 


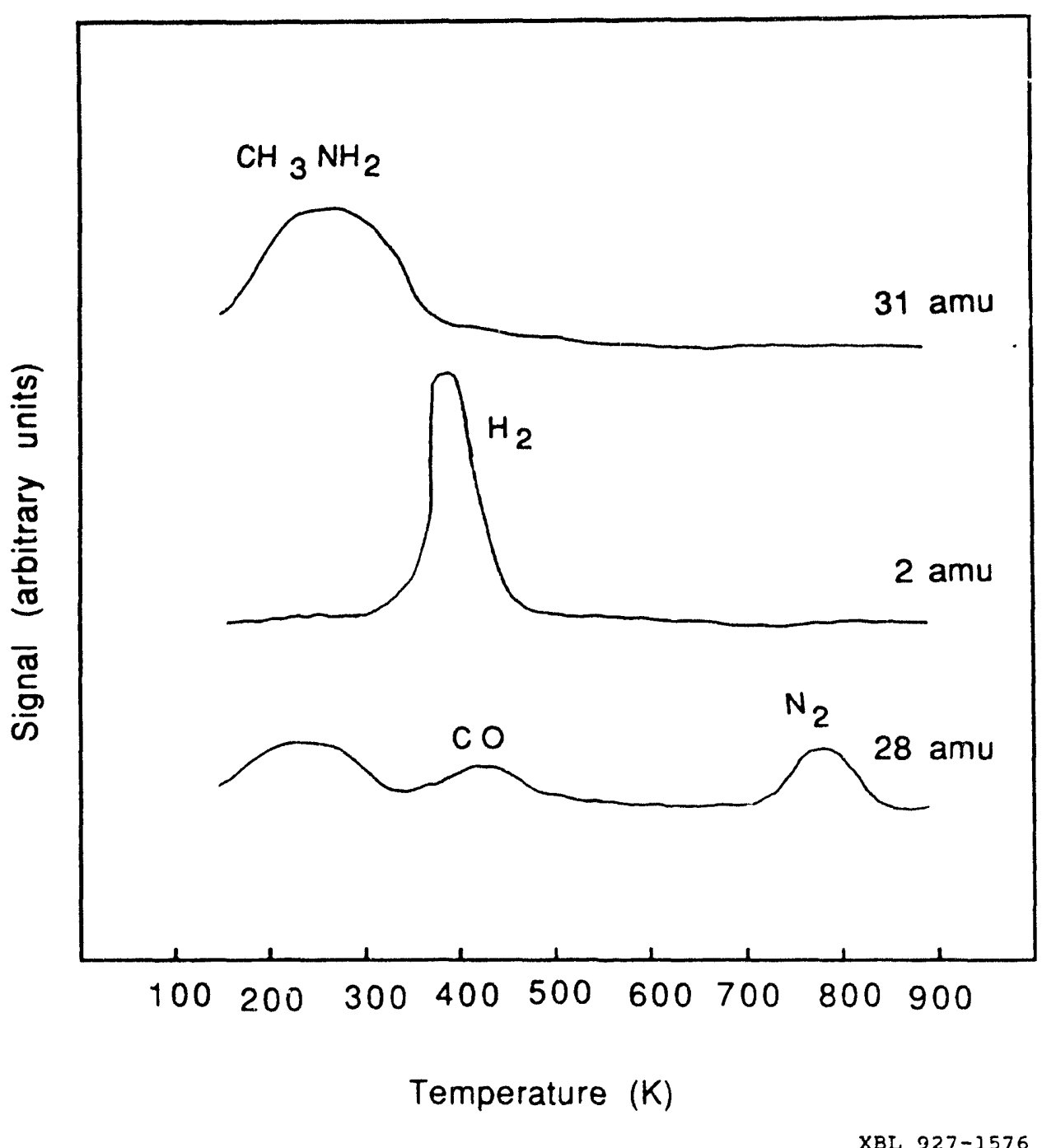

Figure 4.4: TD spectrum after adsorption of 1 monolayer $(3 \mathrm{~L})$ of methylamine on $\mathrm{Ni}(111)$ at $150 \mathrm{~K}$. Heating rate is $8 \mathrm{~K} / \mathrm{s}$. 


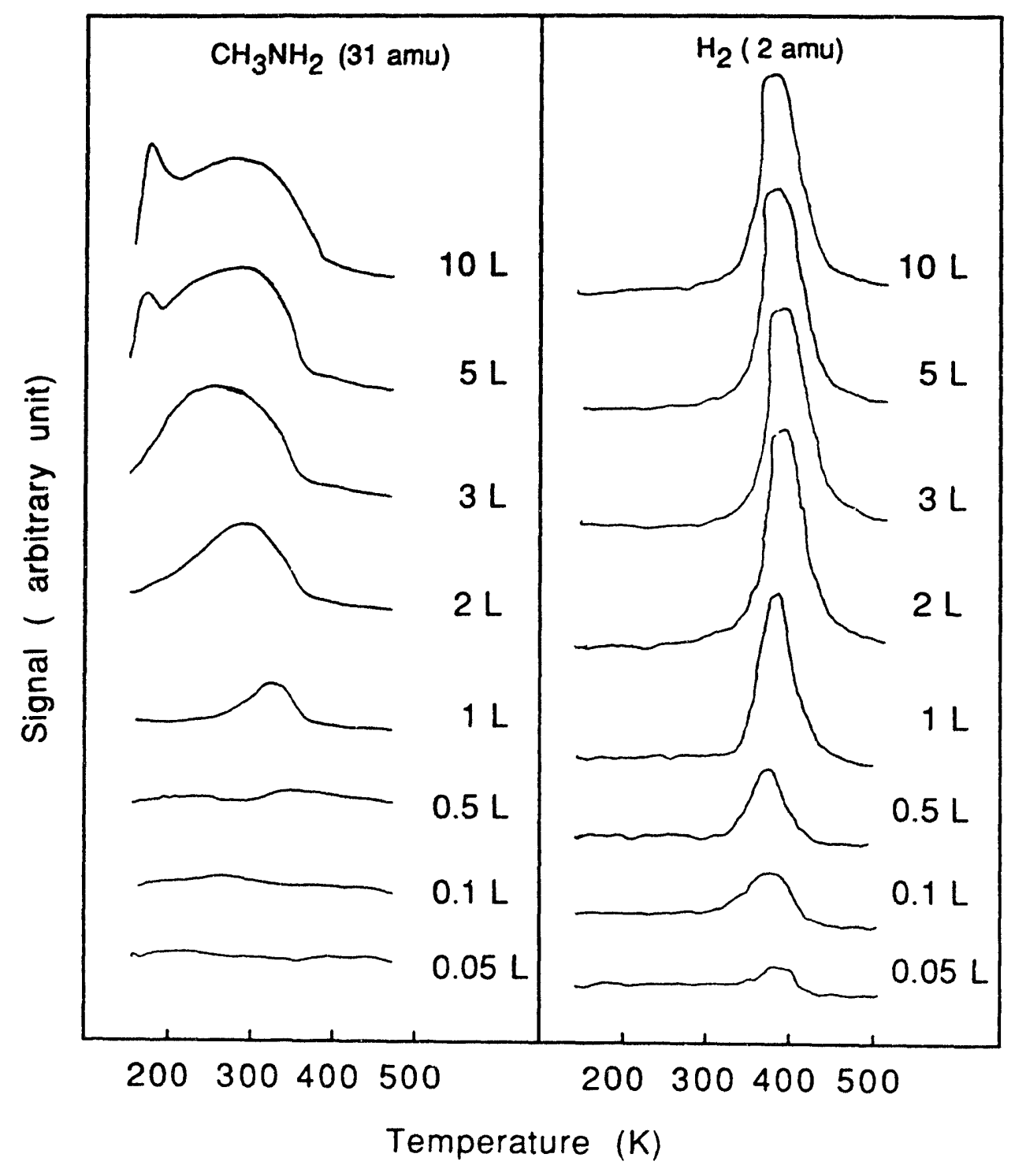

XBL $927-1577$

Figure 4.5: Evolution of the TDS spectra showing $\mathrm{CH}_{3} \mathrm{NH}_{2}$ and $\mathrm{H}_{2}$ desorption as a function of $\mathrm{CH}_{3} \mathrm{NH}_{2}$ exposure at $150 \mathrm{~K}$. 
peak area measurements) has desorbed from the surface. The features remain at about the same position with the same relative intensity, indicating that no major transformation, except $\mathrm{CH}_{3} \mathrm{NH}_{2}$ desorption, takes place on the surface between $150 \mathrm{~K}$ and $270 \mathrm{~K}$. A new band at $1800 \mathrm{~cm}^{-1}$, whose intensity increases with the time the sample sits in the chamber, is attributed to $\mathrm{CO}$ contamination adsorbed on the sites vacated after $\mathrm{CH}_{3} \mathrm{NH}_{2}$ desorption. The band at $2660 \mathrm{~cm}^{-1}$, which was tentatively assigned to 'softened' C-H vibrations, has disappeared.

When the surface is treated at $330 \mathrm{~K}$, a rather different spectrum is observed. The largest band is found at $1800 \mathrm{~cm}^{-1}$, attributed to $\mathrm{CO}$ contamination. Other peaks are observed at $400 \mathrm{~cm}^{-1}, 1630 \mathrm{~cm}^{-1}$ and $3400 \mathrm{~cm}^{-1}$. After a few minutes in the chamber, the surface at $150 \mathrm{~K}$ starts to show features in the spectrum due to $\mathrm{CH}_{3} \mathrm{NH}_{2}$ adsorbing from the background.

At temperatures higher than $360 \mathrm{~K}$, the $1630 \mathrm{~cm}^{-1}$ and $3400 \mathrm{~cm}^{-1}$ peaks disappear, indicating a further decomposition of the species on the surface. Only the $400 \mathrm{~cm}^{-1}$ and $1800 \mathrm{~cm}^{-1}$ bands, due to $\mathrm{CO}$, can still be detected.

The HREELS study of one monolayer of methylamine on $\mathrm{Ni}(111)$ at $150 \mathrm{~K}$ is consistent with methylamine molecularly adsorbed on the surface through its nitrogen lonepair electrons, with hydrogen of the methyl group interacting with the surface. When the temperature is increased up to $270 \mathrm{~K}$, TDS results show that about $2 / 3$ of a monolayer of the adsorbed methylamine desorbs molecularly. The remaining methylamine gives vibrational features similar to those of methylamine adsorbed at $150 \mathrm{~K}$ (figure 4.6), except for the 'softened' C-H mode at $2660 \mathrm{~cm}^{-1}$ which has disappeared. To explain the disappearance of the 'softened' C-H modes, we consider three possibilities. Upon heating, weakened C-H bonds could be broken first leading to a partially dehydrogenated methylamine. But then vibrational modes of the adsorbed methylamine such as $\mathrm{CH}_{3}$ deformation and $\mathrm{CH}_{3}$ rocking modes should also change, which we do not observe. Alternately, at low coverage (only $1 / 3$ of a monolayer is left on the surface after heating up to $270 \mathrm{~K}$ ), the adsorbed methylamine might be able to rotate freely around the $\mathrm{Ni}-\mathrm{N}$ axis, like $\mathrm{NH}_{3}$ on $\mathrm{Ru}(0001)$ [21], preventing the methyl group from interacting with the surface. At higher coverage, the free rotation of methylamine could be hindered by steric interactions betweeen molecules. Hydrogen atoms of the $\mathrm{CH}_{3}$ group would then be able to make bonds with nickel surface atoms, leading to the observed 'softened' C-H mode. Or otherwise, as suggested by theoretical calculations carried out on model surfaces [22], metal-hydrogen interactions may appear 


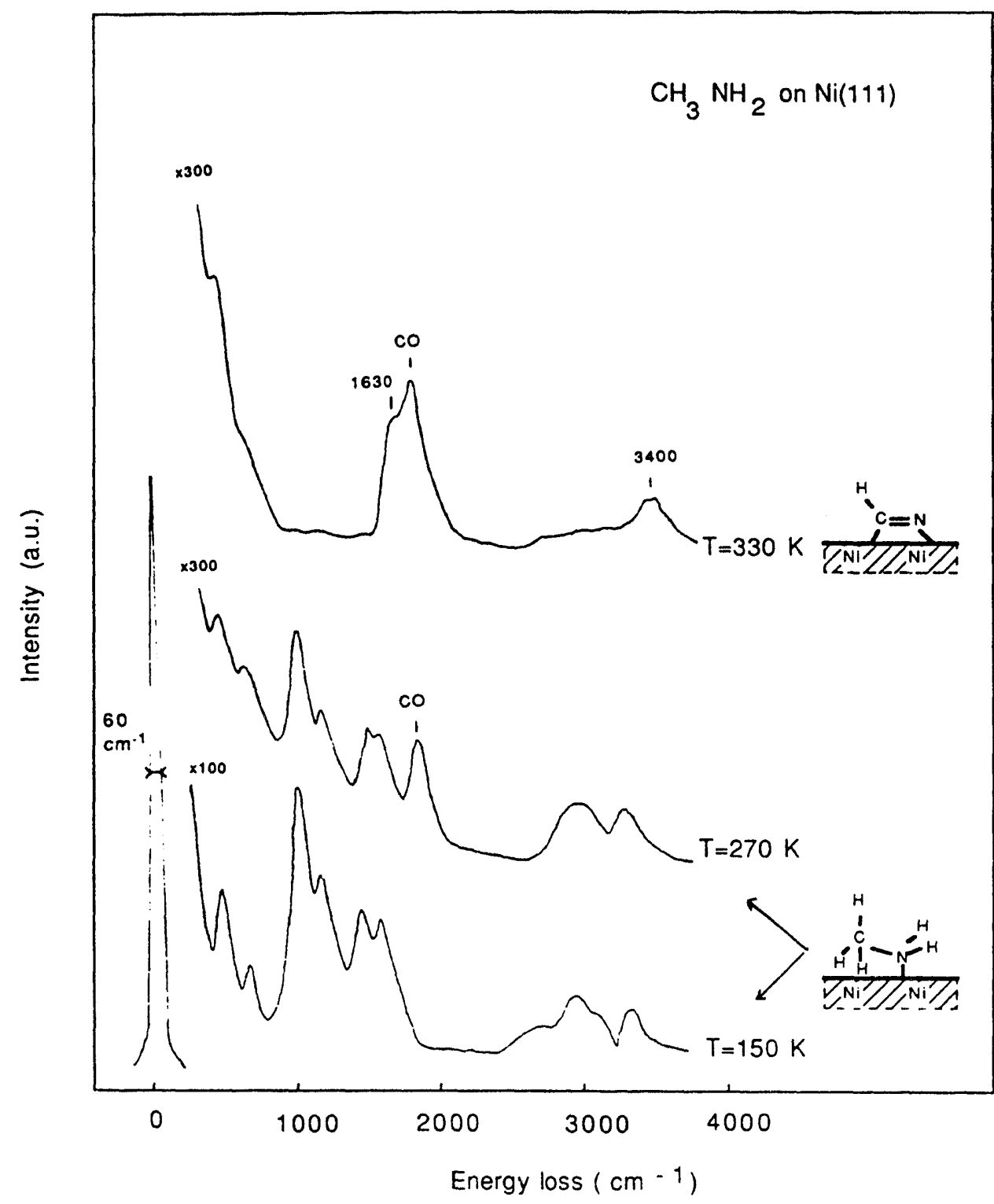

Figure 4.6: Evolution of the HREEL spectra as a function of the treatment temperature after adsorption of 1 monolayer of methylamine $\left(\mathrm{CH}_{3} \mathrm{NH}_{2}\right)$ on $\mathrm{Ni}(111)$ at $150 \mathrm{~K}$. 
only when surface metal orbitals overlap with the antibonding orbital $\sigma^{*}$ of the C-H bonds. This interaction may occur only when the surface is covered with a sufficient amount of the electropositive methylamine. In this case, the $\mathrm{C}-\mathrm{H}$ 'softening' would therefore be coverage dependent. It would be consistent with the observations of Baca et al [1] who did not report any $\mathrm{C}-\mathrm{H}$ 'softened' modes when methylamine was adsorbed on $\mathrm{Ni}(111)$ at $300 \mathrm{~K}$, where only a low surface coverage can be attained.

When the surface temperature is raised up to $330 \mathrm{~K}$, major molecular transformations occur on the surface. From TDS results (figure 4.5), we find that the remaining adsorbed species, corresponding to about $1 / 3$ of a monolayer becomes totally dehydrogenated upon further heating of the surface. The HREELS spectrum at $330 \mathrm{~K}$ (figure 4.6) shows features at $1630 \mathrm{~cm}^{-1}$ and $3400 \mathrm{~cm}^{-1}$ next to the $400 \mathrm{~cm}^{-1}$ and $1800 \mathrm{~cm}^{-1}$ peaks attributed to $\mathrm{CO}$ contamination. Although the $3400 \mathrm{~cm}^{-1}$ peak can be explained by some $\mathrm{OH}$ contamination, we believe that the presence of $\mathrm{HCN}$ adsorbed in a $\eta^{2}(\mathrm{C}, \mathrm{N})$ state is a reasonable interpretation of our spectrum. HCN is observed by HREELS after decomposition of ethylene diamine $\mathrm{NH}_{2}-\mathrm{CH}_{2}-\mathrm{CH}_{2}-\mathrm{NH}_{2}$ on $\mathrm{Pd}$ (111) [23]; it is identified in the HREEL spectrum by its peaks at $1530 \mathrm{~cm}^{-1}$ and $3310 \mathrm{~cm}^{-1}$ [24]. Moreover, the vibrational frequency at $1630 \mathrm{~cm}^{-1}$ is consistent with a $\mathrm{CN}$ bond adsorbed in a $\eta^{2}(\mathrm{C}, \mathrm{N})$ state on the surface [25].

Above $360 \mathrm{~K}$, only CO is observed on the surface. Neither HCN (27 amu) nor NCCN (52 amu) are detected by TDS. TDS results show that surface species are totally dehydrogenated at $450 \mathrm{~K}$, leaving only carbon and nitrogen. While $\mathrm{CN}$ is found after decomposition of $\mathrm{NH}_{2}-\mathrm{CH}_{2}-\mathrm{CH}_{2}-\mathrm{NH}_{2}$ on $\mathrm{Pd}(111)$ [23], the expected C-N vibrational peak expected at $1700-1900 \mathrm{~cm}^{-1}$ could be masked in our experiments by the overlapping contaminant $\mathrm{CO}$ stretching band.

Above $500 \mathrm{~K}$, Chorkendorff et al [2] have shown, by analyzing the carbon and nitrogen Auger line shapes from methylamine, that the carbon evolves to nickel carbide and the nitrogen to nickel nitride. At higher temperature $(T>700 \mathrm{~K})$, the carbon finally diffuses into the bulk, whereas the nitrogen desorbs as molecular nitrogen at about $800 \mathrm{~K}$. 


\subsubsection{Ethylamine decomposition}

TDS

The TD spectra following the exposure of $3 \mathrm{~L}$ of ethylamine on $\mathrm{Ni}(111)$ at 150 $\mathrm{K}$ are presented on figure 4.7. The species detected are ethylamine (45 amu), acetonitrile (41 amu), hydrogen ( $2 \mathrm{amu}$ ), nitrogen (28 amu) and also carbon monoxide (28 amu) from the background. The detection of $\mathrm{CH}_{3} \mathrm{CN}$ ( $41 \mathrm{amu}$ ) is possible by comparing the 41 amu signal (which shows both $\mathrm{CH}_{3} \mathrm{CH}_{2} \mathrm{NH}_{2}$ and $\mathrm{CH}_{3} \mathrm{CN}$ desorption) to the $45 \mathrm{amu}$ signal ( $\mathrm{CH}_{3} \mathrm{CH}_{2} \mathrm{NH}_{2}$ only). $\mathrm{CH}_{3} \mathrm{CH}_{2} \mathrm{NH}_{2}$ desorbs between $\sim 200 \mathrm{~K}$ and $\sim 320 \mathrm{~K} ; \mathrm{CH}_{3} \mathrm{CN}$ desorbs at $350 \mathrm{~K}, 10 \mathrm{~K}$ lower than $\mathrm{CH}_{3} \mathrm{CN}$ adsorbed on clean $\mathrm{Ni}(111)$ [26]; $\mathrm{H}_{2}$ desorbs at $380 \mathrm{~K}$, with a shoulder showing some $\mathrm{H}_{2}$ desorption up to $450 \mathrm{~K} ; \mathrm{N}_{2}$ desorbs at $800 \mathrm{~K}$ and $\mathrm{CO}$ at $420 \mathrm{~K}$.

The evolution of the TD spectra (41 amu and $2 \mathrm{amu}$ ) as a function of ethylamine exposure is shown on figure 4.8. The $41 \mathrm{amu}$ spectrum is used to monitor both ethylamine $\left(\mathrm{CH}_{3} \mathrm{CH}_{2} \mathrm{NH}_{2}\right)$ and acetonitrile $\left(\mathrm{CH}_{3} \mathrm{CN}\right)$ desorption. At low exposures (less than $0.7 \mathrm{~L}$ ), $\mathrm{CH}_{3} \mathrm{CH}_{2} \mathrm{NH}_{2}$ totally decomposes, neither $\mathrm{CH}_{3} \mathrm{CH}_{2} \mathrm{NH}_{2}$ nor $\mathrm{CH}_{3} \mathrm{CN}$ are detected. At exposures greater than $0.7 \mathrm{~L}$, some $\mathrm{CH}_{3} \mathrm{CH}_{2} \mathrm{NH}_{2}$ and $\mathrm{CH}_{3} \mathrm{CN}$ desorption are observed. The amount of $\mathrm{CH}_{3} \mathrm{CH}_{2} \mathrm{NH}_{2}$ and $\mathrm{CH}_{3} \mathrm{CN}$ desorbed increases with $\mathrm{CH}_{3} \mathrm{CH}_{2} \mathrm{NH}_{2}$ exposures. At exposures greater than $3 \mathrm{~L}$, a low temperature peak at $180 \mathrm{~K}$ indicates the growth of a second layer of ethylamine on the nickel surface. The ratio of $\mathrm{CH}_{3} \mathrm{CH}_{2} \mathrm{NH}_{2}$ to $\mathrm{CH}_{3} \mathrm{CN}$ desorbed was estimated by a calibration of our mass spectrometer made by comparing the height of the $41 \mathrm{amu}$ signal when $5 \times 10^{-8}$ torr of $\mathrm{CH}_{3} \mathrm{CH}_{2} \mathrm{NH}_{2}$ or $\mathrm{CH}_{3} \mathrm{CN}$ are introduced inside the chamber. The ratio of $\mathrm{CH}_{3} \mathrm{CH}_{2} \mathrm{NH}_{2}$ to $\mathrm{CH}_{3} \mathrm{CN}$ desorbed is approximately 2. After exposure of $3 \mathrm{~L}$ of $\mathrm{CH}_{3} \mathrm{CH}_{2} \mathrm{NH}_{2}$, which corresponds to a saturated layer of $\mathrm{CH}_{3} \mathrm{CH}_{2} \mathrm{NH}_{2}$ on $\mathrm{Ni}(111), \sim 56 \%$ desorbs molecularly between $200 \mathrm{~K}$ and $320 \mathrm{~K}, \sim 23 \%$ is dehydrogenated to $\mathrm{CH}_{3} \mathrm{CN}$, which desorbs at $350 \mathrm{~K}$, and the $\sim 20 \%$ left on the surface totally decomposes, leaving only carbon and nitrogen on the surface above $450 \mathrm{~K}$. The nitrogen desorbs as $\mathrm{N}_{2}$ and the carbon diffuses into the bulk above $700 \mathrm{~K}$.

\section{HREELS}

Following the adsorption of 1 monolayer of ethylamine on $\mathrm{Ni}(111)$ at $150 \mathrm{~K}$, HREELS spectra are recorded after the various temperature treatments of the surface (figure 4.9). The spectrum obtained after heating the surface to $270 \mathrm{~K}$ shows similar features 


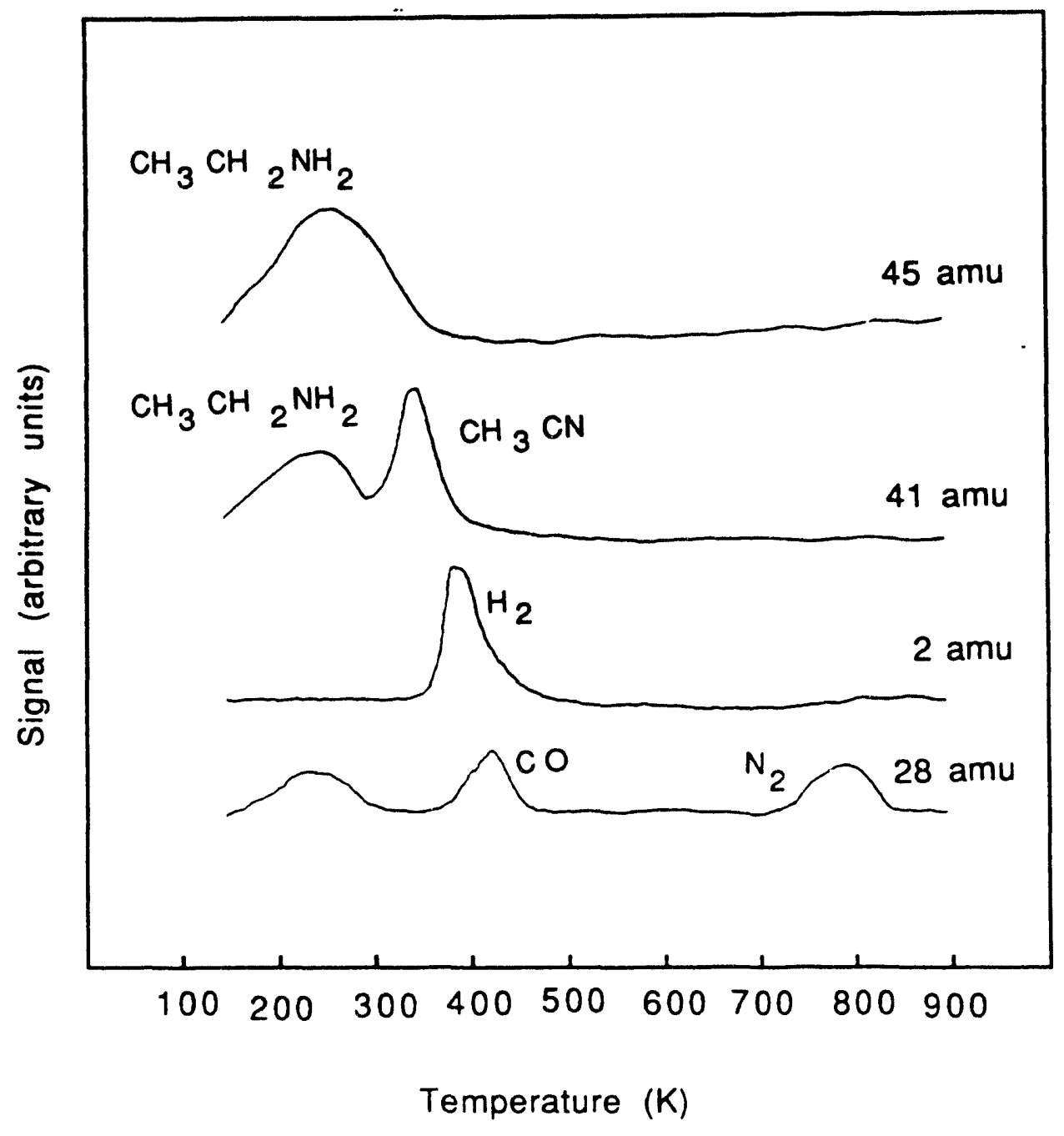

XBL $927-1579$

Figure 4.7: TD spectrum after adsorption of 1 monolayer $(3 \mathrm{~L})$ of ethylamine on $\mathrm{Ni}(111)$ at $150 \mathrm{~K}$. Heating rate is $8 \mathrm{~K} / \mathrm{s}$. 


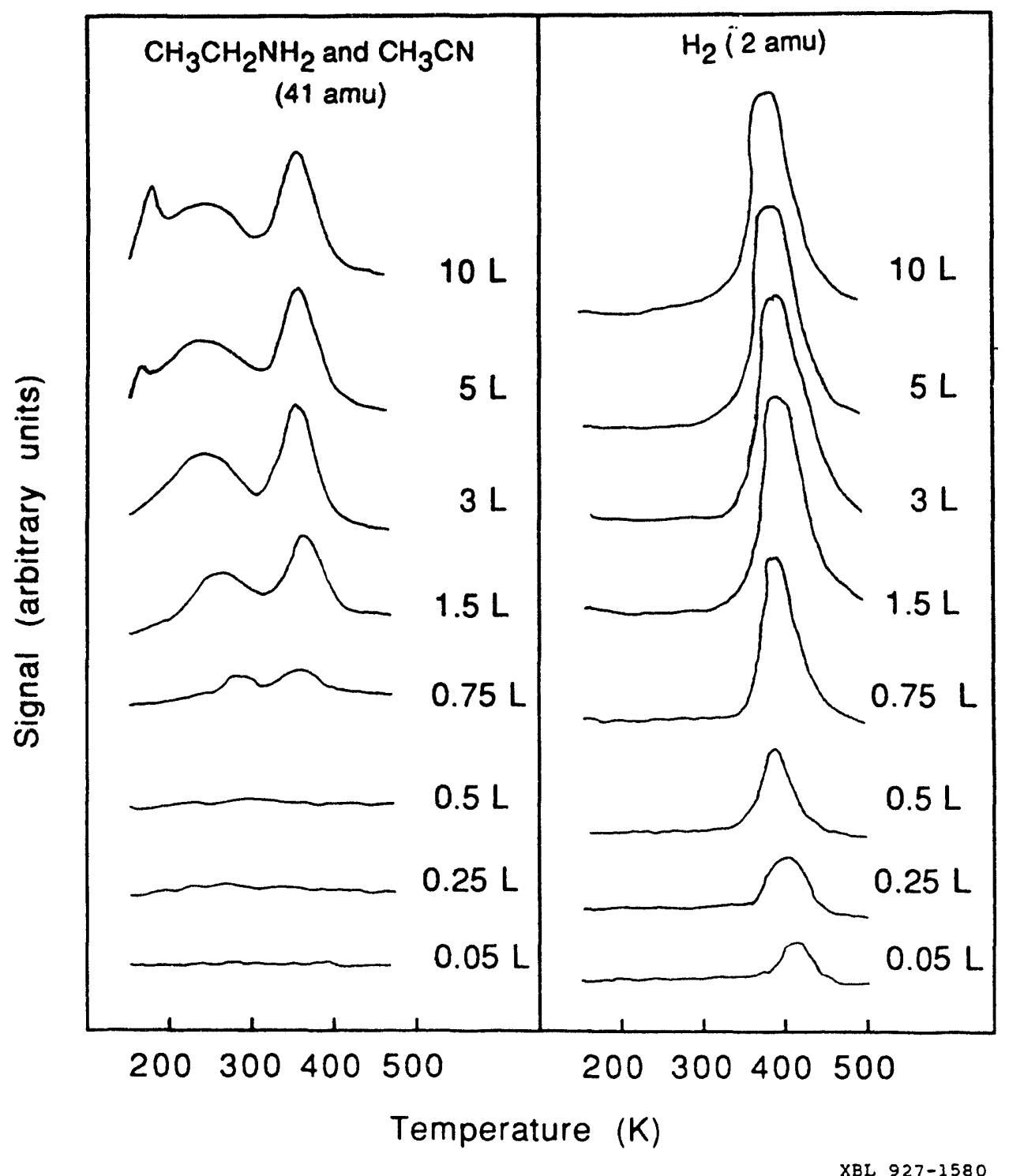

Figure 4.8: Evolution of the TD spectra showing $\mathrm{CH}_{3} \mathrm{CH}_{2} \mathrm{NH}_{2}, \mathrm{CH}_{3} \mathrm{CN}$ and $\mathrm{H}_{2}$ desorption as a function of $\mathrm{CH}_{3} \mathrm{CH}_{2} \mathrm{NH}_{2}$ exposure at $150 \mathrm{~K}$. 
than the one obtained after adsorption of 1 monolayer of ethylamine at $150 \mathrm{~K}$. As with methylamine, we notice the disappearance of the 'softened' $\mathrm{C}-\mathrm{H}$ stretchin's mode at 2680 $\mathrm{cm}^{-1}$.

At $300 \mathrm{~K}$, a different type of spectrum is observed, characterized by intense peaks at $800 \mathrm{~cm}^{-1}$ and $1120 \mathrm{~cm}^{-1}$, a broad band at $1450-1550 \mathrm{~cm}^{-1}$ and peaks at $3200 \mathrm{~cm}^{-1}$ and $3400 \mathrm{~cm}^{-1}$. C-H stretch at $2950 \mathrm{~cm}^{-1}$ and $\mathrm{CO}$ contamination at $1800 \mathrm{~cm}^{-1}$ are also observed.

When the surface is heated up to $330 \mathrm{~K}$, we get an intense band at $750 \mathrm{~cm}^{-1}$, a peak at $1080 \mathrm{~cm}^{-1}$, and a broad band at $1350 \mathrm{~cm}^{-1}$ with a shoulder up to $1550 \mathrm{~cm}^{-1}$. We observe no change in the $\mathrm{C}-\mathrm{H}$ band, but $\mathrm{N}-\mathrm{H}$ stretching vibraticns are now centereri at $3300 \mathrm{~cm}^{-1}$.

At temperatures greater than $350 \mathrm{~K}$, the remaining features are found at $400 \mathrm{~cm}^{-1}$ and $1800 \mathrm{~cm}^{-1}$, due to adsorbed CO from the background, some very weak C-H stretch and $\mathrm{N}-\mathrm{H}$ stretch can still be seen up to about $420 \mathrm{~K}$.

The HREELS study of one monolayer of adsorbed ethylamine at $150 \mathrm{~K}$ is consistent with the proposal that ethylamine binds to the metal through its nitrogen lone-pair. The methyl group points away from the surface and the hydrogen of the $\mathrm{CH}_{2}$ group interacts with the nickel surface atoms. When the surface is heated up to $270 \mathrm{~K}$, TDS experiments show that a large amount of ethylamine desorbs from the surface. The HREELS spectrum indicates that ethylamine is still molecularly adsorbed on $\mathrm{Ni}(111)$ at $270 \mathrm{~K}$. The same explanations as the ones suggested earlier for methylamine (cleavage of the weakened $\mathrm{C}-\mathrm{H}$ bonds, rotation of the molecule around the $\mathrm{Ni}-\mathrm{N}$ axis or overlap of the metal and the $\mathrm{C}-\mathrm{H}$ orbitals at higher coverages only) are proposed to interpret the disappearance of the peak at $2680 \mathrm{~cm}^{-1}$, attributed previously to a 'softened' C-H mode.

When we reach $300 \mathrm{~K}$, TDS results show that most of the reversibly adsorbed ethylamine has desorbed. The HREEL spectrum shows species left on the surface with characteristic vibrational frequencies at $800 \mathrm{~cm}^{-1}, 1080 \mathrm{~cm}^{-1}, 1450-1550 \mathrm{~cm}^{-1}$ and 3400 $\mathrm{cm}^{-1}$. The peak at $3200 \mathrm{~cm}^{-1}$ is attributed to the $\mathrm{N}-\mathrm{H}$ stretching mode of molecular ethylamine on the surface, not yet decomposed or adsorbed from the background. The new band at $3400 \mathrm{~cm}^{-1}$ is attributed to a N-H stretching mode or a contarninating O-H stretching mode. Its relatively high frequency for a $\mathrm{N}-\mathrm{H}$ stretch can be explained if the nitrogen is not bonded directly to the surface; the N-H stretching frequency of gas-phase ethylamine, for comparison, is found at $3343 \mathrm{~cm}^{-1}$ [18]. An electron donating effect from the metal can 


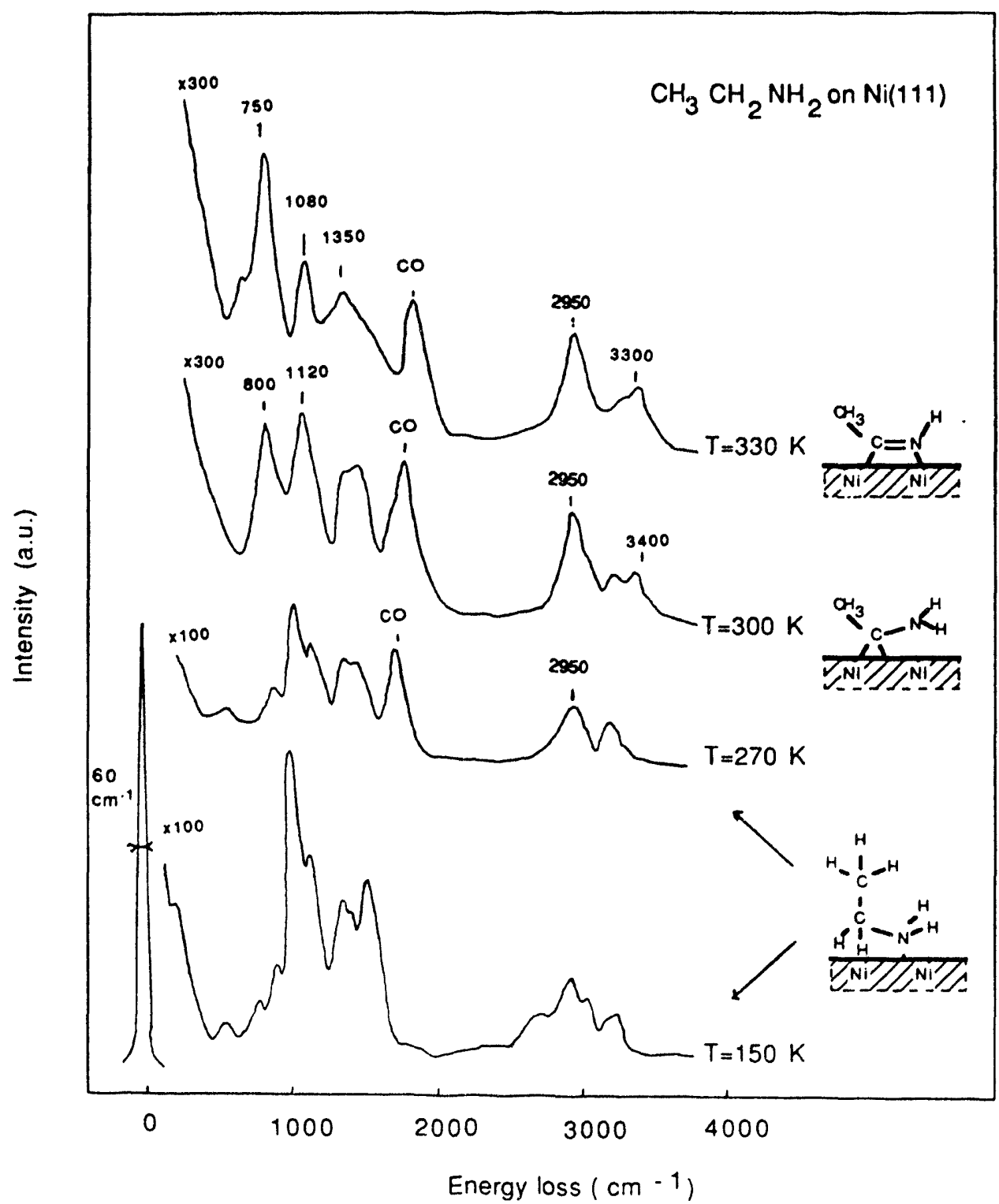

$X B L \quad 927-1581$

Figure 4.9: Evolution of the HREEL spectra as a function of the treatment temperature after adsorption of 1 monolayer of ethylamine $\left(\mathrm{CH}_{3} \mathrm{CH}_{2} \mathrm{NH}_{2}\right)$ on $\mathrm{Ni}(111)$ at $150 \mathrm{~K}$. 
explain the shift to higher frequency $\left(3400 \mathrm{~cm}^{-1}\right)$. The large peak at $800 \mathrm{~cm}^{-1}$ is assigned to a $\mathrm{NH}_{2}$ wagging mode (the wagging mode of gas-phase ethylamine is observed at $789 \mathrm{~cm}^{-1}$ ). We propose that ethylamine is now bonded through the dehydrogenated $\mathrm{CH}_{2}$ group. The $2950 \mathrm{~cm}^{-1}$ band is attributed to the $\mathrm{C}-\mathrm{H}$ stretching modes of the $\mathrm{CH}_{3}$ group, still intact, and the peak at $1120 \mathrm{~cm}^{-1}$ is assigned to the $\mathrm{C}-\mathrm{N}$ stretching vibration, overlapping with the $\mathrm{CH}_{3}$ rocking mode. This model is shown in figure 4.9. This is a speculative interpretation of our spectrum, based on our suggestion that the interactions between the hydrogen of the $\mathrm{CH}_{2}$ group and the nickel surface atoms are a major dehydrogenation pathway on the surface. This is in accordance with the study of Chorkendorff et al [2] that shows that the dehydrogenation of methylamine on $\mathrm{Ni}(111)$ occurs preferentially through the carbon first, and with the results of Seabury et al [27] showing that $\mathrm{N}-\mathrm{H}$ bonds of $\mathrm{NH}_{3}$ adsorbed on $\mathrm{Ni}(111)$ cannot be thermally activated.

When the surface temperature reaches $330 \mathrm{~K}$, the large band at $800 \mathrm{~cm}^{-1}$ assigned to the $\mathrm{NH}_{2}$ wagging mode disappears, while the $3400 \mathrm{~cm}^{-1}$ band is shifted to $3300 \mathrm{~cm}^{-1}$. This indicates changes in $\mathrm{N}-\mathrm{H}$ bonds. In the organo-metallic chemistry literature, we found several stable intermediate complexes in the hydrogenation of acetonitrile on transition metal clusters $[28,29]$. On both triiron [28] and triosmium [29] carbonyl cluster complexes, acetonitrile ( or fluoroacetonitrile) could be reduced to the isomeric acimidoyl $\left(\mathrm{CH}_{3}-\mathrm{C}=\mathrm{NH}\right.$ ) and alkylidenimido $\left(\mathrm{CH}_{3}-\mathrm{CH}=\mathrm{N}\right)$ complexes (shown in figure 4.10 ), both $\eta^{2}-\mu_{3}$ bonded to the trimetallic clusters. The $\mathrm{N}-\mathrm{H}$ stretching frequency of the acimidoyl complexes was found at $3272 \mathrm{~cm}^{-1}$ for the $\mathrm{Fe}$ cluster and $3320 \mathrm{~cm}^{-1}$ for the Os cluster. The $\mathrm{C}=\mathrm{N}$ stretching mode of the $\mathrm{Fe}$ acimidoyl complex was observed at $1353 \mathrm{~cm}^{-1}$. On our spectrum, we tentatively assign the $1350 \mathrm{~cm}^{-1}$ and $3300 \mathrm{~cm}^{-1}$ bands respectively to the $\mathrm{C}=\mathrm{N}$ stretching and $\mathrm{N}-\mathrm{H}$ stretching modes of acimidoyl $\left(\mathrm{CH}_{3}-\mathrm{C}=\mathrm{NH}\right)$ on $\mathrm{Ni}(111)$. The intense peak at 750 $\mathrm{cm}^{-1}$ of the HREEL spectrum can reasonably be attributed to the N-H bending mode of acimidoyl $\left(\mathrm{CH}_{3}-\mathrm{C}=\mathrm{NH}\right)$, lying parallel to the $\mathrm{Ni}(111)$ face. The HREEL spectrum obtained after heating the surface up to $330 \mathrm{~K}$ is therefore compatible with the presence of acimidoyl on $\mathrm{Ni}(111)$. But, because of the lack of comparable data in the organo-metallic chemistry literature, the relatively poor resolution of HREELS, and the possibility of having more than one decomposition pathway for ethylamine on $\mathrm{Ni}(111)$, other interpretations might also be possible.

When the temperature is raised above $330 \mathrm{~K}$, acetonitrile starts to desorb. An HREEL spectra of acetonitrile adsorbed on $\mathrm{Ni}(111)$ is shown in figure 4.11 (see also chapter 


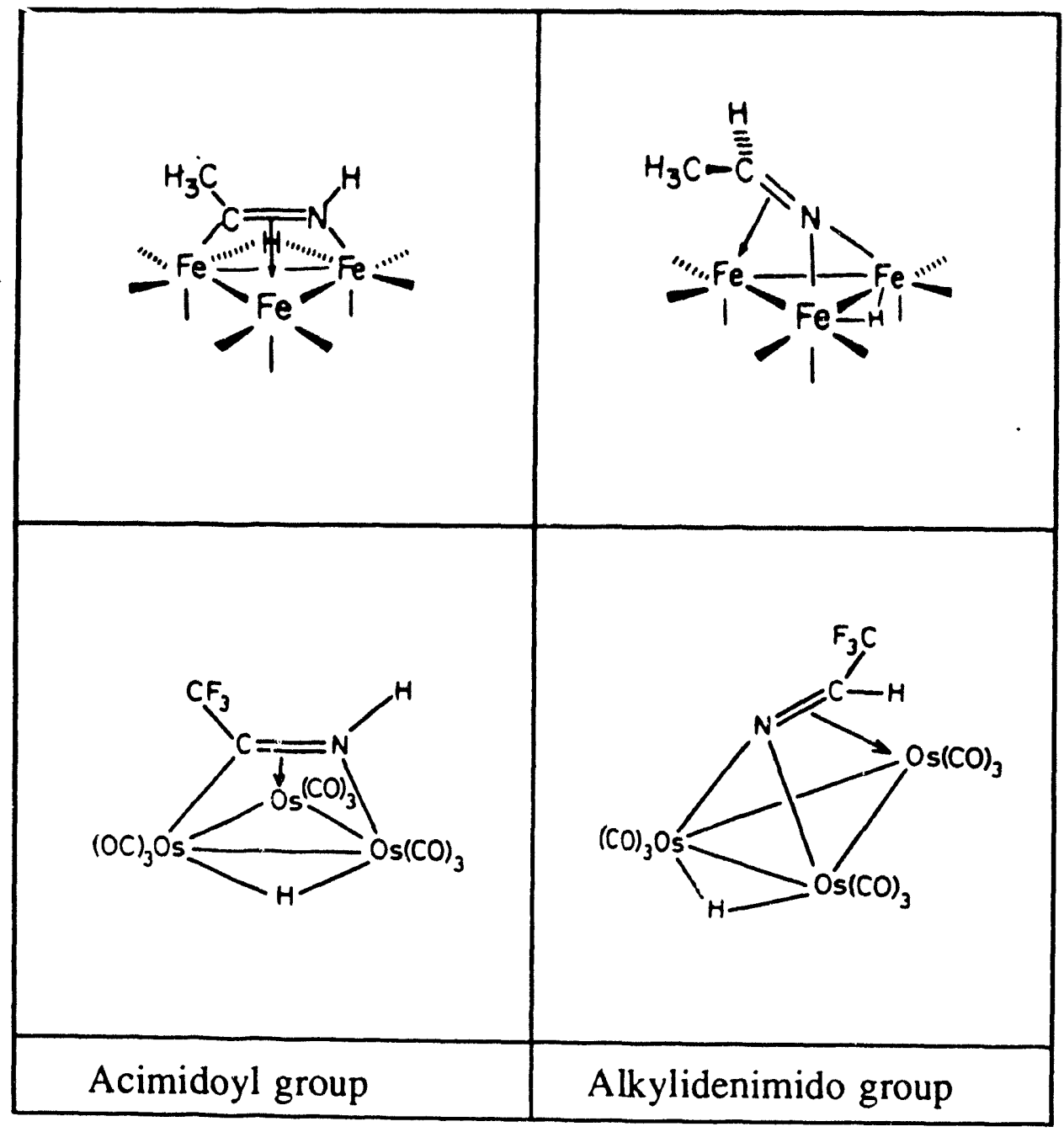

XBL $927-1582$

Figure 4.10: Organometallic complexcs obtained on triiron and triosmium clusters after insertion of a nitrile function $\mathrm{CN}$ in a metal-hydrogen bond $[28,29]$. 


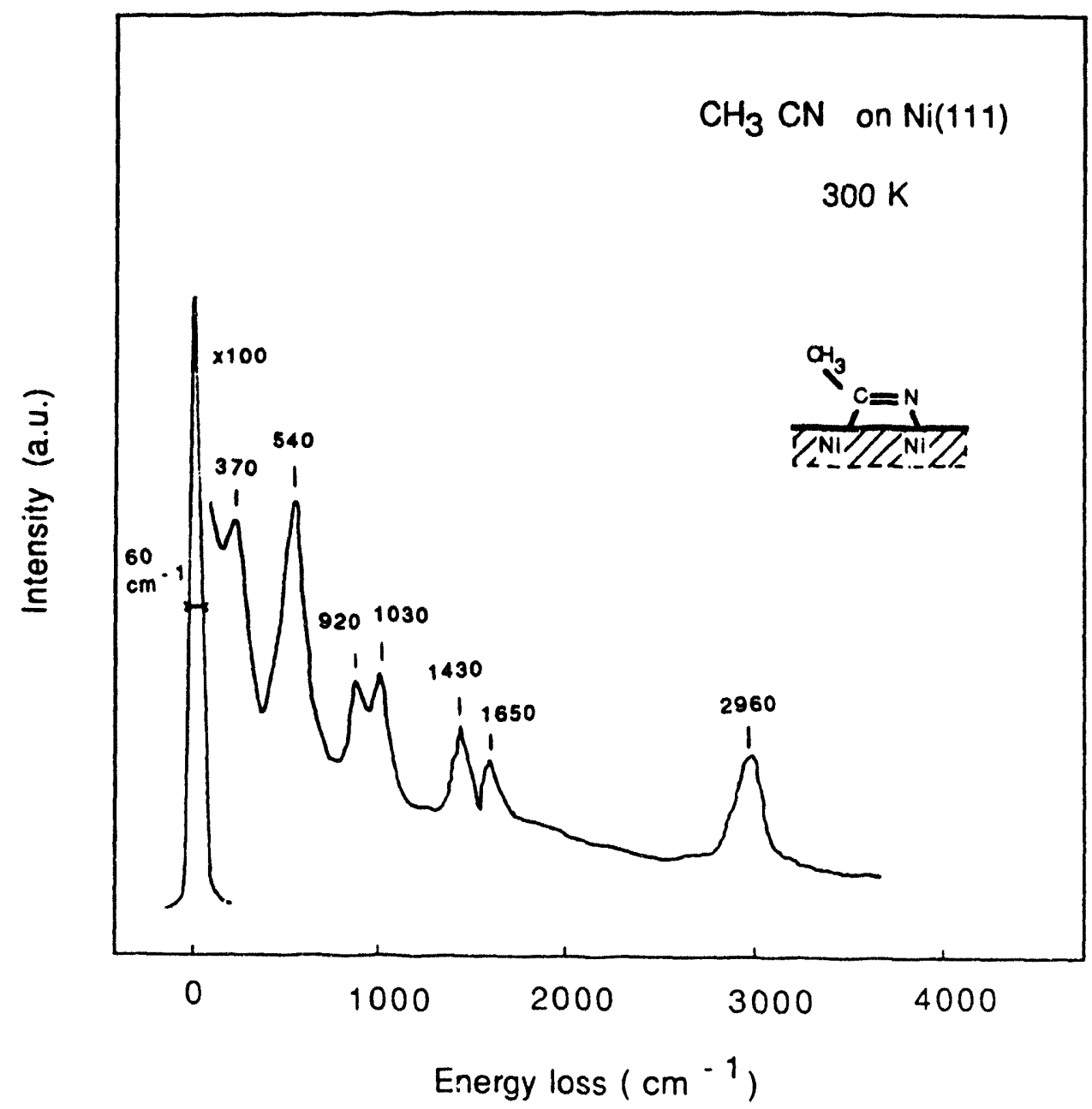

Figure 4.11: HREELS spectrum of a saturated layer of acetonitrile $\left(\mathrm{CH}_{3} \mathrm{CN}\right)$ on $\mathrm{Ni}(111)$ at $300 \mathrm{~K}$.

3 for details). However, none of the spectra obtained after heating the ethylamine precovered $\mathrm{Ni}(111)$ surface to $340 \mathrm{~K}$ and $350 \mathrm{~K}$ shows any similarity with the HREELS spectrum of acetonitrile on $\mathrm{Ni}(111)$. At this tempcrature, acetonitrile is a stable surface species. The acimidoyl complex formed at $330 \mathrm{~K}$ is stable on $\mathrm{Ni}(111)$ up to $350 \mathrm{~K}$. The activation energy to break the $\mathrm{N}-\mathrm{H}$ bond of the acimidoyl complex, necessary to form the acetonitrile, must therefore be as high as the activation energy barrier to acetonitrile desorption, estimated to $21 \mathrm{ksal} /$ mole from our TDS experiments.

From our set of data, and using additional thermodynamic data from the literature, we propose an energy diagram (figure 4.12), describing the mechanism of the dehydrogenation of ethylamine on $\mathrm{Ni}(111)$. The reference model used in this model is the nickel single 
crystal and ethylamine in the gas phase prior to adsorption. This diagram accounts for the enthalpy change during the adsorption of ethylamine, its dehydrogenation to $\mathrm{CH}_{3} \mathrm{CNH}_{2}$ and $\mathrm{CH}_{3} \mathrm{CNH}$, the desorption of acetonitrile and of the two molecules of hydrogen produced. The enthalpies of formation of acetonitrile and ethylamine in the gas phase were obtained from [30]. We assume that adsorption is not an activated process. The heat of desorption of ethylamine, acetonitrile and hydrogen are considered to be equal to the activation energies of their desorption (obtained from TDS experiments). The activation energy for the unimolecular decomposition of ethylamine and of the intermediate surface complexes is estimated from the temperature at which the dehydrogenation is detected by HREELS (assuming a preexponential factor equal to $10^{13} \mathrm{~s}^{-1}$ ). The enthalpies of formation of the $\mathrm{CH}_{3} \mathrm{CNH}_{2}$ and $\mathrm{CH}_{3} \mathrm{CNH}$ complexes are not known. They are estimated by accounting the energy of the bonds created and broken during the process. The values used are $\mathrm{E}(\mathrm{C}-\mathrm{H})=$ $97 \mathrm{kcal} / \mathrm{mol} ; \mathrm{E}(\mathrm{N}-\mathrm{H})=90 \mathrm{kcal} / \mathrm{mol}$ (from [31]). $\mathrm{E}(\mathrm{Ni}-\mathrm{H})=1 / 2\left(\mathrm{E}(\mathrm{H}-\mathrm{H})+\Delta \mathrm{H}_{\text {ads }}(\mathrm{H}-\mathrm{H})\right)=1 / 2$ $(104+23)=64 \mathrm{kcal} / \mathrm{mol} . \mathrm{E}(\mathrm{Ni}-\mathrm{C}) \sim 45 \mathrm{kcal} / \mathrm{mol}$ and $\mathrm{E}(\mathrm{Ni}-\mathrm{N}) \sim 40 \mathrm{kcal} / \mathrm{mol}$.

\subsection{Summary}

The adsorption of methylamine and ethylamine on $\mathrm{Ni}(111)$ at $150 \mathrm{~K}$ have been studied by HREELS. Vibrational spectra are consistent with the model of both amines adsorbed on the surface through the nitrogen lone-pair electrons. The $\mathrm{CH}_{3}$ and $\mathrm{CH}_{2}$ groups, of methylamine and ethylamine respectively, are proposed to interact with the nickel surface atoms causing the broad peak in the spectra at $2660-2680 \mathrm{~cm}^{-1}$, which we attribute to 'softened' C-H stretch.

The surface chemistry of thermal fragmentation of methylamine and ethylamine in the temperature range $150 \mathrm{~K}-900 \mathrm{~K}$ was investigated by TDS and HREELS experiments. Unlike $\mathrm{NH}_{3}$, which is reversibly adsorbed on $\mathrm{Ni}(111)$, some $\mathrm{CH}_{3} \mathrm{NH}_{2}$ and $\mathrm{CH}_{3} \mathrm{CH}_{2} \mathrm{NH}_{2}$ can be partially dehydrogenated upon heating. We propose a plausible explanation for o spectra : methylamine is dehydrogenated to $\mathrm{HCN}$ and ethylamine to $\mathrm{CH}_{3} \mathrm{CN}$ in the $300 \mathrm{~K}$ $350 \mathrm{~K}$ temperature range. While HCN totally decomposes to surface carbon and nitrogen, some $\mathrm{CH}_{3} \mathrm{CN}$ is found to desorb at $350 \mathrm{~K}$. Our models for the decomposition of methylamine and ethylamine on $\mathrm{Ni}(111)$ are summarized in the diagram of figure 4.13. We report also on this figure the behavior of $\mathrm{NH}_{3}$ on $\mathrm{Ni}(111)$ (from [27]) to show the influence of the alkyl chain on the surface chemistry. Some TDS experiments carried out using propylamine on 


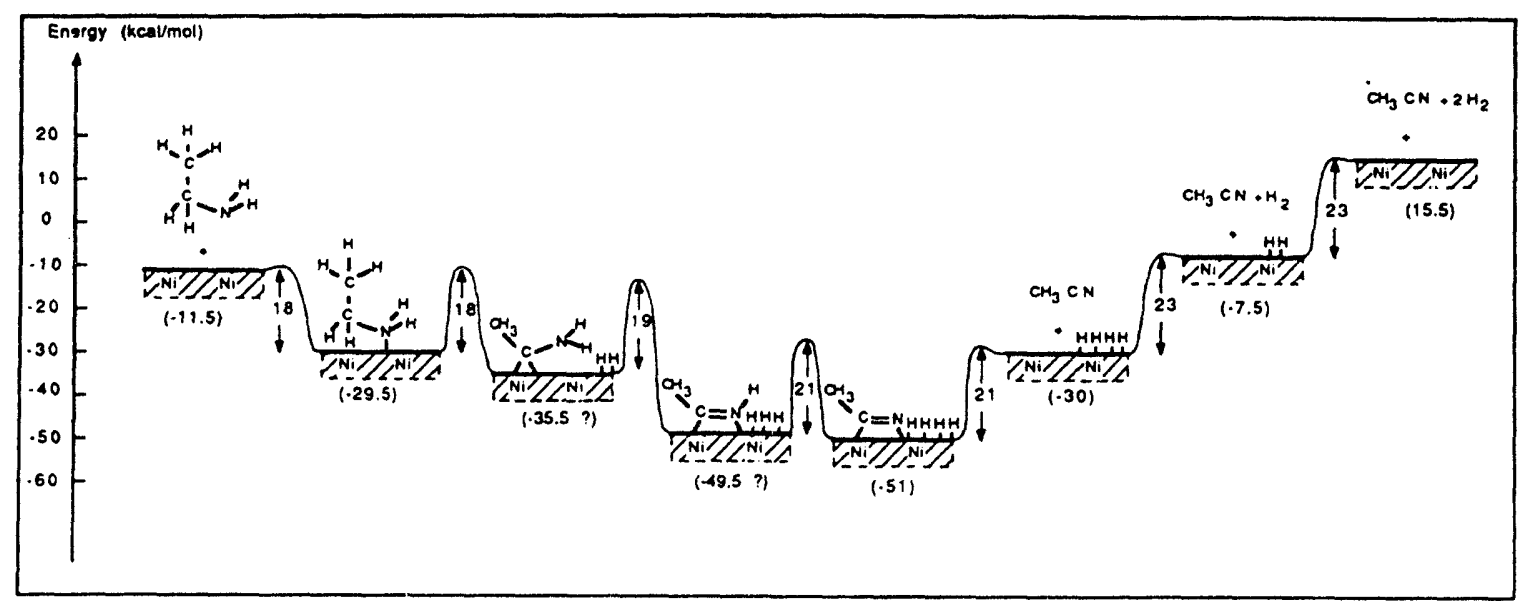

XBL. $927-2586$

Figure 4.12: Proposed reaction mechanism for the dehydrogenation of ethylamine on $\mathrm{Ni}(111)$. Enthalpies and activation energies are determined from the data of this work and the literature, when available. 
Chapter 4. Bonding and Reactivity of $\mathrm{CH}_{3} \mathrm{NH}_{2}$ and $\mathrm{CH}_{3} \mathrm{CH}_{2} \mathrm{NH}_{2}$ on $\mathrm{Ni}(111)$

$\mathrm{Ni}(111)$ have shown that it behaves in a similar way to that of ethylamine. 


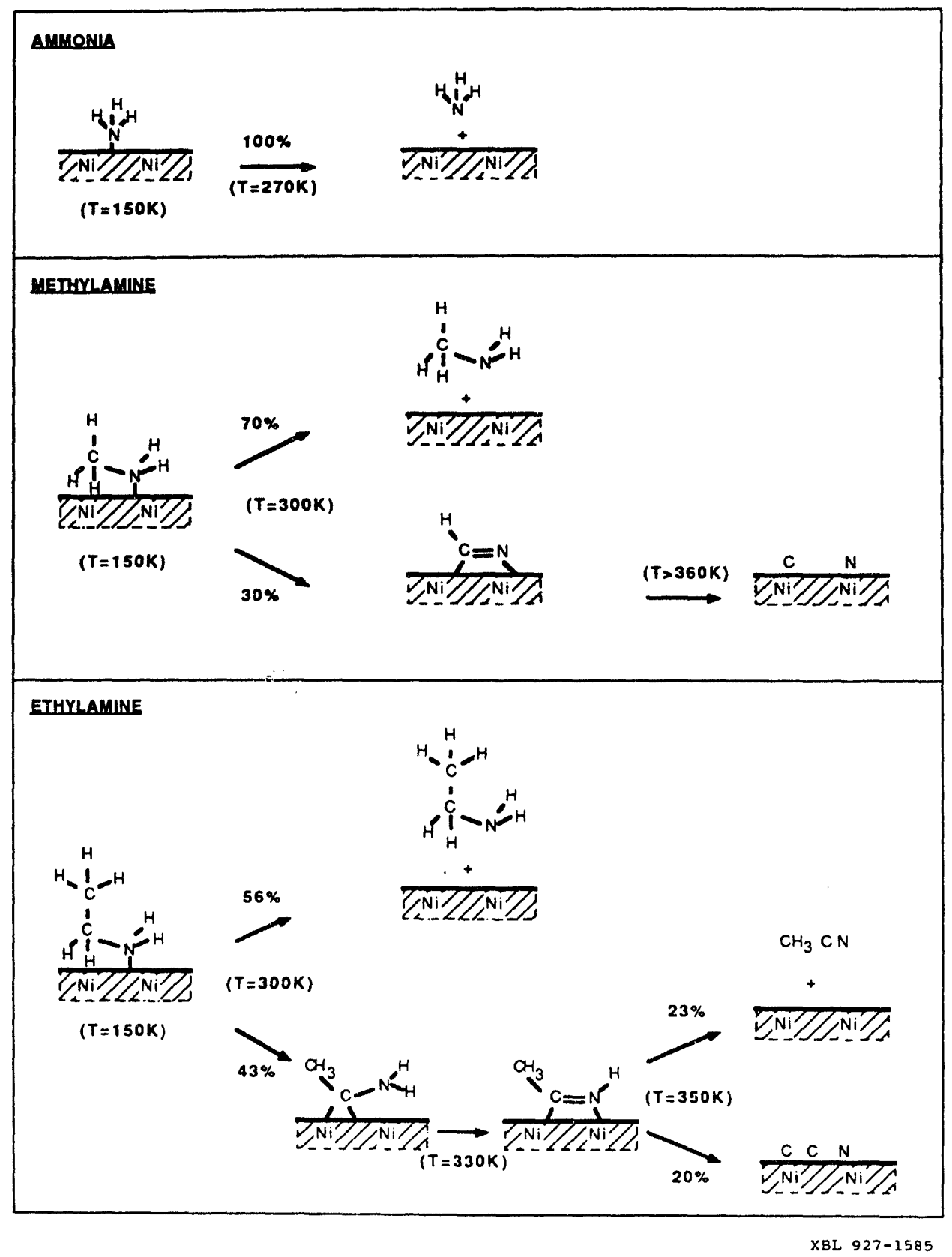

Figure 4.13: A comparison between ammonia, methylamine and ethylamine chemistry on $\mathrm{Ni}(111)$. 


\subsection{References}

[1] A.G. Baca, M.A. Schulz, and D.A. Shirley, J. Chem. Phys.,83 (1985) 6001.

[2] I. Chorkendorff, J.N. Russel,Jr, and J.T. Yates, Jr, J. Chem. Phys., 86 (1985) 4692.

[3] G.R. Schoofs, and J.B. Benziger, J. Phys. Chem., 92 (1988) 741.

[4] S.Y. Hwang, E.G. Seebauer, and L.D. Schmidt, Surf. Sci., 188 (1987) 219.

[5] P.A. Thomas, and R.I. Masel, J. Vac. Sci. Technol., A5(4) (1987) 1106.

[6] B.W. Walker, and P.C. Stair, Surf. Sci., 103 (1981) 315.

[7] K.A. Pearlstine, and C.M. Friend, J. Am. Chem. Soc., 108 (1986) 5842.

[8] S.Y. Hwang, A.C.F. Kong, and L.D. Schmidt, J. Phys. Chem., 93 (1989) 8327.

[9] T. Sasaki, T. Aruga, H. Kuroda, and Y. Iwasawa, Surf. Sci., 249 (1991) L347.

[10] K. Inamura, Y. Inoue, S.Ikeda, and K. Kishi, Surf. Sci., 155 (1985) 173.

[11] K.A. Pearlstine, and C.M. Friend, J. Am. Chem. Soc., 108 (1986) 5837.

[12] C.M. Mate, Ph.D. Thesis (University of California, Berkeley, 1986).

[13] H. Froitzheim, H. Ibach, and S. Lehwald, Rev. Sci. Instr., 46 (1975) 1325.

[14] K. Tamaga, M. Tsuboi, and H. Hirakawa, J. Chem. Phys., 48 (1968) 5530.

[15] G.B. Watt, B.B. Hutchinson, and D.S. Klett, J. Am. Chem. Soc., 89 (1967) 2007.

[16] R. Raval, and M.A. Chesters, Surf. Sci., 219 (1989) L505.

[17] Y. Hamada, et al, J. Mol. Spectrosc., 102 (1983) 123.

[18] H. Wolff, and H.J. Ludwig, Chem. Phys., 56 (1972) 5278; H. Wolff, and E. Wolff, Ber. Bunsenges. Physik. Chem., 69 (1965) 467.

[19] J.L Gland, G.B. Fisher, and G.E. Mitchell, Chem. Phys. Lett., 119 (1985) 89.

[20] K. Christmann, O. Schober, G. Ertl, and M.J. Neumann, Chem. Phys., 60 (1974) 4528. 
[21] T.E. Madey, J.E. Houston, C.W. Seabury, and T.N. Rhodin, J. Vac. Sci. Technol., 18 (1981) 476.

[22] J.Y. Saillard, and R. Hoffmann, J. Am. Chem. Soc., 106 (1984) 2006.

[23] M.E. Kordesch, W. Stenzel, and H. Conrad, Surf. Sci., 186 (1987) 601.

[24] M.E. Kordesch, W. Stenzel, and H. Conrad, Surf. Sci., 175 (1986) L687.

[25] B.A. Sexton, and N.R. Avery, Surf. Sci., 129 (1983) 21.

[26] J.C. Hemminger, E.L. Muetterties, and G.A. Somorjai, J. Am. Chem. Soc., 101 (1979) 7238.

[27] C.W. Seabury, T.N. Rhodin, R.J. Purtell, and R.P. Merril, Surf. Sci., 93 (1980) 117.

[28] M.A. Andrews, and H.D. Kaesz, J. Am. Chem. Soc., 101 (1979) 7238.

[29] Z. Dawoodi, M.J. Mays, and P.R. Raithby, J. Organometal. Chem., 219 (1989) 103.

[30] C.R.C. Handbook of Chemistry and Physics, 72nd ed. (C.R.C. Press, 1991-1992).

[31] J.D. Cox, and G. Pilcher, "Thermochemistry of Organic and Organometallic Compounds" (Academic Press, 1970). 


\section{Chapter 5}

\section{Molecular Modeling of Amine Dehydrogenation}

\subsection{Introduction}

The characterization of adsorbed molecules and their decomposition pathways on metal surfaces is of considerable importance to understand the nature of the surface chemical bond. Studies in ultra-high vacuum (UHV) have increased our understanding of the fundamental molecular processes occurring at the metal surface. Surface vibrational spectroscopies, including high resolution electron energy loss spectroscopy (HREELS), have shown their ability to follow fundamental molecular processes occurring on various metal surfaces in UHV. This includes measuring molecular structures and orientations, thermal decomposition pathways, and effects of coverage and coadsorption of different molecules on bonding. Although surface intermediates and reaction mechanisms can be inferred from these studies very little is known usually about the energetics of these systems, and at present no experimental technique seems to be able to measure the binding energy of intermediate species on surfaces.

In chapter 4, we have investigated the thermal decomposition of ethylamine $\left(\mathrm{CH}_{3} \mathrm{CH}_{2} \mathrm{NH}_{2}\right)$ adsorbed on $\mathrm{Ni}(111)$ at low temperature by thermal desorption spectroscopy (TDS) and HREELS. We found that ethylamine is dehydrogenated to acetonitrile $\left(\mathrm{CH}_{3} \mathrm{CN}\right)$ and hydrogen $\left(\mathrm{H}_{2}\right)$ on the surface. The HREEL spectra observed are consistent with a dehydrogenation process starting by an $\alpha-\mathrm{C}-\mathrm{H}$ bond cleavage in the amine, leading to an 
aminomethylcarbene species $\left(\mathrm{CH}_{3} \mathrm{CNH}_{2}\right)$ bonded through the carbon to the nickel atoms. Before acetonitrile desorption an acimidoyl species $\left(\mathrm{CH}_{3} \mathrm{CNH}\right)$ was detected. From these results, an energy diagram for the transformation of ethylamine $\left(\mathrm{CH}_{3} \mathrm{CH}_{2} \mathrm{NH}_{2}\right)$ to acetonitrile $\left(\mathrm{CH}_{3} \mathrm{CN}\right)$ and hydrogen $\left(\mathrm{H}_{2}\right)$ on $\mathrm{Ni}(111)$ was proposed (figure 4.12). Energies of the different species were estimated by use of the data obtained from the experiment and from data found in the literature.

In the work that we report in this chapter, binding energy calculations were performed on the ethylamine-Ni(111) system, and its evolution to acetonitrile-hydrogen$\mathrm{Ni}(111)$. Empirical pair potential repulsive terms were introduced as a correction of the energy calculated within a tight-binding scheme based on the extended-Hückel theory of the molecules. This semi-empirical model has been used previously to characterize the energetics and reaction pathways of the ethylene and acetylene decomposition on platinum single crystal surfaces [1]. The model has enabled us to calculate the binding energies of the stable and metastable surface species. These energies are not directly accessible by TDS or other experiments since the desorption temperatures are above decomposition temperatures. It is found that the calculated energy diagram for the dehydrogenation process of ethylamine compares well qualitatively with the one proposed from experiments.

\subsection{The Energy Calculation}

The energetics of hydrocarbon fragments on metal surfaces have been previously studied by extended-Hückel theory [1-6]. The extended Hückel theory can be viewed as a crude, non-self-consistent approximation, in comparison with Hartree-Fock theory, but at present the examination of these systems is not feasible with more accurate methods. Therefore it sometimes provides grossly inaccurate results. With these limitations in mind we believe however that the extended-Hückel theory does provide useful information on the energetics of the hydrocarbon species adsorbed on the surface, particularly for illuminating trends. 


\subsubsection{Extended-Hückel theory}

In the extended-Hückel theory, the ground-state energy of the system is determined variationally within the space of Slater-type orbitals of the atoms in the system,

$$
\delta(<\psi|H| \psi>-E<\psi \mid \psi>)=0
$$

where $\psi=\sum_{i} c_{i} \psi_{i}$ is the variational ground-state wave-function. In matrix form we have,

$$
\operatorname{det}\left(H_{i j}-E S_{i j}\right)=0
$$

where $S_{i j}=<\psi_{i}\left|\psi_{j}\right\rangle$ is the orbital overlap. The matrix elements of the Hamiltonian are given by (in atomic units),

$$
\begin{aligned}
H_{i j} & =\left\langle\psi_{i}|H| \psi_{j}\right\rangle \\
& =\left\langle\psi_{i}\left|\frac{1}{2} \nabla^{2}+\sum_{K} V_{K}+\frac{1}{2} \sum_{k} \int d r_{k} \frac{\left|\psi_{k}\right\rangle\left\langle\psi_{k}\right|}{\left|r-r_{k}\right|}\right| \psi_{j}\right\rangle
\end{aligned}
$$

where $V_{K}=-Z_{K} /\left|r-R_{K}\right|$ is the potential of the $K$ th ion and $\sum_{k} \int d r_{k}\left|\psi_{k}><\psi_{k}\right| /\left|r-r_{k}\right|$ is the repulsion from the $k$ th electron. Neglecting 3 center integrals, (5.4) becomes

$$
H_{i j}=<\psi_{i}\left|\frac{1}{2} \nabla^{2}+\tilde{V}_{I}+\tilde{V}_{J}+\frac{1}{2}\left(\int d r_{j} \frac{\left|\psi_{j}><\psi_{j}\right|}{\left|r-r_{j}\right|}+\int d r_{i} \frac{\left|\psi_{i}><\psi_{i}\right|}{\left|r-r_{i}\right|}\right)\right| \psi_{j}>
$$

where the effective atomic potential of the $I$ th atom, except for electron $i$, is defined as,

$$
\tilde{V}_{I} \equiv V_{I}+\sum_{k \in I \neq i} \int d r_{k} \frac{\left|\psi_{k}><\psi_{k}\right|}{\left|r-r_{k}\right|}
$$

where the sum is over all electrons, $k$, except for electron $i$ belonging to atom $I$. Now the matrix element (5.5) can be expressed in terms of the atomic Hamiltonians corresponding to the atomic eigenstates,

$$
\begin{gathered}
H_{i j}=\frac{1}{2}\left(<\psi_{i}\left|\frac{1}{2} \nabla^{2}+\tilde{V}_{I}\right| \psi_{j}>+<\psi_{i}\left|\frac{1}{2} \nabla^{2}+\tilde{V}_{J}\right| \psi_{j}>\right)+ \\
<\psi_{i} \mid \frac{1}{2}\left(\tilde{V}_{I}+\tilde{V}_{J}\right)+\frac{1}{2}\left(\int d r_{j} \frac{\left|\psi_{j}><\psi_{j}\right|}{\left|r-r_{j}\right|}+\int d r_{i} \frac{\left|\psi_{i}><\psi_{i}\right|}{\left|r-r_{i}\right|} \mid \psi_{j}>\right. \\
=\frac{1}{2}\left(H_{i i}+H_{j j}\right) S_{i j}- \\
\frac{1}{2} \int d r d r^{\prime} \psi_{i}(r) \psi_{j}(r)^{*}\left[\frac{\delta\left(r^{\prime}-R_{I}\right)-\left|\psi_{i}\left(r^{\prime}\right)\right|^{2}+\delta\left(r^{\prime}-R_{J}\right)-\left|\psi_{j}\left(r^{\prime}\right)\right|^{2}}{\left|r-r^{\prime}\right|}\right]
\end{gathered}
$$


where we have approximated $\tilde{V}_{I} \approx-1 /\left|r-R_{I}\right|$.

The matrix elements of the extended-Hückel theory are defined as,

$$
H_{i j}=\frac{1}{2}\left(H_{i i}+H_{j j}\right) K S_{i j}
$$

with $K=1.75$ [7]. A very good discussion of the extended-Hückel theory and the factor $K$ can be found in reference [8].

The last term in (5.7) is the sum of the electron-ion attraction and the electronelectron repulsion; it becomes small when the distance between atoms $I$ and $J$ is big. By comparing (5.7) and (5.8) it is readily seen that the major assumption of the extendedHückel theory is to neglect the repulsive term. This assumption breaks down when the distance between the atoms is small. Thus, the extended-Hückel theory is not self-consistent with respect to describing the repulsive electronic term of the Hamiltonian.

In order to describe the interatomic repulsion at small distances, repulsive pair potentials are added to the molecular orbital energy; the description of this approach is found in the next paragraph.

\subsubsection{Model}

We have calculated the binding energies of species involved in the dehydrogenation of ethylamine $\left(\mathrm{CH}_{3} \mathrm{CH}_{2} \mathrm{NH}_{2}\right)$ to acetonitrile $\left(\mathrm{CH}_{3} \mathrm{CN}\right)$ and hydrogen $\left(\mathrm{H}_{2}\right)$ on the $\mathrm{Ni}(111)$ surface. The reaction pathway considered in this study is the one proposed earlier in chapter 4. We have used a semi-empirical model based on the extended-Hückel theory. The extended-Hückel parameters for the matrix elements and Slater orbitals are the ones found in the literature [9]. The extended-Hückel theory does not give an adequate description of the repulsive part of the potential, and in general overestimates binding energies. In order to correct for that, we introduce empirical repulsive pair-potential terms [1]. This approach is rather similar to the ASED-MO method [10] and other schemes [11]. The repulsive corrections for $\mathrm{H}-\mathrm{H}, \mathrm{C}-\mathrm{H}, \mathrm{N}-\mathrm{H}$, and $\mathrm{C}-\mathrm{N}$ bonds are chosen so that the calculated energies of hydrogen $\left(\mathrm{H}_{2}\right)$, methane $\left(\mathrm{CH}_{4}\right)$, ammonia $\left(\mathrm{NH}_{3}\right)$, and hydrocyanic acid $(\mathrm{HCN})$ reproduce the measured values $[12,13]$;

$$
\begin{aligned}
E_{\text {rep }}(H-H) & =E_{\text {exp }}\left(H_{2}\right)-E_{E H T}\left(H_{2}\right) \\
E_{\text {rep }}(H-C) & =\frac{1}{4}\left(E_{\text {exp }}\left(C H_{4}\right)-E_{E H T}\left(C H_{4}\right)\right)
\end{aligned}
$$




$$
\begin{aligned}
E_{\text {rep }}(H-N) & =\frac{1}{3}\left(E_{\exp }\left(N H_{3}\right)-E_{E H T}\left(N H_{3}\right)\right) \\
E_{\text {rep }}(R, C-N)+E_{\text {rep }}(H-C) & =E_{\text {exp }}(H C N)-E_{E H T}(H C N)
\end{aligned}
$$

In the case of C-N bonds, the bond length changes from $1.1 \AA$ to $1.5 \AA$ when going from the triple bond in $\mathrm{CH}_{3} \mathrm{CN}$ to the single bond in $\mathrm{CH}_{3} \mathrm{CH}_{2} \mathrm{NH}_{2}$. So in this case the dependence of the repulsive term on bond length is important. We use an exponential form,

$$
E_{\text {rep }}(R)=a e^{-R / b},
$$

for the repulsion between two atoms separated by a distance $R$. The parameters $a$ and $b$ are fitted to the measured values of the $C-N$ bond length and the total energy of hydrocyanic acid, and we get,

$$
a=607.87 \mathrm{eV} \text { and } b=0.20 \AA
$$

The repulsive energies are listed in table 5.1. In order to justify the approach, we caiculated the energy of methylamine $\left(\mathrm{CH}_{3} \mathrm{NH}_{2}\right)$,

$$
E\left(C_{3} \mathrm{NH}_{2}\right)=E_{E H T}\left(\mathrm{CH}_{3} N H_{2}\right)+3 E_{\text {rep }}(H-C)+2 E_{\text {rep }}(H-N)+E_{\text {rep }}(R, C-N)
$$

and found agreement with experiments to within $0.4 \mathrm{eV}$. Because of the lack of experimental data to estimate the repulsive energies between the adsorbate and the surface, we have omitted any adsorbate-surface repulsion and as a consequence overestimated the binding energies of the molecules to the surface. This is the main inaccuracy of our calculations.

The adsorption geometries of $\mathrm{CH}_{3} \mathrm{CNH}, \mathrm{CH}_{3} \mathrm{CHN}$, and $\mathrm{CH}_{3} \mathrm{CN}$ are taken from $x$-ray crystallography measurements [14] of cluster complexes in which the molecules are bonded to 3-atom clusters of $\mathrm{Fe}$. In the case of $\mathrm{CH}_{3} \mathrm{CN}$, the geometry is taken from that of $\mathrm{Fe}_{3}\left(\mathrm{CH}_{3} \mathrm{CH}_{2} \mathrm{CH}_{2} \mathrm{CN}\right)(\mathrm{CO})_{9}$ [15] by substituting the $\mathrm{CH}_{3} \mathrm{CH}_{2}$ group with $\mathrm{H}$ and adjusting the geometry to that of the methyl group. The 3 metal atoms form equilateral triangles with bond lengths varying between $2.48 \AA$ and $2.70 \AA$. The cluster has been substituted by 3 surface atoms of the $\mathrm{Ni}(111)$ surface, with a nearest neighbor $\mathrm{Ni}-\mathrm{Ni}$ distance of 2.49 $\AA$. The adsorption geometry of $\mathrm{CH}_{3} \mathrm{CH}_{2} \mathrm{NH}_{2}$ is taken to be on-top binding through the nitrogen lone-pair, the $\mathrm{N}-\mathrm{Ni}$ bond length is taken to be $1.9 \AA$, which is a typical value for a nitrogen-metal bond in organo-metallic complexes. We have calculated the binding energy 


\begin{tabular}{|c|c|c|c|c|}
\hline Bond & H-H & H-C & H-H & C-N \\
\hline E $_{\text {rep }}$ & 3.10 & 1.46 & 1.60 & $607.87 \exp (-\mathrm{R} / 0.20)$ \\
\hline
\end{tabular}

Table 5.1: Repulsive energy corrections $E_{\text {rep }}$ in $\mathrm{eV}$ ( $\mathrm{R}$ is the $\mathrm{C}-\mathrm{N}$ bond length in $\AA$ ).

for different orientations on the surface and for different orientations of the methyl group; this does not alter the binding energy significantly. The adsorption geometry of $\mathrm{CH}_{3} \mathrm{CNH}_{2}$ is obtained by substituting the two $\mathrm{C}-\mathrm{H}$ bonds of ethylamine with two $\mathrm{C}-\mathrm{Ni}$ bonds, thus yielding a bridge bonded species. The $\mathrm{C}-\mathrm{Ni}$ bond length is taken to be $2.0 \AA$. The methyl group has been rotated $60^{\circ}$ around the C-C axis in order to obtain optimum binding energy. The surface is represented in all cases by a periodic slab of 3 metal layers and a $(4 \times 2)$ lateral unit cell, one amine molecule and appropriate number of hydrogen atoms. The geometries of the surface species are shown in figure 5.1.

\section{$5.3 \quad$ Results}

The calculated binding energies are shown in table 5.2. The C-C bond and the methyl group do not change through the reactions so that the $\mathrm{C}-\mathrm{C}$ and $\mathrm{C}-\mathrm{H}$ repulsions for the methyl group are omitted from the calculation. The calculated energy change of the gas-phase reaction $\mathrm{CH}_{3} \mathrm{CH}_{2} \mathrm{NH}_{2} \rightarrow \mathrm{CH}_{3} \mathrm{CN}+2 \mathrm{H}_{2}$ is $1.31 \mathrm{eV}$, in reasonable agreement with the measured value of $1.17 \mathrm{eV}$ [12]. The calculated adsorption energies are expected to be too large since we have not included repulsion terms between the metal atoms and the adsorbates. This is confirmed by comparison with TDS measurements of the adsorption energies for $\mathrm{H}, \mathrm{CH}_{3} \mathrm{CN}$ and $\mathrm{CH}_{3} \mathrm{CH}_{2} \mathrm{NH}_{2}$ which are listed in table 5.3. In this table, we have also reported the binding energy of the acetonitrile $\left(\mathrm{CH}_{3} \mathrm{CN}\right)$ adsorbed end-on through the nitrogen in a hollow site with the $\mathrm{C}-\mathrm{N}$ axis perpendicular to the surface. We find that the binding energy for the acetonitrile adsorbed perpendicular to the surface is slightly more favorable than for the $\eta^{2}$ bonded acetonitrile, in agreement with other extendedHückel cluster calculations [16]. But acetonitrile bonded perpendicular to the surface is not supported by LEED (chapter 3).

The calculated energy diagram is in close qualitative agreement with the diagram that was proposed from experiments (figure 5.2). The general trend, favoring dehydrogenation is the same for the amines as for the hydrocarbons [1]. The cnergy diagram (figure 5.2) 


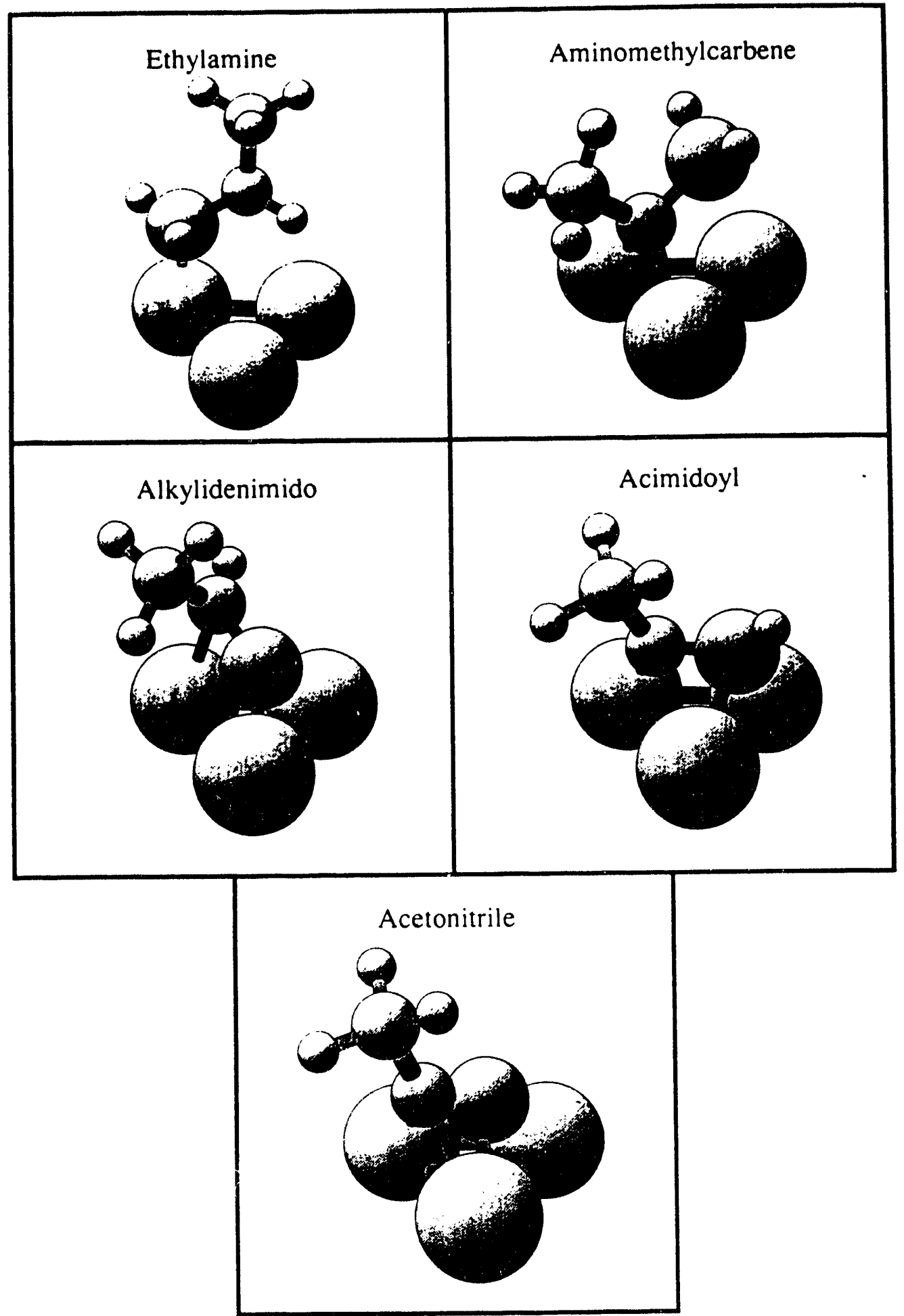

Figure 5.1: Adsorption geometries of the various adsorbates on the Ni(111) surface. The atomic sizes represent, in growing order, $\mathrm{H}, \mathrm{C}, \mathrm{N}$, and $\mathrm{Ni}$, but have no physical significance. 


\begin{tabular}{|l|l|r|r|r|r|}
\hline & & $E_{E H T}$ & $E_{\text {rep }}$ & $E_{\text {total }}$ & $\mathrm{E}_{b}$ \\
\hline ethylamine & $\mathrm{CH}_{3} \mathrm{CH}_{2} \mathrm{NH}_{2}(\mathrm{~g})$ & -364.25 & 6.50 & -357.75 & 0.00 \\
& $\mathrm{CH}_{3} \mathrm{CH}_{2} \mathrm{NH}_{2}(\mathrm{a})$ & -365.96 & 6.50 & -359.46 & -1.71 \\
aminomethyl- & $\mathrm{CH}_{3} \mathrm{CNH}_{2}(\mathrm{a})+2 \mathrm{H}(\mathrm{a})$ & -363.33 & 3.58 & -359.75 & -2.00 \\
carbene & & & & & \\
acimidoyl & $\mathrm{CH}_{3} \mathrm{CNH}(\mathrm{a})+3 \mathrm{H}(\mathrm{a})$ & -364.16 & 2.33 & -361.83 & -4.08 \\
alkylidenimido & $\mathrm{CH}_{3} \mathrm{CHN}(\mathrm{a})+3 \mathrm{H}(\mathrm{a})$ & -364.47 & 2.28 & -362.19 & -4.44 \\
acetonitrile & $\mathrm{CH}_{3} \mathrm{CN}(\mathrm{a})+4 \mathrm{H}(\mathrm{a})$ & -363.65 & 1.11 & -362.54 & -4.79 \\
& $\mathrm{CH}_{3} \mathrm{CN}(\mathrm{g})+4 \mathrm{H}(\mathrm{a})$ & -361.98 & 1.86 & -360.12 & -2.37 \\
& $\mathrm{CH}_{3} \mathrm{CN}(\mathrm{g})+2 \mathrm{H}(\mathrm{a})+$ & -360.14 & 4.96 & -358.28 & -0.53 \\
& $+\mathrm{H}_{2}(\mathrm{~g})$ & & & &. \\
& $\mathrm{CH}_{3} \mathrm{CN}(\mathrm{g})+2 \mathrm{H}_{2}(\mathrm{~g})$ & -364.50 & 8.06 & -356.44 & 1.31 \\
\hline
\end{tabular}

Table 5.2: Calculated binding energies, in $\mathrm{eV}$, of the gas-phase and adsorbed amines. The energy of the clean Ni(111) surface has been subtracted. The binding energy is defined as $E_{b}=E_{\text {total }}-E_{b}($ ethylamine $)$.

\begin{tabular}{|l|r|r|}
\hline & calculated & measured \\
\hline $\mathrm{H}(\mathrm{a})$ & 3.17 & 2.75 \\
$\mathrm{CH}_{3} \mathrm{CH}_{2} \mathrm{NH}_{2}(\mathrm{a})$ & 1.71 & $\sim 0.8$ \\
$\mathrm{CH}_{3} \mathrm{CN}-\eta^{2}$ & 2.42 & $\sim 0.9$ \\
$\mathrm{CH}_{3} \mathrm{CN}-\eta^{1}$ & 2.87 & \\
\hline
\end{tabular}

Table 5.3: Binding energies (eV) of hydrogen, ethylamine, and acetonitrile. The measured values are extracted from TDS experiments of $\mathrm{H}_{2}$ [17], $\mathrm{CH}_{3} \mathrm{CH}_{2} \mathrm{NH}_{2}$ [chapter 4], $\mathrm{CH}_{3} \mathrm{CN}$ [18], assuming first order desorption kinetics. The geometry of the $\eta^{2}$ bonded acetonitrile is taken from $\mathrm{x}$-ray crystallographic data [15] and the $\eta^{1}$ bonded acetonitrile is adsorbed end-on with the N-C axis perpendicular to the surface, see text. 

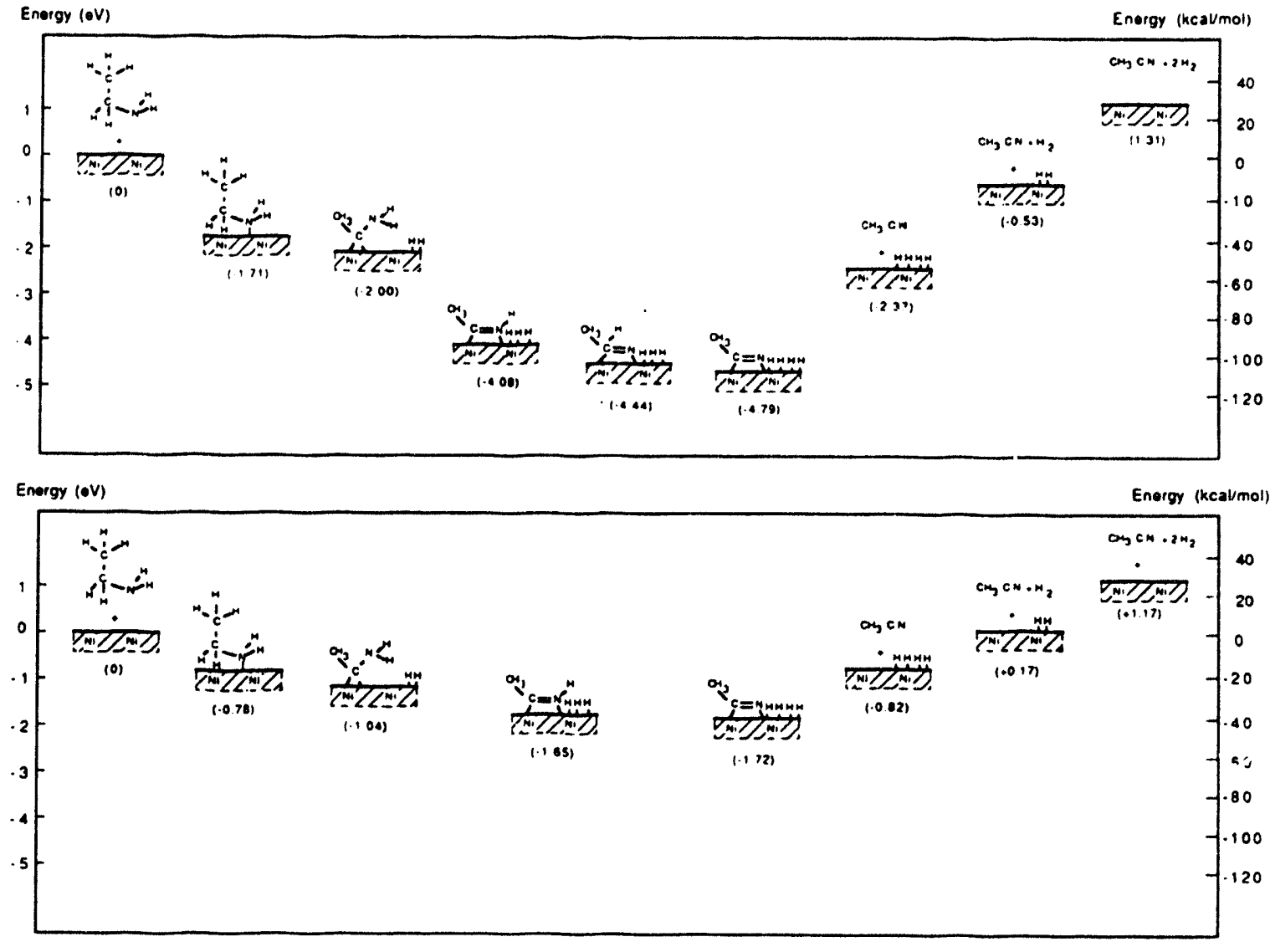

XBC $927-1586$

Figure 5.2: Energy diagram for the binding of amines to the Ni(111) surface. The upper panel is the calculated diagram and the lower panel is the diagram adopted from the experimental study [chapter 4]. We have indicated the binding energy in $\mathrm{eV}$ under each specie with the ethylamine in the gas phase taken to be the reference. The alkylidenimido specie $\left(\mathrm{CH}_{3} \mathrm{CHN}\right)$ was not found in the HREELS study of ethylamine $\left(\mathrm{CH}_{3} \mathrm{CH}_{2} \mathrm{NH}_{2}\right)$ thermal decomposition on $\mathrm{Ni}(111)$, although its calculated binding energy (upper panel) is lower than that of the acimidoyl specie $\left(\mathrm{CH}_{3} \mathrm{CNH}\right)$, see text. 

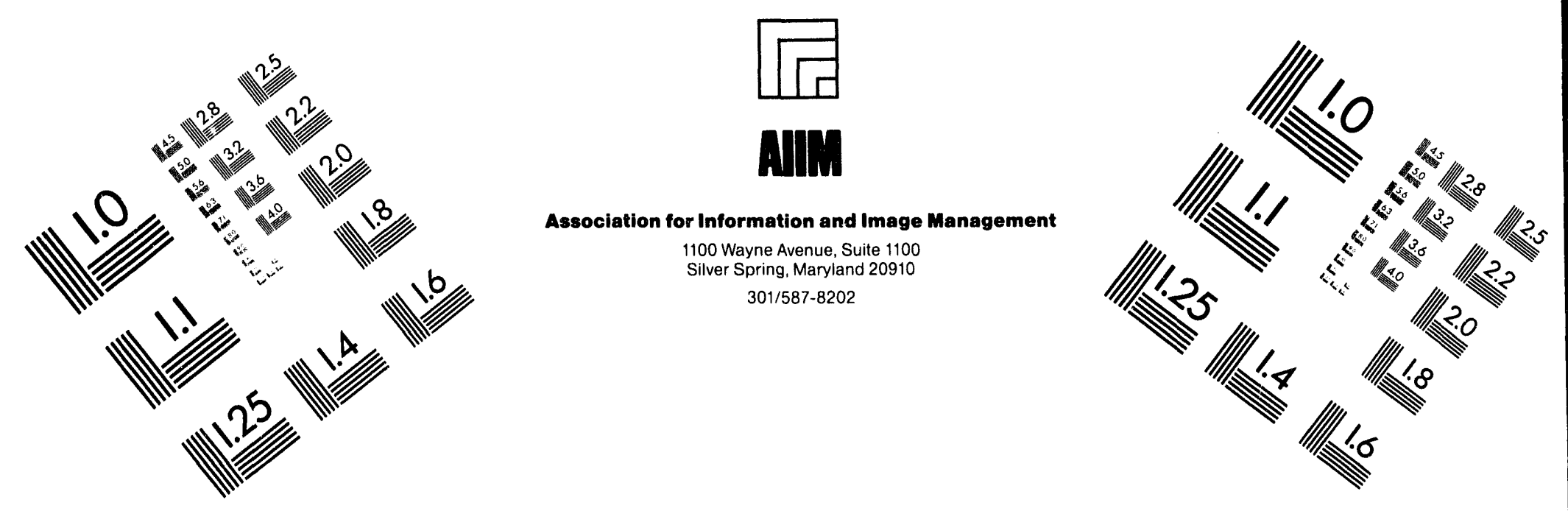

Centimeter

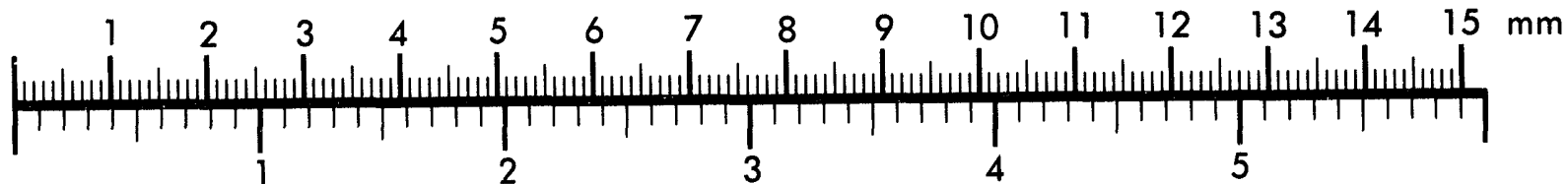
Inches
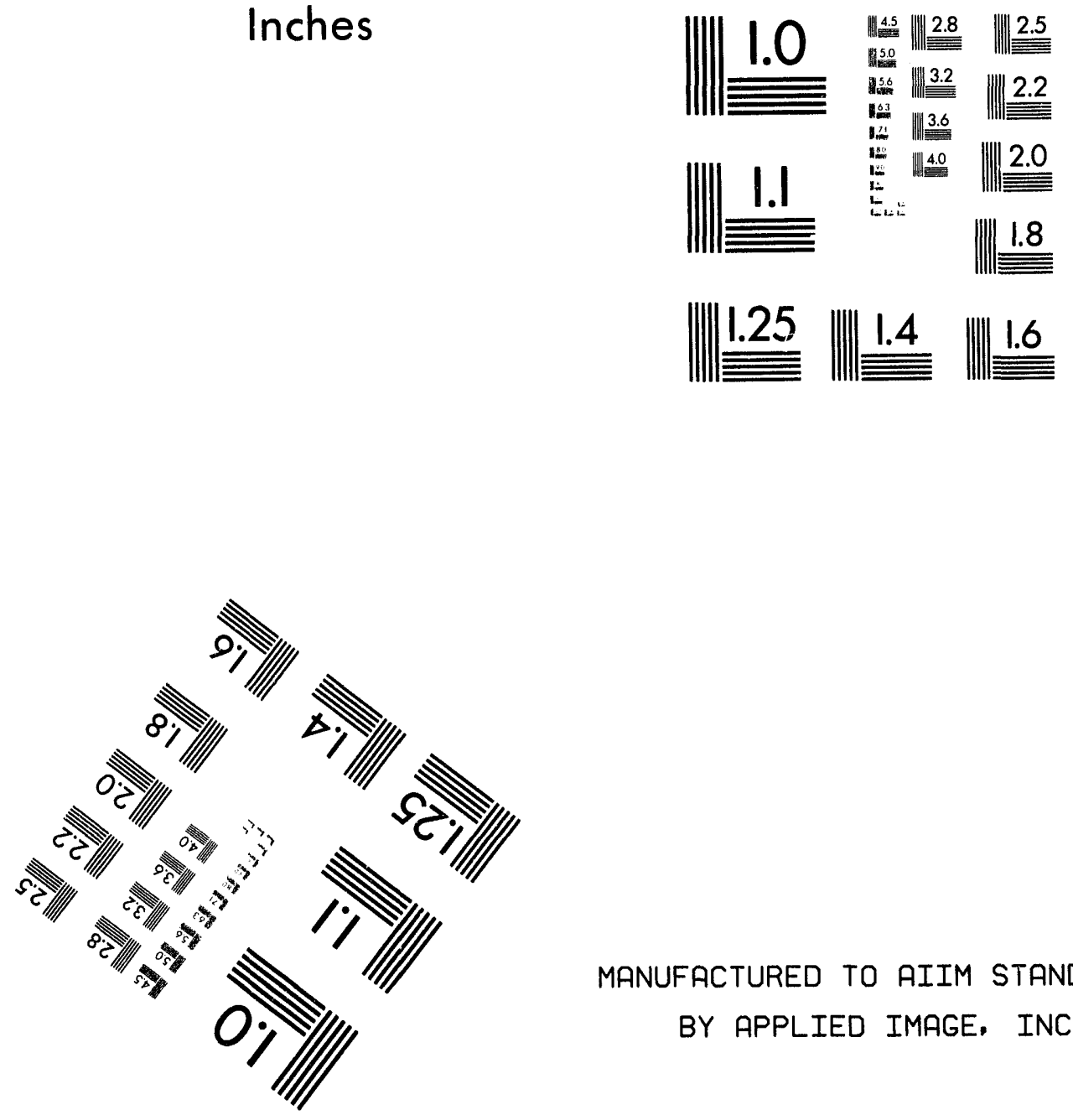

MANUFACTURED TO AIIM STANDARDS

BY APPLIED IMAGE, INC.

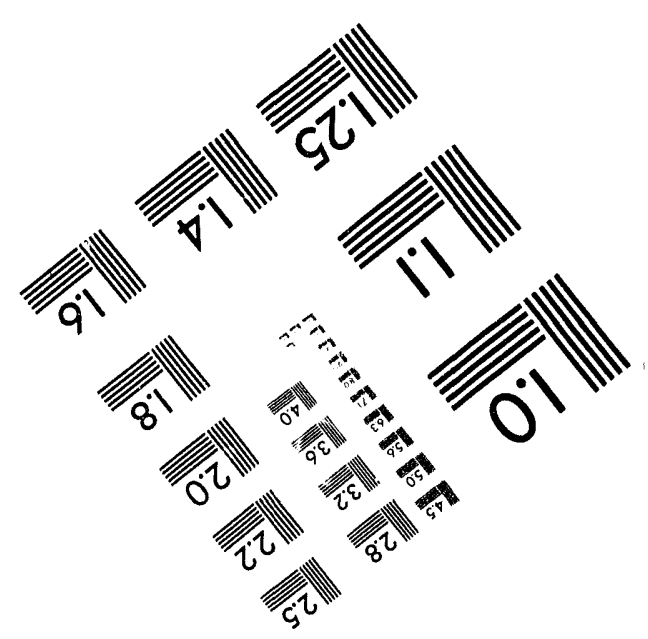



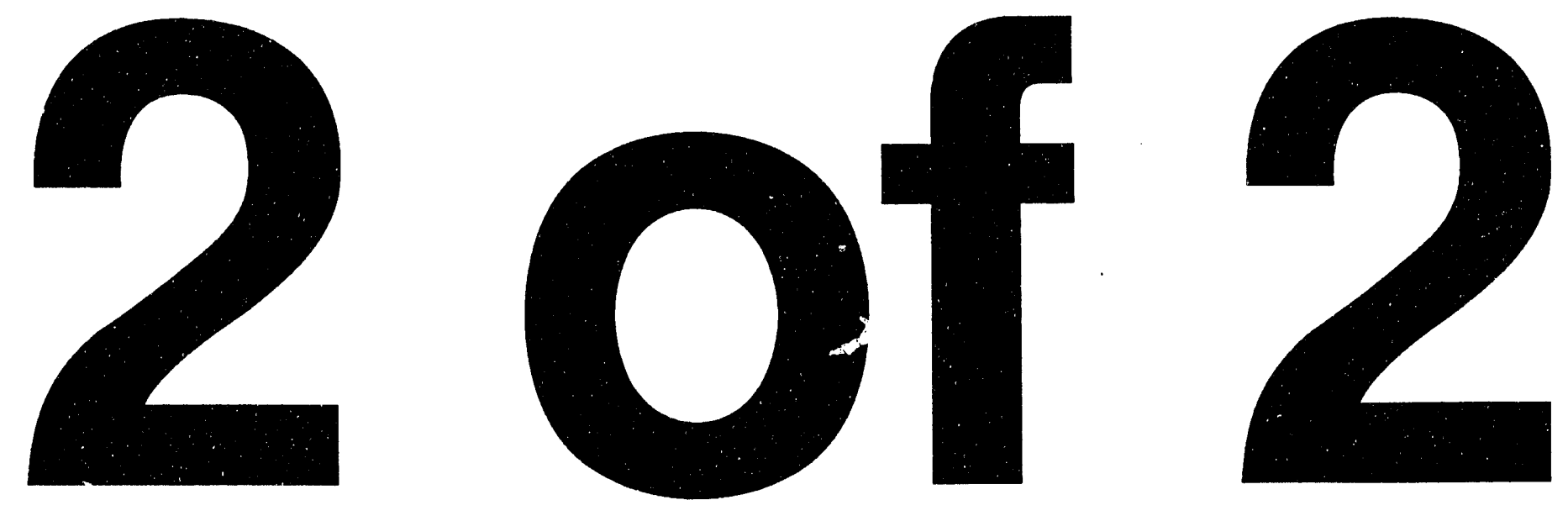
is arranged in order to suggest a decomposition pathway, namely molecular adsorption of ethylamine $\left(\mathrm{CH}_{3} \mathrm{CH}_{2} \mathrm{NH}_{2}\right)$, then breaking the $\mathrm{C}-\mathrm{H}$ bonds to form the aminomethylcarbene specie $\left(\mathrm{CH}_{3} \mathrm{CNH}_{2}\right)$, then breaking $\mathrm{N}-\mathrm{H}$ bonds to form the acimidoyl specie $\left(\mathrm{CH}_{3} \mathrm{CNH}\right)$ and finally acetonitrile $\left(\mathrm{CH}_{3} \mathrm{CN}\right)$. The binding energy of the alkylidenimido specie $\left(\mathrm{CH}_{3} \mathrm{CHN}\right)$ is also estimated and found to be stronger than that of the acimidoyl specie $\left(\mathrm{CH}_{3} \mathrm{CNH}\right)$ by about $0.3 \mathrm{eV}$. This result that the alkylidenimido ligand is more stable than the acimidoyl specie on the $\mathrm{Ni}(111)$ surface is also observed experimentally for binding to Fe clusters [19]. However, the alkylidenimido specie was not detected by HREELS when decomposing ethylamine $\left(\mathrm{CH}_{3} \mathrm{CH}_{2} \mathrm{NH}_{2}\right)$ on the $\mathrm{Ni}(111)$ surface [chapter 4]. This can be explained by the argument that the abundance of the different surface species observed during TDS experiments (non-equilibrium conditions) is not governed by the thermodynamics of the surface, but by the relative reaction barrier heights of the possible surface reactions. A decomposition pathway to form the alkylidenimido specie $\left(\mathrm{CH}_{3} \mathrm{CHN}\right)$ on the surface could be through initial breaking of the hydrogen-nitrogen bonds via $\mathrm{CH}_{3} \mathrm{CH}_{2} \mathrm{~N}$. But this is not observed on $\mathrm{Ni}(111)$, the main reason being that the N-H bonds point away from the surface so that the surface cannot easily participate in $\mathrm{N}-\mathrm{H}$ bond cleavage. Similarly for ammonia $\left(\mathrm{NH}_{3}\right)$ on $\mathrm{Ni}(111)$, the $\mathrm{N}-\mathrm{H}$ bond breaking cannot be thermally activated [20]. In contrast, $\mathrm{C}-\mathrm{H}$ bonds of the adsorbed ethylarnine $\left(\mathrm{CH}_{3} \mathrm{CH}_{2} \mathrm{NH}_{2}\right)$ are pointing toward the surface, allowing bond breaking by hydrogen transfer to the surface [21]. The alternative pathway to make the alkylidenimido specie $\left(\mathrm{CH}_{3} \mathrm{CHN}\right)$ would involve isomerization of the acimidoyl specie $\left(\mathrm{CH}_{3} \mathrm{CNH}\right)$, but this type of reaction was found in a theoretical study to have a much higher reaction barrier than hydrogenation -dehydrogenation [1]. From this calculation, on the other hand, we could expect to see the alkylidenimido specie $\left(\mathrm{CH}_{3} \mathrm{CHN}\right)$ on the surface when carrying out the hydrogenation reaction by coadsorbing acetonitrile $\left(\mathrm{CH}_{3} \mathrm{CN}\right)$ and hydrogen $\left(\mathrm{H}_{2}\right)$, but we have shown in chapter 3 that acetonitrile and hydrogen do not react on $\mathrm{Ni}(111)$ in $\mathrm{UHV}$.

\subsection{Conclusion}

We have shown that semi-empirical calculations based on extended-Hückel theory can be used to estimate the binding energies of the decomposition products and intermediate species on the $\mathrm{Ni}(111)$ surface, in qualitative agreement with experiments. From our results we see thai there are three different species that are very stable on the surface. These are 
the acetonitrile $\left(\mathrm{CH}_{3} \mathrm{CN}\right)$, the acimidoyl $\left(\mathrm{CH}_{3} \mathrm{CNH}\right)$, and the alkylidenimido $\left(\mathrm{CH}_{3} \mathrm{CHN}\right)$ species. The relative abundances of these species on the surface under equilibrium conditions will probably be important for the selectivity of a nickel surface used as a catalyst. We find the alkylidenimido ligand to be slightly more stable than the acimidoyl ligands, but within the accuracy of the model we expect the alkylidenimido, the acimidoyl and the acetonitrile species to occur with similar abundance on the surface. From the calculated binding energies and rough estimates of reaction barriers, which we have not calculated, and the structures of the surface species we have rationalized the decomposition pathway from ethylamine $\left(\mathrm{CH}_{3} \mathrm{CH}_{2} \mathrm{NH}_{2}\right)$ to acetonitrile $\left(\mathrm{CH}_{3} \mathrm{CN}\right)$ on the $\mathrm{Ni}(111)$ surface. We have proposed an explanation to why the supposedly stable alkylidenimido specie $\left(\mathrm{CH}_{3} \mathrm{CHN}\right)$ is not formed on the surface during the ethylamine decomposition. 


\subsection{References}

[1] P.D. Ditlevsen, M.A. Van Hove, G.A. Somorjai, Surf. Sci., in press.

[2] C. Minot, M. A. Van Hove, and G. A. Somorjai, Surf. Sci., 127 (1982) 441.

[3] Ph. Sautet, and J.-F. Paul, Catalysis Letters, 9 (1991) 245.

[4] A. Gavezzotti, and M. Simonetta, Surf. Sci, 99 (1980) 453.

[5] Y.-T. Wong, and R. Hoffmann, J. Chem Soc. Faraday Trans., 86 (1990) 4090.

[6] B. Schiøtt, R. Hoffmann, M. K. Awad, and A. B. Anderson, Langmuir, 6 (1990) 806.

[7] R. Hoffmann, J. Chem. Phys., 39 (1963) 1397.

[8] G. Calzaferri, L. Forss, and I. Kamber, J. Chem. Phys., 93 (1989) 5366.

[9] Z. Nomikou, B. Schubert, R. Hoffmann, and M.L. Steigerwald, Inorg. Chem., 30 (1992) 1086: E.L. Garfunkel, C. Minot, A. Gavezzotti, and M. Simonetta, Surf. Sci., 167 (1986) 177.

[10] A.B. Anderson, R.W. Grimes, and S.Y. Hong, J. Phys. Chem., 91 (1987) 4245.

[11] L.W. Anders, R.S. Hansen, and L.S. Bartell, J. Chem. Phys., 59 (1973) 5277.

[12] CRC Handbook of Chemistry and Physics, 64th edition, (CRC Press, Cleveland, 1984).

[13] The binding energies of $\mathrm{H}_{2}, \mathrm{NH}_{3}, \mathrm{CH}_{4}$, and $\mathrm{HCN}$ were calculated from the heats of formation $\Delta H f$ found in thermochemical tables [12] like,

$\mathrm{C}($ atom $)+4 \mathrm{H}($ atom $) \rightarrow \mathrm{C}($ graphite $)+2 \mathrm{H}_{2} \rightarrow \mathrm{CH}_{4}$

$\Delta H=\Delta E+\Delta(P V)=\Delta H f_{0}\left(C H_{4}\right)-\Delta H f_{0}(C($ atom $))-4 \Delta H f_{0}(H($ atom $))$

$\triangle(P V)=-4 R T$ so we get,

$\Delta E=\Delta H f_{o}\left(C H_{4}\right)-\Delta H f_{o}(C($ atom $))-4 \Delta H f_{o}(H($ atom $))+4 R T$

[14] M.A. Andrews, G.V. Buskirk, C.B. Knopler, and H.D. Kaesz, J. Am. Chem. Soc., 101 (1979), 7245.

[15] M.A. Andrews,C.B. Knopler, and H.D. Kaesz, J. Am. Chem. Soc., 101 (1979) 7260. 
[16] B. Bigot, Private communication.

[17] K. Christmann, O. Schober, G. Ertl, and M. Neumann, J. Chem Phys., 60 (19"74) 4528.

[18] J.C. Hemminger, E.L. Muetterties, and G.A. Somorjai, J. Am. Chem. Soc., 101 (1979) 62.

[19] M.A. Andrews, and H.D. Kaesz, J. Am. Chem. Soc., 101 (1979) 7238.

[20] C.W. Seabury, T.N. Rhodin, R.J. Purtell, and R.P. Merrill, Surf. Sci., 93 (1980) 117.

[21] D.B. Kang, and A.B. Anderson, Surf. Sci., 155 (1985) 639. 


\section{Chapter 6}

\section{Adsorbate Induced}

\section{Reconstruction of the $\mathrm{Ni}(111)$}

\section{Surface}

\subsection{Introduction}

In chapter 4, we have reported the adsorption and decomposition of ethylamine $\left(\mathrm{CH}_{3} \mathrm{CH}_{2} \mathrm{NH}_{2}\right)$ on a clean $\mathrm{Ni}(111)$ crystal surface. Ethylamine adsorbed at low temperature $(150 \mathrm{~K})$ can be dehydrogenated to acetonitrile $\left(\mathrm{CH}_{3} \mathrm{CN}\right)$ which desorbs at $350 \mathrm{~K}$. The dehydrogenation of the amine to the nitrile competes with $\mathrm{C}-\mathrm{C}$ and $\mathrm{C}-\mathrm{N}$ bond breaking within the molecule. As a consequence, part of the adsorbed ethylamine is totally decomposed leaving atomic carbon and nitrogen on the surface after desorption of all the hydrogen above $450 \mathrm{~K}$.

When this $\mathrm{Ni}(111)$ surface that is covered with carbon and nitrogen atoms is cooled and exposed to more ethylamine, the same experiment can be repeated, acetonitrile and hydrogen are again produced and desorb from the surface. Auger electron spectroscopy (AES) of the surface composition shows that more carbon and nitrogen atoms are deposited on the surface. After three or four such cycles, the surface composition no longer changes as shown by AES. Adsorption-desorption experiments of ethylamine indicate that the surface is still able to dehydrogenate ethylamine to acetonitrile but is no longer active for $\mathrm{C}-\mathrm{C}$ or $\mathrm{C}-\mathrm{N}$ bond breaking. Low energy electron diffraction (LEED) from this carbon and nitrogen 
covered $\mathrm{Ni}(111)$ surface exhibits a complex diffraction pattern similar to one reported by others after reaction of $\mathrm{H}_{2} \mathrm{~S}$ [1], $\mathrm{C}_{2} \mathrm{H}_{4}$ [2], $\mathrm{CO}$ [3], $\mathrm{NO}$ [4] and $\mathrm{CH}_{3} \mathrm{CN}$ [5] with a $\mathrm{Ni}(111)$ surface at moderate temperatures $(500-800 \mathrm{~K})$. The unit cell of this structure was identified by McCarroll et al [2]; it can be labeled $c(5 \sqrt{3} \times 9)$ rect or in the matrix notation $\left(\begin{array}{ll}2 & 7 \\ 7 & 2\end{array}\right)$. McCarroll et al [2] proposed to interpret the LEED pattern as due to the formation of a pseudo- $\mathrm{Ni}(100)-(2 \times 2)$ monolayer on top of the $\mathrm{Ni}(111)$ surface. Thus, if this interpretation is correct, the hexagonal (111) surface of nickel restructures in the presence of these adsorbates to form a square lattice of (100) orientation and the coincidence of atomic positions between the top layer (with the almost square unit mesh) and the substrate layer (with hexagonal symmetry) generates the complex diffraction pattern and surface structure.

When a $\mathrm{Ni}(111)$ surface is exposed to $\mathrm{H}_{2} \mathrm{~S}$ [1] or $\mathrm{NH}_{3}$ [6], or $\mathrm{NO}+\mathrm{H}_{2}$ [4] other complex surface structures can be observed by LEED. The LEED patterns produced by sulfur $(\mathrm{Ni}(111)-(5 \sqrt{3} \times 2)$ rect-S [1]) and nitrogen (Ni(111)-'(2x6)'-N [4]) look very similar and could be due to similar surface structures. The Ni(111)-(5 $\sqrt{3} \times 2)-\mathrm{S}$ structure was studied by SEXAFS and among three possible models the authors favored the one involving the reconstruction of the surface into a pseudo- $\mathrm{Ni}(100)$ surface $[7,8]$.

In this chapter, we present measurements made on the $\mathrm{Ni}(111)-\mathrm{c}(5 \sqrt{3} \times 9)$ rect-C, $\mathrm{Ni}(111)-\mathrm{c}(5 \sqrt{3} \times 9)$ rect- $\mathrm{N}, \mathrm{Ni}(111)-\mathrm{c}(5 \sqrt{3} \times 9)$ rect-S and $\mathrm{Ni}(111)-(2 \times 6)-\mathrm{N}$. We propose new arguments to support the adsorbate induced reconstruction to form a nickel surface with (100) orientation upon reactions of $\mathrm{Ni}(111)$ with carbon, nitrogen and sulfur, where the adsorbate atom $(\mathrm{C}, \mathrm{N}$ or $\mathrm{S})$ occupies a four-fold site.

\section{$6.2 \mathrm{Ni}(111)-\mathrm{c}(5 \sqrt{ } 3 \times 9)$ rect- $\mathrm{C}$ and $\mathrm{Ni}(111)-\mathrm{c}(5 \sqrt{ } 3 \times 9)$ rect- $\mathrm{N}$ Surface Structures}

\subsubsection{Preparation method of the Ni(111) $-c(5 \sqrt{ } 3 \times 9)$ rect-C structure}

Exposure of the clean $\mathrm{Ni}(111)$ surface to $5 \times 10^{-8}$ torr $\mathrm{C}_{2} \mathrm{H}_{4}$ for 20 s $(1$ Langmuir exposure) at $570 \mathrm{~K}$ produces a complex $\mathrm{c}(5 \sqrt{3} \times 9)$ rect LEFD pattern. At $3 \mathrm{~L}$, the overlayer diffraction spots are sharp and intense (figure 6.1). No other simpler LEED patterns can be formed. When scanning the incident LEED beam across the sample, one, two or more domain orientations of this structure are observed. When the experiment is performed on 
a rougher surface ( $\mathrm{Ar}^{+}$sputtering followed by short annealing of the sample at $770 \mathrm{~K}$ ) a maximum of six domain orientations are seen simultaneously (figure 6.2). This shows that surface steps and other defects influence the orientation of the various domains with respect to the $\mathrm{Ni}(111)$ substrate. If the cracking of $\mathrm{C}_{2} \mathrm{H}_{4}$ is carried out in a background pressure of $\mathrm{O}_{2}\left(1 \times 10^{-8}\right.$ torr $\left.\mathrm{O}_{2}\right)$, all the domain orientations are also obtained. On our sample annealed at $1100 \mathrm{~K}$ after $\mathrm{Ar}^{+}$sputtering, it was always possible to find an area on the surface with only a single domain orientation. This made the analysis of spot intensities much easier.

The AES analysis of the surface shows the presence of carbidic carbon on the surface. The carbon coverage can be estimated by comparing the ratio $\mathrm{C}_{272 \mathrm{eV}} / \mathrm{Ni}_{848 \mathrm{eV}}$ to the ratio obtained when the $\mathrm{Ni}(111)-\mathrm{c}(4 \times 2)-\mathrm{CO}$ structure is formed ( 0.5 monolayer $\mathrm{CO})$. We estimate the carbon coverage of the $\mathrm{Ni}(111)-c(5 \sqrt{3} \times 9)$ rect-C surface to be $\theta=0.5$ monolayer (C atoms per surface $\mathrm{Ni}$ atoms).

The $c(5 \sqrt{3} \times 9)$ rect structure is very stable in UHV up to $690 \mathrm{~K}$. Above that temperature, the LEED pattern transforms to the (1x1) structure of the clean surface and the Auger spectrum shows that very little carbon is left on the metal surface, indicating that the surface carbon has diffused into the bulk. The structure is also very stable in hydrogen. At pressures up to $10^{-5}$ torr of hydrogen, and temperatures up to $690 \mathrm{~K}$, the $\mathrm{Ni}(111)-\mathrm{c}(5 \sqrt{3} \times 9)$ rect-C LEED pattern stays intact. When exposed to oxygen however, the nickel is progressively oxidized leading to the formation of a layer of nickel oxide with its characteristic hexagonal LEED pattern.

\subsubsection{LEED intensity analysis of the $\mathrm{Ni}(111)-c(5 \sqrt{ } 3 \times 9)$ rect-C siructure}

As noticed by McCarroll et al [2], the most intense LEED spots at lower energies (up to $150 \mathrm{eV}$ ) form a mesh whose dimensions are very close to a $\mathrm{Ni}(100)-(2 \times 2)$ unit mesh (figure 6.3). We have tracked the intensities of these diffraction spots with a video-camera from $50 \mathrm{eV}$ to $250 \mathrm{eV}$. To simplify the identification of the diffraction beams measured, we label those spots using the pseudo- $\mathrm{Ni}(100)-(2 \times 2)$ unit cell vectors as shown in italics in figure 6.3.

In figure 6.4, we report the I-V curves which we collected. We compare in each panel the I-V curves of the superstructure beams which should be equivalent if we had an undistorted $\mathrm{Ni}(100)-(2 \times 2)$ superstructure, the average of those beams and the corresponding beam measured by others $[9,10]$ for the $\mathrm{Ni}(100)-(2 \times 2)-2 \mathrm{C}$ structure. The I-V curves of the 


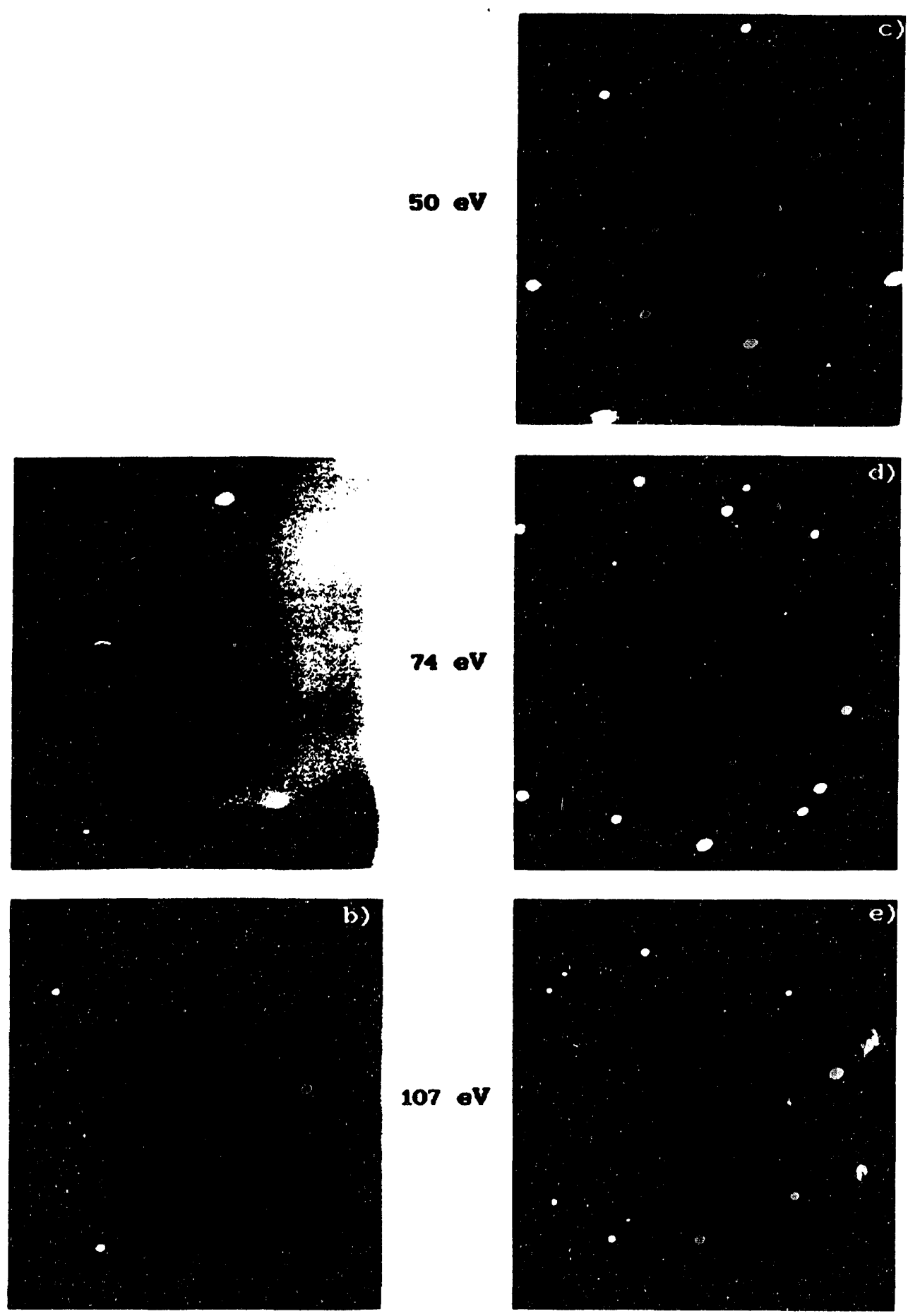

Figure 6.1: LEED patterns of the clean $\mathrm{Ni}(111)$ surface at $74 \mathrm{eV}$ (a) and $107 \mathrm{eV}$ (b) and of the $\mathrm{Ni}(111)-\mathrm{c}(5 \sqrt{ } 3 \times 9)$ rect-C structure at $50 \mathrm{cV}$ (c), $74 \mathrm{eV}$ (d) and $107 \mathrm{eV}$ (e). The LEED beam samples a part of the crystal with only one domain orientation of the superstructure. 


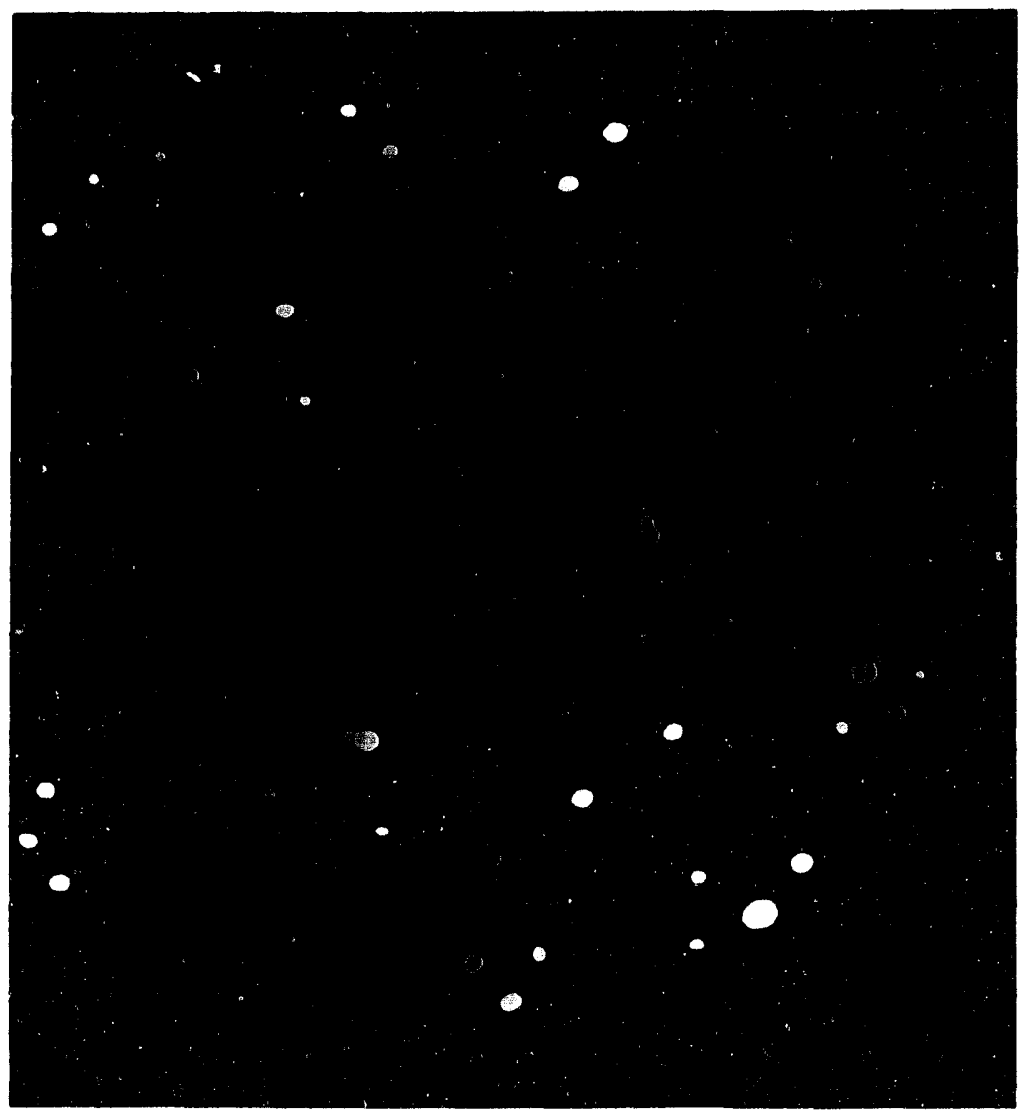

\section{$73 \mathrm{eV}$}

Figure 6.2: LEED pattern at $73 \mathrm{eV}$ of the $\mathrm{Ni}(111)-\mathrm{c}(5 \sqrt{ } 3 \times 9)$ rect-C structure obtained on an $\mathrm{Ar}^{+}$sputtered surface. All the possible domain oricntations are observed. 


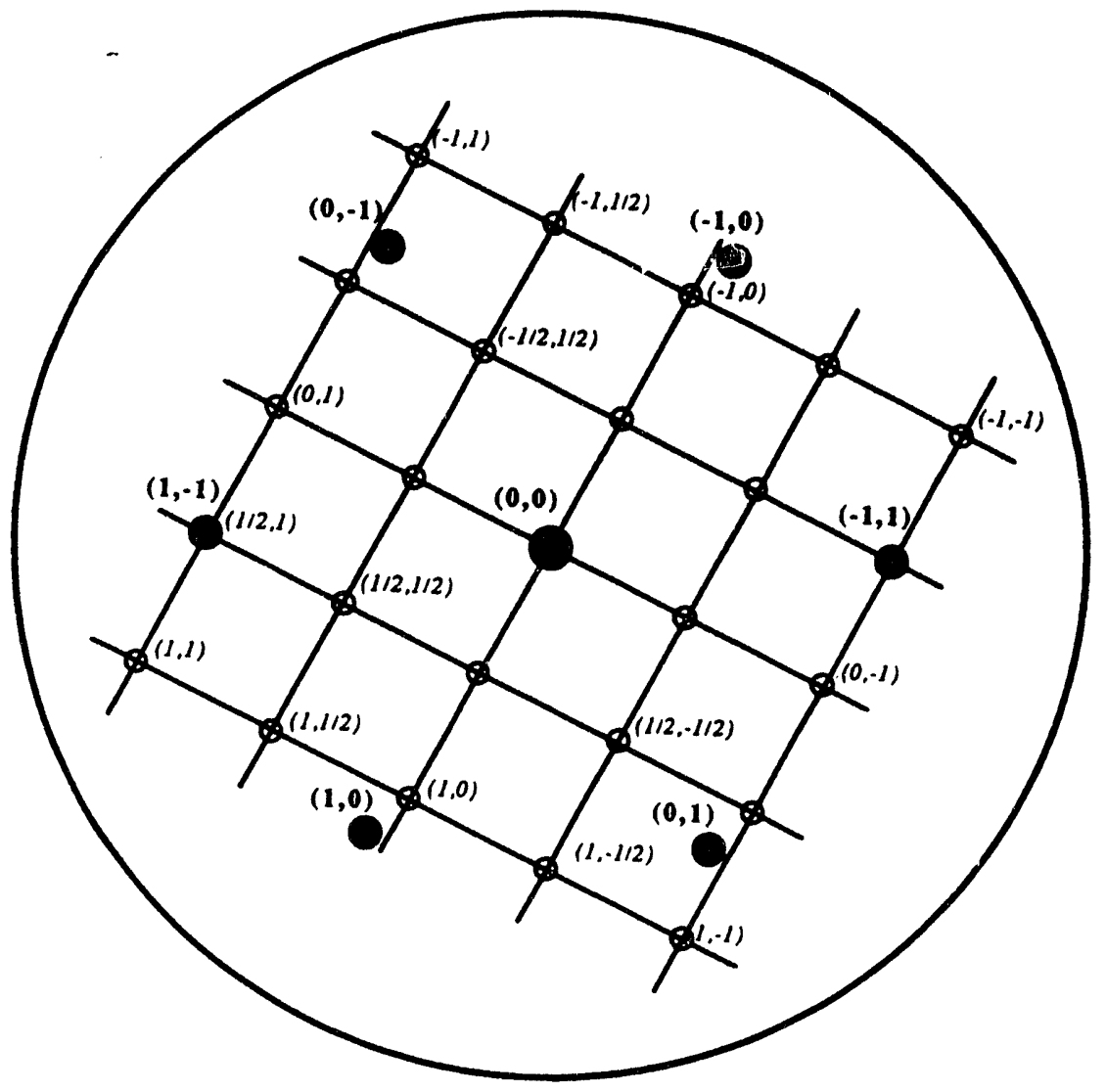

XBL $9311-1570$

Figure 6.3: Schematic of the $\mathrm{Ni}(111)-\mathrm{c}(5 \sqrt{ } 3 \times 9)$ rect-C LEED pattern for a single domain orientation, showing the substrate spots (full circles) and the most intense spots (open circles) due to the superstructure. These spots are located on a nearly square mesh whose dimensions are very close to a $\mathrm{Ni}(100)-(2 \times 2)$ mesh but which has an angle of $88^{\circ}$ between unit cell vectors. This mesh is used to labcl the superstructure diffraction spots for convenience (in italics). 

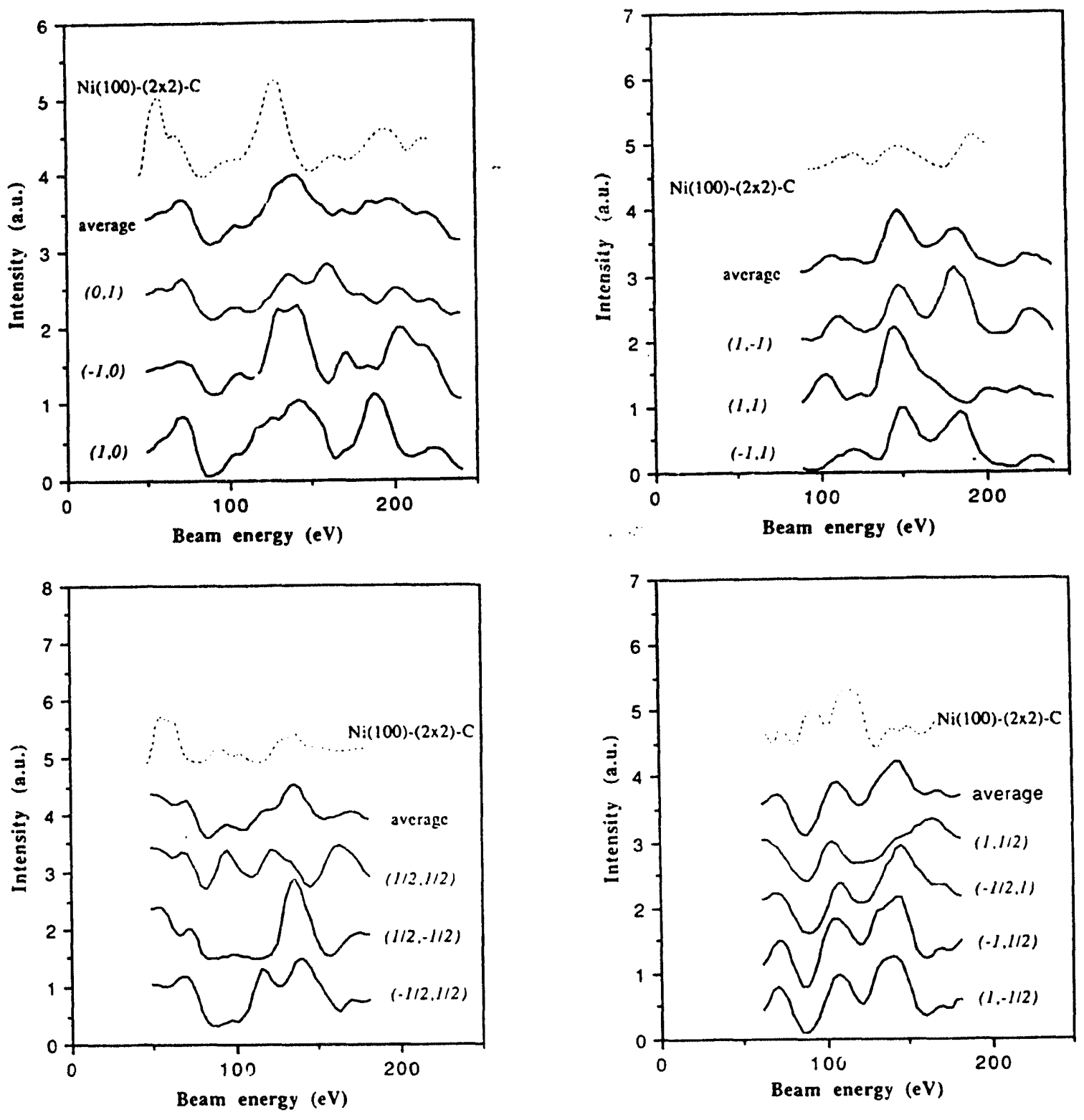

XBL $9311-1571$

Figure 6.4: I-V curves of the $\mathrm{Ni}(111)$-c $(5 \sqrt{ } 3 \times 9)$ rect-C structure, taken at normal incidence. The spots are labeled using the superstructure mesh described in figure 6.3. I-V curves are compared to the corresponding I-V curves of the $\mathrm{Ni}(100)-(2 \times 2)-2 \mathrm{C}$ structure. 
beams which would be equivalent if we had a $\mathrm{Ni}(100)-(2 \times 2)$ superstructure show some surprising similarities. Comparin the beam averages to the experimental I-V curves for the $\mathrm{Ni}(100)-(2 \times 2)-2 \mathrm{C}$ structure $[9,10]$, we observe that integer order beams match to some extent and half-order beams show some similarities. Because of the distortion away from the $\mathrm{Ni}(100)-(2 \times 2)$ mesh which changes the LEED scattering angles, I-V curves cannot be expected to match much better than this even for nearly identical structures. We believe that the closeness to the $\mathrm{Ni}(100)-(2 \times 2)$ superstructure and the similarities in I-V curves are strong arguments in favor of a model involving a reconstruction of the $\mathrm{Ni}(111)$ surface in a $\mathrm{Ni}(100)$ type surface, perhaps with the local adsorption structure of the $\mathrm{Ni}(100)-(2 \times 2)-2 \mathrm{C}$ system. To explain similarities between the I-V curves, it is reasonable to believe that at least two metal layers are reconstructed in a $\mathrm{Ni}(100)$ type geometry.

If we compare the beams of the clean $\mathrm{Ni}(111)$ surface (figure 6.5), however, via see that they are not strongly modified when the $\mathrm{Ni}(111)-\mathrm{c}(5 \sqrt{3} \times 9)$ rect-C structure is presunt. One interpretation would be the formation of islands of reconstructed surface on the nonreconstructed $\mathrm{Ni}(111)$ surface. However when Bertolini et al [11] studied the adsorption of $\mathrm{CO}$ on this surface by TDS and high-resolution electron energy loss spectroscopy (HREELS) they detected only one type of $\mathrm{CO}$ on this surface, bonded more weakly than on a clean surface. If we had different types of sites, from the reconstructed and non-reconstructed surface, we would expect to detect more than one type of CO by HREELS. It therefore seems more likely that the entire surface reconstructs to a depth of a few metal layers. Due to the screening of the top layers, we would then expect a decrease in the intensity of the diffracted spots from the (111) substrate relative to the clean substrate. Experimentally, we measure that the intensity of the substrate beams decreases by a factor of 8 . From an estimation of the mean free path of electrons in nickel we find that 2 to 3 nickel layers (5 $\AA$ thickness) need to be reconstructed to explain the observed decrease in the substrate beams intensity.

In the case of $\mathrm{Ni}(100)-(2 \times 2)-2 \mathrm{C}[10]$ the two top metal layers are strongly relaxed, in such a way that each $\mathrm{C}$ atom is allowed to penetrate into a 4 -fold hollow site and to bond to a fifth nickel atom in the second metal layer. The optimal bonding of the carbon atoms to the nickel in this geometry is also an argument in favor of such reconstruction on the $\mathrm{Ni}(111)$ surface. In figure 6.6, we show the model proposed by McCarroll et al [2] for the $\mathrm{Ni}(111)$-c $(5 \sqrt{3} \times 9)$ rect-C structure that is supported by our analysis. A complete dynamical LEED analysis of the I-V curves would be necessary to determine the exact structure of 

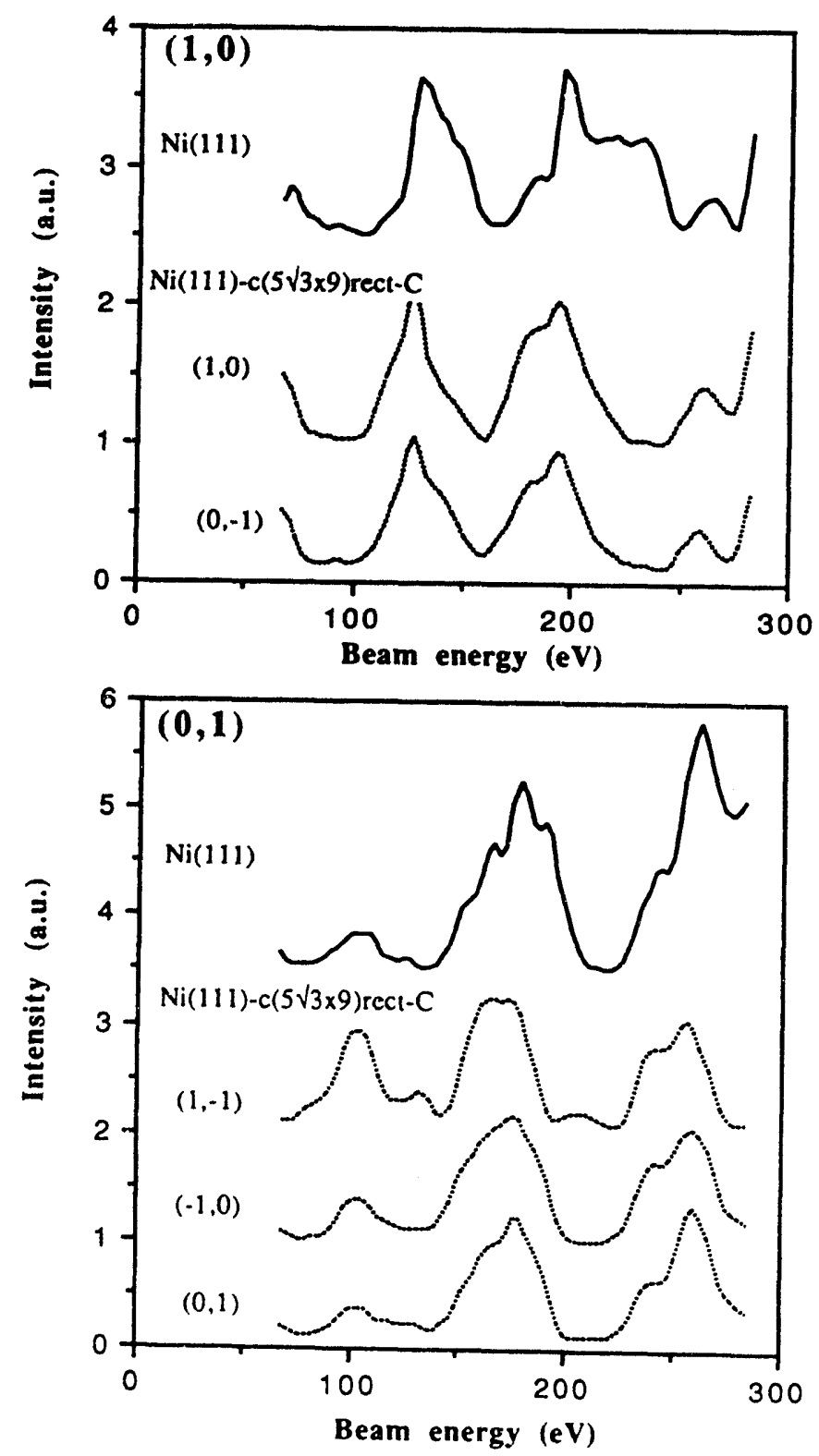

XBL $9311 \cdot 1572$

Figure 6.5: IV curves of the substrate spots $(a)(1,0)$ and (b) $(0,1)$. The absolute intensity of these spots in the $\mathrm{Ni}(111)-\mathrm{c}(5 \sqrt{ } 3 \times 9)$ rect-C structure is about 8 times lower than those of the clean $\mathrm{Ni}(111)$ surface. 


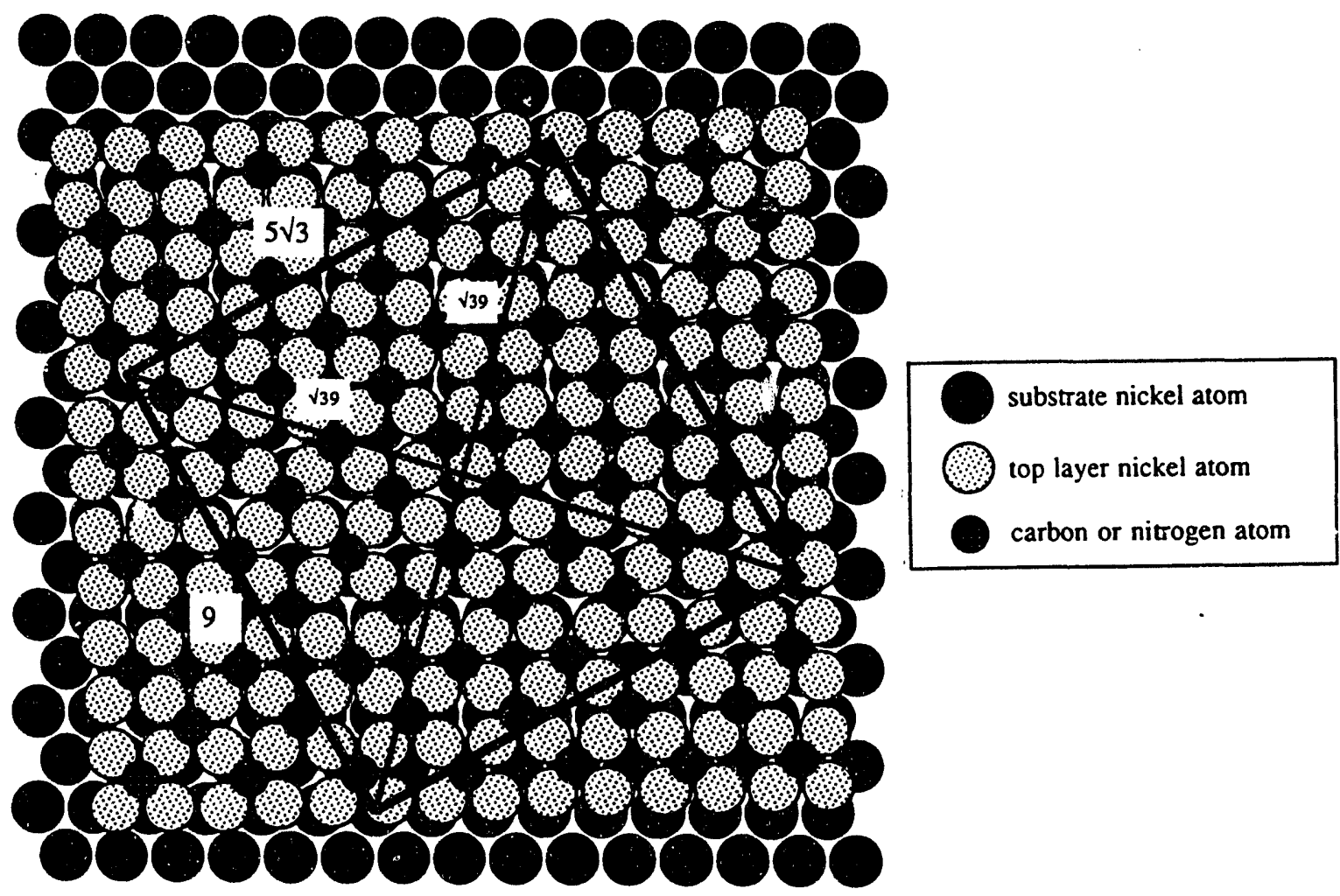

Figure 6.6: Proposed model for the $\mathrm{Ni}(111)-\mathrm{c}(5 \sqrt{ } 3 \times 9)$ rect-C and $-\mathrm{N}$ structures, with the unreconstructed substrate bared for visibility. This schematic shows only one reconstructed metal layer, and does not include individual atomic relaxations which likely exist, as in the $\mathrm{Ni}(100)-(2 \times 2)-2 \mathrm{C}$ and $\mathrm{N}$ structures. The heavily outlined coincidence unit cell is not quite square, and its center is equivalent to its corners.

this surface.

\subsubsection{Formation of the $\mathrm{Ni}(111)-\mathrm{c}(5 \sqrt{ } 3 \times 9)$ rect- $N$ structure by decomposi- tion of nitrogen containing molecules}

Molecular nitrogen $\left(\mathrm{N}_{2}\right)$ does not decompose on the $\mathrm{Ni}(111)$ surface. One method to cover a $\mathrm{Ni}(111)$ surface with nitrogen atoms is the bombardment of the surface with $\mathrm{N}_{2}^{+}$ ions produced and accelerated by a sputtering ion gun. This method partly disorganizes surface atoms, so that annealing of the surface is necessary to obtain a sharp LEED pattern. This method leads to a mixture of $c(5 \sqrt{3} \times 9)$ rect structure and of a slightly incommensurate ' $(2 \times 6)$ ' structure. No simple LEED pattern was observed. When the surface is bombarded for longer times and annealed, onc produces only the ' $(2 \times 6)$ ' structure. Conrad et al were 
able to form the $\mathrm{c}(5 \sqrt{3} \times 9)$ rect overlayer by decomposing $\mathrm{NO}$ on $\mathrm{Ni}(111)$ [4]. After annealing this surface for 30 minutes in $5 \times 10^{-7}$ torr $\mathrm{H}_{2}$, they obtained the ' $(2 \times 6)$ ' superstructure. It is not clear yet what governs the formation of one or the other structure. We found that one method to produce the $\mathrm{Ni}(111)-\mathrm{c}(5 \sqrt{3} \times 9)$ rect-N structure is to decompose methylamine $\left(\mathrm{CH}_{3} \mathrm{NH}_{2}\right)$ at $570 \mathrm{~K}$. The surface is initially covered with carbon and nitrogen in a 1:1 ratio but after heating the surface above $700 \mathrm{~K}$, carbor. starts to diffuse into the bulk, while nitrogen stays on the surface. After a 1 minute treatment in $10^{-8}$ torr $\mathrm{O}_{2}$ at $700 \mathrm{~K}$ AES shows only nitrogen on the surface. The nitrogen coverage of the surface can be estimated to $\theta=0.4$ monolayer by comparison of the ratio $\mathrm{N}_{380 \mathrm{eV}} / \mathrm{Ni}_{880 \mathrm{eV}}$, in the AES spectrum, to the corresponding ratio measured for $\mathrm{Ni}(111)-\mathrm{c}(4 \times 2)-\mathrm{NO}$, which we have proved recently in a LEED structure analysis to have a coverage of $\theta=0.5$ [12]. This structure is stable up to about $800 \mathrm{~K}$. Above that temperature, nitrogen desorbs as molecules $\left(\mathrm{N}_{2}\right)$ leaving a clean $\mathrm{Ni}(111)-(1 \times 1)$ surface.

\subsubsection{LEED intensities of the $\mathrm{Ni}(111)-\mathrm{c}(5 \sqrt{ } 3 \times 9)$ rect- $\mathrm{N}$ structure}

The Ni(111)-c $(5 \sqrt{3} \times 9)$ rect-N LEED pattern is stable up to $800 \mathrm{~K}$. The same diffraction spots as the ones tracked for the $\mathrm{Ni}(111)-\mathrm{c}(5 \sqrt{3} \times 9)$ rect-C structure were monitored for the nitrogen structure as a function of the electron-beam energy. I-V curves of the $\mathrm{Ni}(111)-\mathrm{c}(5 \sqrt{3} \times 9)$ rect- $\mathrm{N}$ structure are very similar to the ones obtained with $\mathrm{Ni}(111)$ $\mathrm{c}(5 \sqrt{3} \times 9)$ rect-C. As seen in figure $6.7, \mathrm{I}-\mathrm{V}$ curves show strong similarities between the $\mathrm{N}$ and $\mathrm{C}$ structures. Only small shifts of peaks at lower energies allow one to distinguish between these two structures. On $\mathrm{Ni}(100)$, carbon and nitrogen also behave very similarly, leading to the same type of surface reconstruction [13]. To our knowledge, I-V curves for the $\mathrm{Ni}(100)-(2 \times 2)-2 \mathrm{~N}$ structure have not been measured. The close structural similarities $[13,14,15]$ would be consistent with similarity in I-V curves seen in figure 6.7. SEXAFS measurements have provided precise nearest-neighbor bond distances, showing that the $\mathrm{Ni-N}$ distance $(1.89 \AA)[14]$ is slightly larger than the Ni-C distance (1.82 $\AA$ ) [15]. Similar SEXAFS experiments should also be performed on the $\mathrm{Ni}(111)-\mathrm{c}(5 \sqrt{3} \times 9)$ rect-C and $\mathrm{Ni}(111)-\mathrm{c}(5 \sqrt{3} \times 9)$ rect-N structures. 

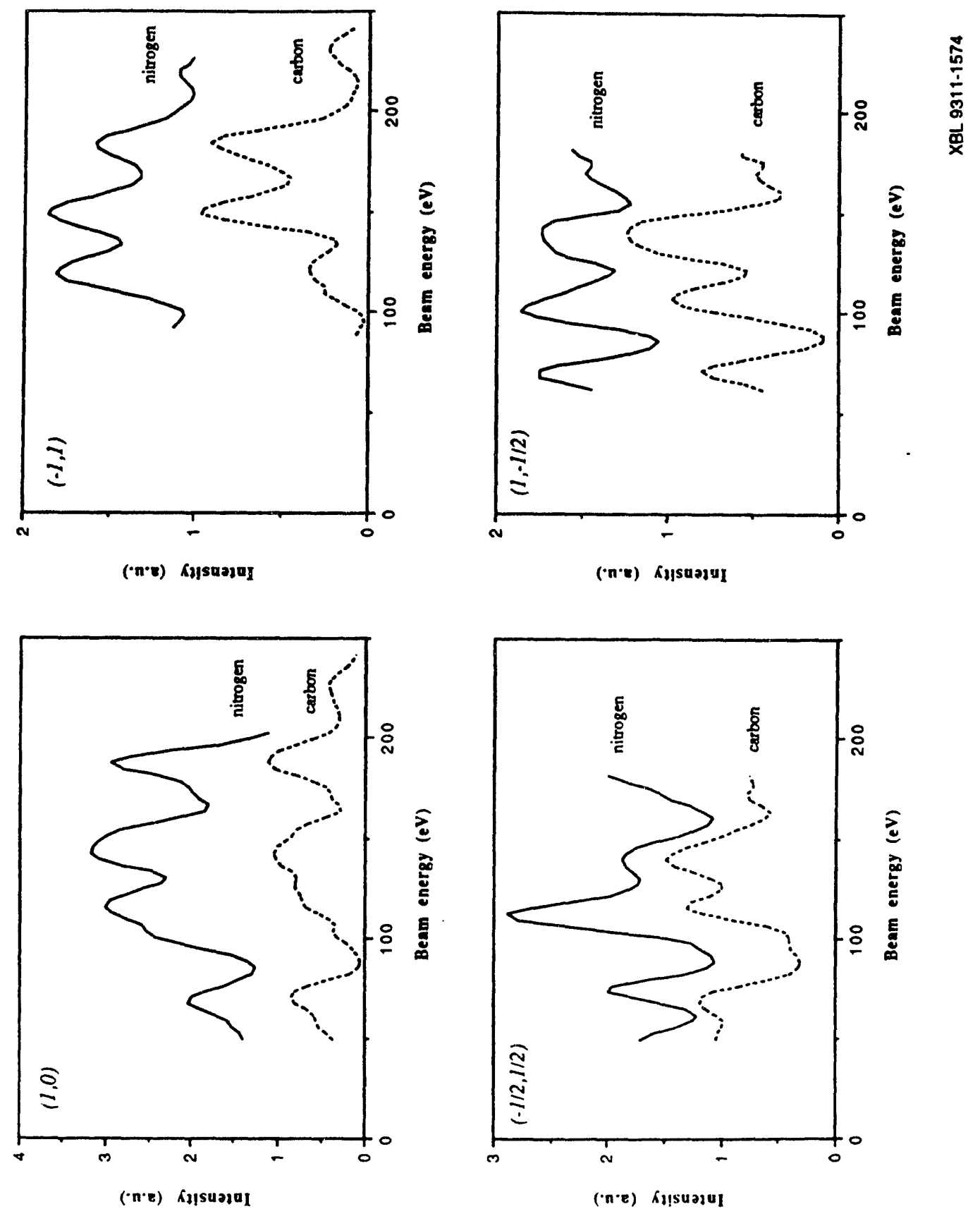

Figure 6.7: Comparison of $\mathrm{I}-\mathrm{V}$ curves for $\mathrm{Ni}(111)-\mathrm{c}(5 \sqrt{ } 3 \times 9)$ rect-C and $-\mathrm{N}$, using the notation of figure 6.3 . 


\subsubsection{Formation of $\mathrm{Ni}(111)-\mathrm{c}(5 \sqrt{ } 3 \times 9)$ rect-S by $\mathrm{H}_{2} \mathrm{~S}$ decomposition}

This experiment was carried out in a chamber equipped with a scanning tunneling microscope, where it was not possible to measure LEED I-V curves at normal incidence because of the limited degrees of freedom of the manipulator. The $c(5 \sqrt{3} \times 9)$ rect structure can be produced by heating to $570 \mathrm{~K}$ the $\mathrm{Ni}(111)-(2 \times 2)-\mathrm{S}$ structure obtained from $\mathrm{H}_{2} \mathrm{~S}$ decomposition at $300 \mathrm{~K}$. The structure is stable up to at least $1100 \mathrm{~K}$ which is much higher than for the carbon $(690 \mathrm{~K})$ and nitrogen $(800 \mathrm{~K})$ structures. The Alifer spectrum shows only $S$ on the surface. The coverage of this structure was estimated at $\theta=0.23$ by ${ }^{35} \mathrm{~S}$ radio tracing experiments [1] which is smaller than the coverage that we estimated for the carbon $(\theta=0.5)$ and nitrogen $(\theta=0.4)$ structures. STM imaging of the surface showed no identifiable atomic features. The sulfur could be removed from the surface only by cycles of $\mathrm{Ar}^{+}$sputtering.

\subsection{Formation of the Ni(111)-'(2x6)'-N Structure}

As we mentioned earlier, when a clean $\mathrm{Ni}(111)$ surtace is bombarded with $\mathrm{N}_{2}^{+}$ions $\left(10^{-6}\right.$ torr $\mathrm{N}_{2}, 5$ minutes, $\left.300 \mathrm{eV}\right)$ and then annealed for few minutes at $750 \mathrm{~K}$, one observes an ordered LEED pattern that has been attributed in the literature to a $(2 \times 6)$ overlayer of nitrogen on the $\mathrm{Ni}(111)$ surface $[4,6]$. The Auger $\mathrm{N}_{380 \mathrm{eV}} / \mathrm{Ni}_{880 \mathrm{eV}}$ ratio indicates a nitrogen coverage of about 0.5 monolayer. This surface structure is stable up to $800 \mathrm{~K}$. Above that temperature, nitrogen desorbs from the surface as molecular $\mathrm{N}_{2}$.

As in the case of the $\mathrm{Ni}(111)-\mathrm{c}(5 \sqrt{3} \times 9)$ rect carbon, nitrogen and sulfur structures, it was possible to find a region of the surface with only one domain orientation, as shown in figure 6.8. It is noticeable in these pictures that the distance between diffraction spots is not exactly $1 / 6$ of the distance between two substrate spots, unlike the case of a true (2x6) superstructure. This indicates that the real space unit cell of the superstructure has dimensions $(2 \times L)$ where $L$ is not commensurate with the Ni(111) substrate or where $L$ is randomly distributed with an average value close to 6 . Pictures of the similar pattern obtained with sulfur shows the same feature.

In the case of sulfur, the LEED pattern was interpreted as a $(5 \sqrt{3} \times 2)$ rect superstructure. Three models were proposed in the literature to explain the LEED pattern obtained $[1,16,17]$. SEXAFS experiments however, performed by two independent research 


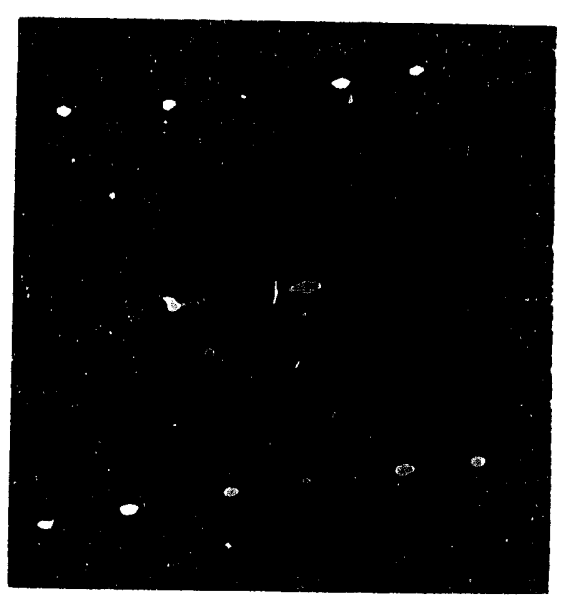

$25 \mathrm{eV}$

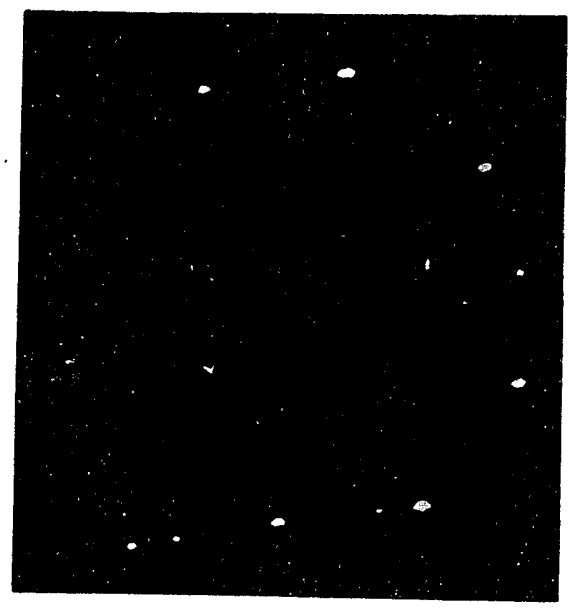

$73 \mathrm{eV}$

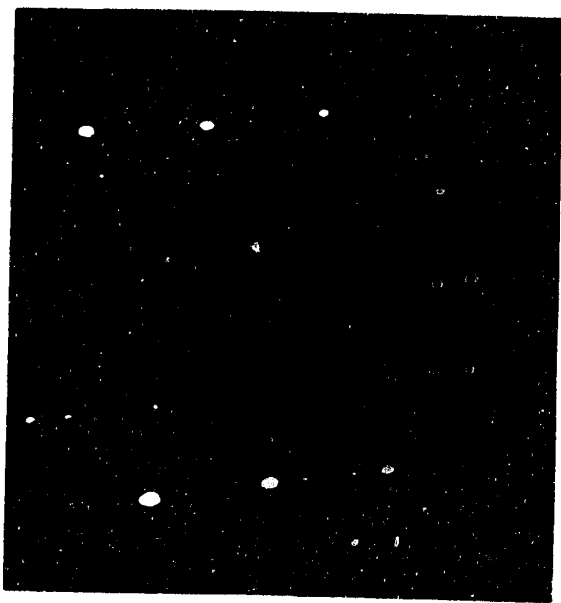

$10 f$ iV

Figure 6.3: LEED patterns at $25 \mathrm{eV}$ (a), $73 \mathrm{eV}(\mathrm{b})$ and $106 \mathrm{eV}$ (c) for the $\mathrm{Ni}(111))^{-}(2 \times 6)^{\prime}-\mathrm{N}$ structure (single domain). Notice that the overlayer spots are not equidistant. 
groups $[7,8]$, support the reconstruction of the $\mathrm{Ni}(111)$ surface in a pseudo- $\mathrm{Ni}(100)$ overlayer, with the sulfur atoms sitting in the four-fold hollow sites, strongly bonded to the first two nickel layers.

If this is also true for nitrogen, one can easily imagine the top nickel and nitrogen atoms, with a $\mathrm{Ni}(100)-(2 \times 2)$ geometry, on top of the $\mathrm{Ni}(111)$ substrate, cf. figure 6.9. The lattice of the (100)-like overlayer can relatively easily arrange its rows of atoms parallel to the rows of atoms of the $\mathrm{Ni}(111)$ substrate, while in the perpendicular direction the match of atoms is more difficult, leading to the incommensurability of the two lattices in that direction (figure 6.9). When nitrogen is st'bstituted for sulfur, one expects to observe some changes in the $\mathrm{Ni}-\mathrm{Ni}$ bond lengths of the overlayer. It is not surprising therefore that the overlayer expands or contracts slightly in the direction where it is not strongly anchored to the surface. This is how we explain the slight differences observed for the ' $(2 \times 6)$ '- $N$ and $(2 \times 5 \sqrt{3})$ rect-S superstructures.

\subsection{Molecular Adsorption and Decomposition on the $\mathrm{Ni}(111)-c(5 \sqrt{ } 3 \times 9)$ rect-C Superstructure}

The adsorption of $\mathrm{CO}[11]$, the reaction of $\mathrm{CO}+\mathrm{H}_{2}$ [18] and the adsorption of $\mathrm{CH}_{3} \mathrm{CN}$ [19] on the $\mathrm{Ni}(111)-\mathrm{c}(5 \sqrt{3} \times 9)$ rect-C surface were studied by TDS and HREELS. The main observation about $\mathrm{CO}$ adsorption was a decrease in the binding energy of CO to the surface by $4.5 \mathrm{kcal} / \mathrm{mole}$. The same effect was observed for acetonitrile $\left(\mathrm{CH}_{3} \mathrm{CN}\right)$ with a decrease of the binding energy by $3 \mathrm{kcal} / \mathrm{mol}$ [19]. HREELS spectra show some small changes in the vibrational frequencies of the adsorbed molecules : there is a shift of the CO stretching frequency from $1863 \mathrm{~cm}^{-1}$ on clean $\mathrm{Ni}(111)$ to $1945 \mathrm{~cm}^{-1}$ on carbided $\mathrm{Ni}(111)$, related to the weaker bonding of the molecules to the surface.

When $\mathrm{CO}$ and $\mathrm{H}_{2}$ were introduced together at room temperature on the $\mathrm{Ni}(111)$ $(5 \sqrt{3} \times 9)$ rect-C surface [18], some oxyhydrocarbonated surface species $\left(\mathrm{H}_{2} \mathrm{CO}, \mathrm{HCO}\right.$ or $\mathrm{HCO}_{2}$ ) were detected by HREELS; this implies the formation of $\mathrm{C}-\mathrm{H}$ or $\mathrm{O}-\mathrm{H}$ bonds, without breaking the $\mathrm{CO}$ bonds. Such species are not seen when the same experiment is performed on a clean $\mathrm{Ni}(111)$ surface.

Our observation that the reconstructed $\mathrm{Ni}(111)$ surface can selectively break $\mathrm{C}-\mathrm{H}$ and N-H bonds without breaking $\mathrm{C}-\mathrm{N}$ or $\mathrm{C}-\mathrm{C}$ bonds seems to indicate that the weaker 
a)

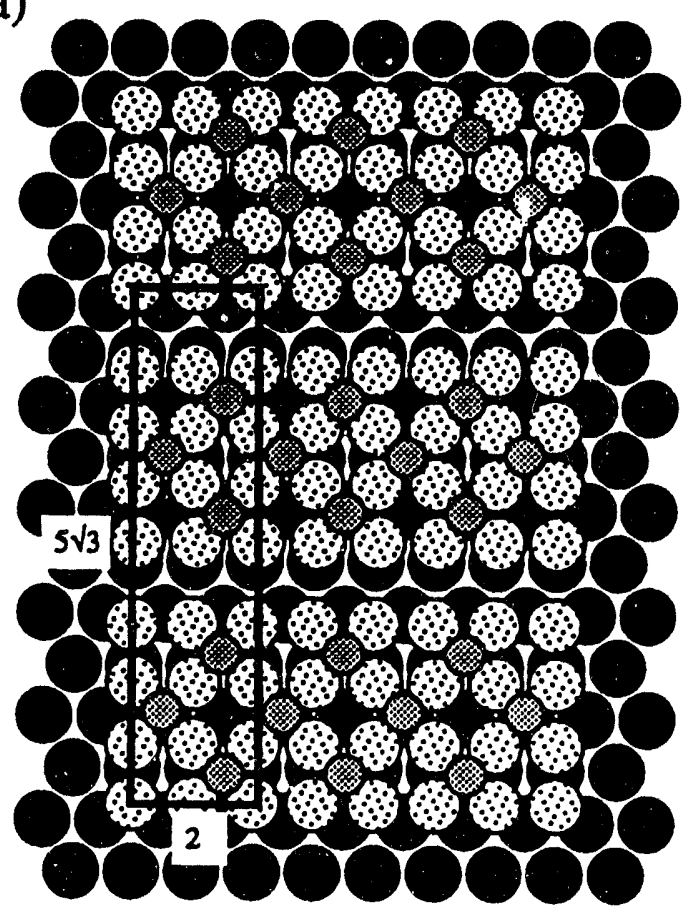

b)

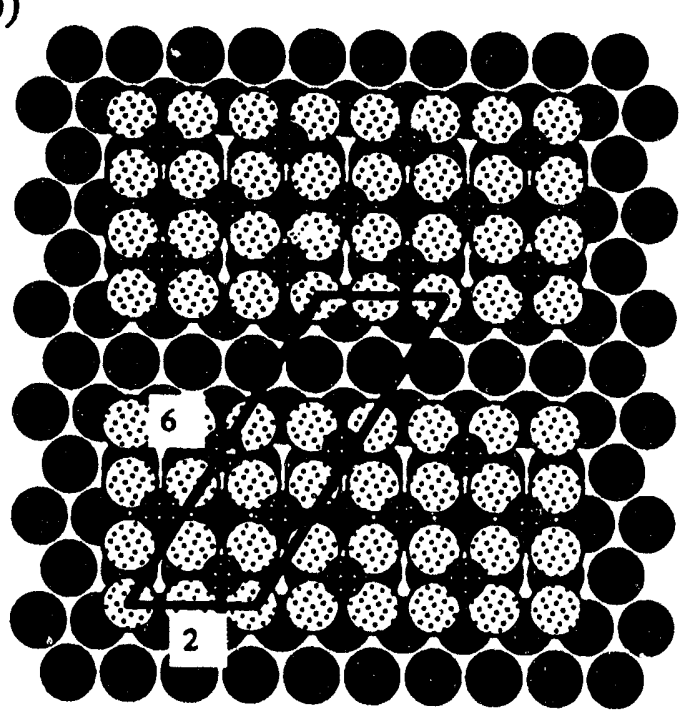

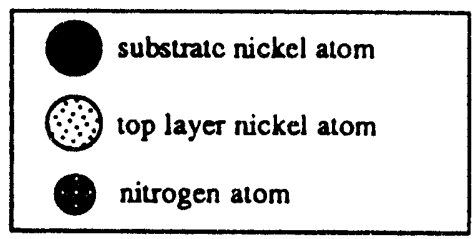

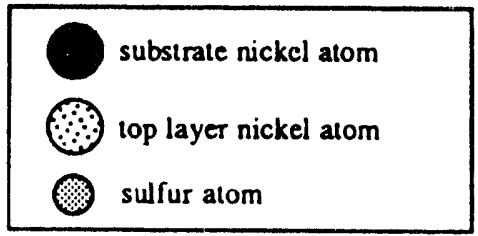

$\mathrm{Ni}(111)-(2 \times 6)-\mathrm{N}$

\section{$\mathrm{Ni}(111)-(5 \sqrt{3} \times 2)$ rect-S}

Figure 6.9: Proposed model for the Ni(111)- $(5 \sqrt{ } 3 \times 2)$ rect-S overlayer (a) and Ni(111)-'(2x6)'$\mathrm{N}$ overlayer (b), shown as in figure 6.6. 
bonding of adsorbates to this surface prevents the breaking of the molecular skeleton but still allows the C-H and N-H bond chemistry to take place.

These observations suggest that the reconstruction of the $\mathrm{Ni}(111)$ surface, by weakening the surface-adsorbate bond, allows more reactions between adsorbates to take place on the surface.

\subsection{Conclusion}

We have reported LEED measurements which were carried out on the $\mathrm{Ni}(111)$ $c(5 \sqrt{3} \times 9)$ rect-C and $\mathrm{Ni}(111)-\mathrm{c}(5 \sqrt{3} \times 9)$ rect- $\mathrm{N}$ structures. The almost perfect match of the I-V curves collected for these two surfaces shows that they have almost the same structure. The examination of the intensity of the most intense diffraction spots, which are located on a mesh whose dimensions are very close to a $\mathrm{Ni}(100)-(2 \times 2)$ superstructure, and their similarity to the I-V curves of the $\mathrm{Ni}(100)-(2 \times 2)-2 \mathrm{C}$ structure supports the model of adsorbate induced reconstruction of the $\mathrm{Ni}(111)$ surface to an almost square (100) like nickel superstructure, with the adsorbed atoms in four-fold hollow sites. A full dynamical LEED analysis, although not impossible, would be rather complex. SEXAFS experiments on these surfaces would be useful to confirm our LEED observations and to determine some of the structure parameters. We have also compared the $\mathrm{Ni}(111)-{ }^{-}(2 \times 6)^{\prime}-\mathrm{N}$ and the $\mathrm{Ni}(111)-(5 \sqrt{3} \times 2)$ rect-S LEED patterns, which we believe to be due to similar surface reconstructions. Based on SEXAFS results, which for the $\mathrm{Ni}(111)-(5 \sqrt{3} \times 2)$ rect-S structure support the reconstruction of the surface in a pseudo- $\mathrm{Ni}(100)$ superstructure, we have proposed a model for both structures explaining the incommensurability in one direction. 


\subsection{References}

[1] M. Perdereau, and J. Oudar, Surf. Sci., 20 (1970) 80.

[2] J.J. McCarroll, T. Edmonds, and R.C. Pitkethly, Nature, 223 (1969) 1262.

[3] J.P. Coad, and J.C. Rivière, Surf. Sci., 27 (1971) 379.

[4] H. Conrad, G. Ertl, J. Küppers, and E.E. Latta, Surf. Sci., 50 (1975) 296.

[5] J.C. Hemminger, E.L. Muetterties, and G.A. Somorjai, J. Am. Chem. Soc., 101 (1979) 62.

[6] C.W. Seabury, T.N. Rhodin, R.J. Purtell, and R.P. Merrill, Surf. Sci., 93 (1980) 117.

[7] D.R. Warburton, P.L. Wincott, G. Thornton, F.M. Quinn, and D. Norman, Surf. Sci., $211 / 212(1989) 71$.

[8] Y. Kitajima, T. Yokoyama, T. Ohta, M. Funabashi, N. Kosugi, and H. Kuroda, Surf. Sci., 214 (1989) L261.

[9] L. Ruan, I. Stengaard, F. Besenbacher, and E. Laegsgaard, submitted to Phys. Rev. Lett.

[10] J.H. Onuferko, D.P. Woodruff, and B.W. Holland, Surf. Sci., 87 (1979) 357.

[11] Y. Gauthier, R. Baudoing-Savois, K. Heinz, and H. Landskron, Surf. Sci., 251/252 (1991) 493.

[12] J.C. Bertolini, and B. Tardy, Surf. Sci., 102 (1981) 131.

[13] N. Materer, A. Barbieri, D.E. Gardin, J.D. Batteas, M.A. Van Hove, and G.A. Somorjai, Phys. Rev. B, 48 (1993) 2859.

[14] W. Daum, S. Lehwald, and H. Ibach, Surf. Sci., 178 (1986) 528.

[15] M. Bader, C. Ocal, B. Hillert, J. Haase, and A.M. Bradshaw, Phys. Rev. B, 35 (1987) 5900.

[16] L. V'venzel, D. Arvanitis, W. Daum, H.H. Rotermund, J. Stöhr, H. Baberschke, and H. Ibach, Phys. Rev. B, 36 (1987) 7689. 
[17] T, Edmonds, J.J. McCarroll, and R.C. Pitkethly, J. Vas. Sci. Technol., 8 (1971) 68.

[18] W. Erley, and H. Wagner, J. Catalysis, 53 (1978) 287.

[19] J.C. Bertolini, and B. Imelik, Surf. Sci., 80 (1979) 586.

[20] C.M. Friend, E.L. Muetterties, and J.L. Gland, J. Phys. Chem., 85 (1981) 3256. 


\section{Chapter 7}

\section{Liquid Phase Hydrogenation over Well-Characterized Surfaces}

\subsection{Introduction}

Liquid phase catalytic reactions, such as the hydrogenation of olefins or nitriles, are very important in the chemical industry, particularly for the synthesis of complex pharmaceitical molecules. All these reactions require to work close to room temperature. One important goal of research in catalysis is to learn how to prepare catalysts that are able to catalyse the hydrogenation of a given molecule, with a selectivity as close as possible to $100 \%$. Today, very little is known about the influence of the structure and composition of a catalyst on its reactivity or selectivity for a liquid phase reaction. The techniques of surface science, which have been successful in the elucidation of the mechanisms and adsorbed intermediates in the gas phase hydrogenation of hydrocarbons [1] should also be applied to the study of liquid phase catalytic reactions.

In chapter 2 , we have described the design of a reaction cell, that was built in our laboratory, for the study of liquid phase catalytic reactions on well-characterized surfaces. This novel apparatus was tested with the hydrogenation of cyclohexene to cyclohexane on a polycrystalline foil, and then with the hydrogenation of 1-hexene to $n$-hexane. These results are reported in the following sections. 


\subsection{Cyclohexene Hydrogenation}

The hydrogenation of cyclohexene to cyclohexane has been studied on various platinum catalysts both in the gas phase [2] and the liquid phase [3, 4]. Hydrogenation rates on model surfaces ( $\mathrm{Pt}$ foil and $\mathrm{Pt}(223)$ ) have also been reported in the literature for a wide range of gas pressures [5]. One of the main difficulties of working with cyclohexene is due to the rather stable cyclohexene epoxide which forms when cyclohexene is in contact with air. It is a poison to the catalyst. On a $1 \mathrm{~cm}^{2}$ surface area catalyst, it is of crucial importance to eliminate these contaminants. To achieve that goal, the $99.7 \%$ pure cyclohexene is treated with $\mathrm{CaH}_{2}$ at reflux for two hours. The cyclohexene is then conserved with an excess of $\mathrm{CaH}_{2}$ under an argon atmosphere. Cyclohexene $(40 \mathrm{ml})$ is introduced in the glass manifold (see figure 2.14) with a syringe. After a series of 4 freeze-pump-thaw cycles, the cyclohexene is evaporated in the second compartment, where it is heated up to the reaction temperature. At the same time, the $0.1 \mathrm{~mm}$ thick platinum foil is cleaned by argon sputtering and oxygen treatment. The cleanliness of the foil is checked by Auger electron spectroscopy. The platinum foil is then transfered in vacuum into the reaction cell and $32.5 \mathrm{ml}$ of cyclohexene are introduced in the reaction cell, pushed by a pressure of Helium purified by circulating in a liquid nitrogen bath. The hydrogen pressure in the cell is adjusted to the desired reaction pressure. In this series of experiments, we use a total pressure of $1.5 \mathrm{~atm}$. The liquid recirculation pump is then turned on, which produces a jet of liquid impinging on the sample surface. This sets the starting time of the reaction. The progress of the reaction is monitored by gas chromatography (HP5790A). We use 4 $\mathrm{ft}$ of a $1 / 8$ in. O.D. stainless steel column filled with TCEQ to separate the cyclohexane from the cyclohexene. Because of the very large difference between the surface area of the cyclohexane peak and the cyclohexene peak due to the large excess of cyclohexene, we added $2 \mu \mathrm{l}$ of $\mathrm{n}$-hexane and methylcyclopentane to the $40 \mathrm{ml}$ of cyclohexene, which we use as internal standards. In figure 7.1, we show a typical chromatogram that we obtain. During the analysis, we measure both the ratio cyclohexane/methylcyclopentane and the ratio cyclohexane/ $\mathrm{n}$-hexane. A calibration of our analysis was made by adding a determined mass of cyclohexane (weighted with an analytical balance with a precision of $0.1 \mathrm{mg}$ ) to the $32.5 \mathrm{ml}$ of cyclohexene. 


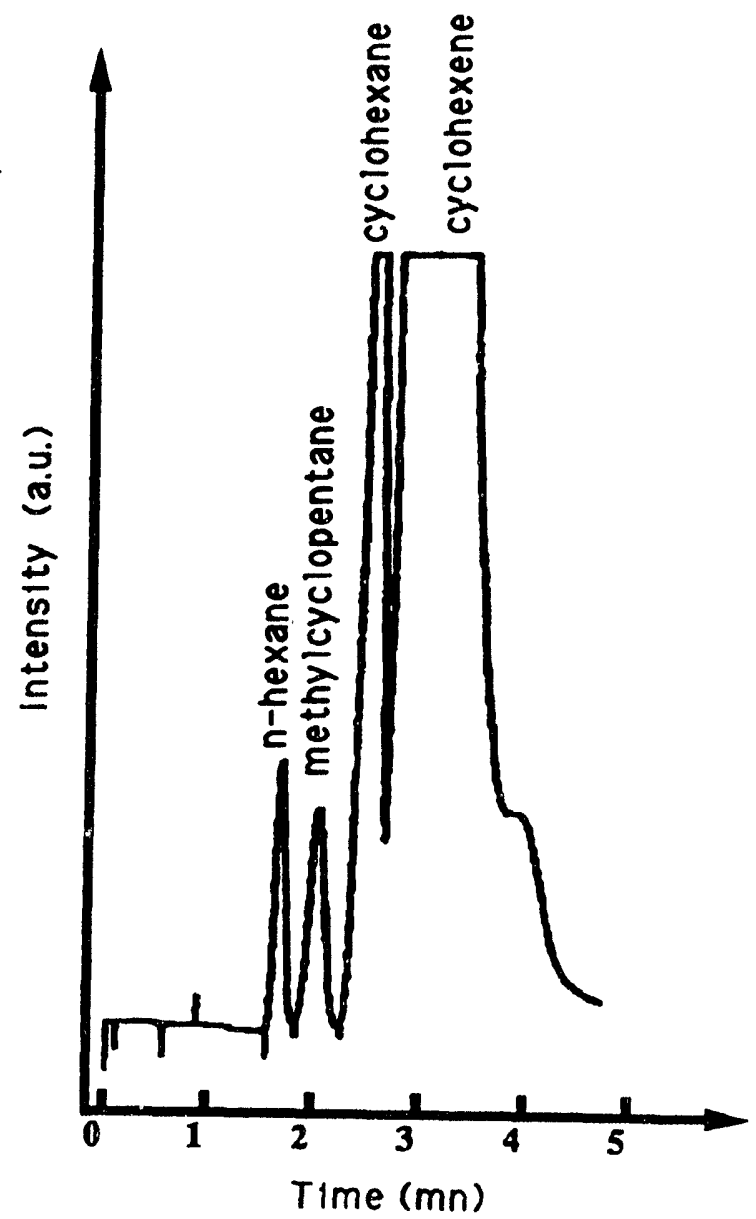

XBL 9311-1576

Figure 7.1: A typical chromatogram during the analysis of the formation of cyclohexane in cyclohexene. Added n-hexane and methylcyclopentane are used as internal standards. 


\subsubsection{Reaction rate at $50^{\circ} \mathrm{C}$}

The cyclohexane accumulation curve for a reaction temperature of $50^{\circ} \mathrm{C}$ and a jet velocity of $5.8 \mathrm{~m} / \mathrm{s}$ is shown on figure 7.2. A blank experiment, reported on the same graph, was performed by running the reaction on a carbon contaminated platinum foil. The total conversion of cyclohexene to cyclohexane after a reaction time of 80 minutes is $2.8 \times 10^{-3} \mathrm{~mol} \%$. The calculated turnover rate for these conditions, assuming that $10^{15}$ surface platinum atoms are working, is 1.1 molecule of cyclohexane/site/s. This number is about an order of magnitude lower than the one reported by Madon et al [3] for the liquid phase hydrogenation of cyclohexene on a supported platinum catalyst, but it is close to the turnover rate reported by others [4]. In figure 7.3, we show the dependence of the reaction rate on the liquid jet velocity. At low jet velocities, the rate increases with the jet velocity. At jet velocities greater than $4 \mathrm{~m} / \mathrm{s}$, the rate reaches a constant value. This behaviour is typical of mass transfer limitations. In the low jet velocity regime, the rate of cyclohexane formation is limited by hydrogen diffusion in the boundary layer at the liquid-solid interface. The rate measured in this circumstance corresponds to the flux of hydrogen from the liquid to the platinum surface. At higher jet velocities, the rate measured is no longer diffusion limited and therefore, is a measurement of the pure reaction kinetics.

This example illustrates the importance of having a high enough liquid velocity at the sample surface in order to be able to measure kinetic data of liquid phase catalytic reactions and to avoid mass transfer limitations due to diffusion of reactants or products in the liquid phase.

After the reaction, when the sample is back in UHV, Auger spectra show that the surface is covered by a large amount of carbon species, mostly cyclohexene which can be desorbed from the surface and examined by thermal desorption spectroscopy.

\subsubsection{Reaction rate as a function of temperature}

The rate of the hydrogenation of cyclohexene to cyclohexane was also measured at $40^{\circ} \mathrm{C}$ and $60^{\circ} \mathrm{C}$, in the same conditions as at $50^{\circ} \mathrm{C}$. In figure 7.4 , the results are shown in a Arrhenius plot and compared to the ones obtained with a supported Pt catalyst [3]. The activation energy for the hydrogenation of cyclohexene to cyclohexane on a polycrystalline $\mathrm{Pt}$ foil is estimated to be $6 \mathrm{kcal} / \mathrm{mol}$, which is close to the activation energy estimated by Madon et al, for a supported Pt catalyst. 


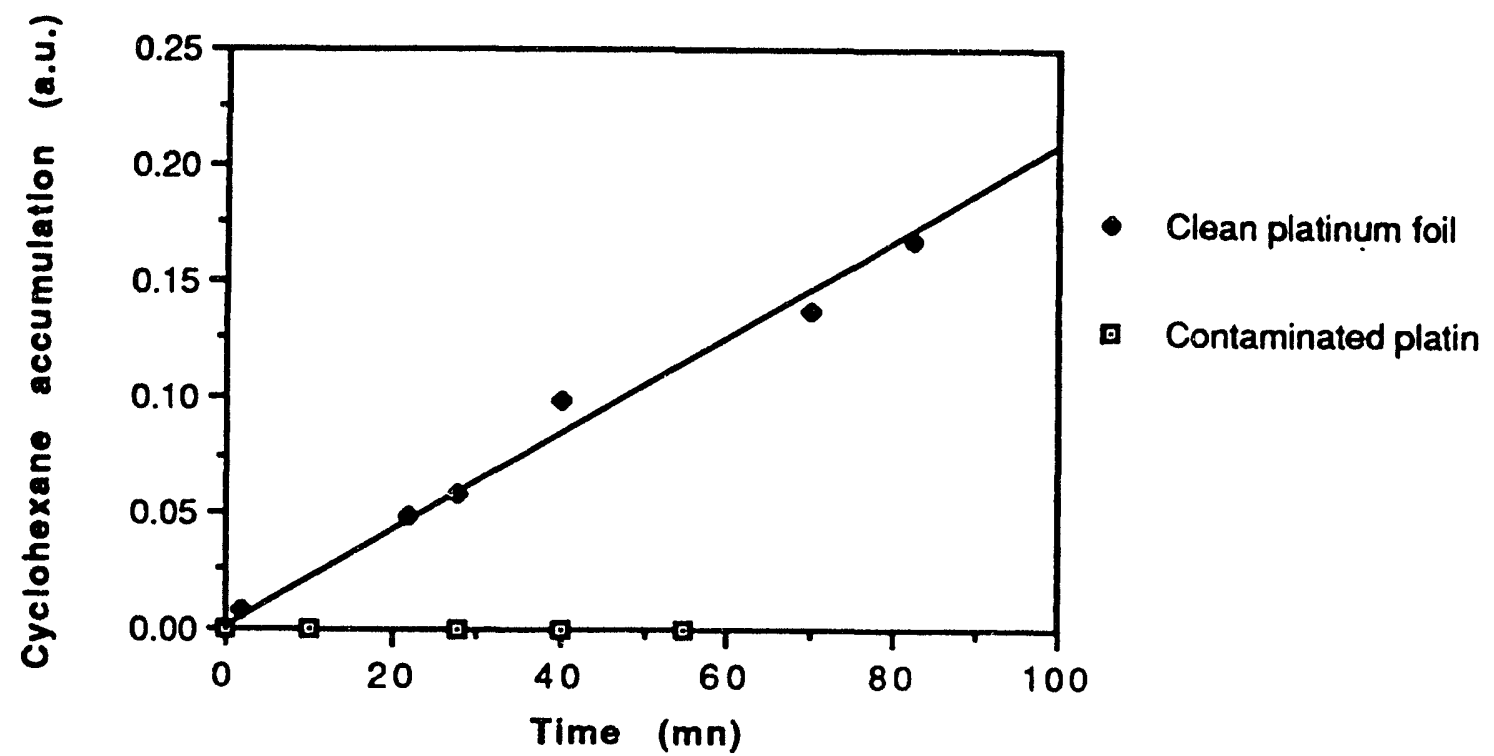

XBL 9311-1577

Figure 7.2: Cyclohexane accumulation curve during the reaction of $32.5 \mathrm{ml}$ of cyclohexene on a $1 \mathrm{~cm}^{2}$ clean platinum foil (a) and on a carbon contaminated platinum foil (b) at $\mathrm{T}=323$ $\mathrm{K}, \mathrm{P}_{\mathrm{H}_{2}}=1.5 \mathrm{~atm}$, Jet Velocity $=5.8 \mathrm{~m} / \mathrm{s}$. 


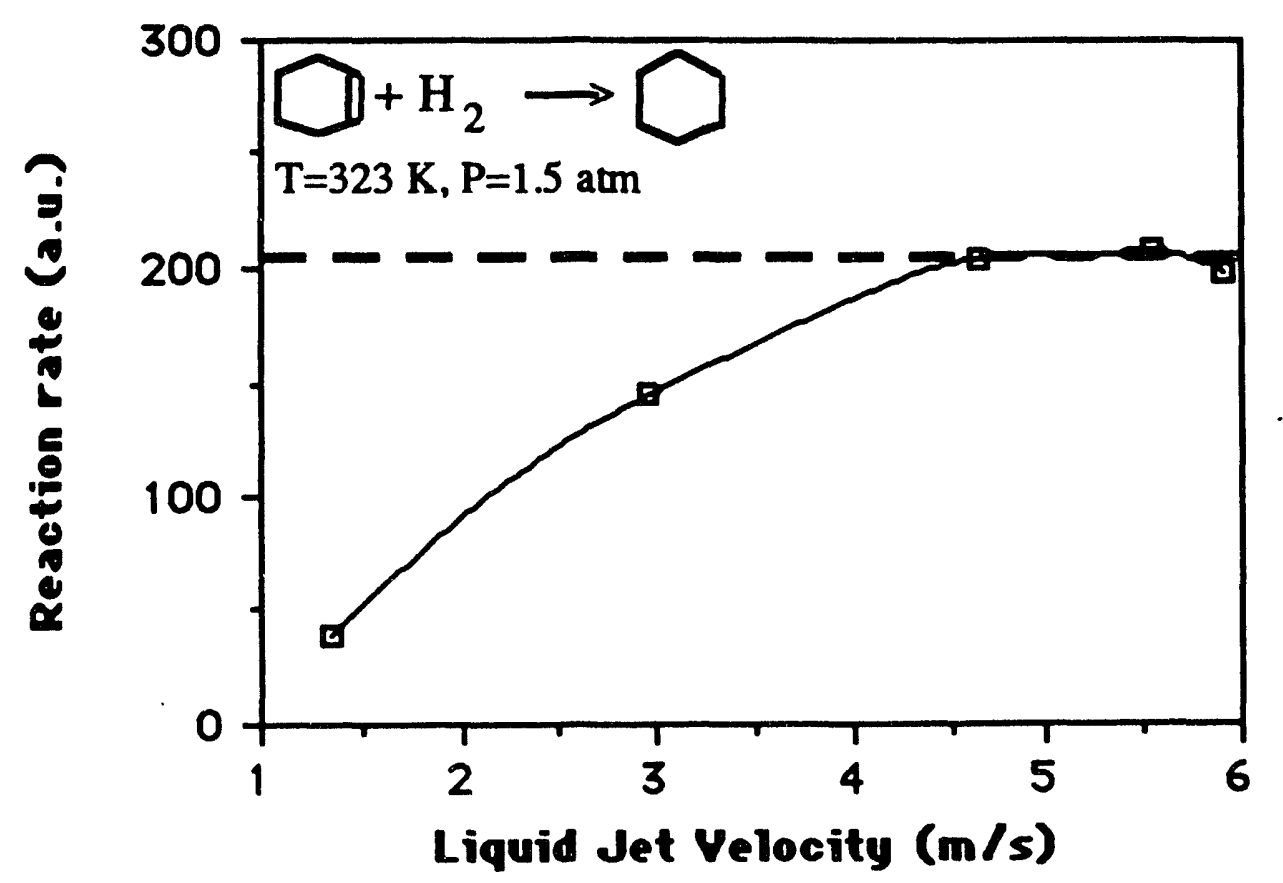

XBL 9311-1578

Figure 7.3: Cyclohexene hydrogenation reaction rate versus liquid jet velocity at $\mathrm{T}=323$ $\mathrm{K}$ and $\mathrm{P}_{\mathrm{H}_{2}}=1.5 \mathrm{~atm}$. In the low jet velocity regime, the rate of cyclohexane formation is limited by hydrogen diffusion in the boundary layer at the liquid-solid interface. The rate measured in this circumstance corresponds to the flux of hydrogen from the liquid to the platinum surface. At higher jet velocities, the rate measured is no longer diffusion limited and therefore, is a measurement of the pure reaction kinetics. 


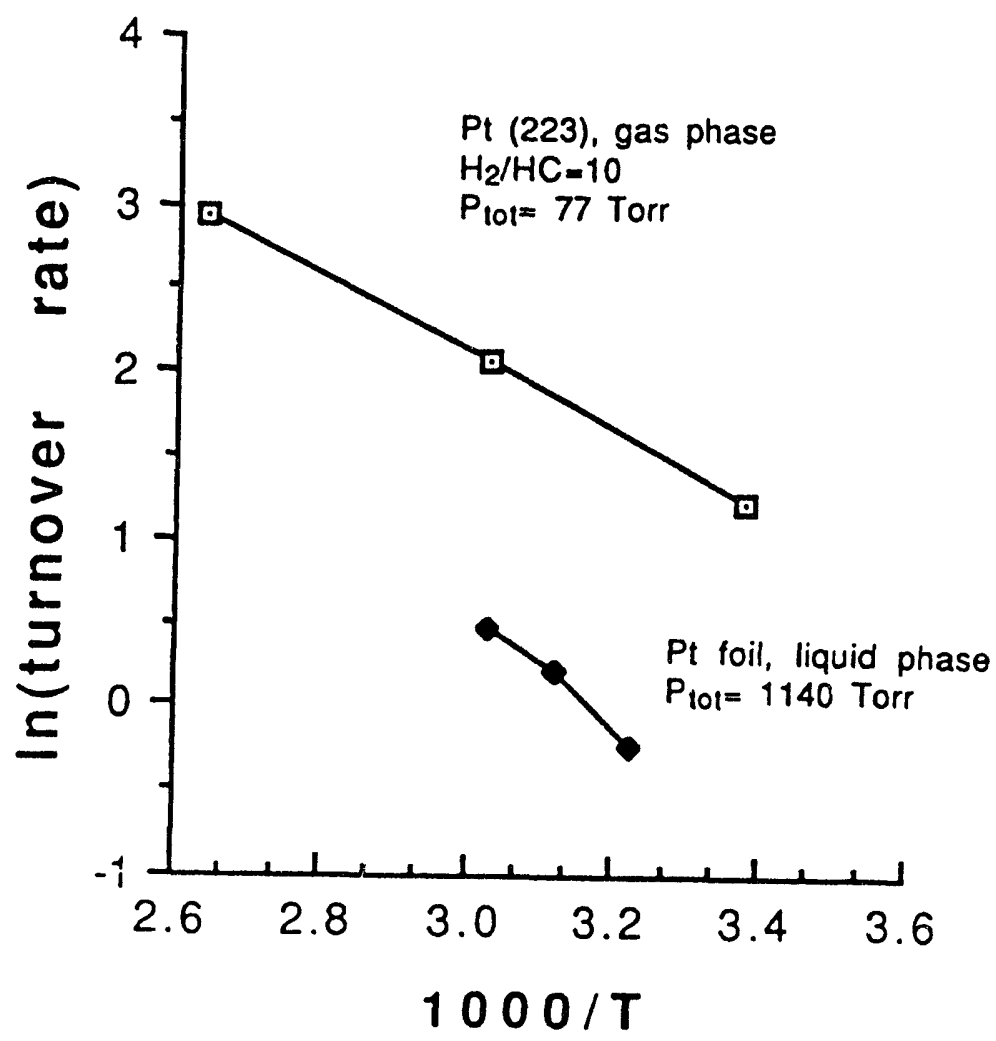

Figure 7.4: Arrhenius plot of $\ln ($ rate) vs $1000 / T$ for cyclohexene hydrogenation over (a) a $\mathrm{Pt}(223)$ crystal face in the gas phase [5], and (b) over a $\mathrm{Pt}$ foil in the liquid phase [this work]. 
The main difference that we find with the results obtained with a supported catalyst is in the absolute value of the reaction rate. A partial contamination of our surface, which is possible because of its very low surface area, could be the explanation to our low rate. One other explanation would be the underestimation of the number of active sites by the methods which are used to determine the number of metallic sites on supported catalyst. However, when Davis and Somorjai [5] compared the gas phase cyclohexene hydrogenation rate on $\mathrm{Pt}(223)$ and supported $\mathrm{Pt}$ catalyst, they did not reported any discrepancies between the two rates. A third explanation could be that a large proportion of the cyclohexane that is made evaporates in the gas phase, and therefore would not been detected during the analysis of the liquid. Hence our rate would be underestimated. But when we calculate the relative amount of cyclohexane (gas) we find that, at $60^{\circ} \mathrm{C}$, no more than $10 \%$ of.the total cyclohexane should be in the gas phase. Moreover, if we had a significant evaporation of cyclohexane, we would see drastic differences between the amount of cyclohexane detected at $40^{\circ} \mathrm{C}$ and that at $60^{\circ} \mathrm{C}$. In conclusion, we think that a partial contamination of the surface by residual oxides is possible and can explain our low reaction rate.

\subsection{1-Hexene Hydrogenation}

The hydrogenation of 1-hexene was studied in the same conditions as the hydrogenation of cyclohexene. We started from $99.5 \%$ pure 1-hexene (Aldrich) that we treated with $\mathrm{CaH}_{2}$ before introduction in the glass manifold. The reaction was studied in the exact same conditions as for the hydrogenation of cyclohexene, except that the 1-hexene was dissolved in octane (Fischer Scientific, $>99 \% \mathrm{GC}$ ). We used $50 \mathrm{ml}$ of octane per $5 \mathrm{ml}$ of 1-hexene.

In figure 7.5 , we report the reaction rate measured as a function of the liquid jet velocity $\left(\mathrm{P}=1.5 \mathrm{~atm}\right.$ and $\left.\mathrm{T}=50^{\circ} \mathrm{C}\right)$. This curve shows that the measured rate increases with jet velocity, even at the highest velocities. This indicates that the hydrogenation is always diffusion limited. We then attempted to increase the hydrogen pressure up to 2.0 atm, but even at this pressure the rcaction is diffusion controlled. This is understandable since the hydrogenation of linear olefins are known to be faster than cyclic ones (such as cyclohexene) on a Pt catalyst. In the case of cyclohexene, we showed that we need to use the highest jet velocities, to not be limited by hydrogen diffusion.

This result does not provide any really useful information on the hydrogenation of 


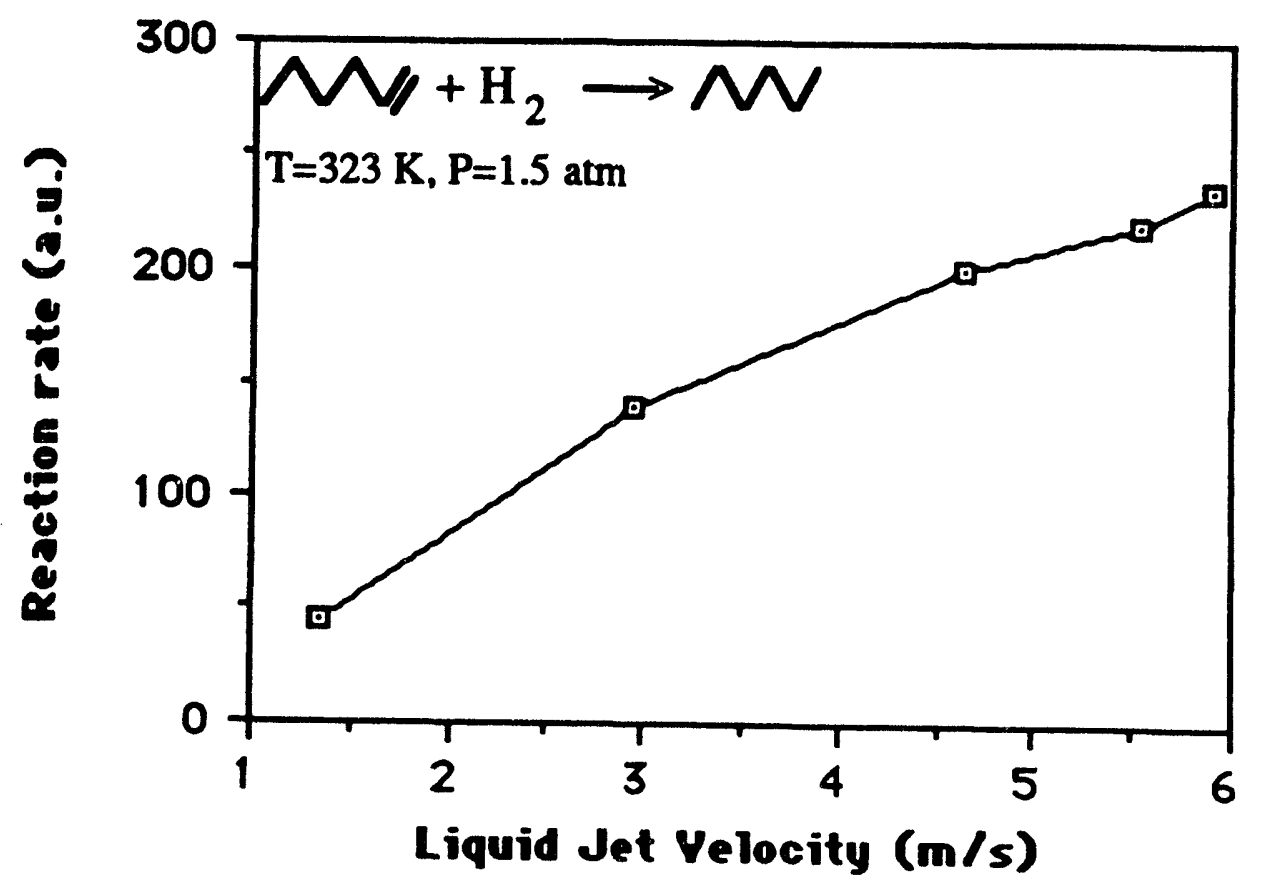

XBL 9311-1579

Figure 7.5: 1-hexene hydrogenation reaction rate versus liquid jet velocity at $\mathrm{T}=323 \mathrm{~K}$ and $\mathrm{P}_{\mathrm{H}_{2}}=1.5 \mathrm{~atm}$. The rate increases with the jet velocity. This behavior is typical of mass transfer limitations. 
1-hexene, but the shape of the rate as a function of jet velocity is a measure of the hydrogen diffusion rate as a function of the jet velocity.

\subsection{Miscellaneous}

\subsubsection{Hydrogenation on nickel}

Liquid-phase hydrogenations of cyclohexene and 1-hexene were also attempted on $\mathrm{Ni}(111)$. We were not able to detect any significant amount of product. Our nickel model catalyst appears to be completely inactive at temperatures up to $70^{\circ} \mathrm{C}$ and hydrogen pressures up to 2 atm. After the reaction, the nickel sample was brought back in UHV and its surface composition was analysed by AES. Large amounts of carbon and oxygen were found on the surface. The presence of carbon on the surface can be explained by the adsorption of hydrocarbon reactants from the liquid phase, but oxygen implies that the surface is partially oxidized by contaminants in the reaction mixture. We have calculated that $10^{15}$ oxidizing molecules in the liquid mixture are enough to cover a $1 \mathrm{~cm}^{2}$ surface area of nickel with one oxygen atom per surface nickel atom. For $40 \mathrm{ml}$ of liquid such as cyclohexene, that represents a concentration of contaminant as little as $40 \mathrm{ppb}$. Even with a method such as the one that we used to prepare the liquid, it seems impossible to remove all the contaminants which can be held responsible for the poisoning of our model catalyst. One way to solve that problem would be to modify the experimental set-up so that a higher hydrogen pressure can be used in the reaction cell. Another solution would be to use a sample prepared from a nickel-aluminium alloy such as the one used to prepare Raney nickel. We hope that aluminium atoms would be oxidized before nickel atoms, which would then be available for hydrogenating unsaturated molecules.

\subsubsection{Hydrogenation of nitrile}

The hydrogenation of propionitrile $\left(\mathrm{CH}_{3} \mathrm{CH}_{2} \mathrm{CN}\right)$ was carried out in various conditions on a $\mathrm{Pt}$ foil. Water was used as a solvent because it does not interfere with propionitrile and propylamine in the chromatograrn ( $6 \mathrm{ft}$ long stainless steel column, 1/8 in. O.D., filled with $10 \%$ Carbowax $20 \mathrm{M}+10 \%$ Chromosorb WHP 80-100 mesh). The $\mathrm{pH}$ of the solution was varied between 3 and 11 by adding $\mathrm{HNO}_{3}$ or $\mathrm{NaOH}$ to the reaction mixture $\left(50 \mathrm{ml} \mathrm{H}_{2} \mathrm{O}\right.$ $+5 \mathrm{ml}$ propionitrile). All these atlempts proved unsuccessful. Hydrogen pressure could 
be our main prchlem, since hydrogenation of nitriles are usually carried out at pressures greater than $10 \mathrm{~atm}$. Other solvents should also be tested.

\subsection{References}

[1] C.T. Campbell, Adv. Catal., 36 (1989) 1.

[2] E. Segal, R.J. Madon, and M. Boudart, J. Catal., 52 (1978) 45.

[3] R.J. Madon, J.P. O'Connell, and M. Boudart, AIChE Journal, 24 (1978) 904.

[4] N.M. Dimitrienko, V.S. Boronin, and O.M.Poltorak, Vestn. Mosk. Univ. Ser. II : Khim., 21 (1966) 106.

[5] S.M. Davis, and G.A. Somorjai, J. Catal., 65 (198C) 78. 


\section{Chapter 8}

\section{Correlations of Atomic Structure and Reactivity at Solid-Gas and Solid-Liquid Interfaces}

\subsection{Introduction}

Electrochemistry and heterogeneous catalysis are the two oldest fields of surface chemistry. Their distinguished history dates back to the 1820 's. They represent the first applications of surface chemistry at solid-liquid and solid-gas interfaces, respectively. Since the late 1950's, an ever increasing number.of techniques have become available that permit molecular level investigation of interfaces. These techniques (over 50, by our last count) permit the determination of the atomic surface structure, surface composition, the oxidation states of surface atoms, reveal the nature of bonding of adsorbed atoms and molecules at surfaces, and increasingly aid in the study of the dynamics of surface species, their adsorption, diffusion, reactions, and desorption at surfaces [1].

Our challenge is to place clectrochemistry and heterogeneous catalysis on the firm foundation of molecular surface science. Most of the newly developed techniques of surface science require the use of UHV and are not readily utilized at solid-liquid or solid-gas interfaces. However, when used in combination with environmental cells that introduce liquids or high pressure gases after the surfaces have been prepared and characterized in UHV, the sample can be shuttled between the liquid or gas phase and ultrahigh vacuum 
without being exposed to ambient contaminants. Environmental cell-UHV surface analysis combinations have been developed in our laboratory. The apparatus described in chapter 2 permits liquid phase studies in combination with UHV studies of surfaces and surface reactions [chapter 7], while the system shown in figure 8.1 permits joint solid-gas and UHV studies [3].

If we are to correlate structure and chemical behavior at solid-liquid and solid-gas interfaces, the sample geometries have to be similar. Fortunately, electrochemical studies as well as catalytic reaction studies can be carried out on the external surfaces of model systems; single crystals that are cut in various low or high Miller Index orientations to expose flat surfaces or ordered steps and kinks, or by depositing metals or oxides (sulfides) by atomic layer epitaxy that produces the desired material layer by layer. These types of samples that can be used in model studies are shown schematically in figure 8.2.

The techniques of surface science [1] that can be used at solid-liquid and solidgas interfaces, in the presence of a liquid or high pressure gas, or both respectively, are listed in table 8.1. There are several mostly optical techniques that are available. Recent developments indicate that the scanning tunneling microscopy (STM) and atomic force microscopy (AFM) techniques can be used in liquids and in high pressure gas, even at elevated temperatures. A STM apparatus that could be used at high pressures and at elevated temperatures [4] during adsorption or reactions at surfaces that was developed in our laboratory is shown in figure 8.3.

The experimental conditions utilized during electrochemical studies and heterogeneous catalysis are so different that we must consider several steps in our investigations as bridges that we must build. These are:

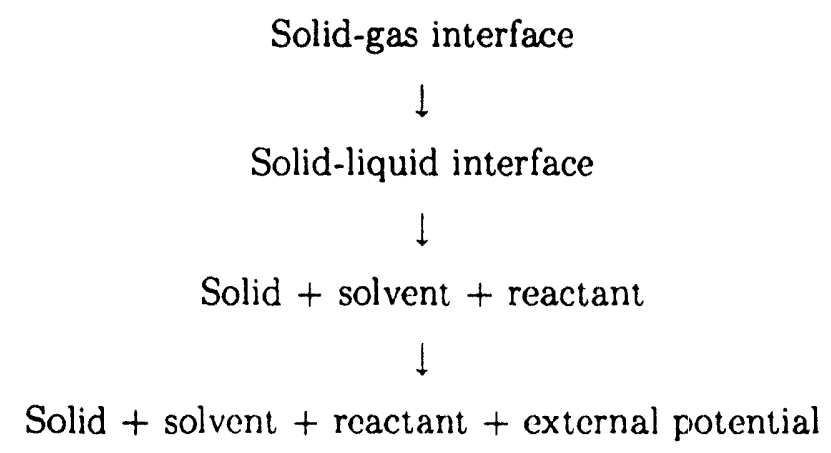

When moving from studies at solid-gas interfaces to solid-liquid interfaces of the same material, the main difference is the coverage of the adsorbate. This, of course, can 


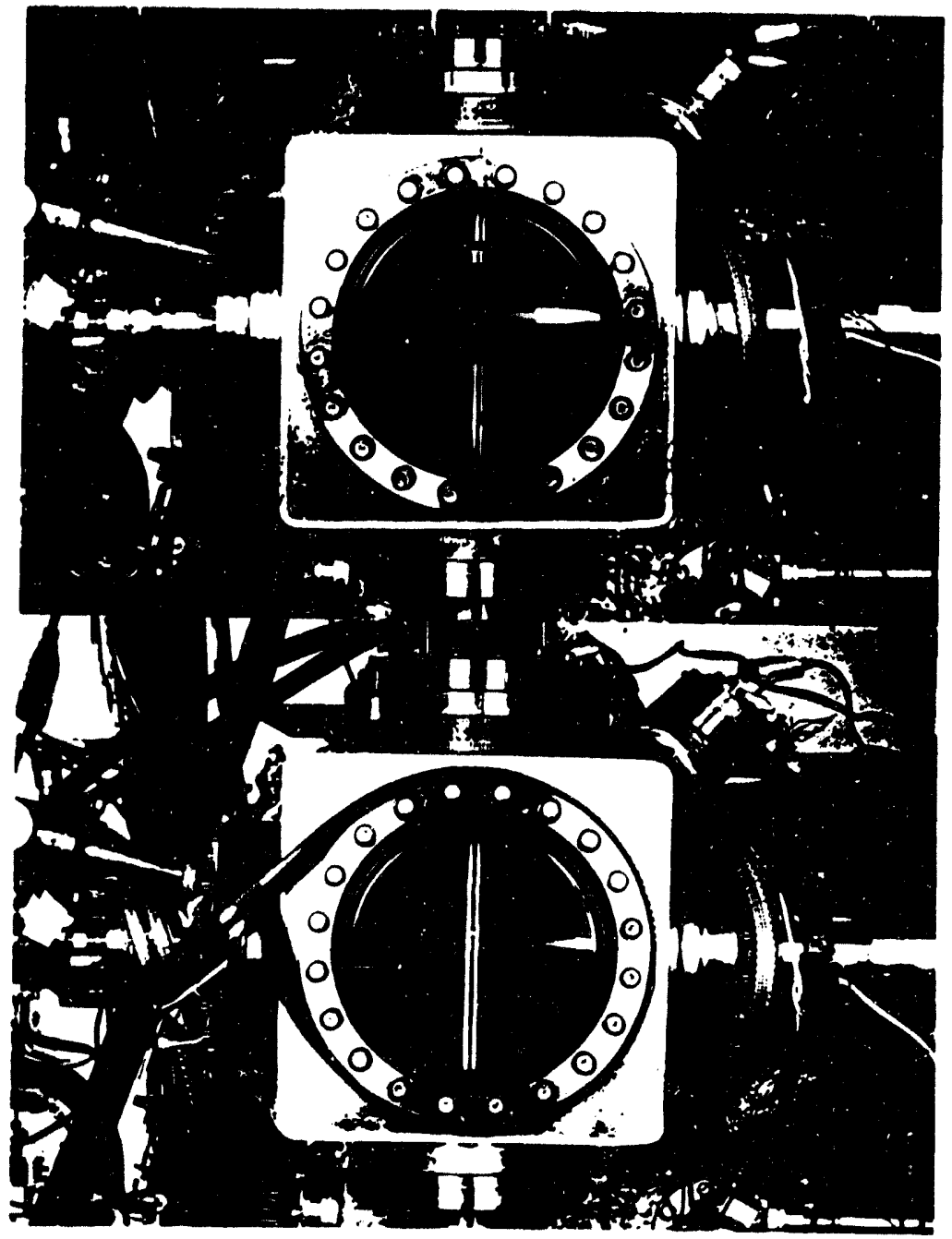

Figure 8.1: Photographs of a stainless stcel chamber used for surface studies. It is equipped with surface characterization instruments that are used in ultra-high vacuum and with a high pressure cell that is shown in both open (upper) and closed (lower) positions. The cell is used to expose the samples to high pressures and high temperatures. 


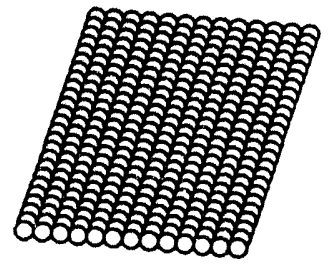

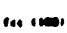

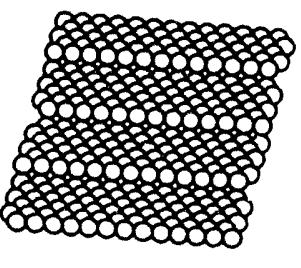

in and

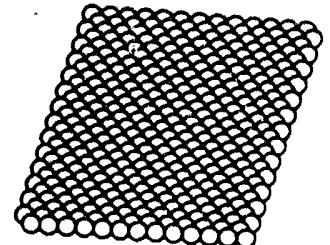

(1)."1"1"

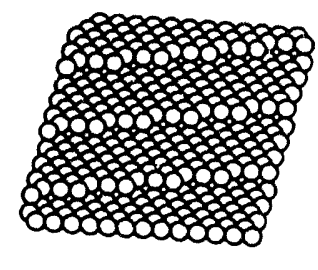

in ine.r.

Preperotion of Ordered Metel Oxide Thin films

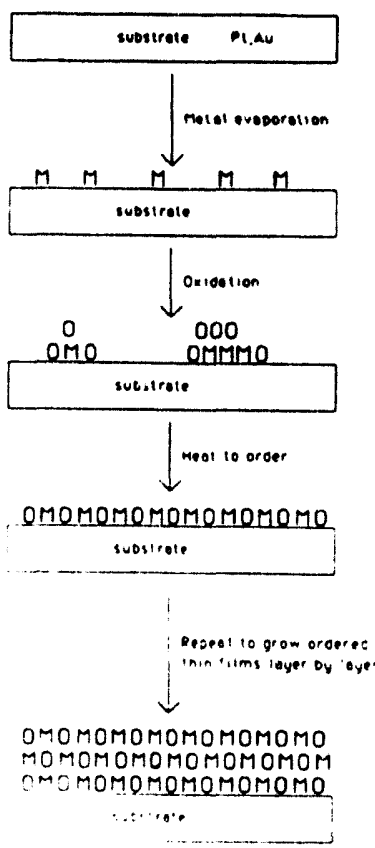

Figure 8.2: Schematic of the types of model samples that are desirable for surface studies. The top portion of the figure shows single crystals cut in different orientations to expose various flat, stepped, and kinked surfaces. The lower portion shows how atomic layer epitaxy can be used to grow metal oxide thin films layer by layer. 


\begin{tabular}{|l|c|c|}
\hline \multicolumn{3}{|c|}{ Studies of Surface Structure } \\
\hline Technique & solid/gas interface & solid/liquid interface \\
\hline STM & $\sqrt{ }$ & $\sqrt{ }$ \\
STM & $\sqrt{ }$ & $\sqrt{ }$ \\
IRARS & $\sqrt{ }$ & $\sqrt{ }$ \\
RAMAN & $\sqrt{ }$ & $\sqrt{ }$ \\
SFG, SHG & $\sqrt{ }$ & 0 \\
SEXAFS, XRD & $\sqrt{ }$ & 0 \\
LEED & $\sqrt{ }$ & \\
HREELS & \multicolumn{3}{|c|}{} \\
\hline \multicolumn{3}{|c|}{ Complementary Techniques for Studies of Adsorption } \\
Technique & solid/gas interface & solid/liquid interface \\
\hline TPD & $\sqrt{ }$ & 0 \\
Voltammetry & 0 & $\sqrt{ }$ \\
\hline \multicolumn{3}{|c|}{ Complementary Techniques for Studies of Surface Diffusion } \\
\hline
\end{tabular}

Table 8.1: Some techniques that can be used to study surface structure at solid-gas and solid-liquid interfaces. 


\section{Cross-Sectional View}

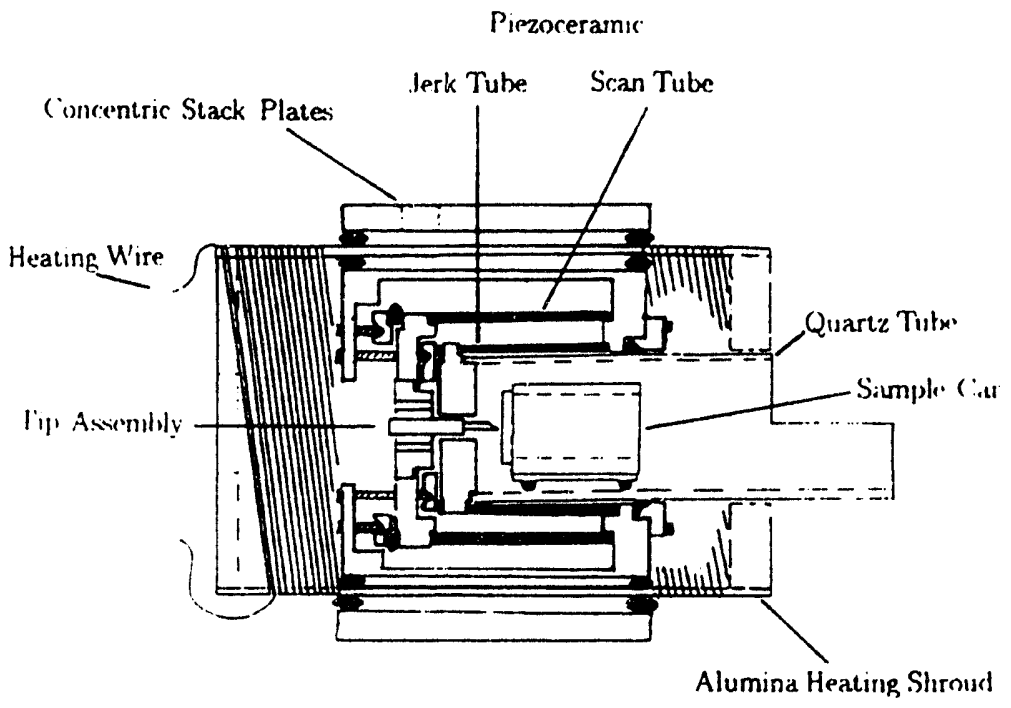

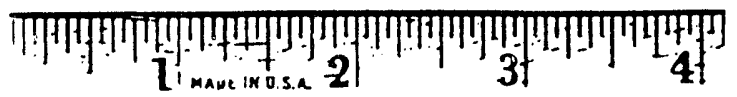

Figure 8.3: Cross-sectional view of the head of an STM built in this laboratory that can operate at high pressures and temperatures [4]. 
markedly effect the substrate and the adsorbate structures, their mobility, bonding, and thus their reactivity. When a solvent is introduced that is usually an electrolyte (like water), the reactant must coadsorb with the solvent molecules, which will influence its orientation and bonding and all other physical chemical properties. The application of an external potential brings about an additional driving force that can modify structure, orientation, bonding and the kinetics of surface processes. We propose that by systematically exploring surface behavior of adsorbates in this manner, we should be able to bridge chemisorption, heterogeneous catalysis and electrochemistry. This way we provide a road map for the molecular level understanding accumulated in one field, and how it might be used in the other.

The correlations of various surface properties at solid-gas and solid-liquid interfaces which we need to establish include:

1-Surface chemical bond

2-Surface and adsorbate structure

3-Coadsorption

4-Dynamics of surfaces

5-Surface reactions

We shall discuss each of these areas separately and review what is known from solid-gas and solid-liquid interface studies that were carried out un the molecular level. Since the number of surface studies at solid-gas interfaces overwhelm those performed at the solid-liquid interface, our review and discussions are unbalanced. Nevertheless, it should serve as a starting point for investigations for the future.

\subsection{The Surface Chemical Bond}

\subsubsection{Cluster-like bonding}

Ultraviolet photoelectron spectroscopy has been used to study the vibrational spectrum of metal carbonyl structures and their spectrum when chemisorbed on transition metal surfaces. One such study is shown in figure 8.4 [5]. The $\mathrm{Ir}_{4}$ carbonyl cluster exhibits a vibrational spectrum which is nearly identical to that of CO chemisorbed on the (100) crystal face of Ir. This type of information indicates that the nature of the surface chemical bond is 


\begin{tabular}{|c|c|c|c|c|}
\hline & \multicolumn{2}{|c|}{ UHV } & \multicolumn{2}{|c|}{ Aqueous Solution 1} \\
\hline & Cn coverage & $\nu_{C O}\left(\mathrm{~cm}^{-1}\right)$ & CO coverage & $\nu_{C O}\left(\mathrm{~cm}^{-1}\right)$ \\
\hline $\operatorname{Pt}(111)$ & $\theta=0.5$ & $\begin{array}{l}2095 \text { (top site) } \\
1850 \text { (bridge) }\end{array}$ & $\theta=0.55$ & $\begin{array}{l}2100 \text { (top site) } \\
1885 \text { (bridge) }\end{array}$ \\
\hline $\operatorname{Pt}(110)$ & $\theta=1.0$ & 2115 (top) & $\theta=1.0$ & 2090 (top) \\
\hline $\operatorname{Pt}(100)$ & $\theta=0.8$ & 2095 (top) & $\theta=0.8$ & 2100 (top) \\
\hline $\operatorname{Rh}(111)$ & $\theta=0.75$ & $\begin{array}{l}2065 \text { (top) } \\
1855 \text { (bridge) }\end{array}$ & $\theta=0.75$ & $\begin{array}{l}2075 \text { (top) } \\
1870 \text { (bridge) }\end{array}$ \\
\hline
\end{tabular}

Table 8.2: Vibrational frequencies of $\mathrm{CO}$ adsorbed at the solid-gas and solid-liquid interfaces on $\mathrm{Pt}$ and $\mathrm{Rh}$ single crystal surfaces as determined by Infrared Reflection-Absorption Spectroscopy [7].

cluster-like. A four atom cluster has very similar structure to that of a chemisorbed species. Similar studies using hydrocarbon molecules and hydrocarbon fragments clearly indicate the cluster-like bonding of surface species. Figure 8.5 shows several hydrocarbon species on surfaces and in their organometallic cluster form [6]. Their vibrational spectra are almost identical, providing evidence that the surface chemical bond can be described by cluster models. Table 8.2 shows the vibrational frequencies of $\mathrm{CO}$ adsorbed at the solid-gas and solid-liquid interfaces on $\mathrm{Pt}$ and Rh sur faccs [7]. More correlations of this type of bonding at solid-liquid interfaces using vibrational spectroscopy would be important to establish.

\subsubsection{Binding energy trends across the periodic table}

The heat of adsorption of $\mathrm{CO}$ is shown across the transition metal series in the periodic table in figure $8.6[8]$. The data was taken using polycrystalline surfaces where changes of bonding at different surfacc sites are averaged. There is a clear trend of decrease

\footnotetext{
${ }^{1}$ Frequencies are extrapolated from frequency-surface potentials equal to the work functions for the corresponding CO-saturated metal-UHV interfaces
} 


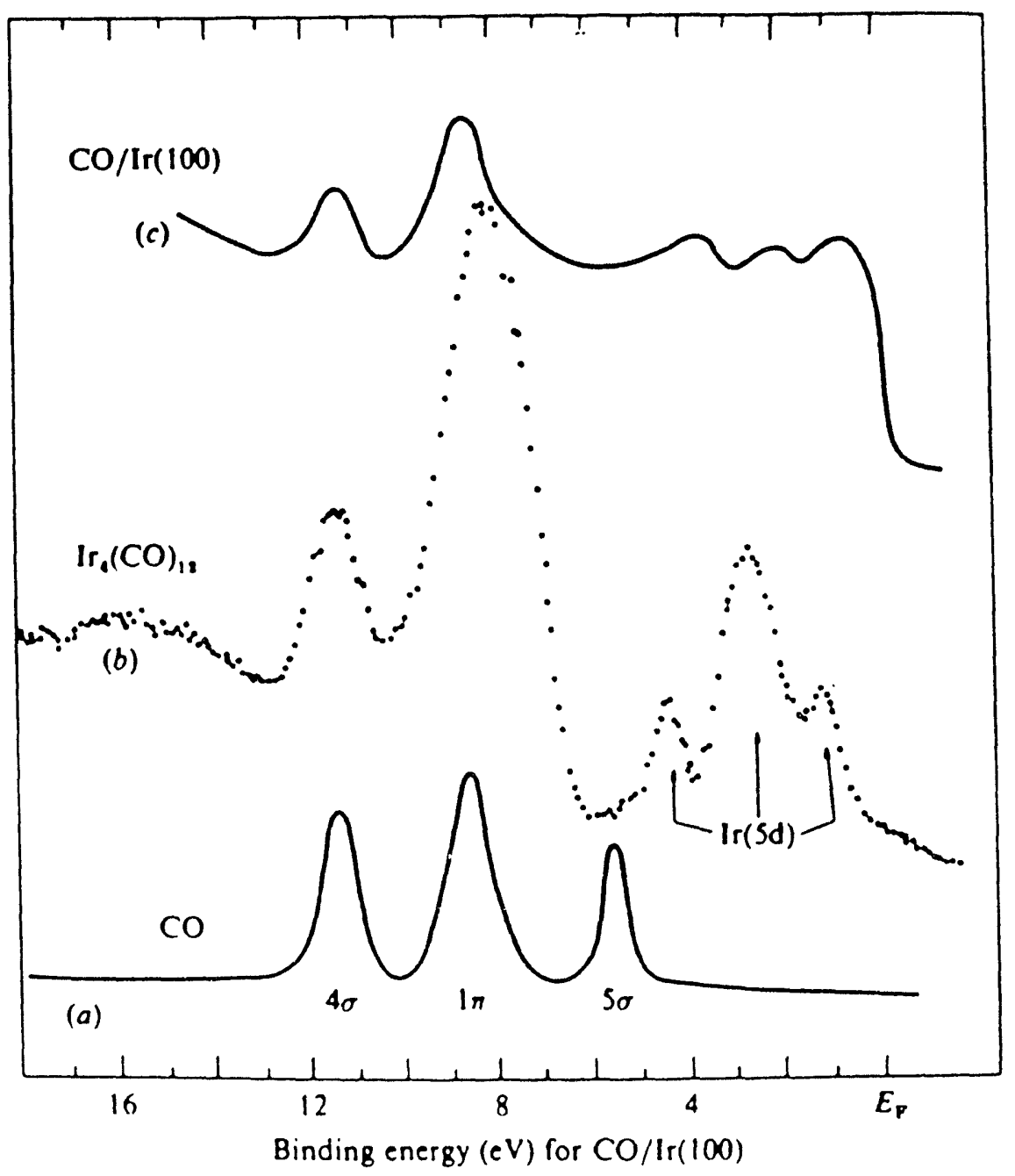

XBL $9110-2214$

Figure 8.4: Photoelectron spectra [5] of (a) $\mathrm{CO}$ in the gas phase, (b) the $\operatorname{Ir}_{4}(\mathrm{CO})_{12}$ cluster, and (c) CO chemisorbed on $\operatorname{Ir}(100)$. 
Chapter 8. Correlations of Atomic Structure and Reactivity ...

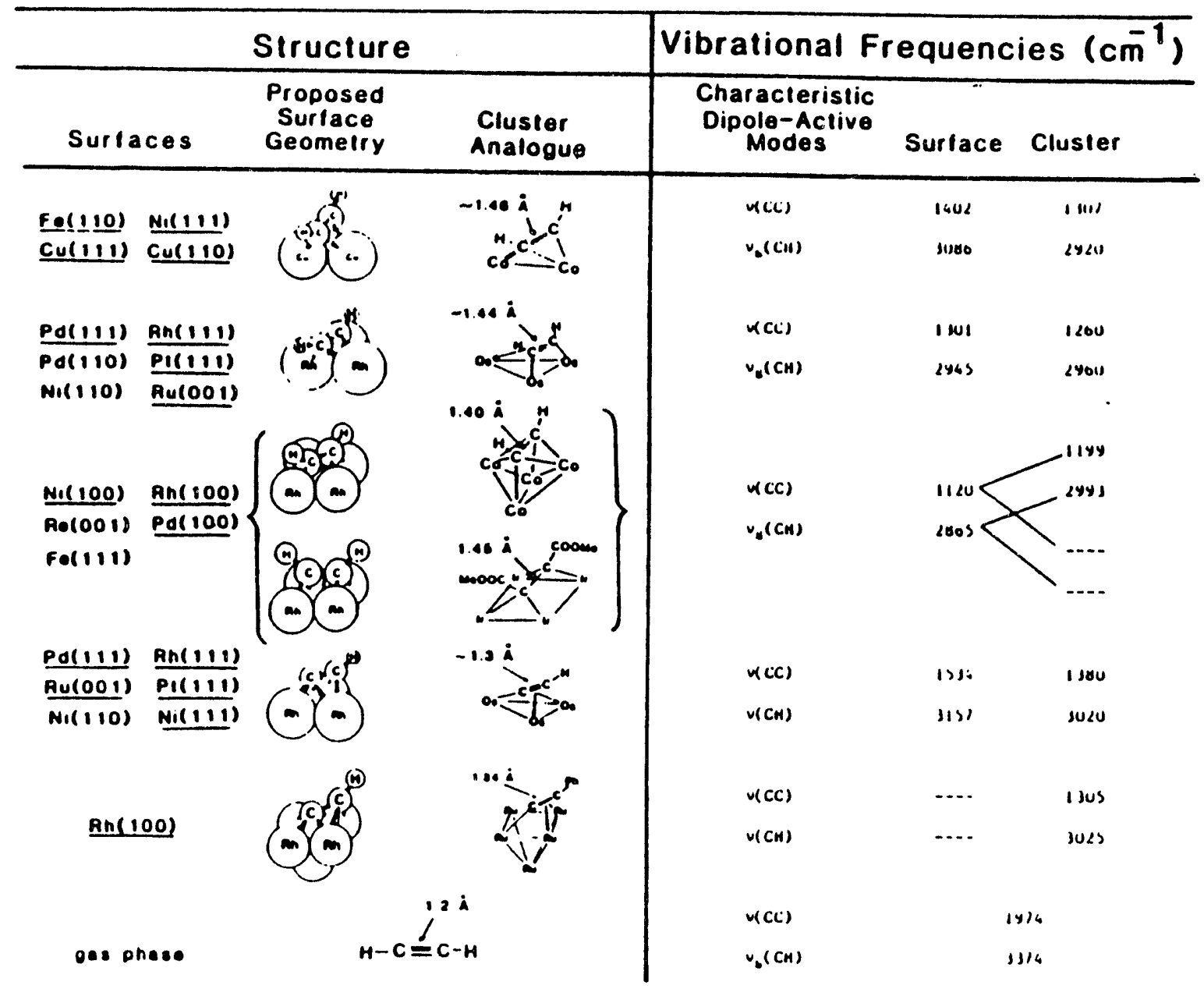

XBL $914-817$

Figure 8.5: The vibrational frequencies, and structure of acetylide on surfaces and in organometallic clusters [6]. 


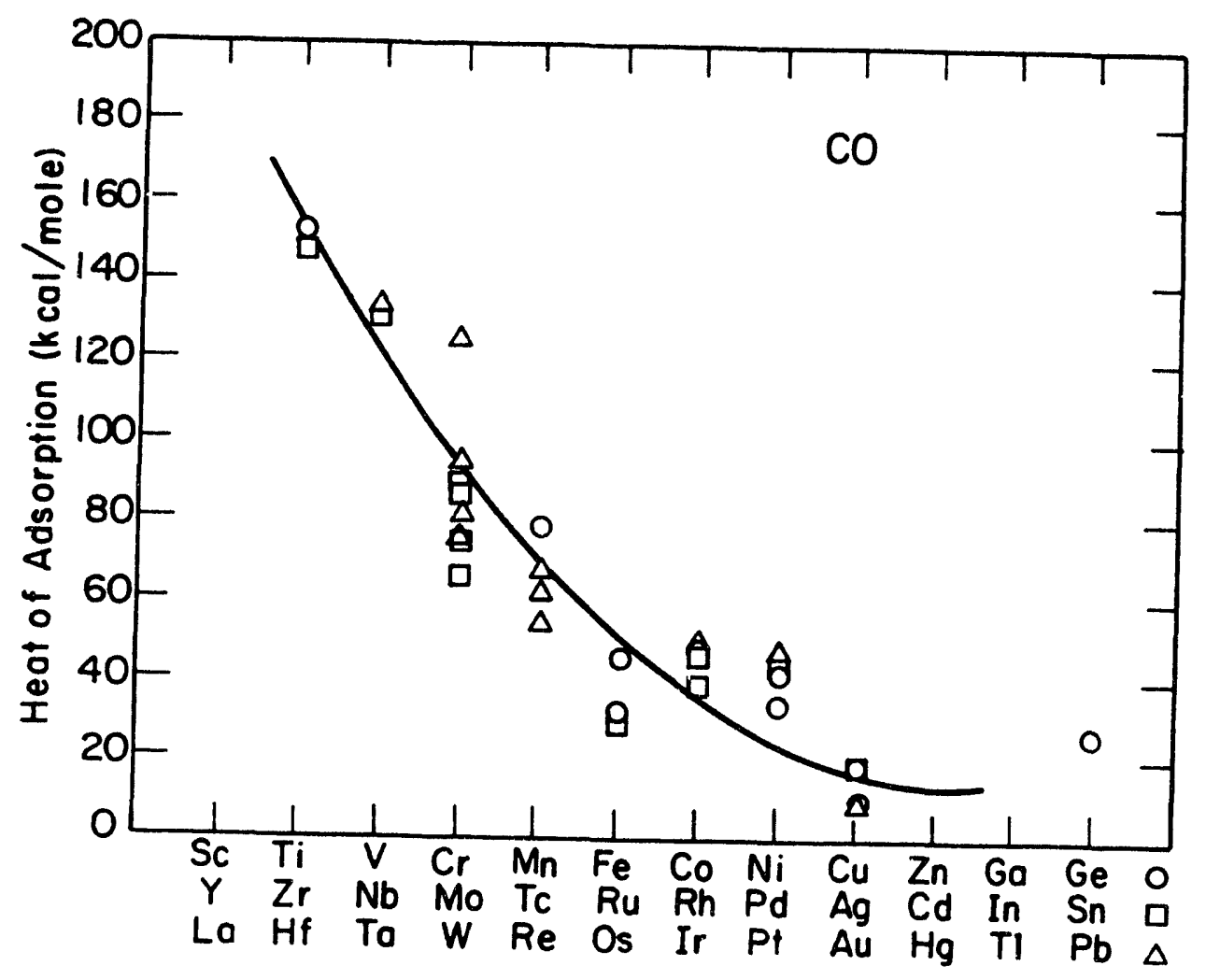

$X B L 773-5236$

Figure 8.6: Heats of adsorption of $\mathrm{CO}$ on polycrystalline transition metal surfaces.

in heats of adsorption from left to right in the periodic table. Data of this type, if it was available at solid-liquid interfaces, would provide an opportunity to develop a theoretical interpretation of bonding in the same manner that it was carried out at solid-gas interfaces. Figure 8.7 shows the variation of the heat of adsorption from site to site on various crystal faces for a given metal [8]. The variations can be large, sometimes significantly larger than the variation from metal to metal. The surface structure sensitivity of the heat of adsorption is also an important factor that should be explored at solid-liquid interfaces.

Trends of catalytic activity across the periodic table have also been established at solid-gas interfaces. These are shown for breaking $\mathrm{CC}, \mathrm{CN}$ and $\mathrm{CCl}$ bonds in figure 8.8 [9]. These trends have been observed for ammonia synthesis, as shown in figure 8.9 [10], which have also been interpreted theoretically by calculations involving variations in the strength 
Chapter 8. Correlations of Atomic Structure and Reactivity ...

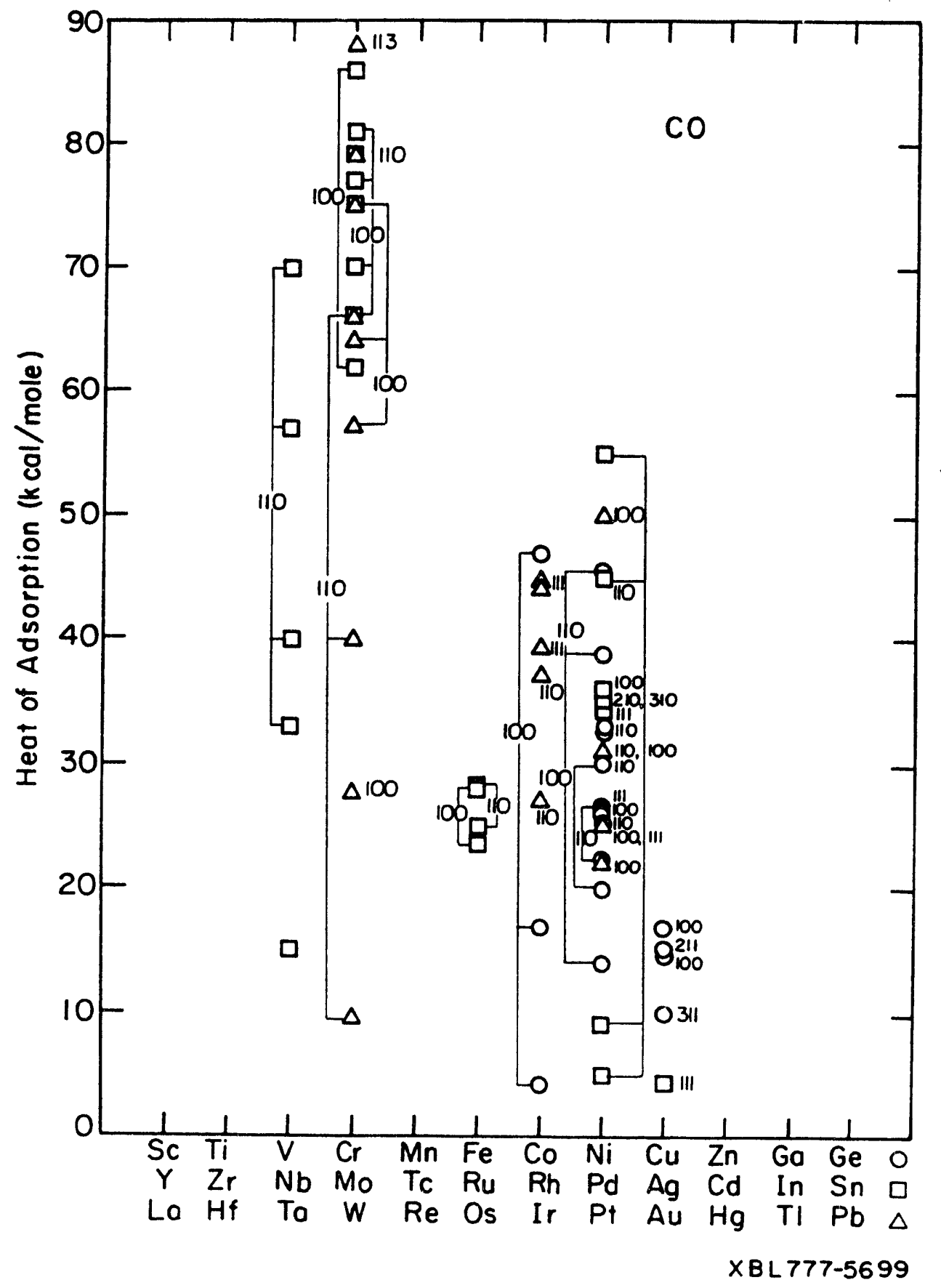

Figure 8.7: Heats of adsorption of $\mathrm{CO}$ on various single crystal surfaces of transition metals. 


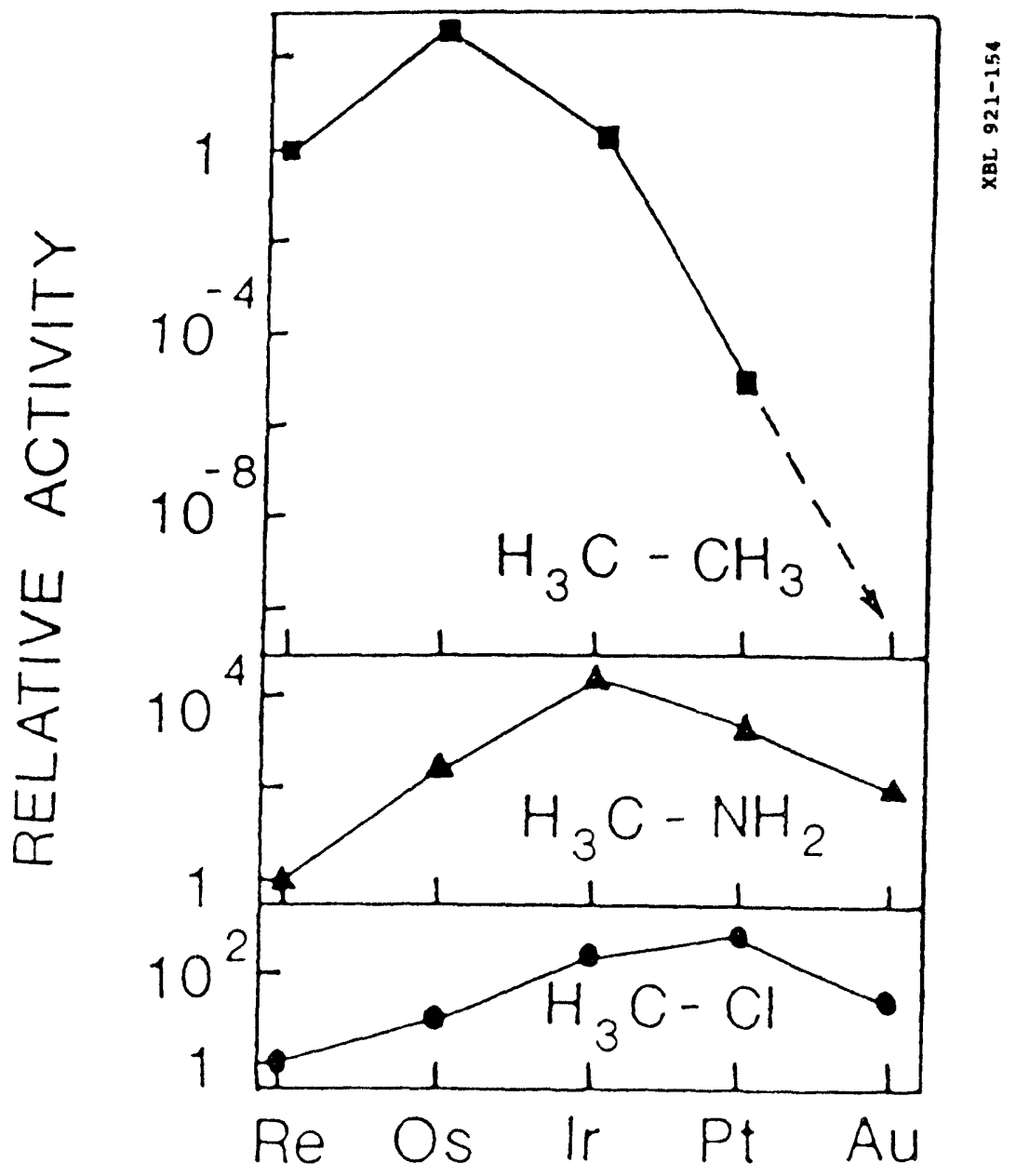

Figure 8.8: Catalytic activities of transition metals across the Periodic Table for (a) the hydrogenolysis of the C-C bond in ethane, (b) the C-N bond in methylamine and , (c) the $\mathrm{C}-\mathrm{Cl}$ bond in methylchloride [9].

of the chemisorption bond as well as the dissociative adsorption probability of dinitrogen on the various transition metal surfaces [11].

Figure 8.10 shows another correlation obtained at solid-gas interfaces. Here the heat of adsorption on zirconium oxide is studicd as a function of the chain length of the various molecules in a homologous series [12]. Since the heat of adsorption for a given homologous series correlates with the polarizability of these molecules, Van der Waal's bonding of these species are implicated. Such studies would be very important to carry out also at high coverages at the solid-liquid interface. 


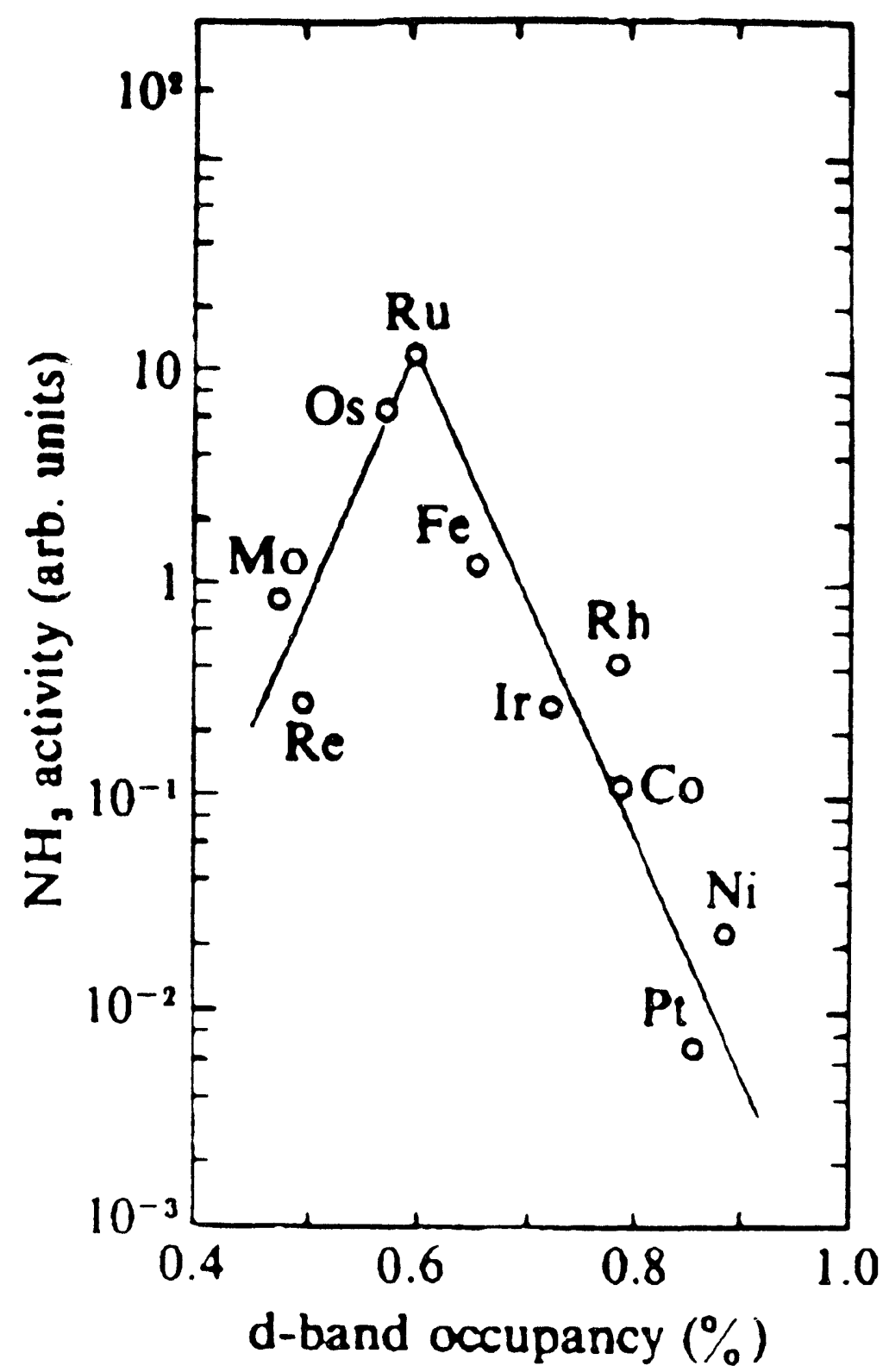

Figure 8.9: The activity of various transition metals for ammonia synthesis as a function of the degree of filling of the d-band [10]. 


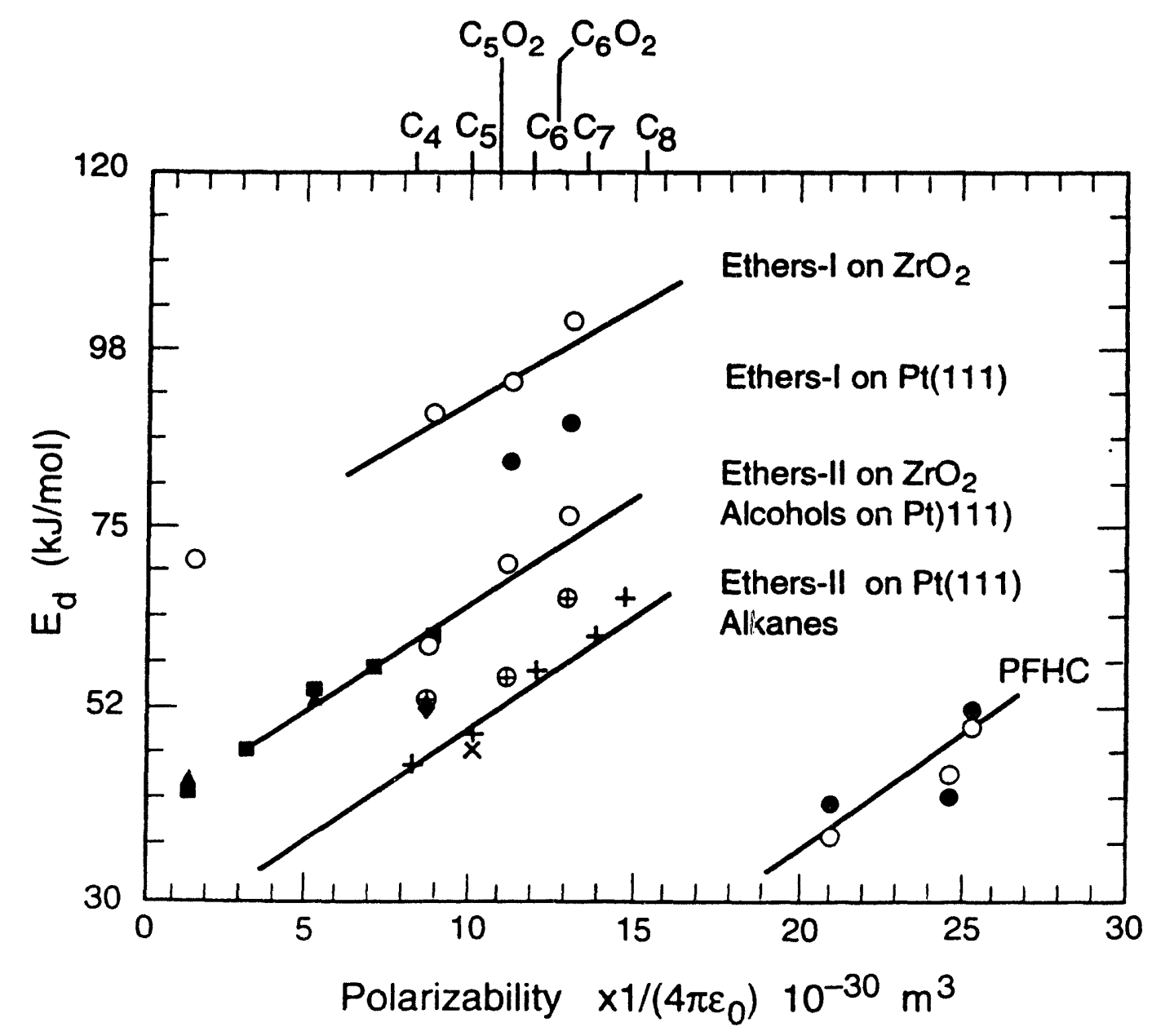

XBL912-6015

Figure 8.10: Plot of desorption energies for main monolayer peaks against the molecular polarizability [12]. Open circles refer to adsorbates on $\mathrm{ZrO}_{2}$. Ethers and diethers are labelled in the graph. Closed squares and closed triangles refer to alcohols on $\mathrm{Pt}(111) ;(+$, $\mathrm{x})$ give results for alkanes on $\mathrm{Pt}(111)$. Indicated on the top of the figure are the positions of alkanes and diethers indexed according to polarizability. 


\subsubsection{Coverage dependence of the heat of adsorption}

The heat of chemisorption can vary markedly with coverage as shown for $\mathrm{CO}$ on transition metal surfaces in Figure 8.11 [13]. Thus, at high coverages, the average heat of adsorption could be $30 \%$ of the heat of adsorption at very low coverages. This is due to adsorbate-adsorbate interaction which will be discussed again when we discuss the nature of the surface chemical bond and coadsorption. Imaging of the solid-liquid interface with STM and AFM have shown that adsorbed layers are densely packed on the surface and possess a high degree of two-dimensional ordering $[14,15]$. This is the case for example of alcohols and alkanes on graphite surfaces (figure 8.12). Thus, at the solid-liquid interface one expects modified thermodynamic properties of adsorbates because of the crowding of molecules at the surface.

\subsubsection{Temperature dependent changes of structure and bonding.}

Vibrational spectroscopy studies indicate that chemisorbed molecules rearrange as a function of temperature at the solid-gas interface. Such chemical rearrangements are shown for ethylene on the $\mathrm{Rh}(111)$ surface (figure 8.13) [6] and are also shown schematically for paraxylene and orthoxylene on the $\mathrm{Pt}(111)$ crystal face (figure 8.14) [16]. The decomposition of organic molecules also occur at different temperatures depending on the surface structure of the substrate. Ethylene, for example, dissociates on a stepped Ni surface at $\sim 150 \mathrm{~K}$ or below [17], as compared to its dissociation to the same fragments at $230 \mathrm{~K}$ on the $\mathrm{Ni}(111)$ or (110) crystal faces. It would be important to establish the temperature dependence of the chemical rearrangements of chemisorbed molecules and their structure sensitivity at solid-liquid interfaces as well.

\subsection{Surface Structure}

\subsubsection{Surface reconstruction and relaxation}

The techniques which can be applied to study surface structure at solid-gas and solid-liquid interfaces are shown in table 8.1. These techniques permit atomic scale studies of surface structure. The phenomenon of relaxation was first discovered by studies in UHV. It is found that the first layer of atoms is contracted toward the second layer by a large fraction of the interlayer distance in the absence of adsorbed gases [18]. The more open 


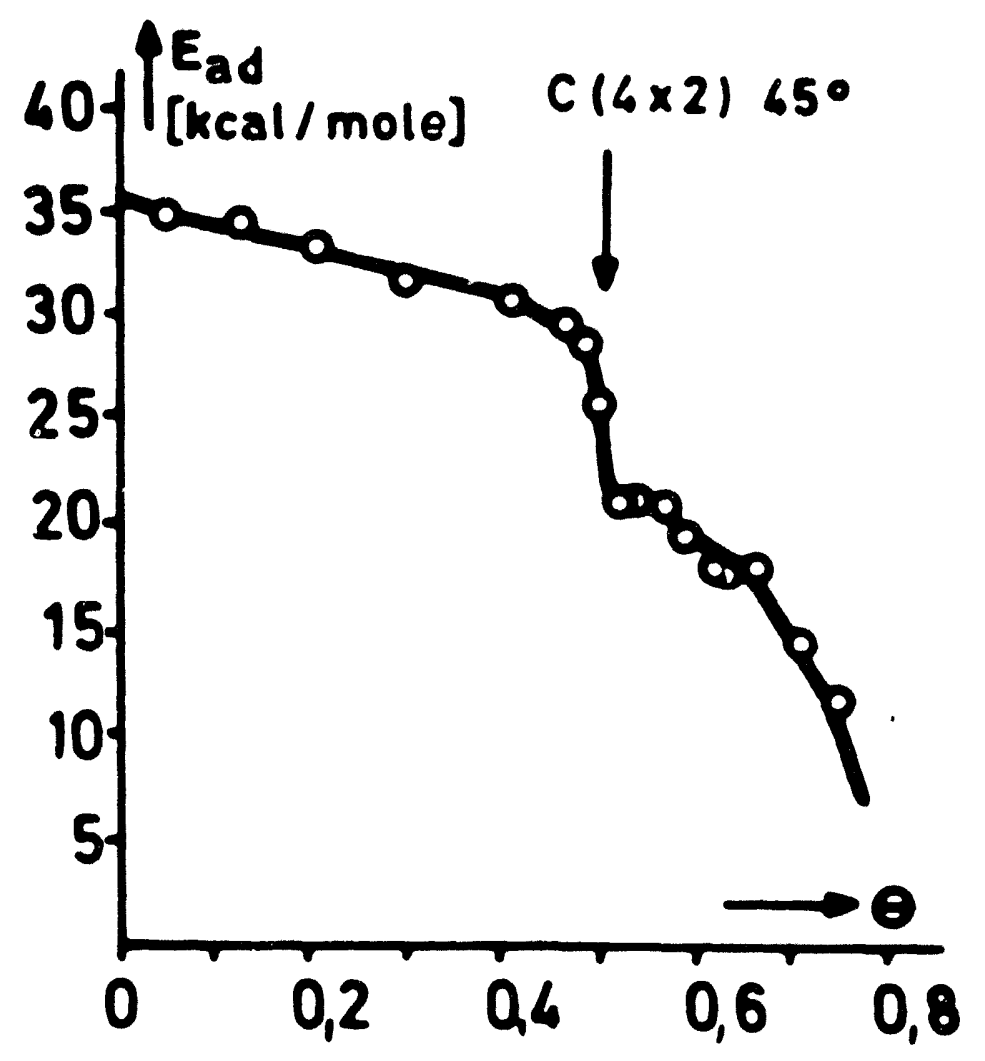

XBL 7911-12823

Figure 8.11: Heat of adsorption for chemisorbed CO on the $\mathrm{Pd}(111)$ crystal face as a function of coverage [13]. 


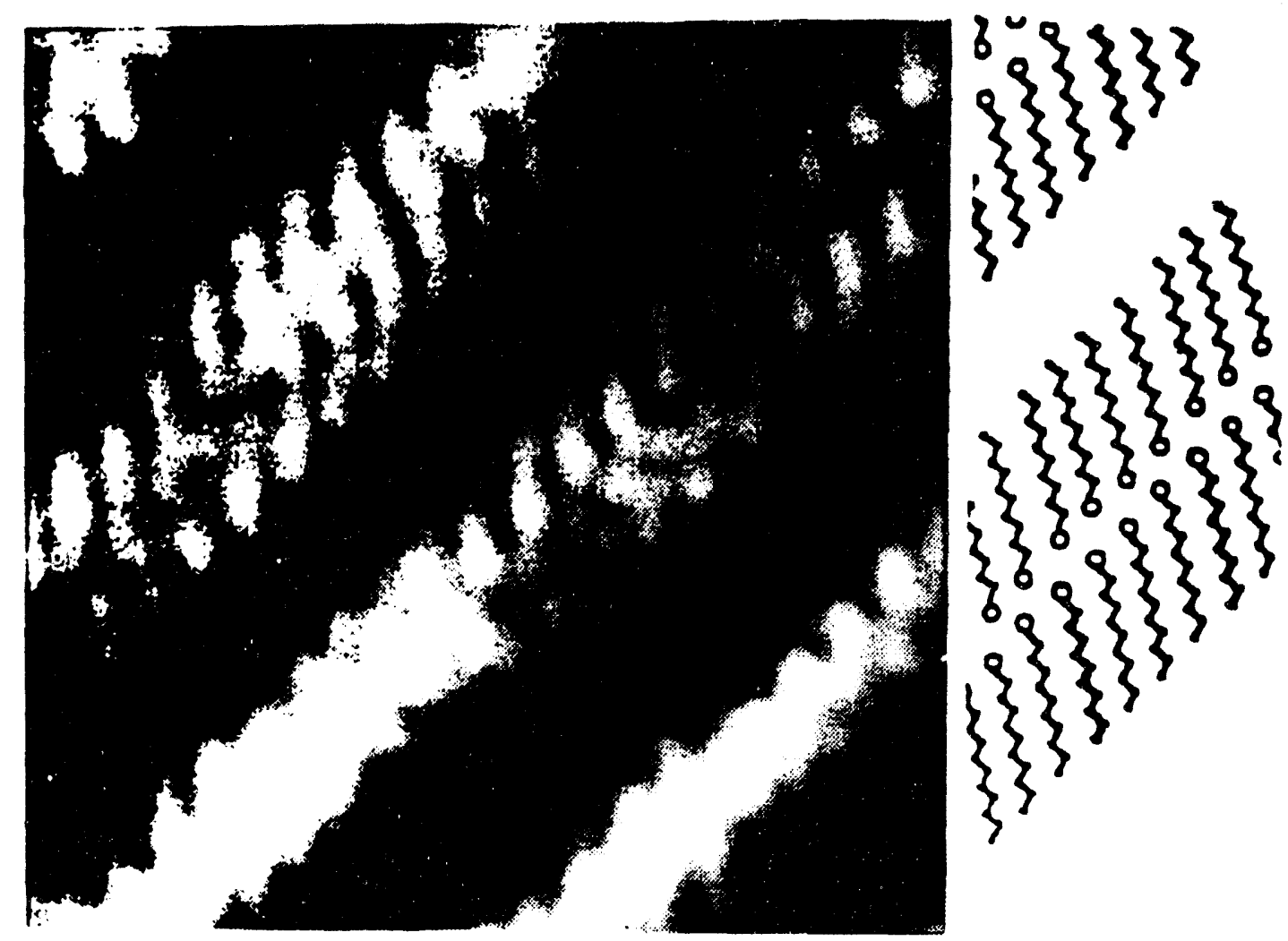

Figure 8.12: STM image of n-decanol molecules adsorbed at the liquid/graphite interface. The $n$-decanol molecules lie parallel to the substrate and are linked together in pairs by the hydrogen bonding of the $\mathrm{OH}$ head groups in alternate rows [15]. 


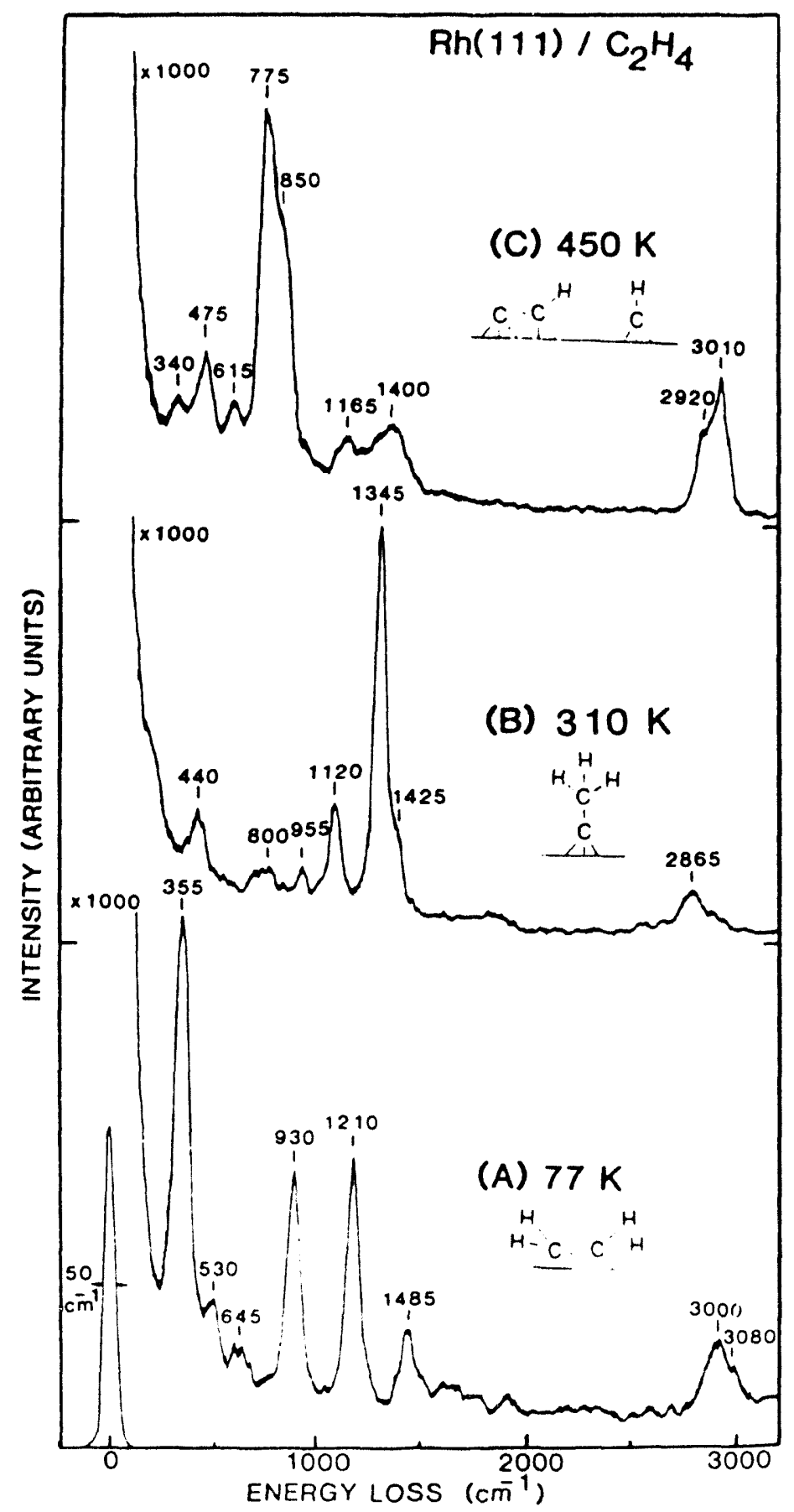

Figure 8.13: Vibrational spectra from chemisorbed ethylene on $\operatorname{Rh}(111)$ at different temperatures obtained by HREELS. Note the sequential dehydrogenation process [6]. 


\section{THERMAL DECOMPOSITION PATHWAY ON PT(111)}

\section{P-XYLENE}
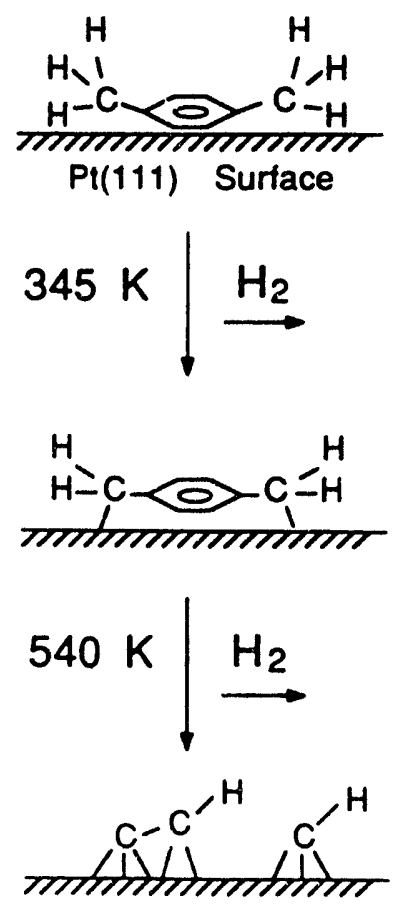

O-XYLENE
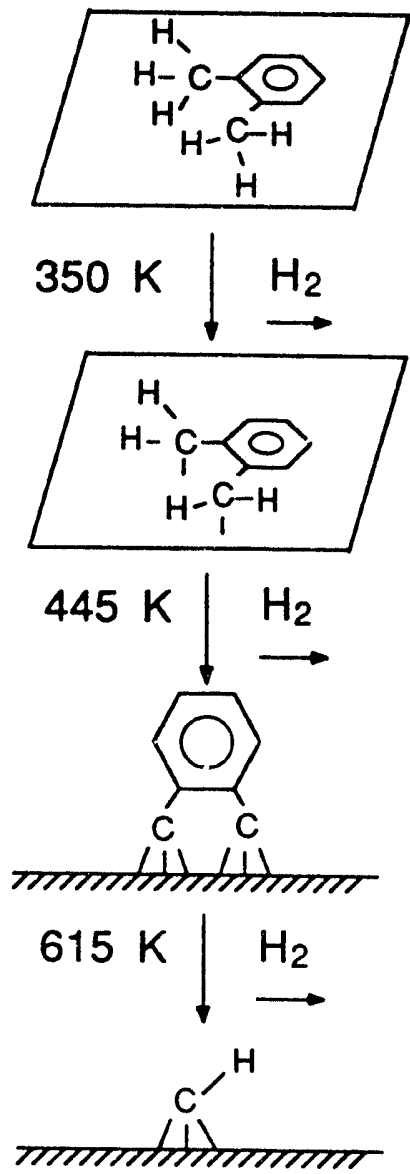

XBL $923-436$

Figure 8.14: Thermal fragmentation pathways for para-xylene and ortho-xylene on $\mathrm{Pt}(111)$ [16]. 
the surface the greater is the contraction. Figure 8.15 shows the contraction observed at siepped surfaces [19]. The corner atom on transition metals can be contracted by as much as $0.2 \AA$, thereby smoothing out the discontinuity in the surface structure. The contraction is plotted as a function of surface roughness in figure 8.16 [19]. The surface roughness is defined as the inverse of the packing density $\left(\frac{1}{\rho}\right)$. That is, the more open the surface the rougher it is on the atomic scale. It can be seen that the rougher the surface, the larger is the inward contraction in UHV. As a result of these studies, the model that emerges is one of the flexible surface. The surface atoms relocate to new equilibrium positions on different crystal faces depending on their coordination number. The atoms on the closely packed, smooth surfaces are the most rigid. They contract only by a small amount with respect to the bulk interatomic distance. The more open the surface, the more flexible the atoms are. Of course, a cluster with the smallest number of nearest neighbors is the most flexible. One expects the atoms to contract and relax the most on these surfaces.

When adsorbates are introduced on surfaces, the inward contraction or relaxation is changed. The substrate atoms move in the opposite direction (outward). This is shown as a function of hydrogen coverage in figure 8.17 [20]. As one increases the coverage the $\mathrm{Rh}$ atoms move outward more and more. Similar expansion of interlayer spacing at the surface has been observed at the solid-liquid interface by recent studies using grazing angle $\mathrm{x}$-ray diffraction [21]. Adsorption of hydrogen causes the expansion at the $\mathrm{Pt}$ surface by $\sim 5 \%$ with respect to the bulk interlayers distance. Thus chemisorption causes the motion of substrate atoms to new equilibrium positions, usually outward with respect to their relaxed, contracted position in UHV.

Large relaxation of surface atoms often leads to reconstruction, that is, the formation of new equilibrium positions and new surface structures because of the directionality of the surface bonds. Such a reconstruction is shown in figure 8.18 for the $\operatorname{Ir}(100)$ surface [22]. The surfaces rearrange into a hexagonal structure and the presence of a hexagonal layer on top of a square layer creates the coincidence lattice that gives rise to the extra diffraction features. Figure 8.19 shows the missing row reconstruction of the $\operatorname{Ir}(110)$ crystal face [23]. Several transition metal (110) crystal faces undergo this type of reconstruction [24]. Figure 8.20 shows the reconstruction of the $\mathrm{Si}(100)$ surface into a $(2 \times 1)$ surface structure [25]. The asymmetrical dimer model clearly indicates the large structural changes that occur at surfaces.

Surface reconstruction of metal surfaces at the solid-liquid interface has recently 


\section{The Structure of Stepped Surfaces....}
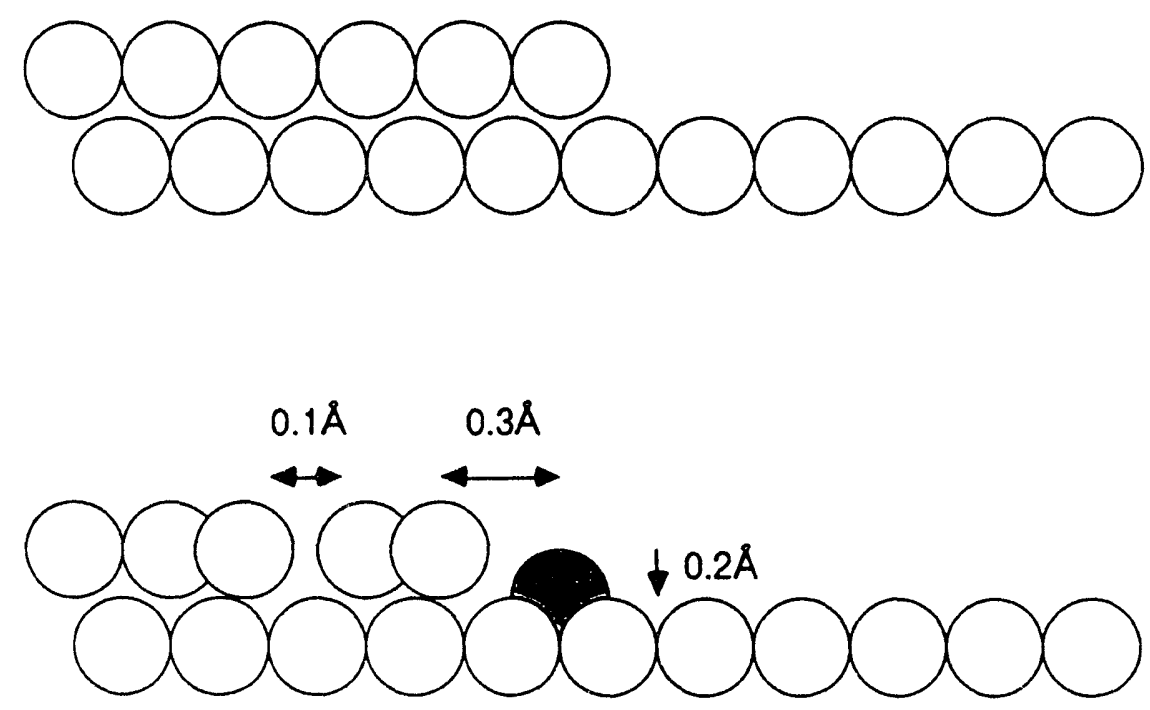

"Cracks" open close to the step edges

Each atom attemps to optimise its coordination

XBL $909-2972$

Figure 8.15: Relaxation at the stepped surface of $\mathrm{Cu}(410)$ [19]. 


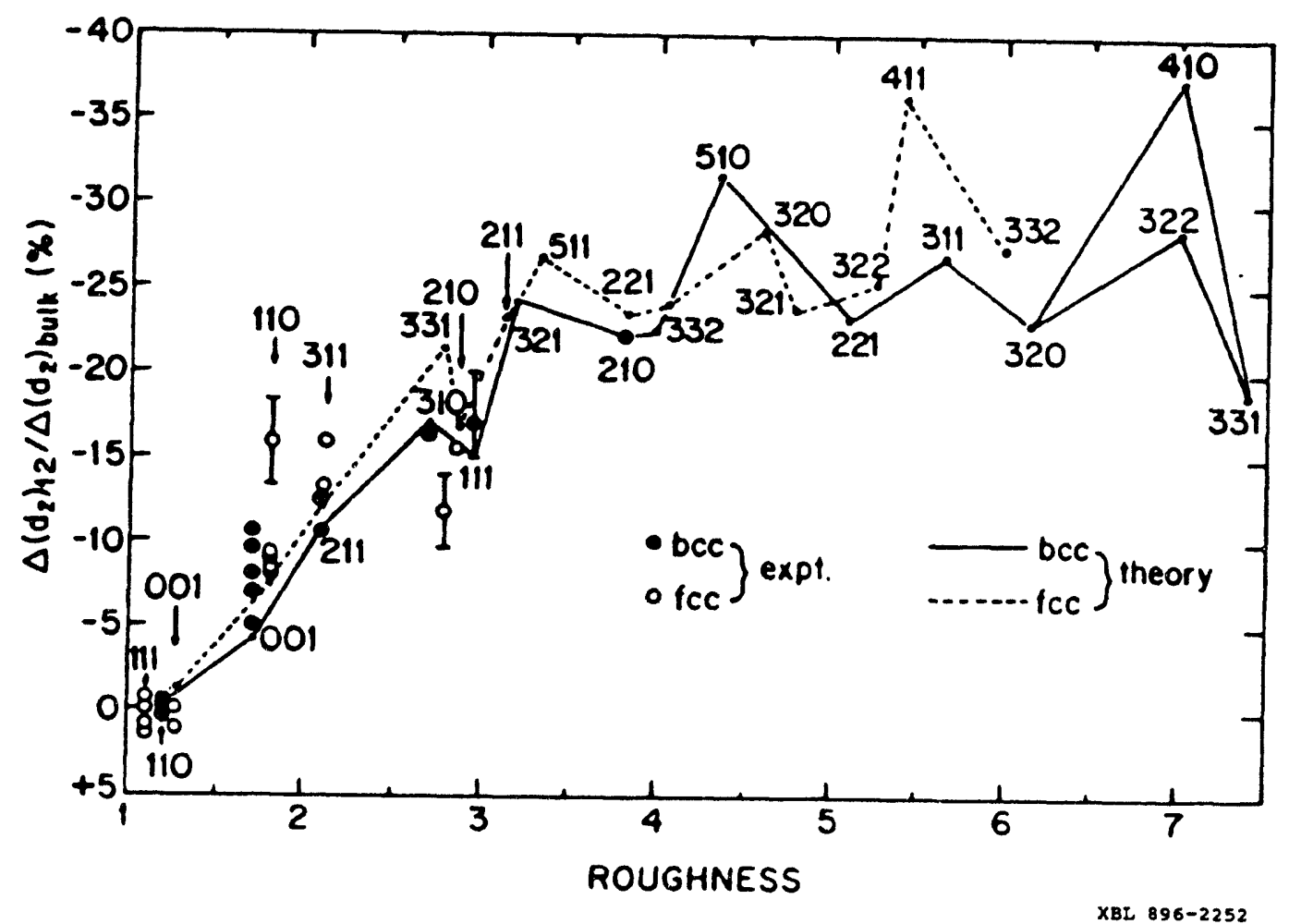

Figure 8.16: Contraction of the interlayer spacing as a function of surface roughness (defined as $1 /$ (packing density)) for several fcc and bcc metal surfaces. The points indicate experimental data, the lines are theoretical fits [19]. 
$\mathrm{H} / \mathrm{Rh}(110)$

W.Nichtl-Pecher, W.Oed, H.Landskron, K.Hein\% and K.Müller, Vacuum $\underline{41}$ (1990) 297
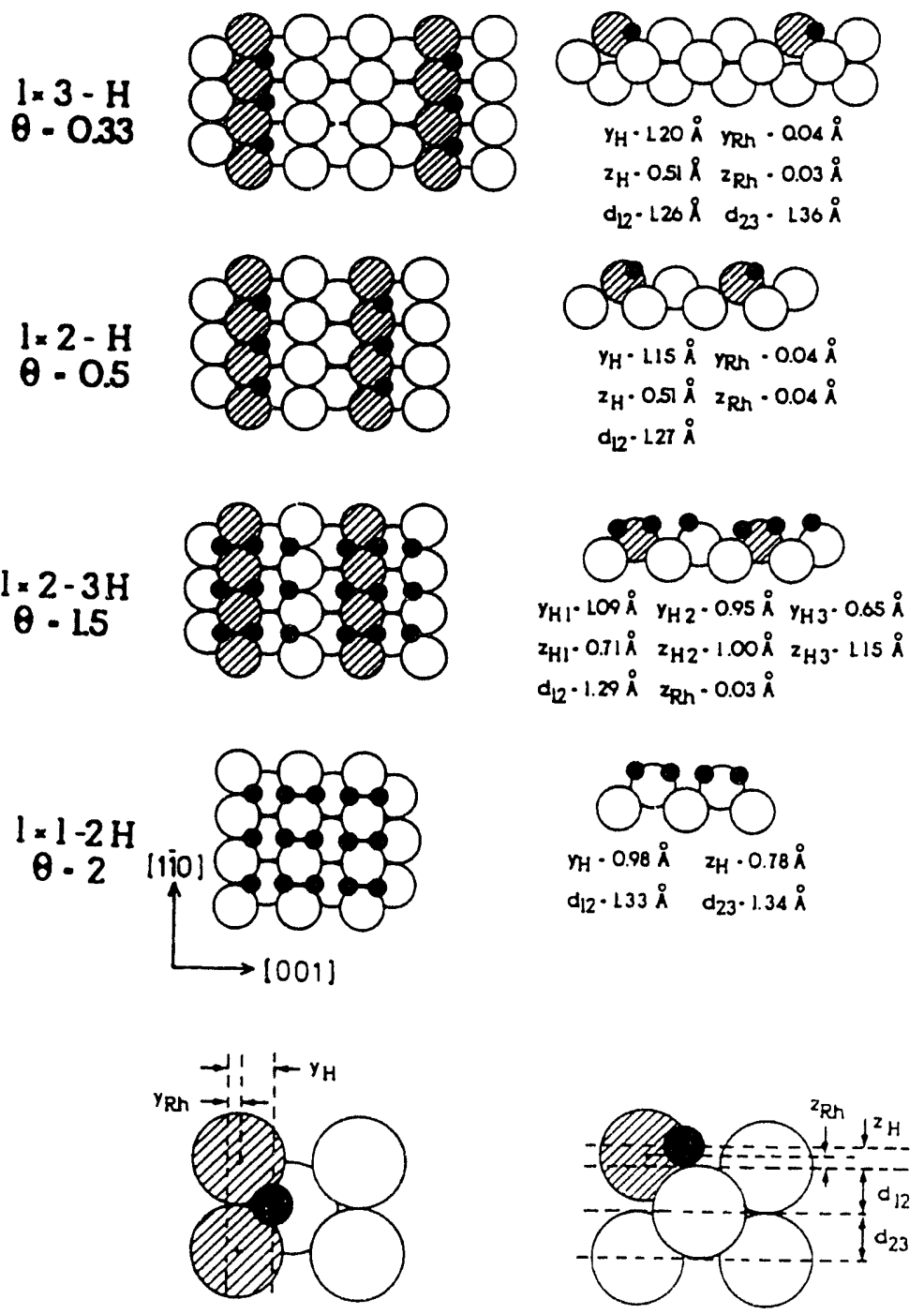

Figure 8.17: Real space configuration of the $\mathrm{Rh}(110)$ surface for different coverages of hydrogen (hydrogen atoms are shown as small, solid circles). The shaded $\mathrm{Rh}$ atoms have relaxed to new positions in the first $\mathrm{Rh}$ layer [20]. 

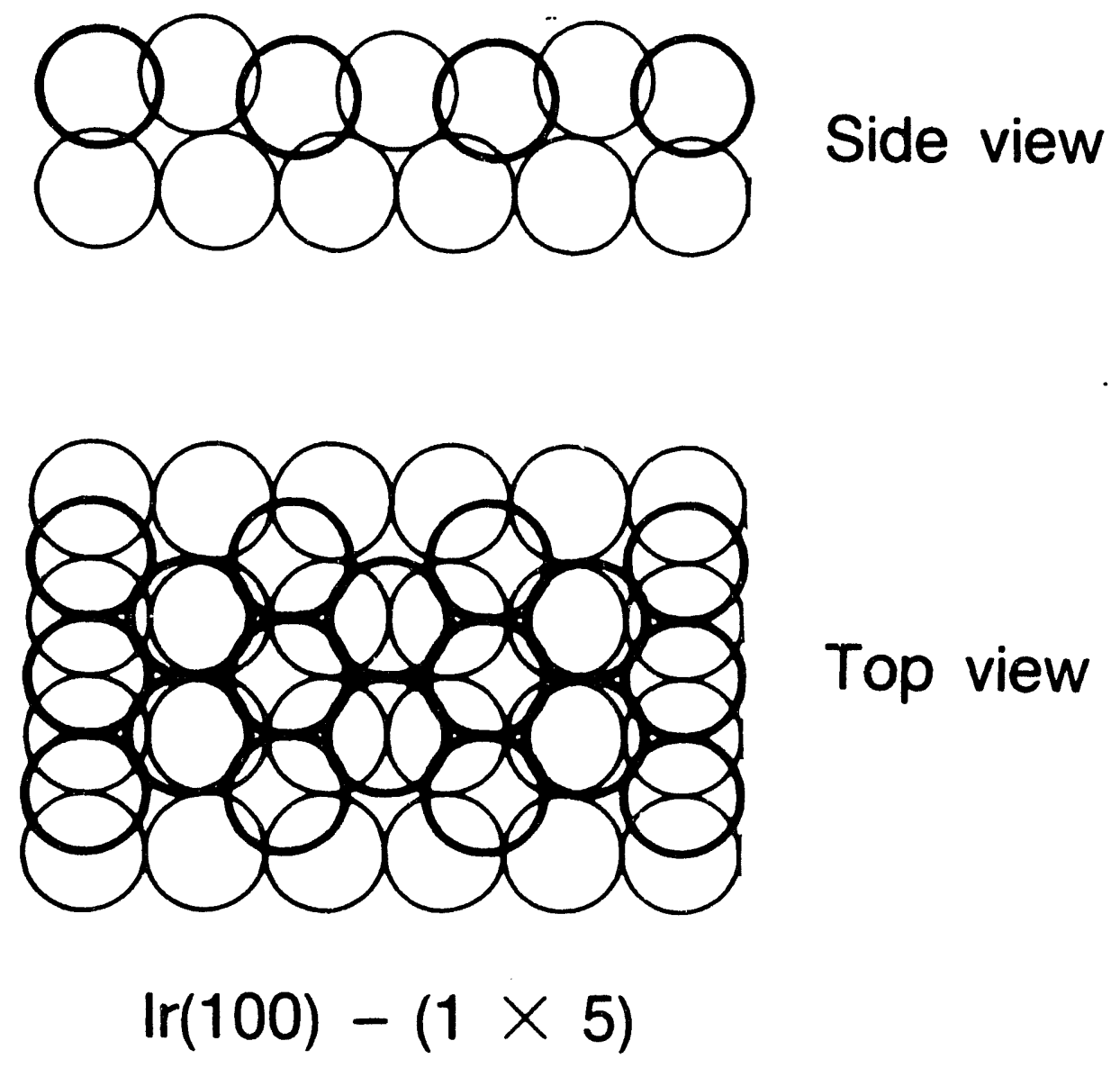

Figure 8.18: The structure of the reconstructed iridium(100) crystal face obtained from LEED-surface crystallography. Hexagonal packing in the surface layer induces buckling. The second layer retains its square unit cell [22]. 


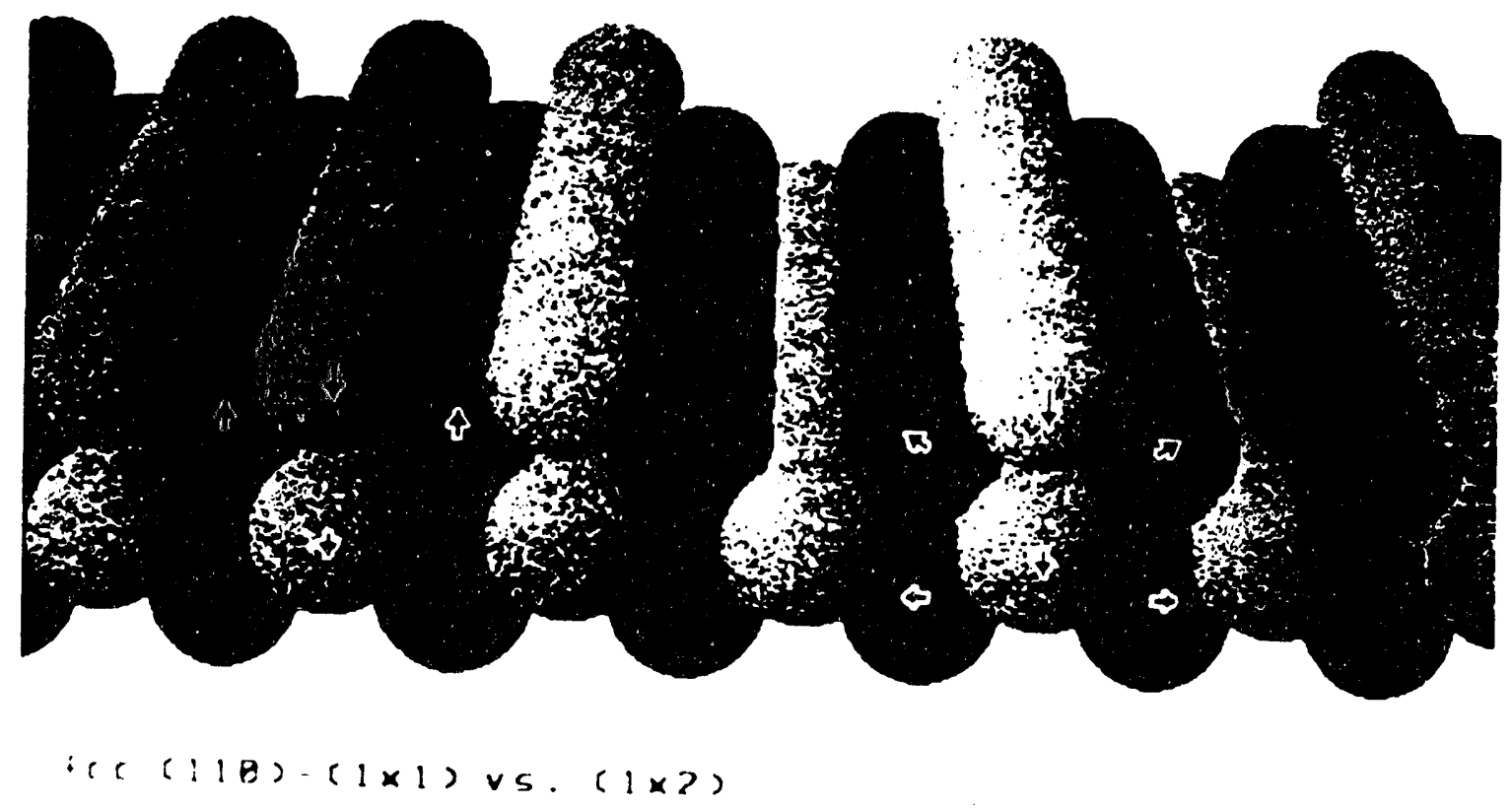

Figure 8.19: The reconstructed iridium(110) crystal face obtained by LEED-surface crystallography. Every second row of atoms is missing. Note that relaxation extends to three atomic layers towards the bulk [23]. 

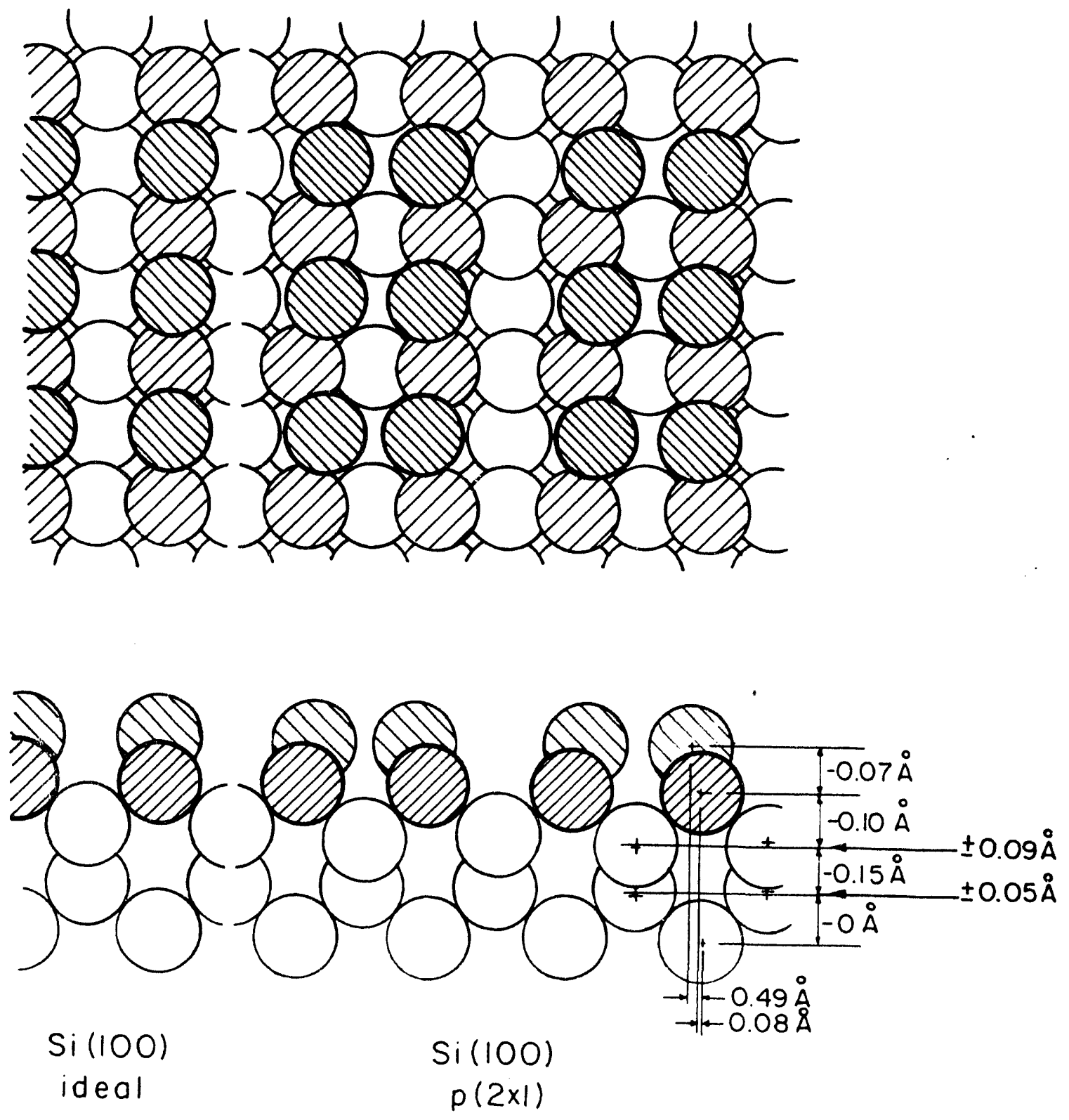

$X B L 7812-6285$

Figure 8.20: The reconstructed silicon(100) crystal face as obtained by LEED-surface crystallography. Note that relaxation extends to three atomic layers into the bulk [25]. 
been studied by STM and SHG. The Au(111)-(1x23) reconstruction for the clean surface in UHV [26] has been observed using SHG for an $\mathrm{Au}(111)$ electrode in an electrochemical cell [27]. The reconstruction can be lifted to give the $\mathrm{Au}(111)-(1 \times 1)$ structure by changing the electrode potential, as shown in figure 8.21. Adsorption of halide ions from solution also lifts the $\operatorname{Au}(111)-(1 \times 23)$ reconstruction [27]. It is hoped that further studies at the solid-liquid interface will determine which surface reconstructions survive from solid-gas to solid-liquid interfaces.

In addition to causing substrate relaxation, chemisorption can often lead to complete restructuring of the substrate metal. This is perhaps best seen in a field ion microscope study of $\mathrm{CO}$ adsorption on a Rh field emission tip [28]. When $\mathrm{CO}$ is adsorbed, all the crystal faces restructure to form new orientations as shown in figure 8.22. Upon removal or $\mathrm{CO}$ and reheating the surface in vacuum, the surfaces go back to their original structure that was established in UHV. Many of these chemisorption studies lead to reversible restructuring, although in some cases the restructuring can be irreversible. Figure 8.23 shows the restructuring of the $\mathrm{Fe}(110)$ surface in the presence of $\mathrm{S}$ [29]. The $\mathrm{S}$ atoms occupy a fourfold site, thereby moving the metal atoms surrounding it to more symmetrical positions. The formation of an $\mathrm{Fe}_{4} \mathrm{~S}$ cluster is implicated. Such an adsorption leads to the weakening of next nearest neighbor metal-metal bonds. The strength of the chemisorption bond provides the thermodynamic driving force that pays for the weakening of next nearest neighbor metal-metal bonds. Figure 8.24 shows similar reconstruction upon $O$ chemisorption on the $\mathrm{Cu}(110)$ surface [30]. A $(2 \times 1)$ surface structure is formed that incorporates $\mathrm{O}$ atoms into the $\mathrm{Cu}$ lattice. Clearly the surface undergoes a major restructuring in the presence of $O$ chemisorption. Figure 8.25 shows the restructuring of the $R h(111)$ surface upon the chemisorption of ethylidyne [31]. The metal atoms move closer to the hollow site where the $\mathrm{C}$ atom closest to the surface is located. The next nearest neighbor metal atoms move downward or upward in the first and second layers respectively, thereby producing a corrugation on the metal surface. The detailed changes of interlayer and interatomic distances are indicated in the figure. These results were obtained by low-energy electron diffraction surface crystallography.

Another technique that is very useful to observe adsorbate induced restructuring is the in situ high pressure scanning tunneling microscope [4]. By heating a $\mathrm{Pt}(110)$ single crystal surface in $\mathrm{H}, \mathrm{O}$ and $\mathrm{CO}$ the restructuring of the surface in various ways is observed [32]. These are indicated by the STM picture and schematically in figure 8.26. 


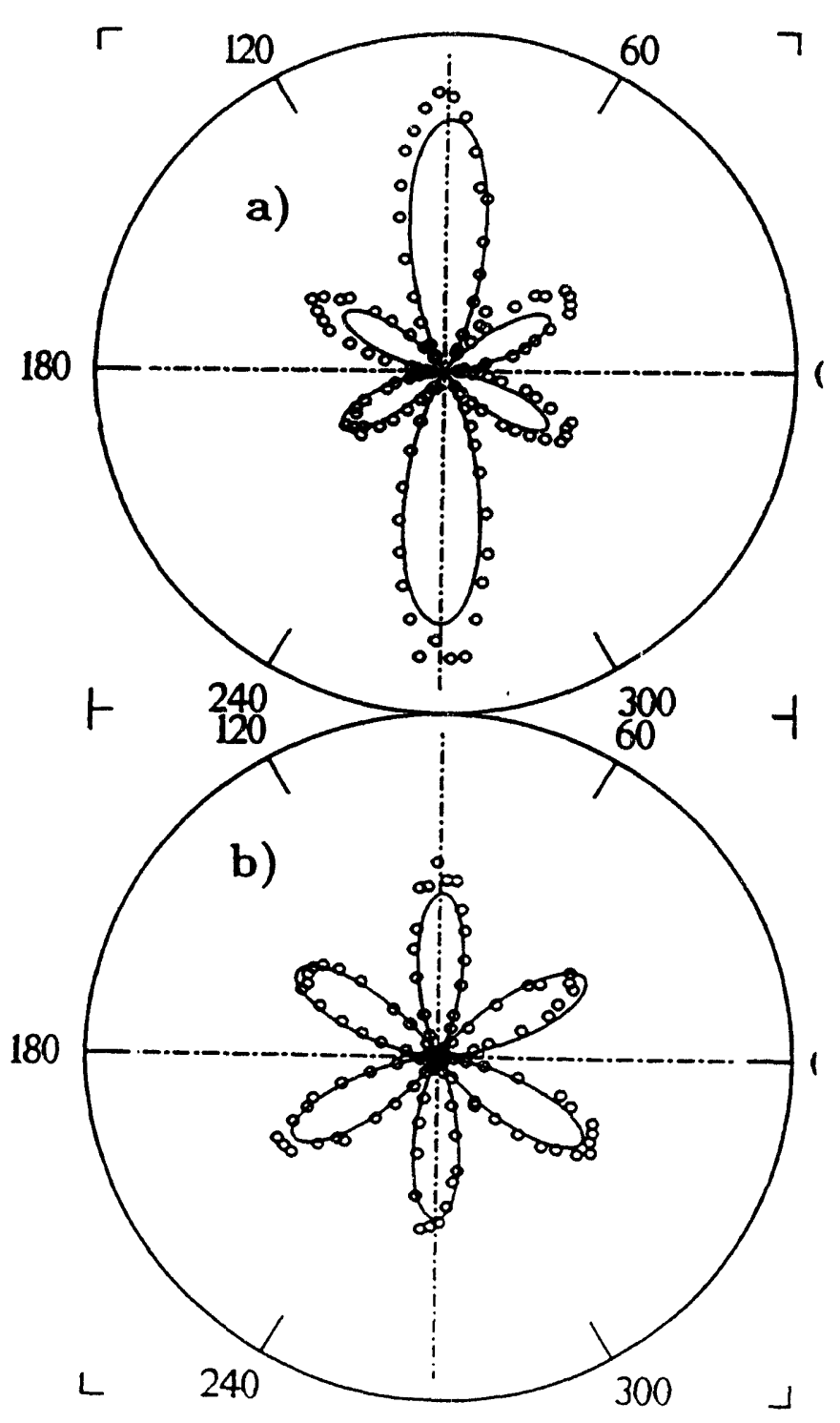

Figure 8.21: Second harmonic generation as a function of rotation angle for $\mathrm{Au}(111)$ in $0.1 \mathrm{M} \mathrm{HClO}_{4}$ at (a) $-0.4 \mathrm{~V}$ and (b) $+0.9 \mathrm{~V}$ vs. SCE. In (a) the surface is reconstructed to $\mathrm{Au}(111)-(1 \times 23)$ and in (b) the reconstruction is lifted, giving $A \mathrm{u}(111)-(1 \times 1)[27]$. 

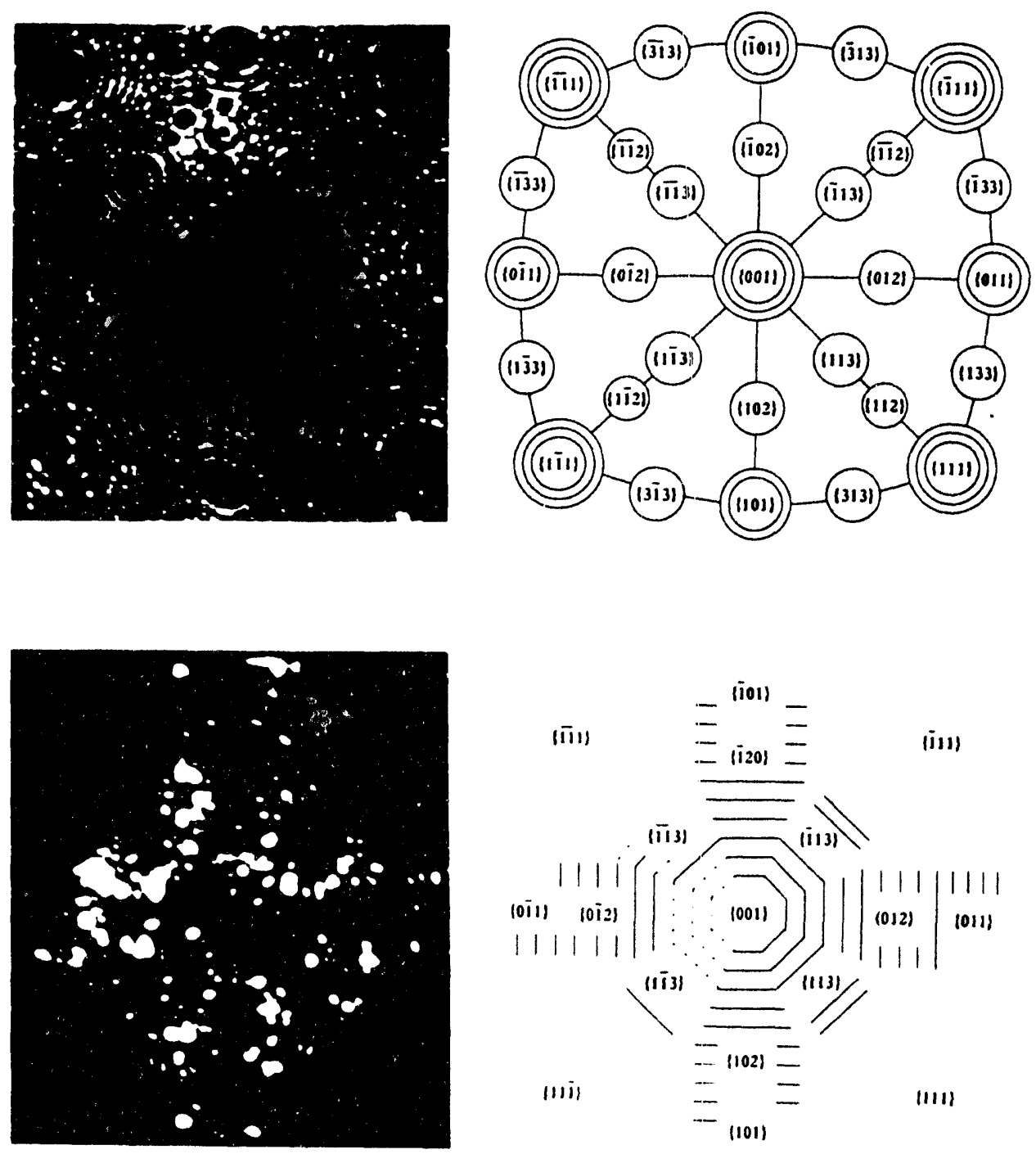

Figure 8.22: Ficld ion micrographs (image gas: $\mathrm{Ne} ; \mathrm{T}=85 \mathrm{~K}$ ) of a (001) oriented Rh tip before (top left) and after reaction with $10^{-4} \mathrm{~Pa} \mathrm{CO}$ for $30 \mathrm{~min}$. at $420 \mathrm{~K}$ (bottom left); stereographic projections at the right demonstrate the change in morphology from nearly hemispherical to polygonal (scheme at the bottom right indicates the coarsening of the crystal and the dissolution of a number of crystallographic planes due to the reaction with CO) [28]. 
Chapter 8. Correlations of Atomic Structure and Reactivity ...

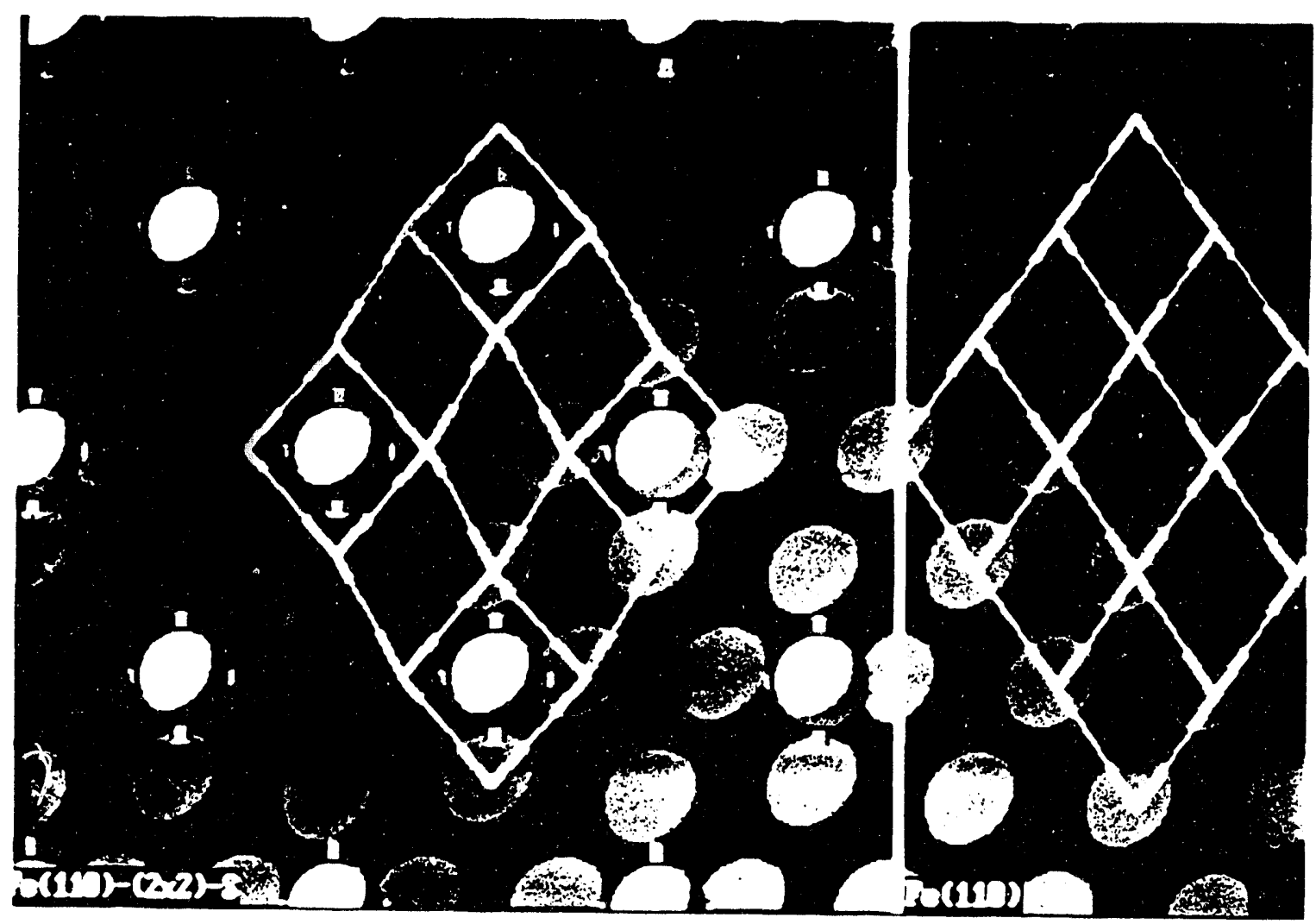

Figure 8.23: Sulfur chemisorption induced restructuring of the $\mathrm{Fe}(110)$ surface [29]. 


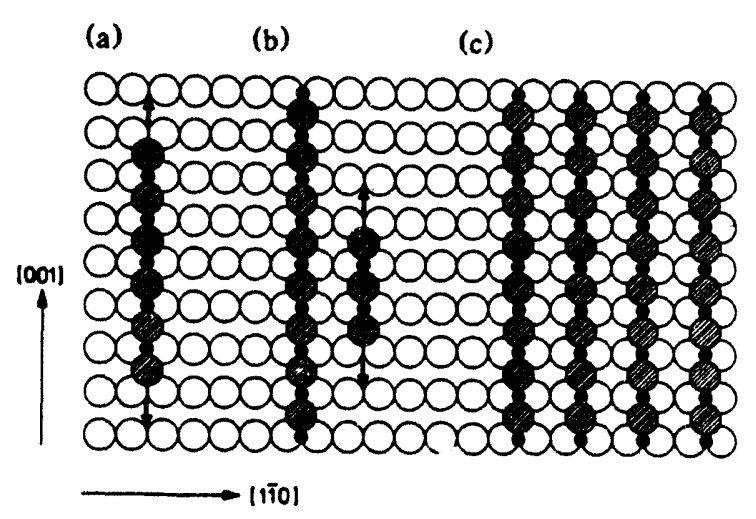

$(2 \times 1)-\mathrm{O} / \mathrm{Cu}(110)$

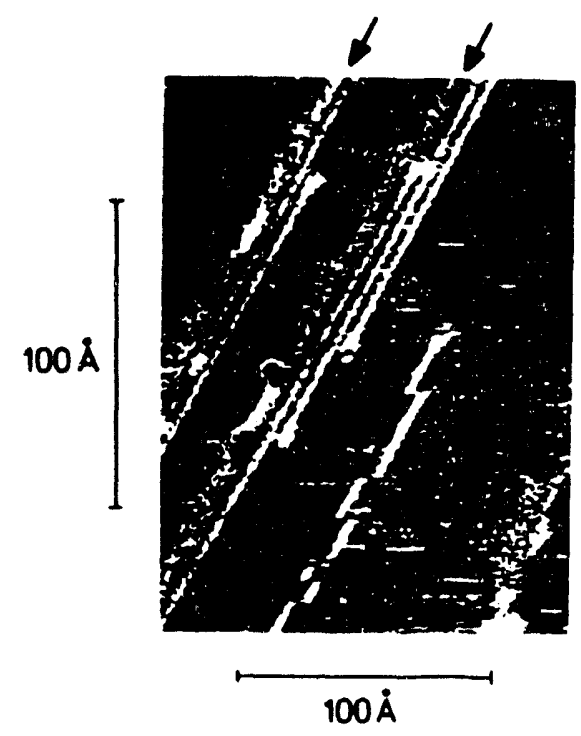

x8: $915-1054$

Figure 8.24: Oxygen chemisorption induced surface structure on $\mathrm{Cu}(110)$ [30]. 


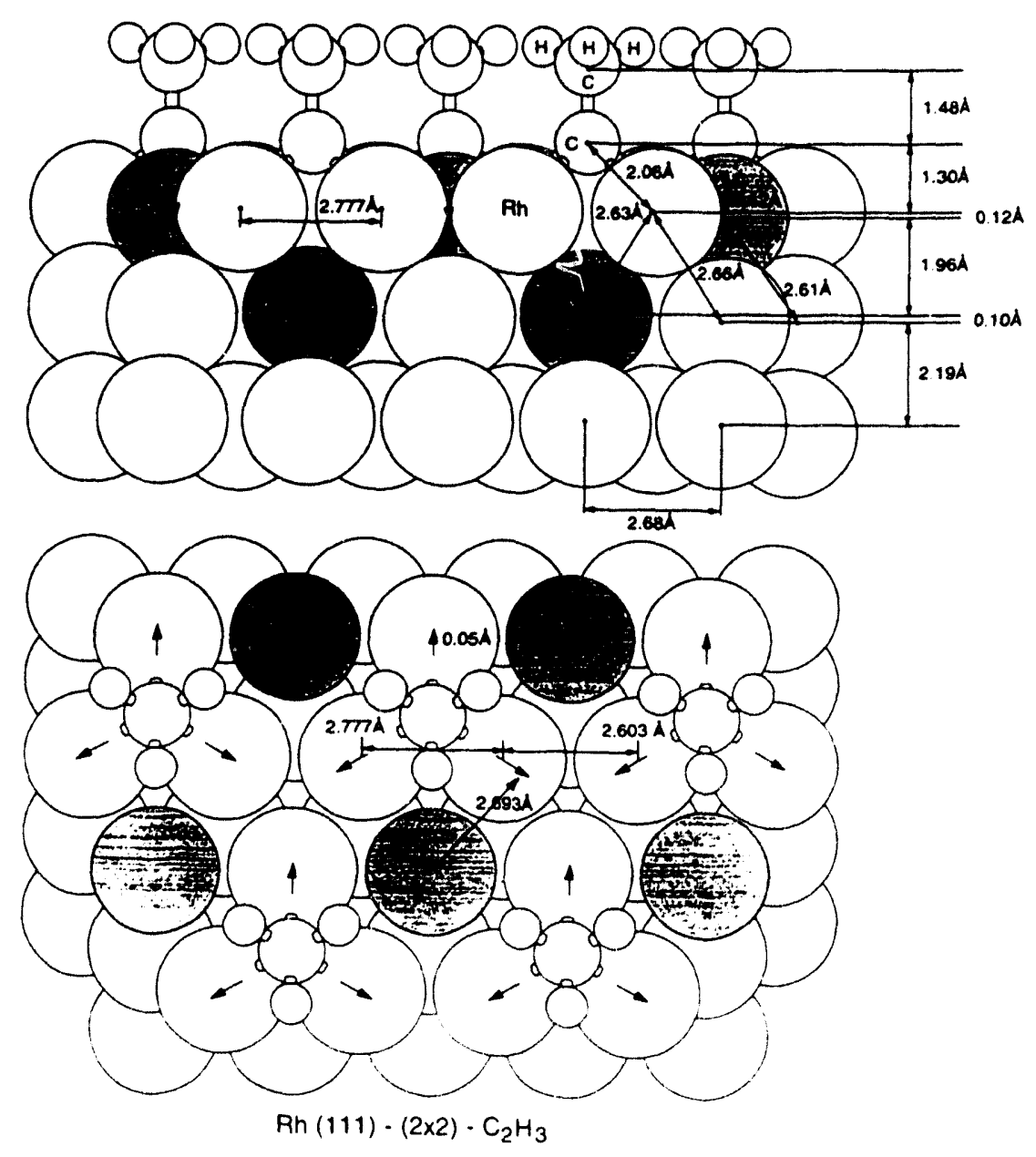

$\times 81914.6952$

Figure 8.25: Ethylidyne chemisorption induced restructuring of the Rh(111) crystal face. Note the expansion of metal atoms around the adsorption site [31]. 


\section{In Situ High Pressure STM} Adsorbate-induced surface reconstructions

$\operatorname{Pt}(110)$ under atmospheric pressures
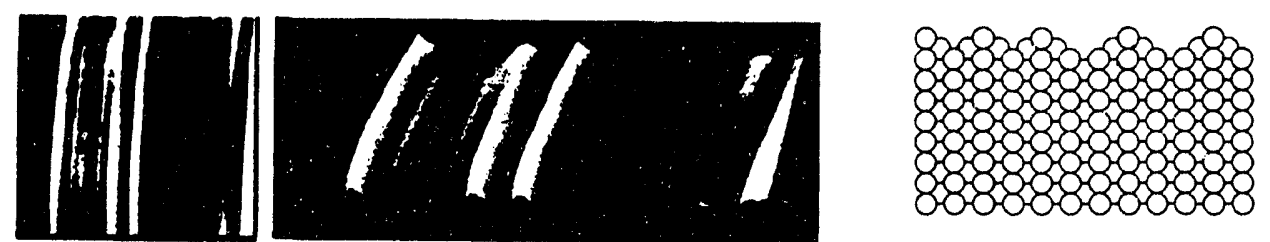

hydrogen: 1.7 atm. $730 \AA \times 700 \AA$.
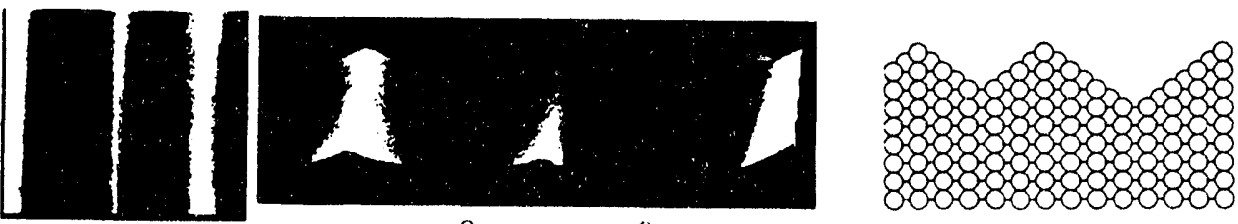

oxygen: 1 atm. $900 \AA$ × $780 \AA$.
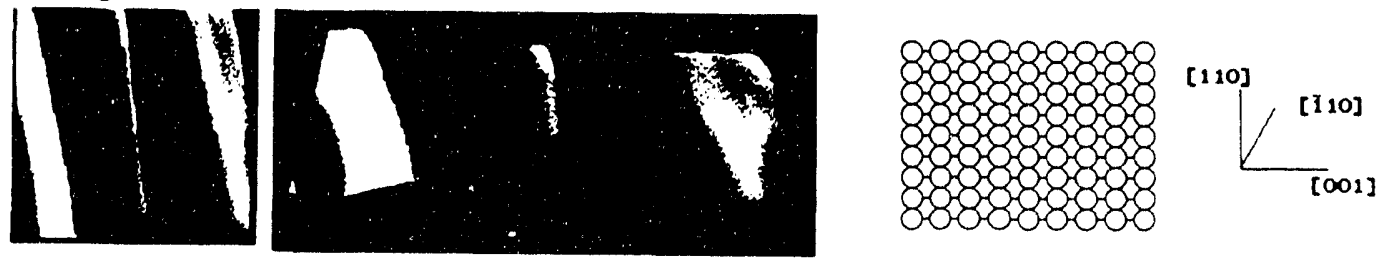

carbon monoxide: 1 atm. $770 \AA \ddot{~ x ~} 740 \AA$.

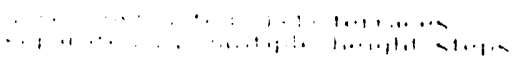

Figure 8.26: In-situ high pressure STM images of a Pt(110) crystal exposed to 1.7 atm of hydrogen (top); 1 atm of oxygen (middle); and 1 atm of CO (bottom). Schematics of the corresponding surface structures are shown at right [32]. 
It is hoped that restructuring that may occur at solid-liquid interfaces will be studied and we could identify the differences between the restructuring of various substrates upon chemisorption at the solid-liquid interface as compared to the solid-gas interface. In one such study, iodine overlayer structures on $\mathrm{Pt}(111)$ electrodes were studied in situ using SHG [33]. Under UHV conditions iodine forms ordered $(\sqrt{7} \times \sqrt{7}) \mathrm{R} 19.1^{\circ}$ and $3 \times 3$ overlayer structures on $\mathrm{Pt}(111)$, depending on the surface coverage [34]. At the appropriate electrode potential in an electrochemical environment the $3 \times 3$ iodine overlayer on $\operatorname{Pt}(111)$ has been observed by in-situ STM and SHG. However, the $(\sqrt{7} \times \sqrt{7})$ R19.1 ${ }^{\circ}$ structure can be verified in ex-situ LEED experiments [35], but in-situ SHG measurements in the electrochemical cell show a $\mathrm{C}_{1 V}$ surface symmetry, rather than the expected $\mathrm{C}_{3}$ symmetry for this structure. This indicates that there is a different surface structure for this system at the solid-liquid interface as compared to the solid-gas interface.

\subsubsection{Adsorbate structure}

Infrared Spectroscopy, SFG, STM and AFM are techniques which can be used to determine the structure of adsorbates both at the solid-gas and solid-liquid interfaces. Recent infrared spectroscopy studies, for example, indicate that $\mathrm{CO}$ occupies bridge and top sites at solid-liquid interfaces behaving in a way very similar to that at the solid-gas interface [7], as shown in table 8.2. SFG studies by Rabinowitz et al [36], of the adsorption of acetonitrile in the gas phase on zirconium oxide, indicate that this molecule binds through the nitrogen end and it is almost perpendicular to the oxide surface. When adsorption at the solid-liquid interface is compared [36], it is found that there is a change in the vibrational spectrum indicating the formation of dimers at the solid-liquid interface, where no such feature is present at the solid-gas interface.

At the solid-gas interface, increasing the coverage for a given molecule leads to lower heat of adsorption, as shown before, as well as relocation of adsorbed species because of repulsive adsorbate-adsorbate interactions. This is clearly shown for $\mathrm{CO}$ in figure 8.27 [37]. As one increases the coverage from half a monolayer to more than half a monolayer, the molecules relocate to increase the adsorbate-adsorbate repulsive interaction. As one increases the coverage molecular reorientation can also occur. This is shown in table 8.3 for pyridine on various transition metal surfaces [38]. The molecule can lie flat or stand upright or bond through the lone pair of $\mathrm{N}$ electrons and undergo perhaps loss of $\mathrm{H}$ as well, as a 
function of coverage and depending on which transition metal it is chemisorbed on. Such studies would be very important to carry out at solid-liquid interfaces.

\subsubsection{Defect sites and rough surfaces are chemically more active}

It is well known from solid-gas interface studies that defect sites, steps and kinks, have higher heats of adsorption for various adsorbates. Figure 8.28 shows the thermal desorption spectrum of $\mathrm{H}$ from a flat, stepped and kinked $\mathrm{Pt}$ surface [8]. The stepped surfaces show two desorption peaks, one from the steps and one from the terrace, and the desorption peak from step atoms for $\mathrm{H}$ is at higher temperature indicating a higher heat of adsorption. From a kinked $(12,9,8)$ surface there are three peaks. The highest temperature desorption peak is for adsorbed $\mathrm{H}$ at the kinks. $\mathrm{H}-\mathrm{D}$ exchange studies using molecular beam scattering [39] clearly indicate the larger reactivity for this catalytic reaction at stepped sites. The reaction probability for H-D exchange in stepped platinum is almost unity, while on flat, defect free Pt surfaces is below $10^{-3}$, the detection limit. Such studies are not available at solid-liquid interface at present. It is hoped that the role of defects will also be explored at solid-liquid interfaces.

\subsection{Coadsorption}

When two different molecules are adsorbed, attractive adsorbate-adsorbate interaction can occur. For example, this is the case for the Coadsorption of $\mathrm{CO}$ and ethylidyne on the $\mathrm{Rh}(111)$ surface [40]. The two molecules form a unit cell in which both molecules participate. The work function change on adsorption of $\mathrm{CO}$ appears to be positive, indicating that $\mathrm{CO}$ is an electron acceptor from the metal surface. When ethylene is adsorbed, the work function of the metal decreases, indicating that the organic molecule is an electron donor. This donor-acceptor interaction, which is shown schematically in figure 8.29 , can lead to a electric Stark effect [40] which can result in attractive interaction of the magnitude of dipole-dipole interactions $(0.1-0.3 \mathrm{cV})$.

Coadsorption can also change the structure of chemisorbed molecules. Figure 8.30 shows the chemisorption of benzene alone on the $\mathrm{Pt}(111)$ crystal face [41]. This molecule is located with its center at a bridge site, and it is bent. Four of the $\mathrm{C}$ atoms are further away from the surface than the other two. When CO coadsorbs with benzene, the molecule 

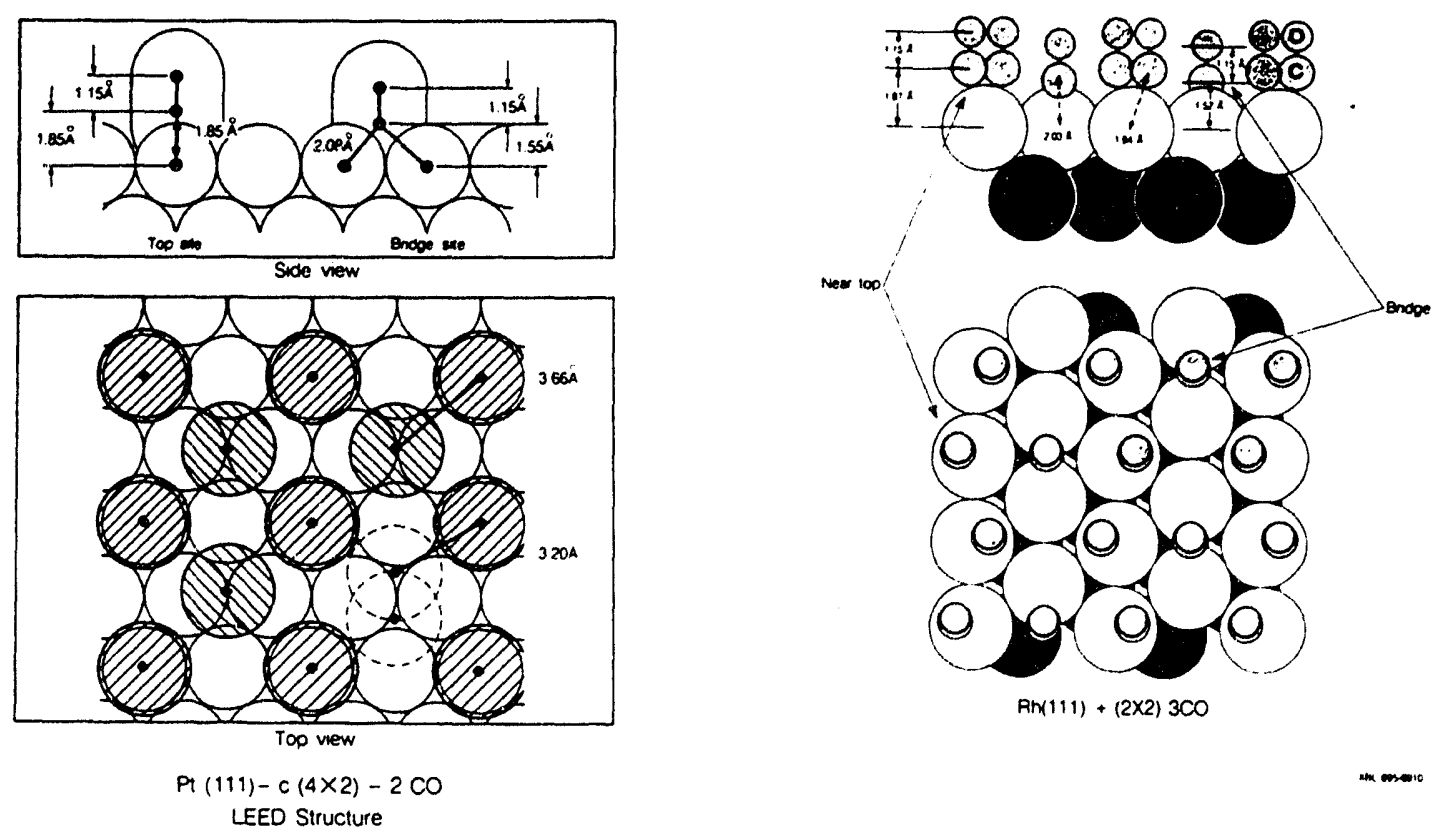

LEED Struclure
at $T=150 \mathrm{~K}$

Figure 8.27: Ordered $\mathrm{CO}$ surface structures on $\mathrm{Pt}(111)$ and $\mathrm{Rh}(111)$. (a) The structure at one half monolayer coverage on $\mathrm{Pt}(111)$, and (b) at higher coverages on $\mathrm{Rh}(111)$. While the bridge and top site occupancy predominate at the lower coverages, repulsion forces the molecules to relocate at higher coverages [37]. 
Chapter 8. Correlations of Atomic Structure and Reactivity ...

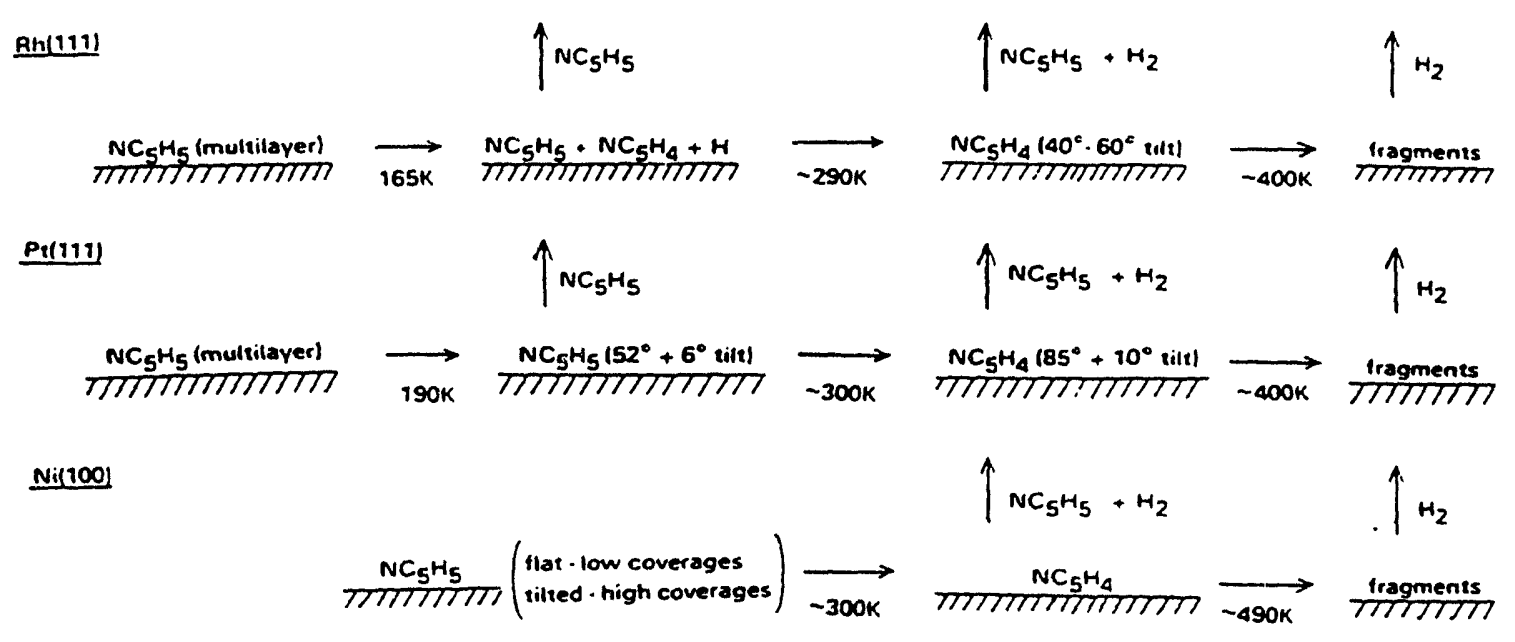

Pad1111

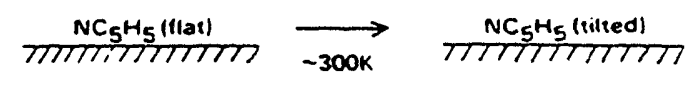

In1111) Cu(1110).P(1110)

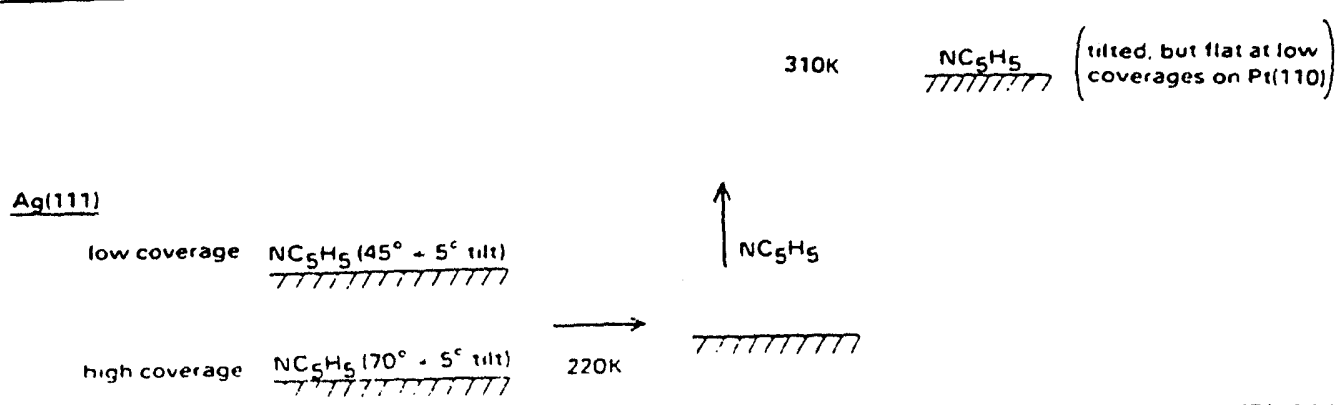

XBL $9311-1581$

Figure 8.28: Schematic of the reaction of pyridine with various metal surfaces as reported in the literature [38]. The tilt angles were measured by NEXAFS or estimated from HREELS peak intensities and correspond to the angle between the plane of the ring and the surface plane. 


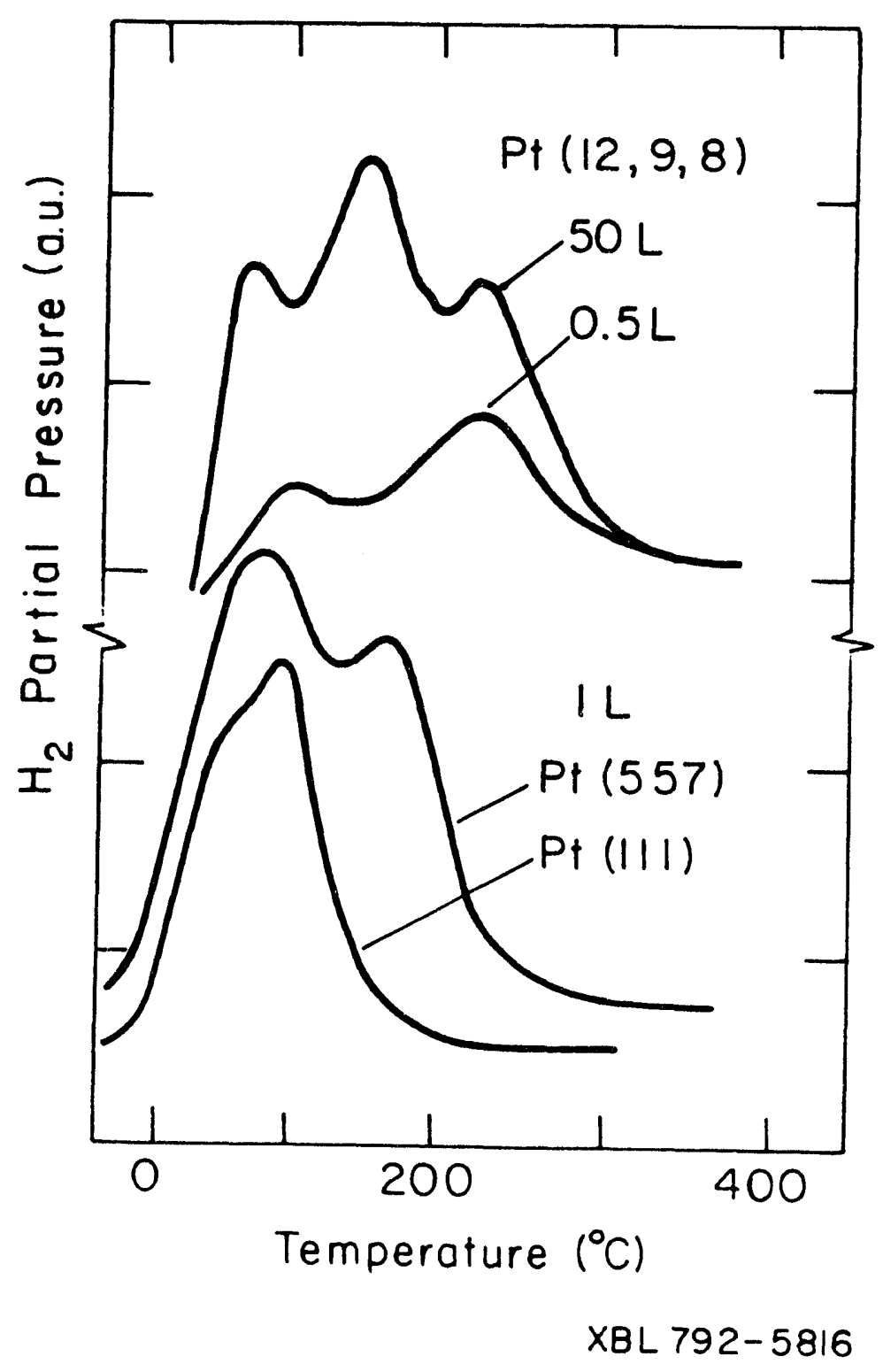

Figure 8.29: Temperature programmed desorption from the flat $\mathrm{Pt}(111)$, stepped $\mathrm{Pt}(557)$, and kinked $\mathrm{Pt}(12,9,8)$ crystal surfaces. 
flattens out [42]. Its CC bond distances are changed. Thus, Coadsorption can lead to changes of bonding.

It would be most important to study coadsorption phenomenon at solid-liquid interfaces as well. Weaver and co-workers [7] investigated $\mathrm{CO}$ adsorption at Pt- and Rhaqueous interfaces by infrared reflection-absorption spectroscopy (IRRAS). They found a greater propensity for bridging $\mathrm{CO}$ coordination at low $\mathrm{CO}$ coverages than is observed for the corresponding system in UHV. It was proposed that this is due to coadsorption of hydrogen and water with $\mathrm{CO}$ in the electrochemical environment. It is interesting that coadsorption of water and $\mathrm{CO}$ on $\mathrm{Pt}(111)$ in UHV also increases the ratio of bridge-bonded to terminally bonded $\mathrm{CO}$ [43].

Coadsorption often occurs by compressing one type of molecule in the adsorbate layer to make room for the molecules of the other type. This is shown by an STM study in figure 8.31 [44]. When $\mathrm{CO}$ is adsorbed on a Re surface that is covered with $\mathrm{S}$ at relatively low coverages the $\mathrm{S}$ layer is compressed into a high coverage structure, thereby creating a hole in which $\mathrm{CO}$ adsorbs. When $\mathrm{CO}$ is desorbed, the $\mathrm{S}$ atoms move back to their original equilibrium ordered positions. This adsorption by compression of the adsorbed layer is perhaps the important mechanism for coadsorption of molecules that react during catalytic reactions at high pressures or at solid-liquid interfaces. The activation energies for surface diffusion to move the already strongly chemisorbed atoms or molecules sideways along the surface is appreciably lower, in the range of $0.5-0.7 \mathrm{eV}$, as compared to desorption energies that are several $\mathrm{eV} /$ molecule.

\subsection{Dynamics at Surfaces}

\subsubsection{Surface diffusion}

When an STM is utilized to scan rapidly $(0.1 \mathrm{msec} / 100 \AA)$ a S covered rhenium surface, the image blurs as shown in figure 8.32 [45]. Using spatial correlations, one can image the $\mathrm{S}$ atoms (figure 8.33) that are caught while they are diffusing along the surface by the rapid scanning method. Employing an Ising model one can determine the pair interaction energy between the $\mathrm{S}$ atoms, which is in the range of $33 \mathrm{meV}$. One can also obtain an activation energy on the order of $0.8 \mathrm{eV}$ for $\mathrm{S}$ on rhenium surfaces. Recent studies indicate that the diffusion cocfficient and the activation energy for diffusion both 
Chapter 8. Correlations of Atomic Structure and Reactivity ...

161

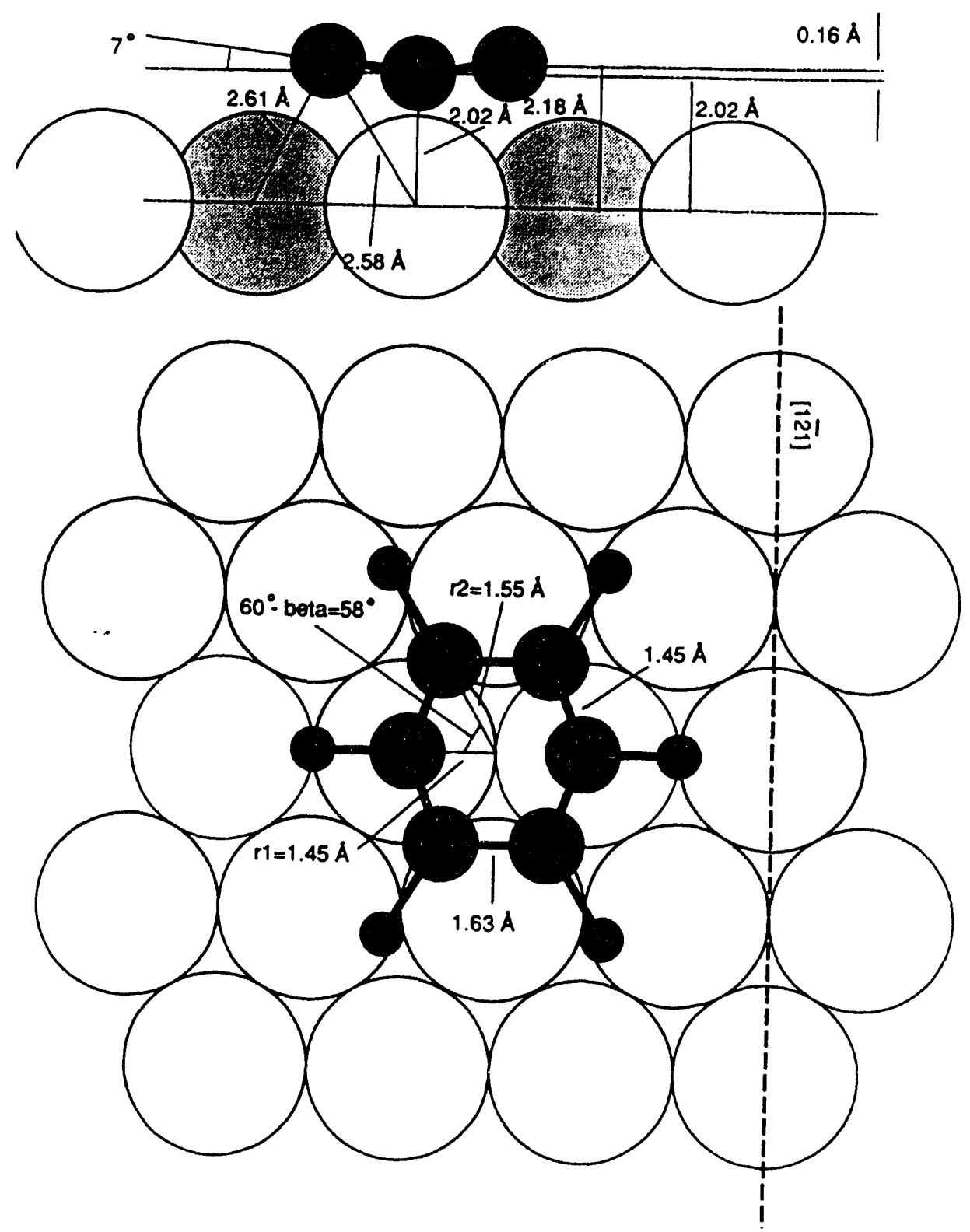

XBL $9011-3575$

Figure 8.30: The surface structure of benzene in a disordered monolayer on $\mathrm{Pt}(111)$. The chemisorbed benzene layer remains disordcred in the absence of coadsorbed $\mathrm{CO}$. Note the bending of the benzene molecule into a boat-like surface structure [41]. 


\section{$\mathrm{C}(2 \times 2) \mathrm{S}$ on $\mathrm{Re}$}

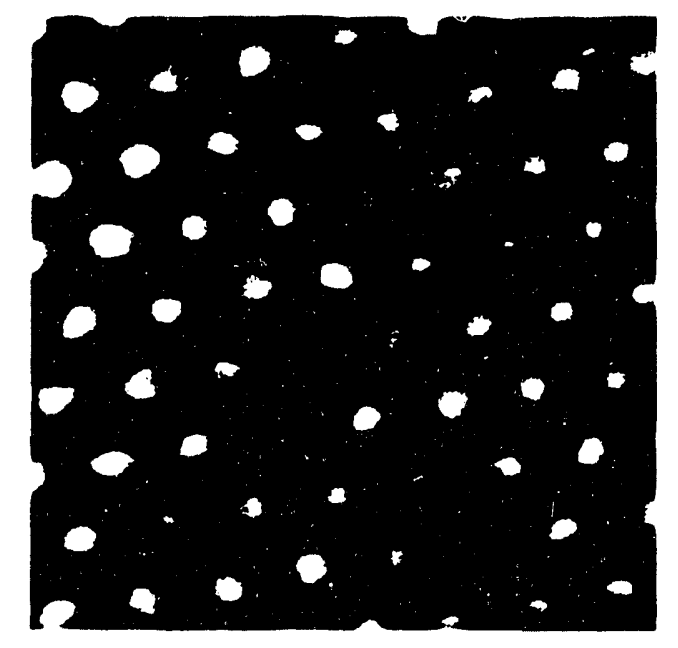

Before CO Exposure $40 \times 40$ Angstroms

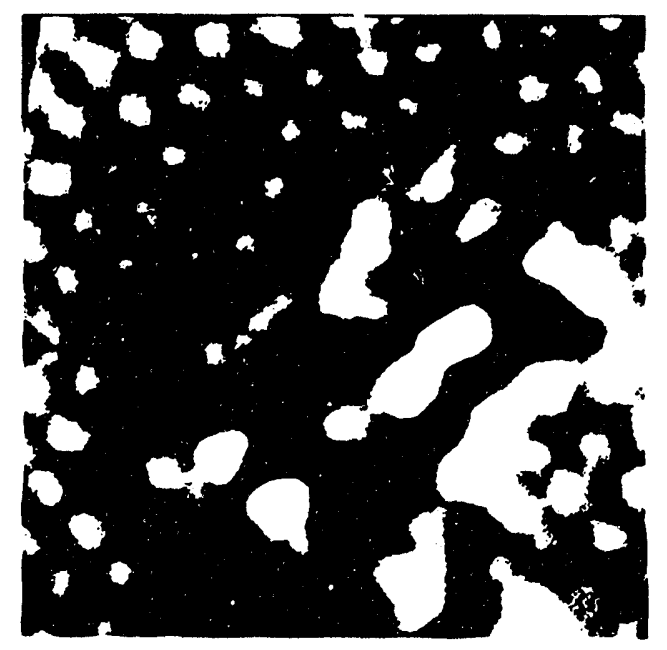

After CO Exposure $55 \times 55$ Angstroms

\section{Compression of overlayer by CO coadsorption.}

Figure 8.31: STM images before and after the reordering of sulfur on $\operatorname{Re}(0001)$ induced by $\mathrm{CO}$ exposure. At left, the round maxima are due to individual $\mathrm{p}(2 \times 2)$ ordered sulfur atoms adsorbed at the hep hollow site of the surface. At right, a hole has formed in the $\mathrm{p}(2 \times 2)$ layer where $\mathrm{CO}$ has adsorbed (CO molccules are not visible in the STM image). The sulfur atoms which were previously in the hole have been compressed to form trimers of three atoms which appear as bright spots surrounding the hole [44]. 
depend on coverage [46]. In one such study the $O$ coverage was varied on the $W(110)$ surface [47]. This data is shown in figure 8.34.

It would be most desirable to measure surface diffusion rates at solid-liquid interfaces and compare them with surface diffusion at solid-gas interfaces. Recently a technique termed scanning electrochemical microscope induced desorption (SECMID) has been proposed for measurements of adsorption/desorption kinetics and surface diffusion rates at the solid-liquid interface [48]. The technique was applied to the adsorption/desorption and diffusion of $\mathrm{H}^{+}$on rutile(001) and the (010) surface of albite. However, the diffusion rate on both surfaces was too slow to be measured. Diffusion processes such as annealing and recrystallization of $\mathrm{Au}(111)$ surfaces at room temperature have been studied by in-situ electrochemical STM [49]. In these studies cooperative adatom motions were found to be important, and step-edge motion was observed to be caused by diffusion of step adatoms along step edges.

\subsubsection{Growth}

Recent STM, AFM and EXAFS studies of $\mathrm{Cu}$ on $\mathrm{Au}[50,51]$ and $\mathrm{Ag}$ on $\mathrm{Au}[51,52]$ indicate that smooth epitaxial metal films can be grown on substrates of other metals at the solid-liquid interface. When growth was studied at the solid-vacuum interface, the growing film was rough and island-like [53]. For reasons that have not been explored, it appears that smooth epitaxial layers can be deposited much better at solid-liquid than solid-gas interfaces. One possible explanation would be that adsorbed ions facilate the diffusion of metal atoms. It appears indeed that the solvent used dramatically modifies the mechanism of nucleation, surface diffusion and growth. This is an important area of research that will be explored in many laboratories in the future because of its technological importance.

\subsection{Surface Reactions}

\subsubsection{Structure sensitive and structure insensitive reactions}

Reaction studies at solid-gas interfaces reveal the existence of two classes. Those reactions with rates that are dependent on surface structure, and those that are not. Ammonia synthesis on Fe [54] or Re [8] surfaces is very structure sensitive. There can be two orders of magnitude variation of chemical reactions rates from one surface structure to an- 


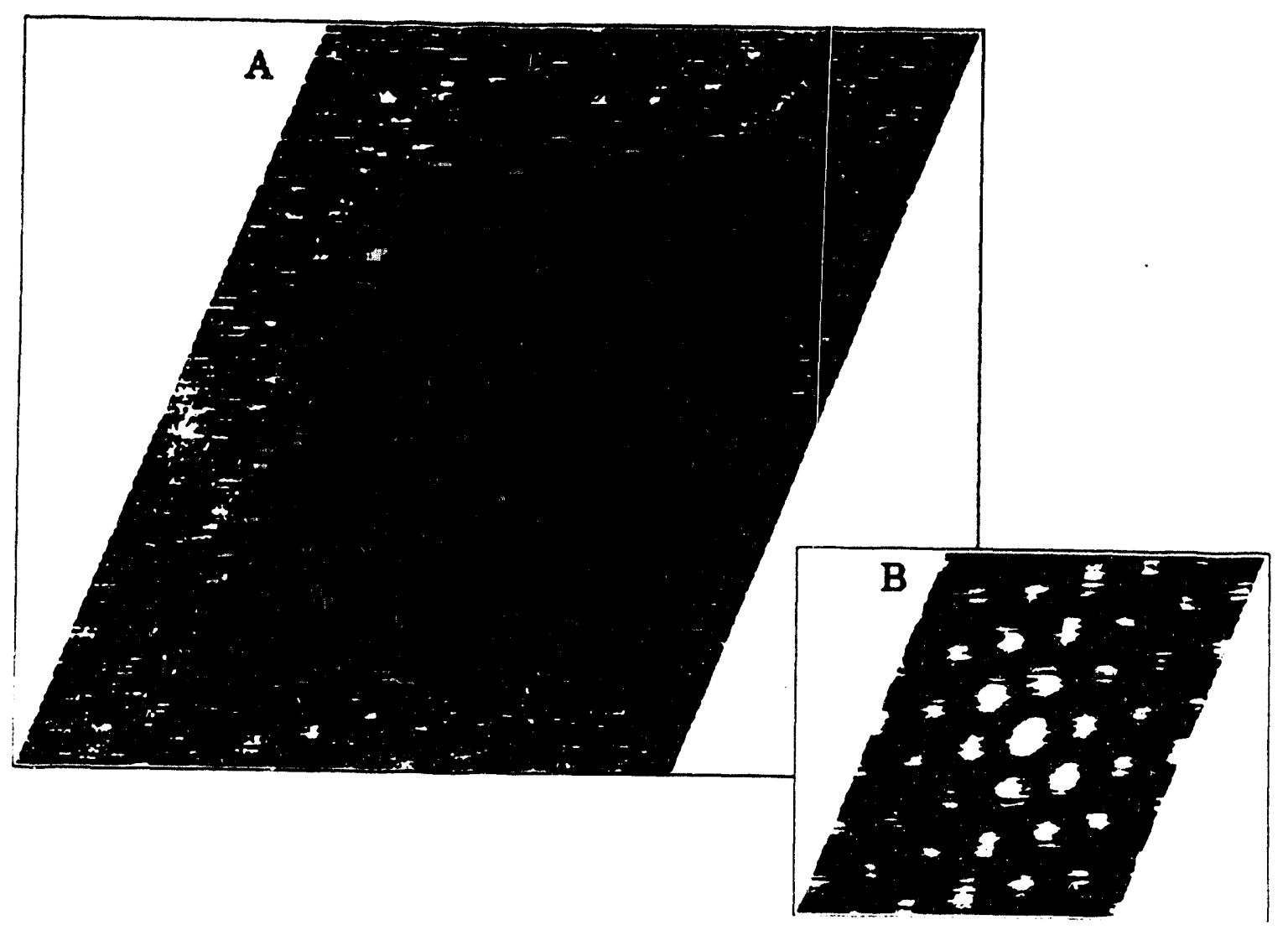

Figure 8.32: At left, a 70x70 $\AA^{2}$ unfiltered STM image of diffusing sulfur atoms on Re(0001). At lower right, the corresponding corrclation image showing that the diffusing sulfur is a lattice gas that maintains a local $\mathrm{p}(2 \times 2)$ order over several lattice distances [45]. 


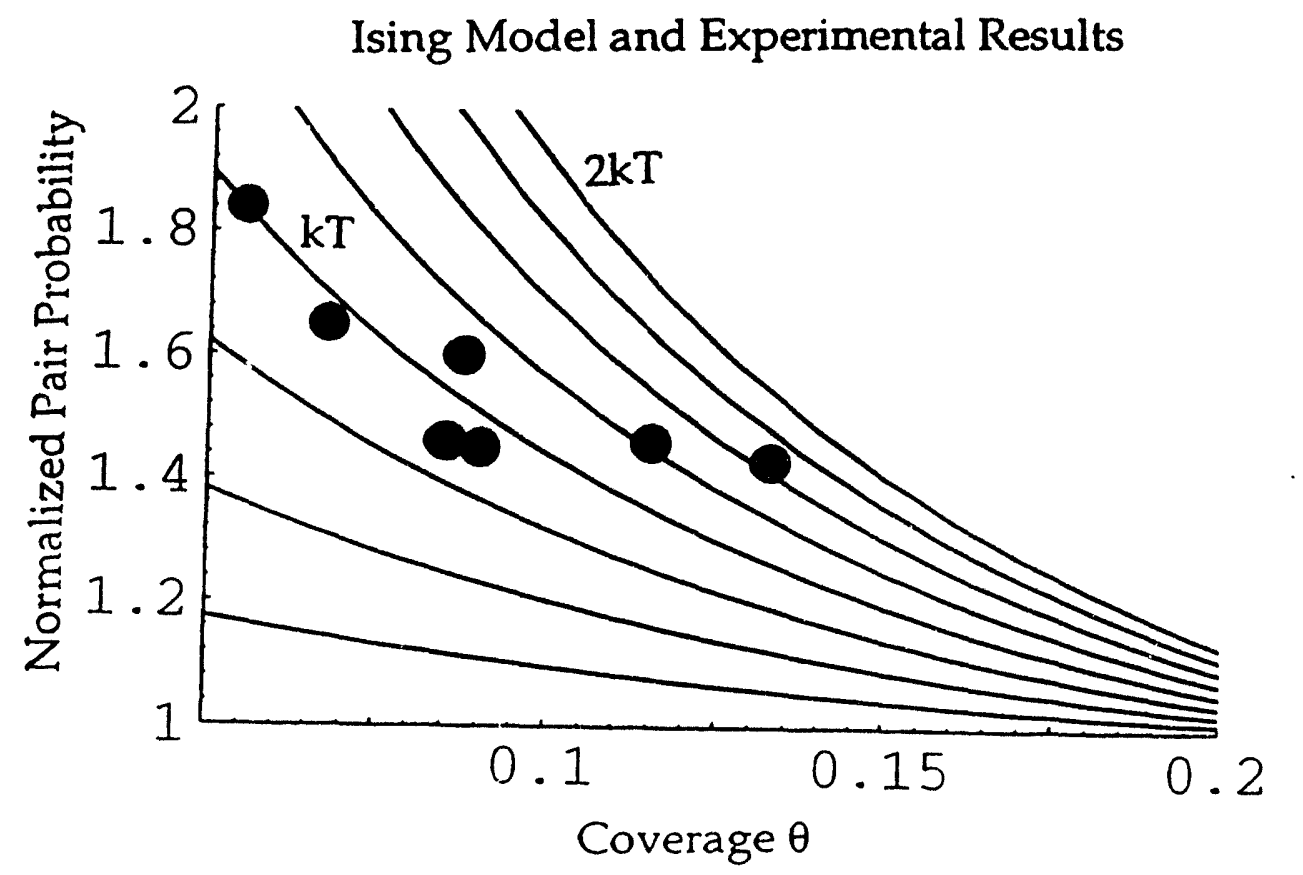

XBL $9311-1558$

Figure 8.33: Contour plot of the pair interaction energy for diffusing sulfur atoms on $\operatorname{Re}(0.001)$ derived from STM data using an Ising model. The vertical axis is the frequency of formation of pairs of atoms at a distance of twice the Re lattice constant (2a). This axis is normalized such that the result is one in the zero interaction energy case in which pairs form randomly. The results of an Ising model are shown as contours of constant interaction energy spaced at intervals of $\frac{1}{4} \mathrm{kT}$. The experimental results are shown as dots, and follow the theoretical contours for low coverages (the first 5 data points) where the model is expected to be accurate. From a fit to the first five data points the attractive interaction energy between sulfur atoms at the 2 a distance was determined to be $24 \pm 5 \mathrm{meV}$ [45]. 


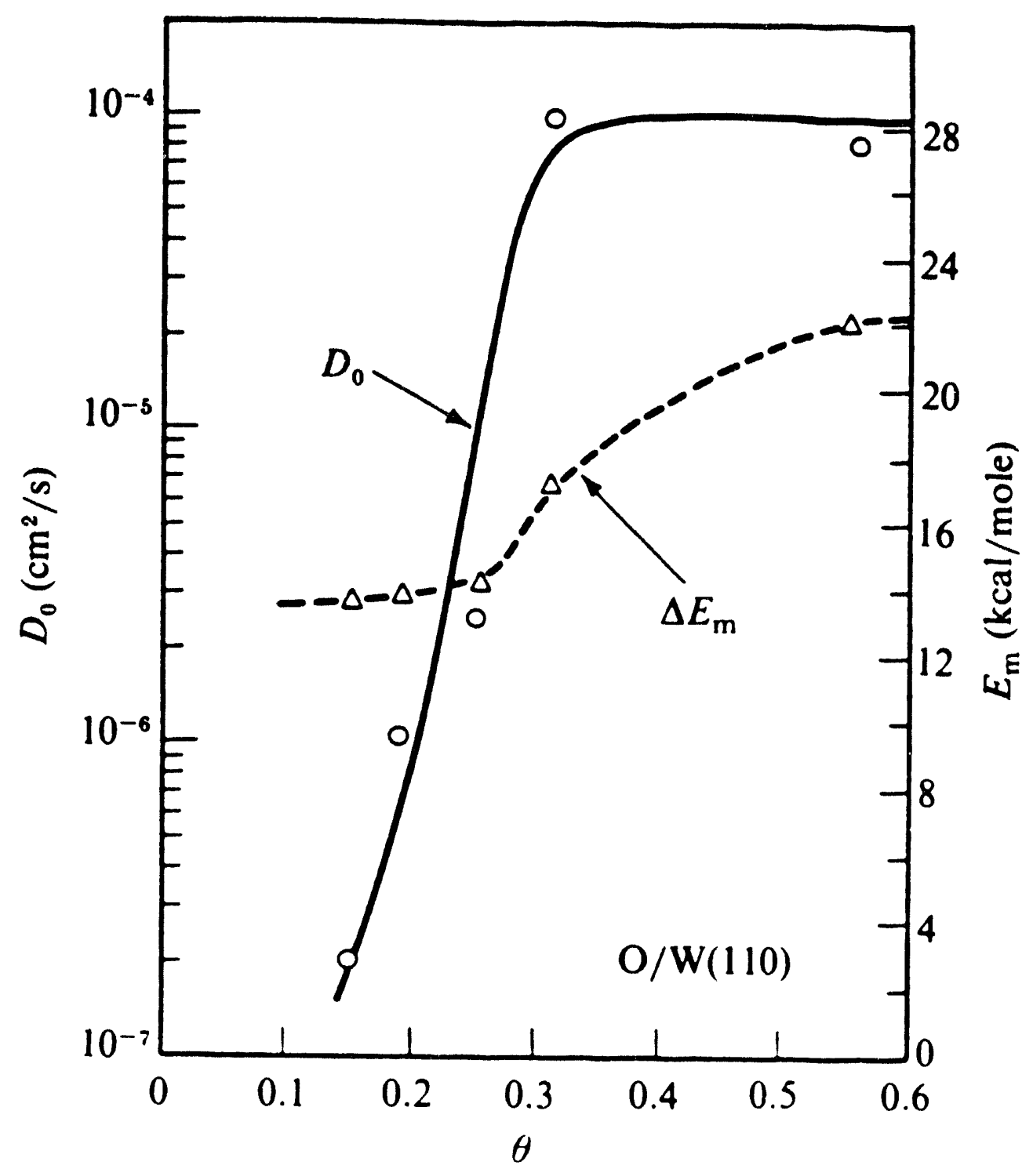

Figure 8.34: Variation in the diffusion constant $\mathrm{D}$, and activation energy $\Delta E_{D}^{*}$, for oxygen atoms on the W(110) surface as a function of oxygen coverage [47]. 
other. However, the hydrogenation of ethylene [55] or CO [8] appears not to be structure sensitive. It woulc be essential to develop similar correlations at solid-liquid interfaces.

The hydrogenation of cyclohexene to cyclohexane has been studied, both on single crystal low surface area $\mathrm{Pt}$ surfaces and on $\mathrm{Pt}$ clusters dispersed on high surface area supports at the solid-gas $[56,57]$ and solid-liquid $[58,59]$ interfaces. The data is shown in figure 8.35. It appears that the reaction rates at solid-gas interfaces are about an order of magnitude greater than at solid-liquid interfaces. It is not clear what the reason for this is. The experiments were done outside the diffusion controlled regime, so diffusion to and from the surface cannot be the cause of this effect. It would be important to further explore the molecular reasons why solid-gas interface reactions are faster. If this is the case, in many applications, for example for fuel cells, one would favor the use of solid-gas.interface reactions in order to increase the reaction rates if this is desired.

It is important to make sure, in solid-liquid interface studies, to avoid diffucion limitations. Figure 8.36 [58] shows, for the same cyclohexene hydrogenation reaction, how the reaction rate is increasing with the jet velocity that stirs the liquid. As long as the reaction rate is velocity dependent, the reaction is in the diffusion controlled mode. As soon as the reaction becomes independent of the velocity, surface reaction control takes over.

The only catalytic reaction for which gas phase and electrocatalysis were compared is for the hydrogenavion of ethylene on $\mathrm{Pt}$ surfaces [60]. From the figure 8.37, it is clear that there is no correlation. The reaction rate equations at the solid-gas and solid-liquid interfaces are different. So are the activation energies. It is hoped that one will develop this type of experimental data for several catalytic reactions and then one could explore the reasons for the differences of the different mechanisms at the solid-gas and solid-liquid interfaces.

\subsubsection{Structure and bonding modifiers}

Most catalytic reactions can be modified by adding various modifiers that change the structure of the catalytic surface or the bonding of adsorbed reactant intermediates and desorbing products. Electron donors, such as $\mathrm{K}$ are used as bonding modifiers, along with $\mathrm{Cl}$, an electron acceptor. These are electron donor and electron acceptor atoms can modify the bonding of coadsorbed reactants [61]. Alumina or $\mathrm{S}$ are often added to surfaces, 


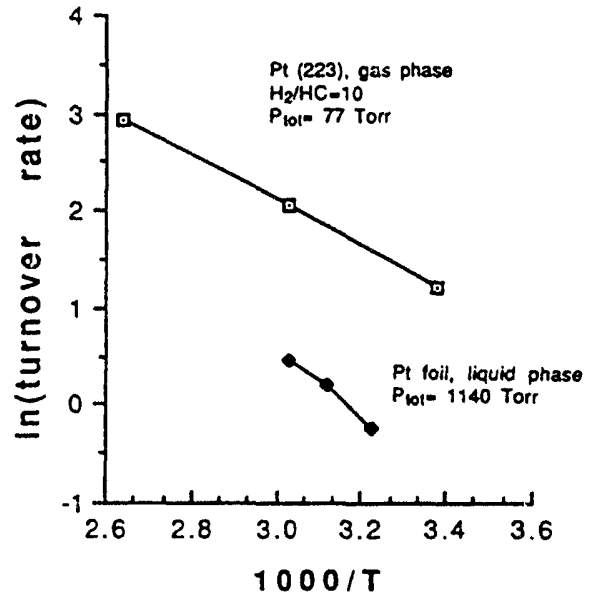

Hydrogenation of Cyclohexene to Cyclohexane on model platinum surfaces. Gas-phase vs. Llquid-phase

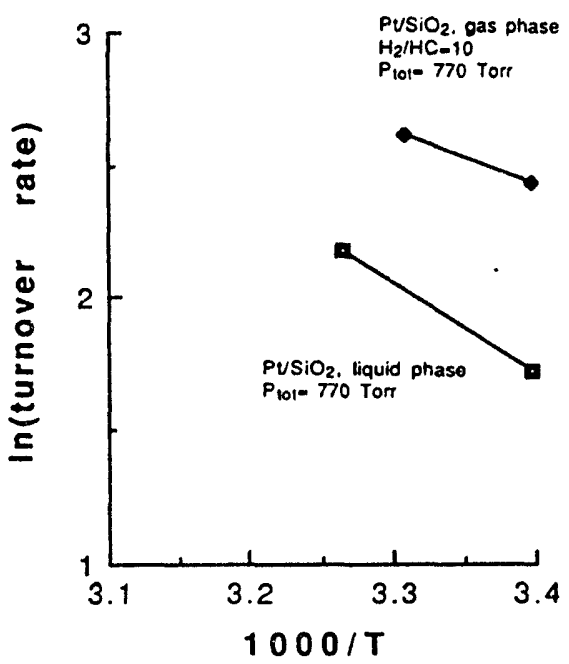

Hydrogenation of cyclohexene to cyclohexane on $\mathrm{P} / \mathrm{SlO}_{2}$ (M. Boudart et al)

XBL 935-724

Figure 8.35: A comparison of the turnover rate for hydrogenation of cyclohexene to cyclohexane at (a) gas-platinum and liquid-platinum interfaces, and (b) gas- $\mathrm{Pt} / \mathrm{SiO}_{2}$ and liquid- $\mathrm{Pt} / \mathrm{SiO}_{2}$ interfaces. Note that in both cases the turnover rate is higher for the gas phase reaction. Data is from references [56-59]. 

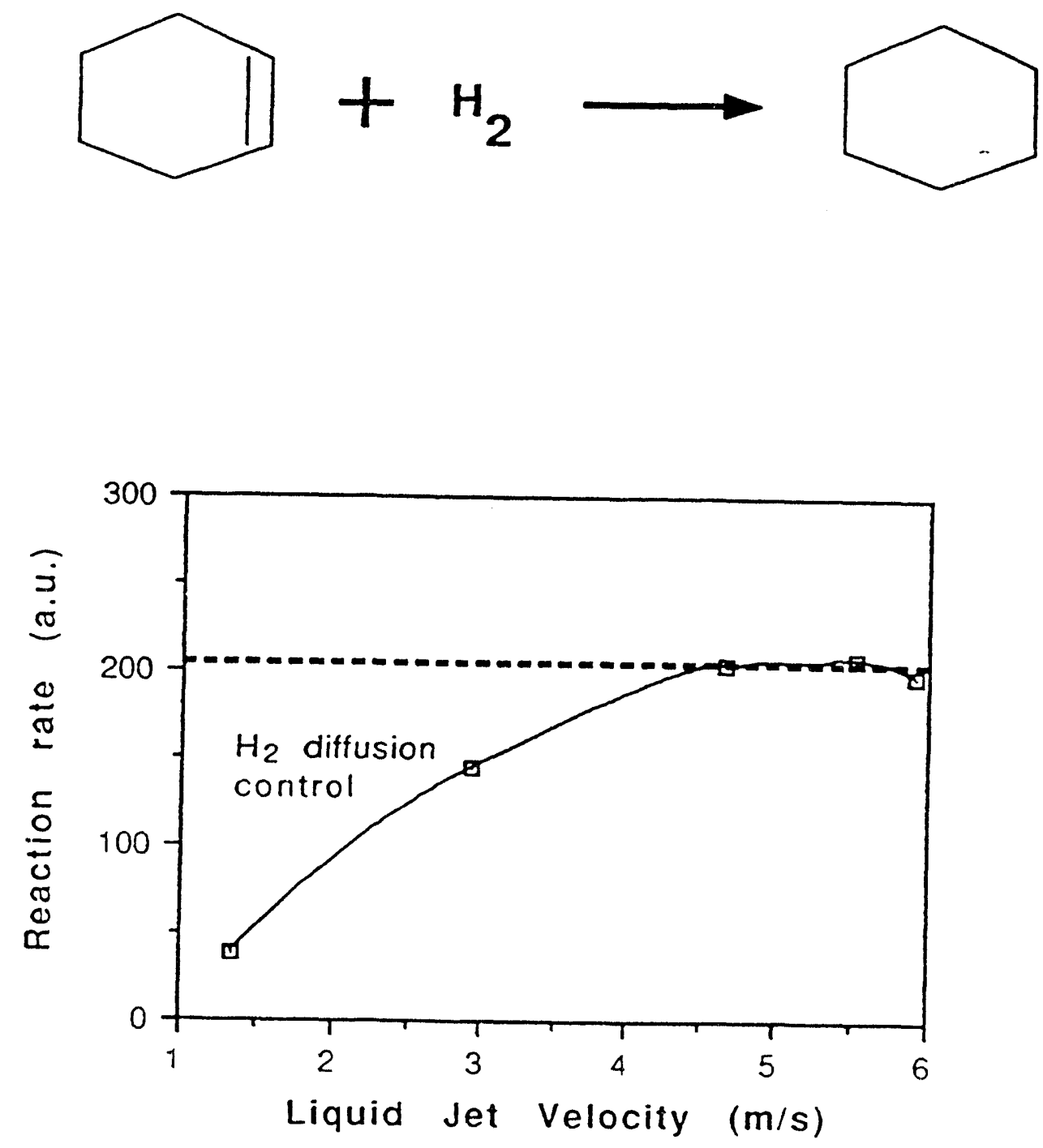

XBL $9311-1559$

Figure 8.36: Cyclohexene hydrogenation reaction rate vs.liquid jet velocity at $\mathrm{T}=50^{\circ} \mathrm{C}$ and $\mathrm{P}_{\mathrm{H}_{2}}=1.5 \mathrm{~atm}$. 


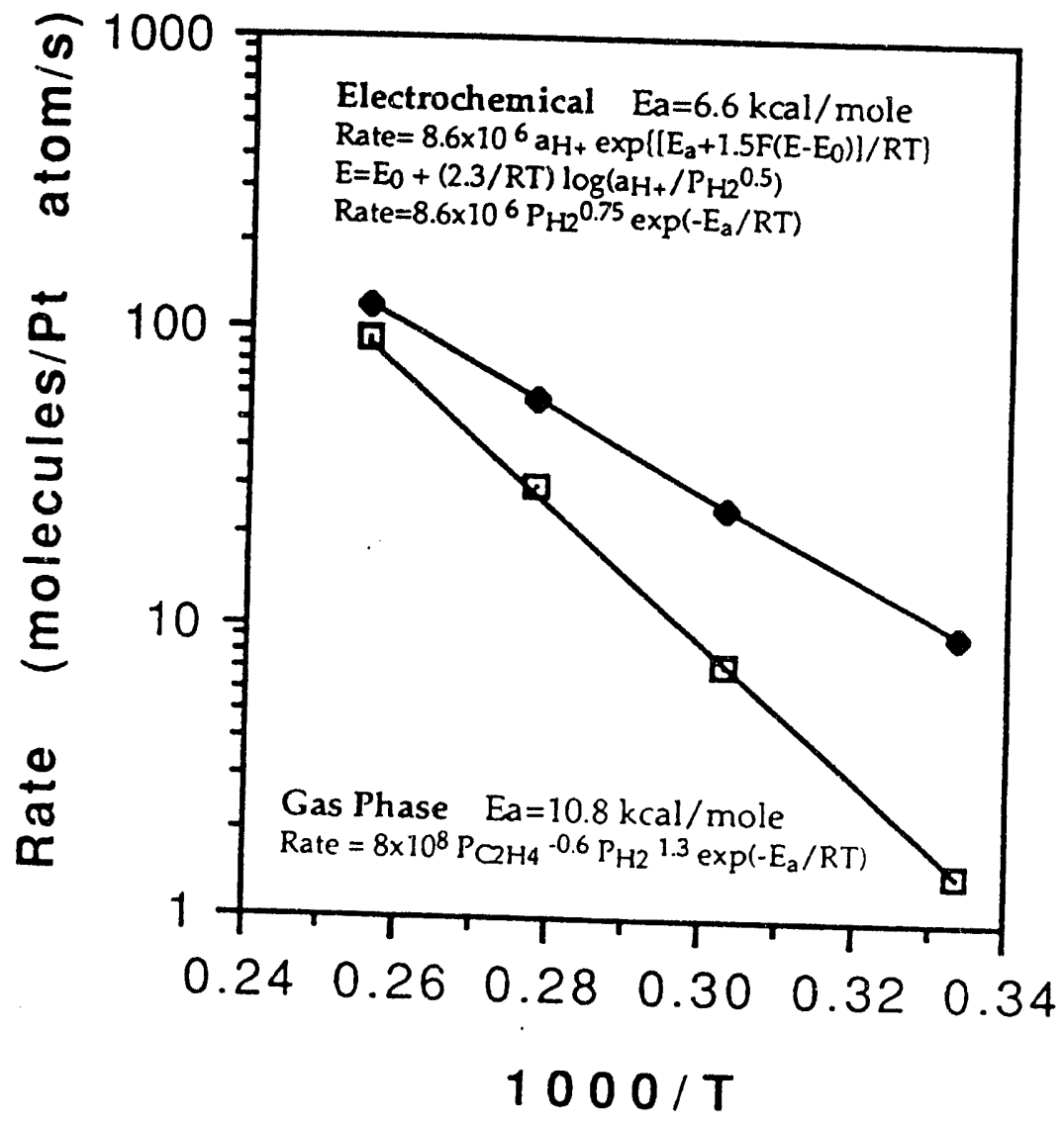

Figure 8.37: Comparison of the gas-phase and electrochemical hydrogenation of ethylene on Pt surfaces. 
which then restructure to another orientation more active for a structure sensitive catalytic reaction [54]. It would be important to explore the role and nature of structure and bonding modifiers at solid-liquid interface catalytic reactions to be able to correlate with the results found at solid-gas interface reactions.

\subsubsection{Enhanced activity at oxide-metal interfaces}

Figure 8.38 shows that by placing the same metal (in this case $\mathrm{Ni}$ ) on various substrates, orders of magnitude changes in catalytic activity results [62]. This phenomenon is called strong metal support interaction, and is predominant at solid-gas interface catalytic reactions. A detailed study on the molecular level, using electron spectroscopies [63] and the scanning tunneling microscope [64], have been carried out for the $\mathrm{TiO}_{x} / \mathrm{Rh}$ system. It has been found that the $\mathrm{TiO}_{x}$ islands that enhance the catalytic activity are reduced at the metal-oxide interface to $\mathrm{Ti}_{3}^{+}$, (figure 8.39) and this reduction is partly responsible for the enhanced catalytic activity. The oxide acts as an electron acceptor (Lewis acid) [65] which induces charge transfer in polar bonds, such as $\mathrm{CO}$ or $\mathrm{CN}$ bonds, thereby enhancing the dissociation probability of these bonds, and as a result the catalytic activity. It would be important to explore the activity of oxide-metal interfaces at solid-liquid interface reactions.

\subsection{The Missing Links}

We have several surface science techniques which can be used to study the structure bonding and reactivity both at solid-liquid and solid-gas interfaces. High coverage studies of surface structure and bonding are essential to be able to make the correlation between solid-gas and solid-liquid interfaces. One new dimension of surface science studies is the time resolved investigations of short-lived adsorbates. There are many spectroscopic techniques that could provide nanosecond to picosecond time resolution to detect, in a non-steady state pulsed reaction mode, the presence and nature of short-lived adsorbates. Time resolved studies of the dynamics of substrate and adsorbate structure would give us further information about the dynamics of adsorbate induced restructuring, which could play an important role in catalytic reactions both at solid-gas and solid-liquid interfaces. The techniques are available to study dynamics on a short time scale at both solid-gas and solid-liquid interfaces.

Studies of solid-liquid interfaces on the molecular level is one of the frontier areas 


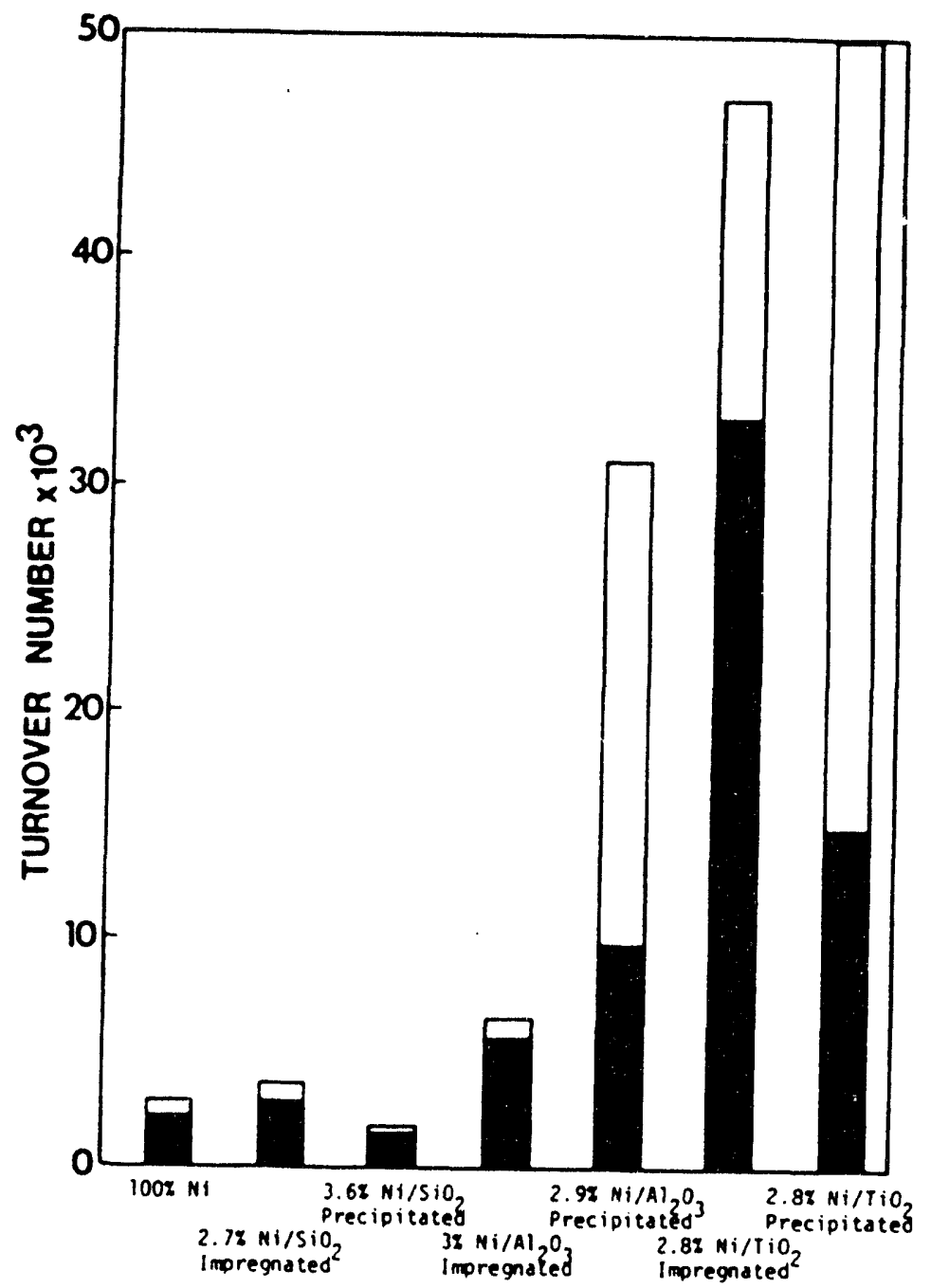

Figure 8.38: Effect of the support on $\mathrm{CO}$ hydrogenation over Ni catalysts. 

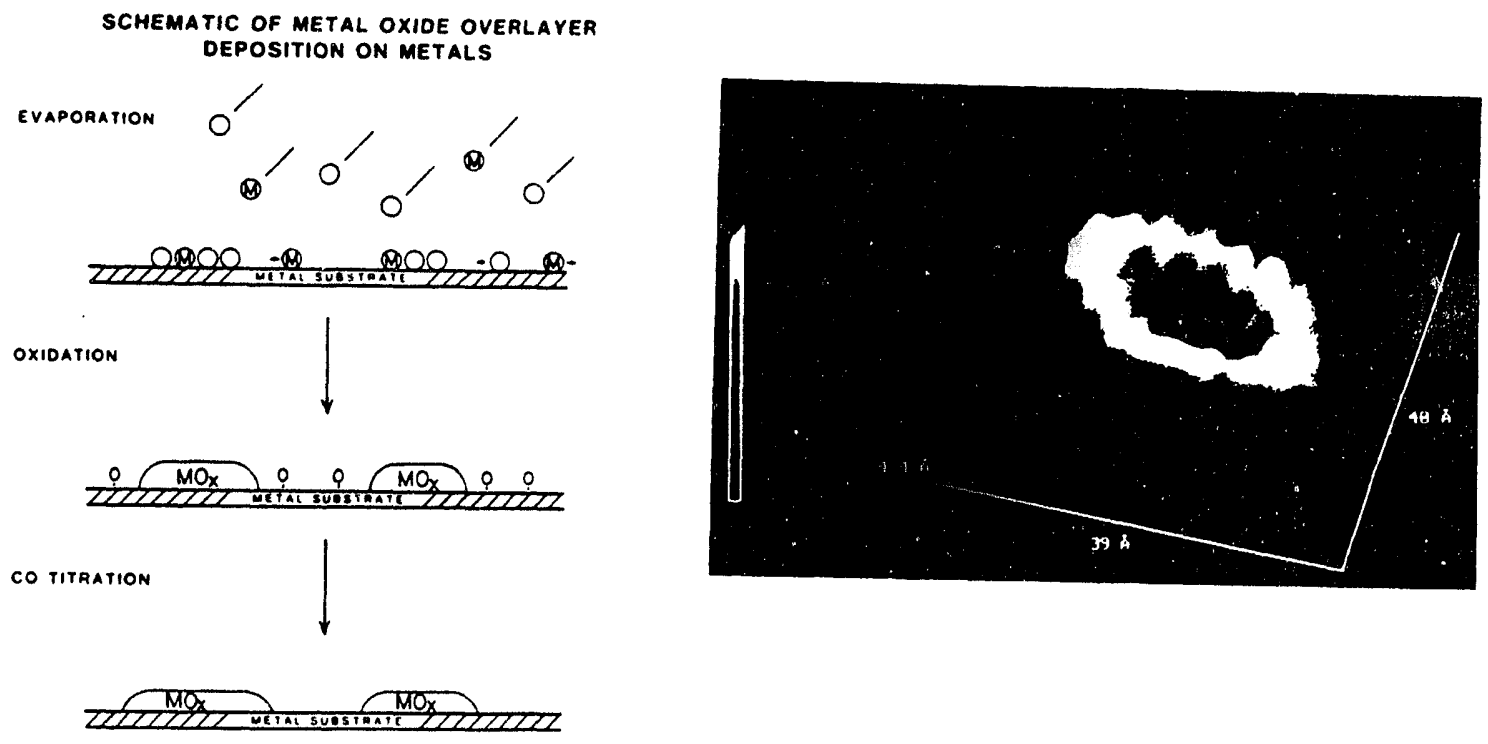

Hydrogenation of $\mathrm{CO}_{2}$ on $\mathrm{TiO}_{\mathrm{x}} / \mathrm{Rh}$

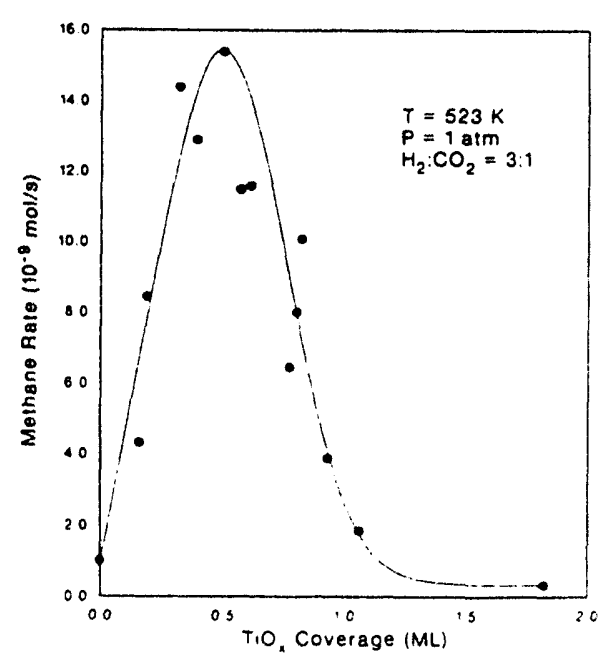

SCHEMATIC MODEL FOR TITANIA OVERLAYERS ON RHODIUM

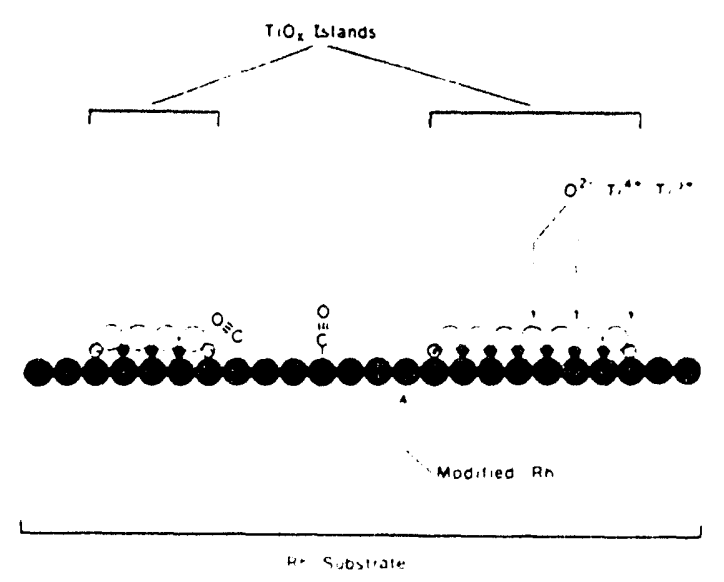

Figure 8.39: STM image and schematic model of titanium oxide islands on Rhodium. Also shown is the methane production rate from the hydrogenation of $\mathrm{CO}_{2}$ on $/ \mathrm{Rh}$ as a function of $\mathrm{TiO}_{x}$ coverage $[64,65]$. 
of modern surface science. Correlations with data that is already available from surface studies in UHV and in gaseous ambients could chart the directions of research and perhaps accelerate the rate of progress in the field. 


\subsection{References}

[1] D.P. Woodruff, and T.A. Delchar, Modern Techniques of Surface Sciences (Cambridge University, Cambridge, 1986).

[2] D.E. Gardin, and G.A. Somorjai, Rev. Sci. Instrum., 64 (1993) 1304.

[3] C.T. Campbell, Adv. Catal., 36 (1989) 1.

[4] B.J. McIntyre, M.B. Salmeron, and G.A. Somorjai, Catalysis Letters, 14 (1992) 263.

[5] E.W. Plummer, W.R. Salaneck, and J.S. Miller, Phys. Rev. B, 18 (1978) 1673.

[6] B. Bent, Ph.D. Dissertation (University of California, Berkeley, 1986).

[7] S.-C. Chang, and M.J. Weaver, Surf. Sci., 238 (1990) 142; S.-C. Chang, J.D. Roth, Y. Ho, and M.J. Weaver, J. Electron. Spectrosc. Relat. Phenom., 54/55 (1990) 1185.

[8] G.A. Somorjai, Chemistry in two dimensions : Surfaces (Cornell University Press Ythaca, New-York, 1981).

[9] J.H. Sinfelt, Cat. Lett., 9 (1991) 159.

[10] A. Osaki and K. Aika, in Catalysis Vol.1, eds J. Anderson and M. Boudart (SpringerVerlag, Berlin, 1981) p.87.

[11] J.K Norskov, and P. Stoltze, Surf. Sci., 189/190 (1987) 91.

[12] K. Takeuchi, M. Salmeron and G.A. Somorjai, Surf. Sci., 279 (1992) 328.

[13] H. Conrad, G. Ertl, J. Koch and E.E. Latta, Surf. Sci., 43 (1974) 462.

[14] G.C McGonigal, R.H. Bernhardt, and D.J. Thomson, Apl. Phys. Lett., 57 (1990) 28.

[15] Y.H. Yeo, K. Yackoboski, G.C McGonigal, and D.J. Thomson, J. Vac. Sci. Tech. A, 10 (1992) 600.

[16] D.E. Wilk, C.D. Stanners, Y.R. Shen, and G.A. Somorjai, Surf. Sci. 280 (1993) 298.

[17] S. Lehwald, and H. Ibach, Surf. Sci., 89 (1979) 425. 
[18] J.M. MacLaren, J.B. Pendry, P.J. Rous, D.K. Saldin, G.A. Somorjai, M.A. Van Hove, and D.D. Vvedensky, "Surface Crystallographic Information Service : A Handbook of Surface Structures", D. Reidel (Dordrecht, Holland, 1987).

[19] F. Jona and P.M. Marcus. Surface Structures from LEED : Metal Surfaces and Metastable Phases. In Springer Series in Surface Sciences Volume 11, eds J.F. Van der Veen and M.A. Van Hove (Springer-Verlag, 1988).

[20] W. Hichtl-Pecher, W. Oed, H. Landskron, K. Heinz, K. Muller, Vacuum, 41 (1990) 297.

[21] I.M. Tidswell, N.M. Markovic, and P.N. Ross, submitted to Phys. Rev. Lett.

[22] E. Lang, K. Muller, K. Heinz, M.A. Van Hove, R.J. Koestner, and G.A. Somorjai, Surf. Sci., 127 (1983) 347.

[23] C.M. Chan, M.A. Van Hove, W.H. Weinberg and E.D. Willians, Surf. Sci., 91 (1980) 440.

[24] W. Moritz, and D. Wolf, Surf. Sci., 163 (1985) L655; C.J. Barnes, M.Q. Ding, M. Lindroos, R.D. Diehl, and D.A. King, Surf. Sci., 162 (1985) 59; D.L. Adams, H.B. Nielsen, M.A. Van Hove, and A. Ignatiev, Surf. Sci. 162 (1985) 59.

[25] W.S. Yang, F. Jona, and P.M. Marcus, Phys. Rev. B, 28 (1983) 2049.

[26] M. A. Van Hove, R. J. Koestner, P. C. Stair, J. P. Biberian, L. L. Kesmodel, I. Bartos, and G. A. Somorjai, Surf. Sci., 103 (1981) 189.

[27] A. Friedrich, C. Shannon, and B. Pettinger, Surf. Sci., 251(1991) 587; B. Pettinger, J. Lipkowski, S. Mirwald, and A. Friedrich, J. Electroanal. Chem., 329 (1992) 289.

[28] N. Kruse, and A. Gaussmann, Surf. Sci., 266 (1992) 51.

[29] H.D. Shih, F. Jona, D.W. Jepsen, and P.M. Marcus, Phys. Rev. Lett., 46 (1981) 731.

[30] S.R. Parkin, H.C. Zeng, M.Y. Zhou, and K.A.R. Mitchell, Phys. Rev. B, 41 (1990) 5432.

[31] A. Wander, M.A. Van Hove, and G.A. Somorjai, Phys. Rev. Lett., 67 (1991) 626. 
[32] B.J. McIntyre, M.B. Salmeron, and G.A. Somorjai, J. Vac. Sci. Technol. A, 11 (1993) 1964.

[33] M. L. Lynch, and R. M. Corn, J. Electroanal. Chem., 318 (1991) 379.

[34] P. Zurawski, L. Rice, M. Houranis, and A. Wieckowski, J. Electroaridl. Chem., 230 (1987) 221.

[35] J. L. Stickney, S. P. Rosasco, G. N. Salita, and A. T. Hubbard, Langmuir , 1 (1985) 66; F. Lu, G. N. Salita, H. Baltruschat, and A. T. Hubbard, J. Electroanal. Chem., 222 (1987) 305.

[36] S.R. Hatch, R.S. Polizzotti, S. Dougal, and P. Rabinowitz, Chem. Phys. Lett., 196 (1992) 97.

[37] M.A. Van Hove, R.J. Koestner, J.C. Frost, and G.A. Somorjai, Surf. Sci., 129 (1983) 482.

[38] C.M. Mate, G.A. Somorjai, H.W.K. Tom, X.D. Zhu, and Y.R. Shen, J. Chem. Phys., 88 (1988) 441.

[39] T.H. Lin, and G.A. Somorjai, J. Chem. Phys., 81 (1984) 704.

[40] C.M. Mate, C.T. Kao, and G.A. Somorjai, Surf. Sci., 206 (1988) 145.

[41] A. Wander, G. Held, R.Q. Hwang, G.S. Blackman, M.L. Xu, P.D. andres, M.A. Van Hove, and G.A. Somorjai, Surf. Sci., 249 (1991) 21.

[42] D.F. Ogletree, M.A. Van Hove, and G.A. Somorjai, Surf. Sci., 187 (1987) 1.

[43] F. T. Wagner, T. E. Moylan, and S. J. Schmieg, Surf. Sci., 195 (1988) 403.

[44] J. C. Dunphy, B. J. McIntyre, J. Gomez, D. F. Ogletree, G. A. Somorjai, and M. B. Salmeron, in press (1993).

[45] J. C. Dunphy, P. Sautet, D. F. Ogletree, and M. B. Salmeron, J. Vac. Sci. Technol. A, 11 (1993) 2145; J. C. Dunphy, P. Sautet, D. F. Ogletree, O. Dabbousi, and M. B. Salmeron, Phys. Rev. B, 47 (1993) 2320.

[46] X.-D. Xiao, X. D. Zhu, W. Daum, and Y.-R. Shen, Phys. Rev. B, 46 (1992) 9732; X.-D. Xiao, Y. Xie, and Y.-R. Shen, accepted Phys. Rev. B (1993). 
[47] J.R. Chen, and R. Gomer, Surf. Sci., 79 (1979) 413.

[48] P.R. Unwin, and A.J. Bard, J. Phys. Chem. 96, (1992) 5035.

[49] D.J. Trevor, and C.E.D. Chidsey, J. Vac. Sci. Technol. B, 9 (1991) 964.

[50] O.R. Melroy, M. G. Samant, G.L. Borges, and J.G. Gordon, II, Langmuir, 4 (1988) 728.

[51] O.M. Magnussen, J. Hotlos, G. Beitel, D.M. Kolb, and R.J. Behm, J. Vac. Sci. Technol. B, 9 (1991) 969 .

[52] A.A. Gerwirth, AIP Conf. Proc., 241 (1991) 190.

[53] D.D. Chambliss, and R.J. Wilson, J. Vac. Sci. Technol. B, 9 (1991) 928.

[54] D.R. Strongin, J. Carrazza, S.R. Bare, and G.A. Somorjai, J. Catal., 103 (1987) 213.

[55] F. Zaera, and G.A. Somorjai, J. Am. Chem. Soc., 106 (1984) 2288.

[56] S. M. Davis, and G.A. Somorjai, J. Catalysis, 65 (1980) 78.

[57] E. Segal, R.J. Madon, and M. Boudart, J. Catalysis, 52 (1978) 45.

[58] Chapter 7.

[59] R.J. Madon, J.P. O'connell, and M. Boudart, AIChE Journal, 24 (1978) 904.

[60] A. Wieckowski, S.D Rosasco, G.N. Salaita, A. Hubbard, B.E. Bent, F.Zaera, and G.A. Somorjai, J. Am. Chem. Soc., 107 (1985) 5910.

[61] G. Ertl, S.B. Lee, and M. Weiss, Surf. Sci., 114 (1982) 527.

[62] C.H. Bartholomew, R.B. Pannell, and J.L. Butlet, J. Catal., 65 (1980) 335.

[63] M. E. Levin, M. Salmeron, A. T. Bell, and G. A. Somorjai, Surf. Sci. 195, (1988) 429.

[64] H.-C. Wang, D.F. Ogletree, and M.B. Salmeron, J. Vac. Sci. Technol B, 9 (1991) 853.

[65] A. B. Boffa, C. Lin, A. T. Bell, and G. A. Somorjai, submitted to J. Catalysis (1993). 

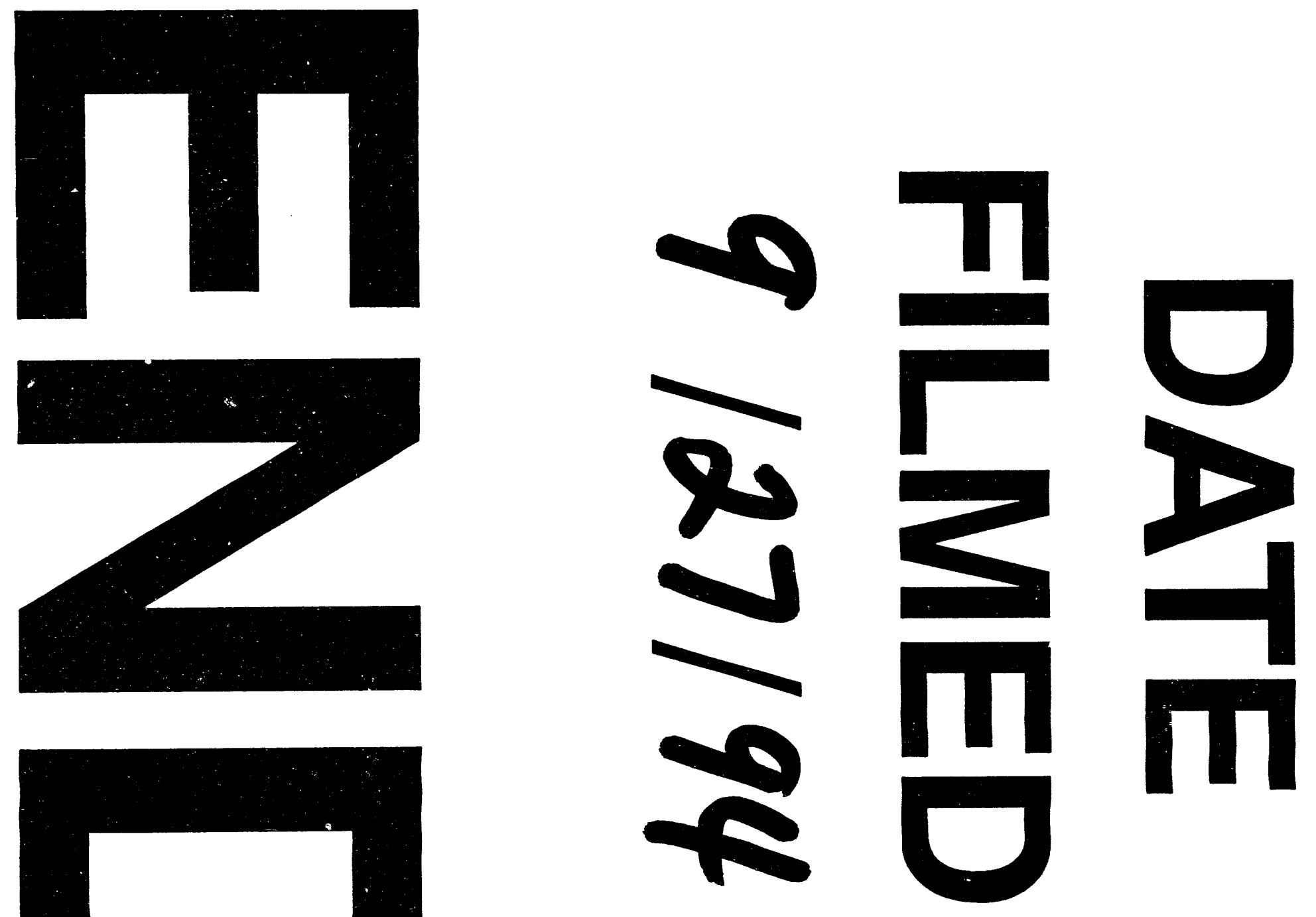
列 